Aus der Klinik für Neurologie

(Prof. Dr. med. M.Bähr)

der Medizinischen Fakultät der Universität Göttingen

\title{
Der Einfluss von humanem Wildtyp-Alpha-Synuclein und seinen Mutationen A30P und A53T auf das Neuritenwachstum primärer dopaminerger Mittelhirnneurone der Ratte
}

\author{
INAUGURAL-DISSERTATION \\ zur Erlangung des Doktorgrades \\ der Medizinischen Fakultät der \\ Georg-August-Universität zu Göttingen \\ vorgelegt von \\ Jessica Franziska Haack \\ aus \\ Cuxhaven
}


Dekan:

Referent:

Ko-Referent/in:

Datum der mündlichen Prüfung:
Prof. Dr. med. W. Brück

PD Dr. med. J. C. Koch

Prof. Dr. Thomas Dresbach 
Hiermit erkläre ich, die Dissertation mit dem Titel „Der Einfluss von humanem Wildtyp-AlphaSynuclein und seinen Mutationen A30P und A53T auf das Neuritenwachstum primärer dopaminerger Mittelhirnneurone der Ratte" eigenständig angefertigt und keine anderen als die von mir angegebenen Quellen und Hilfsmittel verwendet zu haben.

Göttingen, den 15.09.2019

(Jessica Franziska Haack) 


\section{Inhaltsverzeichnis}

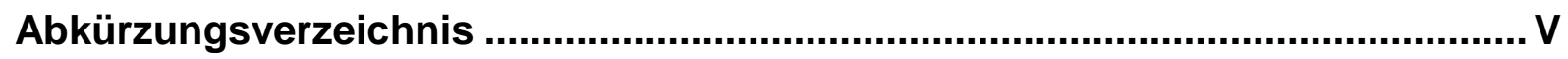

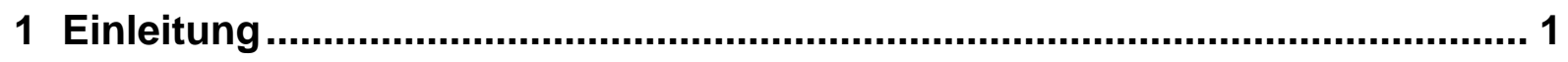

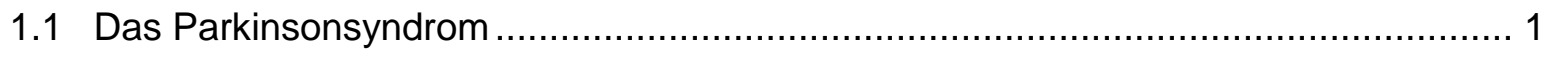

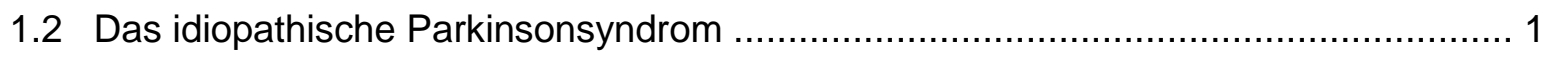

1.2.1 Klinische Symptomatik des idiopathischen Parkinsonsyndroms ........................ 2

1.2.1.1 Primäre motorische Symptome …………........................................... 2

1.2.1.2 Sekundäre motorische Symptome .................................................... 2

1.2.1.3 Nicht-motorische Symptome........................................................... 3

1.2.2 Epidemiologie des idipoathischen Parkinsonsyndroms .................................. 3

1.2.3 Risikofaktoren und Protektion..................................................................... 4

1.2.3.1 Alter und Geschlecht ...................................................................... 4

1.2.3.2 Toxine und Umweltfaktoren ................................................................ 4

1.2.3.3 Das sekundäre Parkinsonsyndrom ........................................................ 5

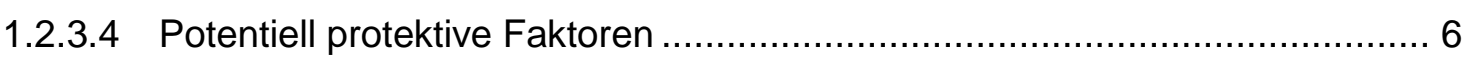

1.2.4 Pathophysiologie und Histopathologie........................................................... 7

1.2.4.1 Histopathologie: Lewy-Körperchen und Lewy-Neuriten ............................. 7

1.2.4.2 Modell der pathologischen Ausbreitung: Braak-Stadien.............................. 8

1.2.4.3 Axonale Degeneration ...................................................................... 9

1.2.5 Genetische Pathophysiologie: Mutationen und Phänotypen ..............................10

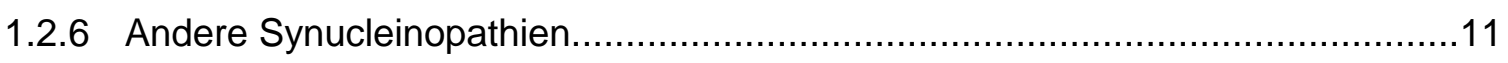

1.3 Das extrapyramidale System: Basalganglien ………….....................................12

1.3.1 Der direkte und indirekte Weg ..............................................................13

1.3.2 Dopaminerge Neurone und ihre Projektionen .................................................14

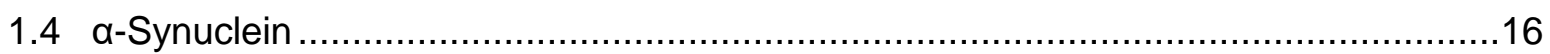

1.4.1 Struktur und physiologische Funktionen .......................................................16

1.4.2 Funktionen an der Synapse, Membranen und Vesikeln...................................17

1.4.3 Lokalisation und Gewebeexpression ...........................................................18

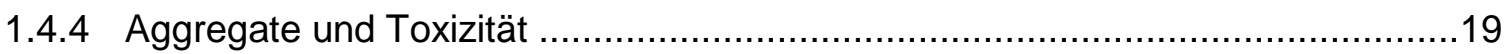

1.4.5 Überexpression, reduzierte Expression und Knockout ......................................20

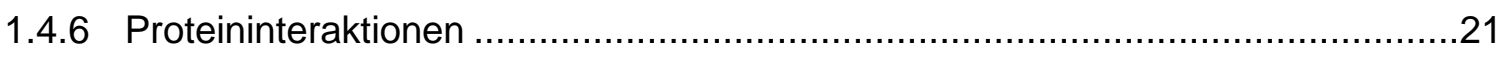

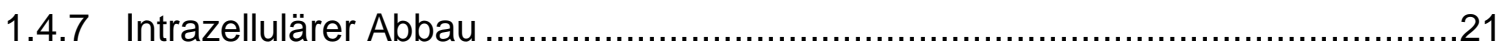

1.5 Fragestellung und Zielsetzung der Arbeit.......................................................... 


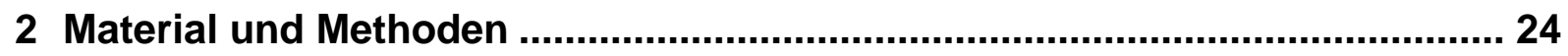

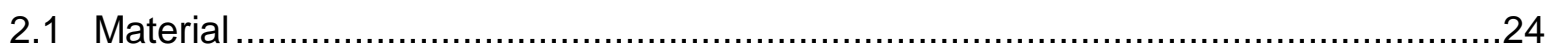

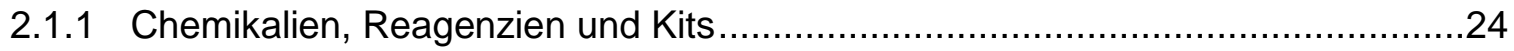

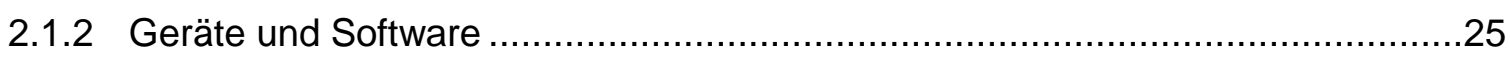

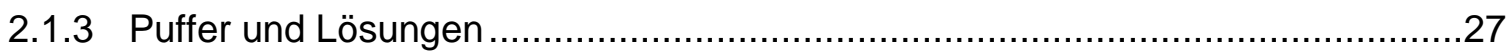

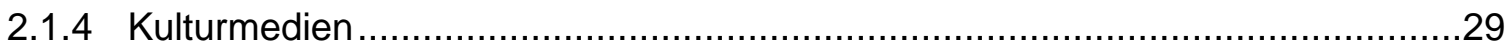

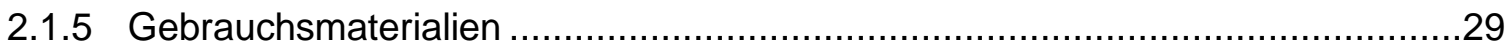

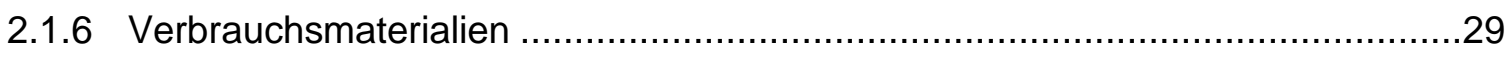

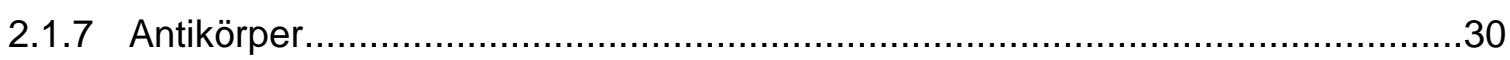

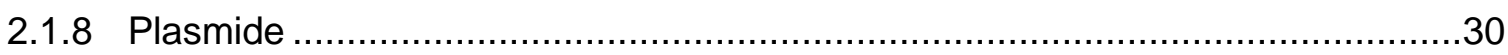

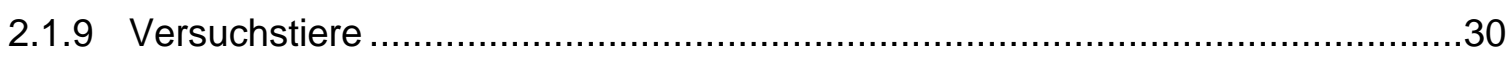

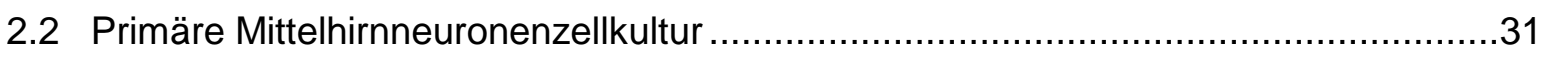

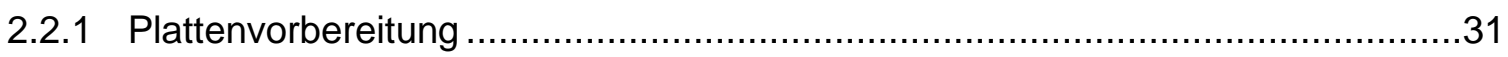

2.2.2 Herstellung der Zellkultur (MDN-Präparation) ...............................................

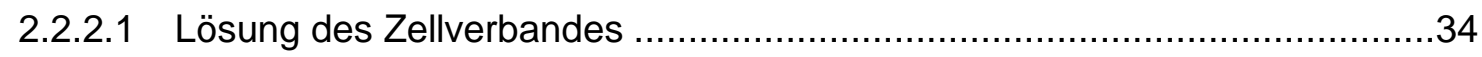

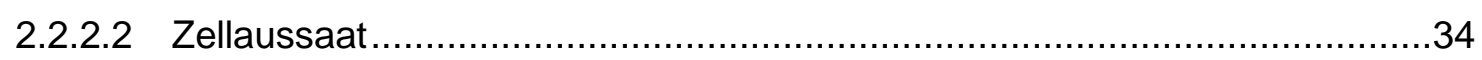

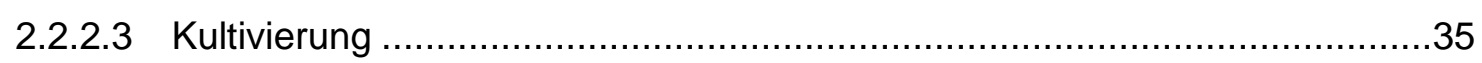

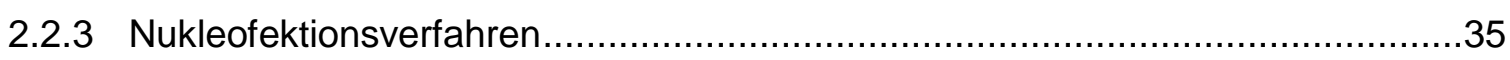

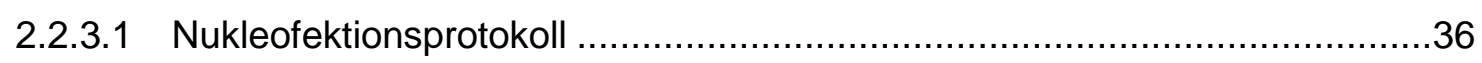

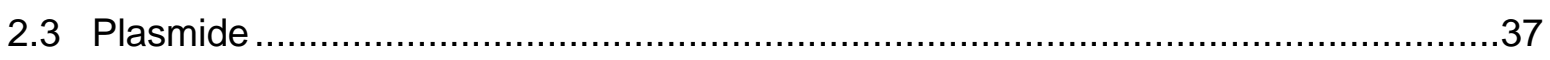

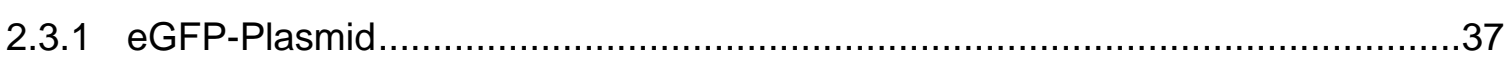

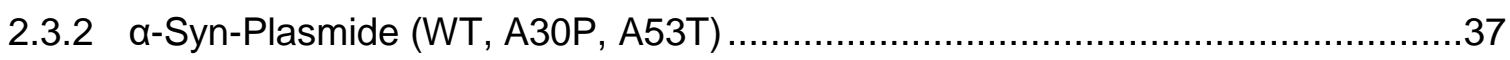

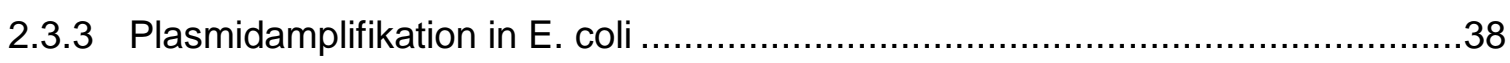

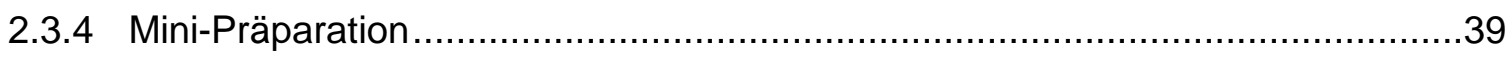

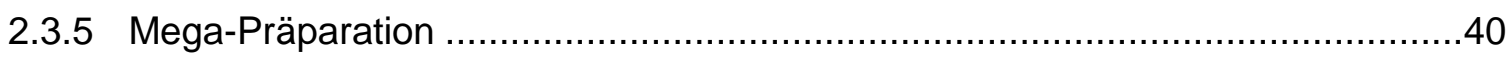

2.3.6 Bestimmung der DNA-Konzentration und Reinheit (OD-Bestimmung) ..............40

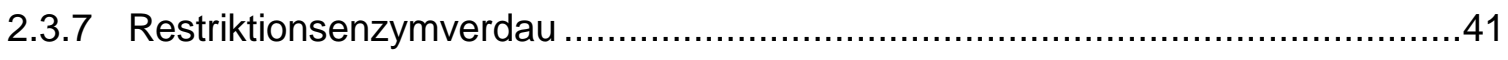

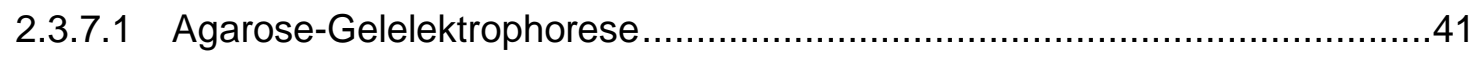

2.3.7.2 Ergebnisse des Restriktionsenzymverdaus ...........................................42

2.4 Immunzytochemie der primären Mittelhirnneurone ................................................43

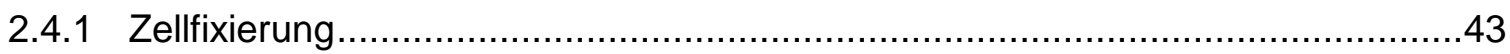

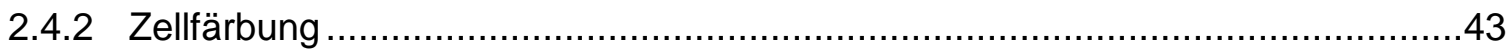

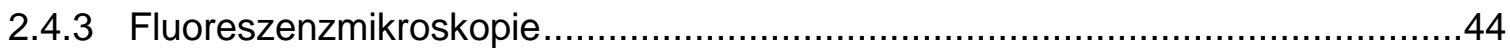

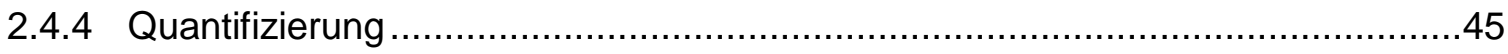

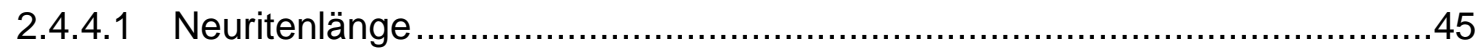

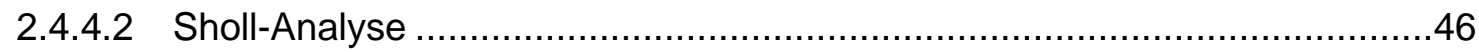




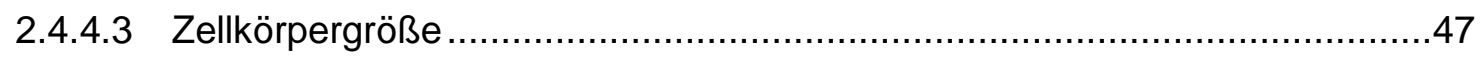

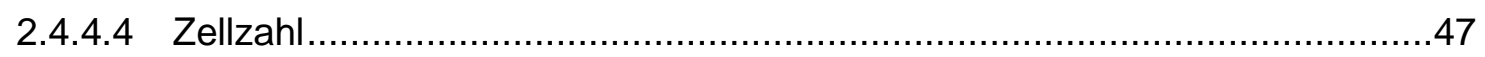

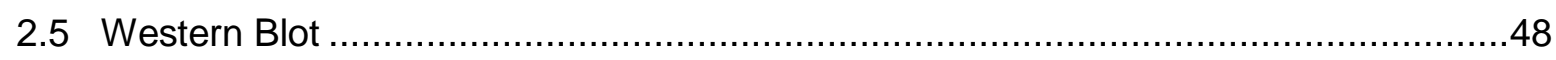

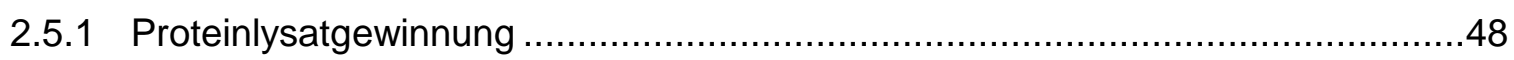

2.5.2 Ultraschallbehandlung (Sonifizierung) .................................................... 48

2.5.3 BCA-Reaktion/Proteingehalt Quantifizierung ...........................................48

2.5.4 SDS-Polyacrylamid-Gelelektrophorese ................................................... 49

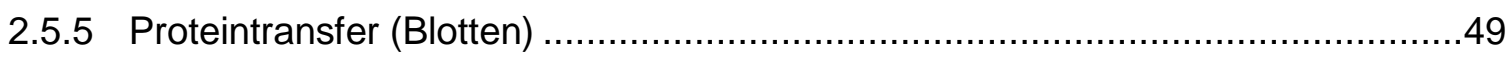

2.5.6 Immundetektion spezifischer Proteine ...................................................... 50

2.5.7 Quantifizierung des Western Blots ......................................................... 50

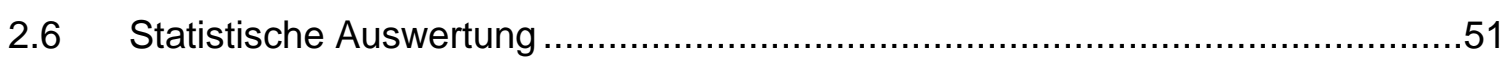

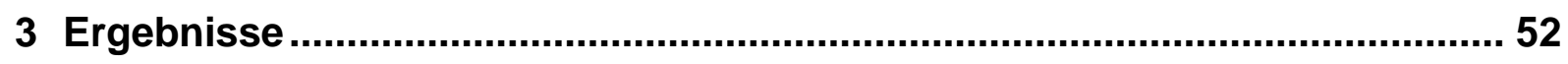

3.1 Charakterisierung der primären Mittelhirnneuronenkultur ....................................52

3.2 Transfektionsetablierung primärer Mittelhirnneurone ........................................52

3.2.1 Vergleich unterschiedlicher Transfektionsprogramme ..................................53

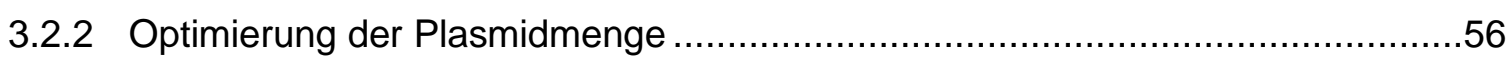

3.2.2.1 Quantifizierung der Transfektionsrate in Abhängigkeit von der Plasmidmenge. .56

3.2.2.2 Quantifizierung der exprimierten Proteinmenge in Abhängigkeit von der

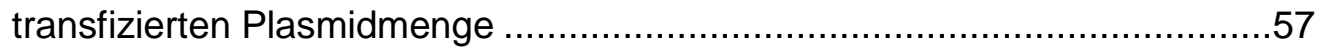

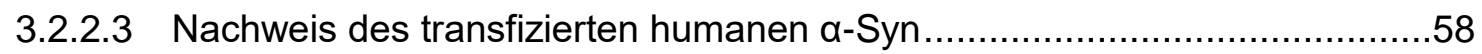

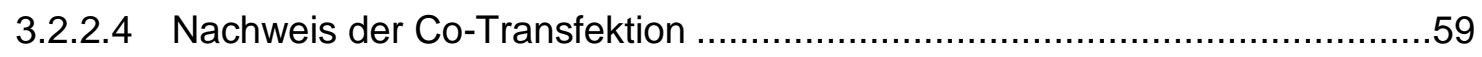

3.2.2.5 Quantifizierung der Überexpression ................................................61

3.3 Einfluss von $\alpha-S y n$ auf das Überleben von Mittelhirnneuronen.................................62

3.3.1 Überleben dopaminerger Mittelhirnneurone nach Transfektion ........................62

3.3.2 Überleben nicht-dopaminerger Mittelhirnneurone nach Transfektion ...................64

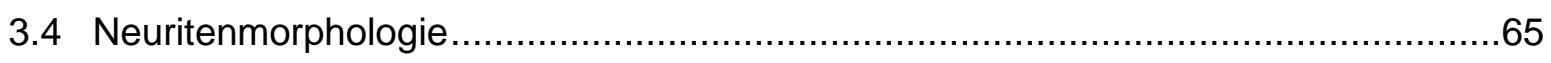

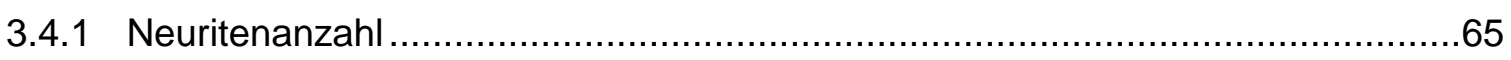

3.4.1.1 Neuritenanzahl dopaminerger Mittelhirnneurone ...................................65

3.4.1.2 Neuritenanzahl nicht-dopaminerger Mittelhirnneurone............................67

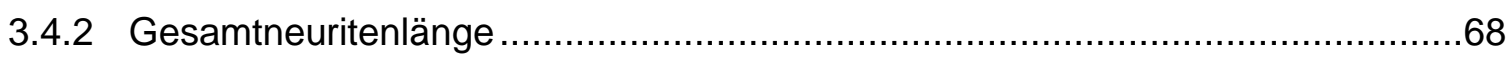

3.4.2.1 Gesamtneuritenlänge dopaminerger Mittelhirnneurone ............................68

3.4.2.2 Gesamtneuritenlänge nicht-dopaminerger Mittelhirnneurone.......................71

3.4.3 Durchschnittliche Neuritenlänge ........................................................... 71

3.4.3.1 Durchschnittsneuritenlänge dopaminerger Mittelhirnneurone .....................71

3.4.3.2 Durchschnittsneuritenlänge nicht-dopaminerger Mittelhirnneurone...............73

3.4.4 Perikaryongröße dopaminerger Mittelhirnneurone........................................ 74 


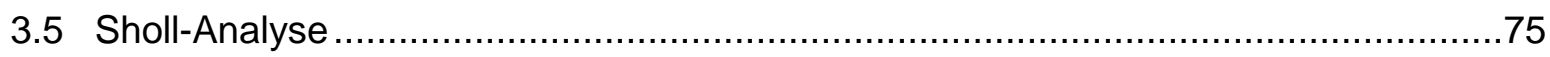

3.5.1 Verzweigungsverhalten dopaminerger und nicht-dopaminerger ..........................

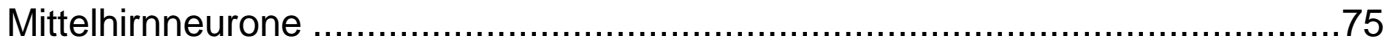

3.5.1.1 Neuritenmaximum dopaminerger Mittelhirnneurone .................................76

3.5.1.2 Neuritenmaximum nicht-dopaminerger Mittelhirnneurone .........................78

3.5.1.3 Kritischer Wert dopaminerger Mittelhirnneuroneurone ...............................79

3.5.1.4 Kritischer Wert nicht-dopaminerger Mittelhirnneurone ...............................79

3.5.1.5 Verzweigungsindex dopaminerger Mittelhirnneurone .............................. 80

3.5.1.6 Verzweigungsindex nicht-dopaminerger Mittelhirnneurone ........................82

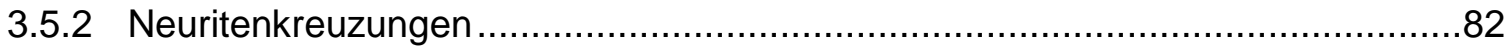

3.5.2.1 Durchschnittliche Neuritenkreuzungen dopaminerger Mittelhirnneurone .....82

3.5.2.2 Durchschnittliche Neuritenkreuzung nicht-dopaminerger Mittelhirnneurone.84

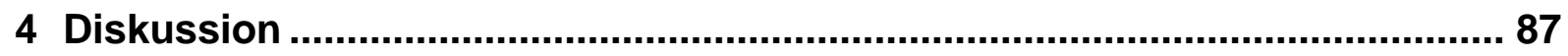

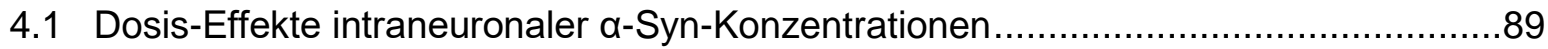

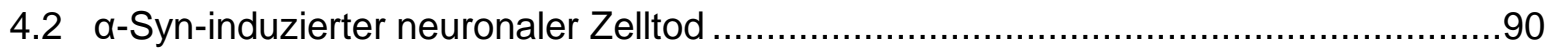

4.3 Neuritenmorphologie primärer Mittelhirnneurone .............................................

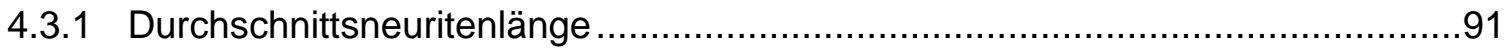

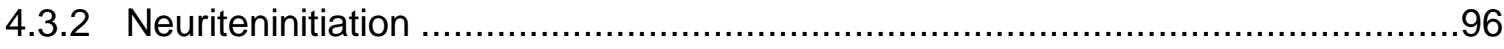

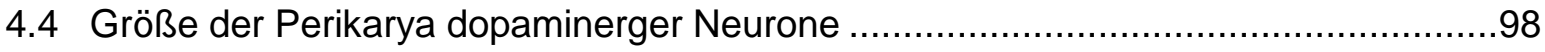

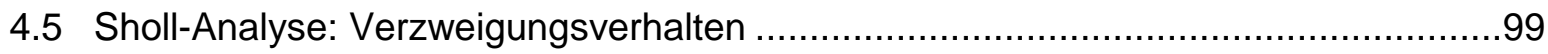

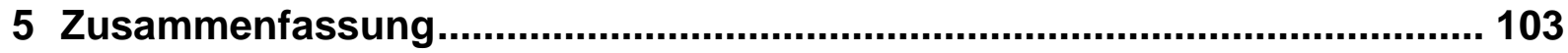

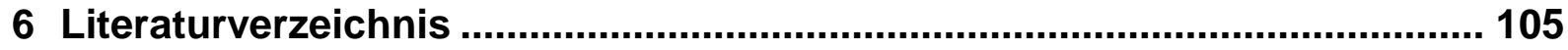




\section{Abkürzungsverzeichnis}

A30P

A53T

AAV

AS

BCA

bp

BSA

CMF

Cy3

Cy5

DAPI

DAT

DCAA

DGN

DLK

DNA

DTT

E14

E46K

EPS

G51D

GABA

$\mathrm{H} 50 \mathrm{Q}$

HRP

Hsc 70
Alanin zu Prolin bei Aminosäure 30 Punktmutation von a-Synuclein

Alanin zu Threonin bei Aminosäure 53 Punktmutation von a-Synuclein

Adeno-assoziierter Virus

Aminosäure

Bicinchoninsäure, bicinchoninic acid

Basenpaare

bovines Serumalbumin

$\mathrm{Ca}^{2+}-, \mathrm{Mg}^{2+}-$ free Hank's balanced salt solution

Indocarbocyanin 3

Indocarbocyanin 5

4',6-Diamidin-2-phenylindol

Dopamin-Transporter

Dopa-Decarboxylase

Deutsche Gesellschaft für Neurologie

Demenz vom Lewy-Körperchen-Typ

Desoxyribonukleinsäure

Dithiothreitol

Embryonaltag 14

Glutaminsäure zu Lysin bei Aminosäure 46

Punktmutation von $\alpha$-Synuclein

extrapyramidal-motorisches System

Glycin zu Asparaginsäure bei Aminosäure 51

Punktmutation von a-Synuclein

Y-Aminobuttersäure

Histidin zu Glutamin bei Aminosäure 50

Punktmutation von a-Synuclein

Horseradish-Peroxidase

heat shock cognate protein of $70 \mathrm{kDa}$ 
Hsp 70

L-Dopa

LK

MAP

MDN

MPP+

MSA

mTOR

MPTP

NAC

NGF

OD

PBS

PFA

RT

Schoenen-RI

SDS-PAGE

SNARE

SNCA

SNP

$\mathrm{SNpc}$

TBS-T

$\mathrm{TH}$

$\mathrm{TH}+$

UCHL1

untrans

WT

aSyn
Hitzeschockprotein 70

L-3,4-Dihydroxyphenylalanin (Vorstufe des Dopamins)

Lewy-Körperchen

Mikrotubuli-assoziertes Protein

midbrain dopaminergic neuron

L-Methyl-Phenyl-Pyridinium-Ion

Multisystematrophie

mechanistic target of rapamycin

1-Methyl-4-Phenyl-1,2,3,6-Tetrahydro-Pyridin

non-Amyloid $\beta$-Komponente

nerve growth factor

optische Dichte

Phosphat-gepufferte physiologische Kochsalzlösung

Paraformaldehyd

Raumtemperatur

Schoenen-Ramifikationsindex

Sodiumdodecylsulfat-Polyacrylamid-Gelelektrophorese

soluble $N$-ethylmaleimide-sensitive-factor attachement proteinreceptor

alpha-Synuclein exprimierendes Gen

single nucleotid-Polymorphismus

Substantia nigra pars compacta

Tris-gepufferte Salzlösung mit Tween

Tyrosinhydroxylase

Tyrosinhydroxylase-positiv

Ubiquitin Carboxyl-Terminal Esterase L1

untransfizierte dopaminerge Mittelhirnneurone

Wildtyp des $\alpha$-Synucleins

$\alpha$-Synuclein 


\section{$1 \quad$ Einleitung}

\subsection{Das Parkinsonsyndrom}

Das Parkinsonsyndrom umfasst eine große Gruppe von Erkrankungen mit unterschiedlicher Gewichtung einer gemeinsamen Leitsymptomatik und heterogener Ätiologie. Die Leitsymptomatik beinhaltet die vier Kardinalsymptome Bradykinese, muskuläre Rigidität/Rigor, Ruhetremor von 4-6 Hz und posturale Instabilität (Bloem et al. 1992, Fearnley und Lees 1991). Durch den Begriff des Parkinsonsyndroms wird lediglich ein syndromatischer Symptomkomplex beschrieben. Ferner gibt es eine Trennung bezüglich der verschiedenen Ätiologien. Man unterscheidet demnach das idiopathische Parkinsonsyndrom (IPS), das familiär-genetisch bedingte Parkinsonsyndrom, die atypischen Parkinsonsyndrome [Multisystematrophie (MSA): vom Parkinson-Typ (MSA-P) oder vom cerebellären Typ (MSA-C), Demenz vom Lewy-Körper-Typ (DLK), progressive supranukleäre Blickparese (PSP), kortikobasale Degeneration (CBD)] und das symptomatische (sekundäre) Parkinsonsyndrom. Des Weiteren werden die neurodegenerativen Parkinsonsyndrome zusätzlich nach pathologischen Kriterien, entweder als Synucleinopathie (IPS, MSA, DLK) oder als Tauopathie (PSP, CBD), bezeichnet.

Die aktuelle Definition des Parkinsonsyndroms fordert die Brady- oder Akinese und mindestens eines der drei weiteren o.g. Symptome in unterschiedlicher Ausprägung (Leitlinie idiopathisches Parkinsonsyndrom 2016). Fakultativ sind sensorische (Hyposmie, Dysästhesien), vegetative (sexuelle Dysfunktionen, Blasen-und Darmstörungen, Temperaturregulationsstörungen), psychische (Schlafstörungen, Depressionen) und kognitive Symptome (Bradyphrenie, Demenz) möglich.

\subsection{Das idiopathische Parkinsonsyndrom}

Erstmalig wurde diese Erkrankung von dem Arzt James Parkinson im Jahre 1817 beschrieben und als "Schüttellähmung“ (shaking palsy oder paralysis agitans) bezeichnet (Parkinson 1817). Die „Schüttellähmung“ beschreibt hierbei das klinische Bild einer Bewegungsverarmung (Lähmung) mit zitternden Begleitbewegungen (Schütteln), welche den Ruhetremor beschreiben.

Das IPS ist eine Erkrankung, welche die diagnostischen Kriterien des Parkinsonsyndroms erfüllt, ohne dass ein definiertes atypisches Parkinsonsyndrom oder eine symptomatische Ätiologie zugrunde liegen. Zusätzlich gibt es weitere diagnostische Kriterien, welche auf ein IPS schließen lassen. Dazu gehört der unilateral betonte Beginn z. B. einer oberen Extremität mit meist persitierender Asymmetrie, gutes Ansprechen auf L-Dopa zu Beginn und für mehr als 5 Jahre sowie ein Krankheitsverlauf, der seit mehr als 10 Jahren andauert und progressiv verläuft. Gegen das Vorliegen eines IPS sprechen konkurrierende Ätiologien 
wie bspw. zerebrale Ischämien oder wiederholte Kopfverletzungen. Zusätzlich sprechen eine Reihe von Symptomen gegen das Vorliegen eines IPS, bspw. eine symmetrisch bilaterale Symptomatik, sehr frühe dementielle Veränderungen, kein Ansprechen auf L-Dopa, pathologische Reflexe (z. B. positiver Babinski) oder cerebelläre Zeichen und viele mehr (Hughes et al. 1992).

\subsubsection{Klinische Symptomatik des idiopathischen Parkinsonsyndroms}

\subsubsection{Primäre motorische Symptome}

Die klassischen primären Symptome des IPS sind motorischer Natur. Insgesamt kommt es zu einer Verlangsamung von Bewegungsabläufen (Bradykinese) sowie einer Bewegungsarmut bis hin zum völligen Fehlen von Bewegung (Hypo- bis Akinese) (van Hilten et al. 1998). Dies äußert sich z. B. in einer Reduktion von spontanen Bewegungen, in einem leisen und undeutlichen Sprechen (Hypophonie), in einem kleinschrittigen Gangbild oder der Beeinträchtigung von schnellen repetitiven Bewegungen (Fingertippen, Handwendung, Fußtapping). Hinzu kommt eine Zunahme des Muskeltonus (muskulärer Rigor), die vom Patienten als Steifigkeit bzw. Rigidität empfunden wird und diagnostisch durch das Zahnradphänomen (rhythmische Unterbrechung beim passiven Durchbewegen der Extremitäten) definiert ist. Klinisch zeigt sich dies bspw. in einem einseitig-betont verminderten Armpendeln beim Gehen, welches ebenso durch die Bradykinese beeinflusst wird. Einseitig betonter Ruhetremor mit $4-6 \mathrm{~Hz}$ (relativ langsames Zittern der oberen Extremität), der in Ruhe zunimmt und bei Bewegung abnimmt, ist weiterhin zu finden.

Ferner zeigt sich eine posturale Instabilität, bei der die Signale der Stellsensoren der Skelettmuskulatur fehlen (Thews et al. 1999). Posturale Kontrolle bedeutet, dass der Mensch unter dem Schwerkrafteinfluss und unter normalen Voraussetzungen eine aufrechte Körperhaltung beibehält.

\subsubsection{Sekundäre motorische Symptome}

Daneben gibt es sekundäre motorische Symptome. Hierzu gehört das „Freezing“, welches sich z. B. in einer Unfähigkeit äußert, das Gehen zu initiieren. Die Patienten fühlen sich, als ob ihre Füße am Boden haften würden. Dieses Symptom wird nicht durch die Rigidität oder die Bradykinese erklärt, wobei verschiedene Hirnareale an der Ätiologie beteiligt scheinen (Shine et al. 2011). Ein verändertes, kleiner werdendes Schriftbild, je länger der Patient schreibt (Mikrographie), gehört ebenfalls zu den sekundären Symptomen. Das Symptom resultiert aus der Rigidität und der Unfähigkeit zu repetitiven Bewegungen. Daneben entwickelt sich als Kombination aus Rigidität und Bradykinese eine Reduktion der Mimik (Hypomimie, „Maskengesicht“). Hinzukommen aber auch zu schnelle, ungewollte und unkoordinierte Bewegungen, welche sich bspw. in verbalen Entäußerungen zeigen können. 
Dadurch können sich Patienten oftmals schwer artikulieren oder haben eine erhöhte Fallneigung.

\subsubsection{Nicht-motorische Symptome}

Interessanterweise kommt es, lange bevor die beschriebenen motorischen Symptomen in Erscheinung treten, zum Auftreten nicht-motorischer Frühsymptome, bspw. vegetativen Beschwerden wie einer Gastroparese (Völlegefühl), Obstipation, einer orthostatischen Dysregulation (Blutdruckabfall beim Aufstehen), erektile Dysfunktion oder einer Hyperhydrosis (Lingor et al. 2011, Chaudhuri und Schapira 2009). Nicht selten ist eine frühzeitige sensorische Beeinträchtigung des Nervus/Bulbus olfaktorius, die eine Störung des Riechens verursacht (Herting et al. 2008). Frühsymptome sind außerdem muskulärer Natur und können ein schmerzhafter Muskelhartspann im Schultergürtel sein, der häufig als rheumatisch-bedingt fehldiagnostiziert wird, obwohl ein beginnender Rigor ursächlich ist. Depressive Episoden aufgrund einer psychischen Mitbeteiligung gehören zu oft fehlgedeuteten Frühsymptomen, wohingegen dementielle Veränderungen erst in späten Erkrankungsstadien auftreten, welche mit der Ausbreitung der Synucleinopathie auf den Kortex korrelieren (s. 1.2.4.2). Des Weiteren treten Beeinträchtigungen des Schlafens sowohl in der REM- als auch in der Nicht-REM-Schlafphase auf. Es finden sich insbesondere lebhafte Träume bis Alpträume, häufiges Erwachen und eine nächtliche Unruhe (Kim CS et al. 2016). Nicht-motorische Symptome treten demzufolge in allen Stadien der Erkrankung auf und betreffen vier verschiedene Bereiche: den neuropsychiatrischen Bereich, z. B. auftretende Depressionen, die Sensorik, insbesondere das Riechen, das Vegetativum und das Schlafverhalten (Lim und Lang 2010). Diese Symptome müssen grundsätzlich von den Nebenwirkungen der medikamentösen Therapie, wie Halluzinationen, Tagesmüdigkeit, Nausea, Diarrhoen u. a. abgegrenzt werden.

\subsubsection{Epidemiologie des idipoathischen Parkinsonsyndroms}

Das IPS ist mit einem Anteil von $75 \%$ das am häufigsten vorkommende Parkinsonsyndrom und die zweithäufigste neurodegenerative Erkrankung nach dem Morbus Alzheimer. Die Inzidenzrate in Deutschland wird mit ca. 20 auf 100000 Personen angegeben (Thümler 2006), und das mittlere Erkrankungsalter liegt bei 55 Jahren (Strickland und Bertoni 2004). Der Anteil der Parkinsonerkrankten an der deutschen Gesamtbevölkerung steigt mit zunehmendem Alter von $1,4 \%$ bei 55 -Jährigen, auf $2 \%$ bei 60 -Jährigen und 3,4 \% bei 75 Jährigen (Thümler 2006). 2005 kam es laut einer Studie zu ca. 110000 Parkinsonfällen in Deutschland (Dorsey et al. 2007). Derzeit liegt die Prävalenz in Deutschland schätzungsweise bei 219579 Parkinsonpatienten (Leitlinie idiopathisches Parkinsonsyndrom 2016). 


\subsubsection{Risikofaktoren und Protektion}

\subsubsection{Alter und Geschlecht}

Das Alter stellt den größten Risikofaktor für die Entstehung eines IPS dar. Die Inzidenzrate nimmt laut einer modifizierten Kaplan-Meier-Analyse bei Männern ab dem 60. Lebensjahr stark zu, erreicht ihren Höhepunkt zwischen einem Alter von 85-89 Jahren und fällt mit 90 Jahren wieder ab (Driver et al. 2009). Das mediane Erkrankungsalter lag bei 73 Jahren. Da die durchschnittliche Lebenserwartung zunehmend ansteigt, wird angenommen, dass sich die Anzahl der Parkinsonpatienten von 2005 bis 2030 verdoppeln wird (Dorsey et al. 2007). Dieser Tatsache zur Folge werden verschiedene altersabhängige Pathomechanismen des IPS diskutiert. Bspw. kommt es zu einer Hochregulation des toxischen Proteins a-Synuclein (a-Syn, s. 1.4.4) mit zunehmendem Alter (Chu und Kordower 2007), einer Abnahme der Proteasomen-Aktivität (Zeng et al. 2005) und einer verminderten Autophagie (Cuervo et al. 2005) sowie einer Zunahme des oxidativen Stresses im alternden Gehirn (Andersen 2004).

Des Weiteren konnten Wooten et al. 2004 in einer Metaanalyse (7 Studien aus Europa, China und USA) ein etwa 1,5-fach höheres IPS-Erkrankungsrisiko für Männer gegenüber Frauen zeigen. Weitere Studien belegten diesen Zusammenhang mit einer Männer-FrauenRatio zwischen 1,1 und 2,3 (Van Den Eeden et al. 2003). Ursächlich hierfür könnten eine erhöhte Toxinexposition, vermehrte Kopfverletzungen oder der fehlende neuroprotektive Aspekt des Östrogens sein.

\subsubsection{Toxine und Umweltfaktoren}

Eine toxische Genese des Parkinsonsyndroms wurde bewiesen, nachdem Drogenabhängige durch das Injizieren verunreinigter Meperidin-Analoga (1-Methyl-4-Phenyl-1,2,3,6-Tetrahydro-Pyridin = MPTP) ein sekundäres Parkinsonsyndrom entwickelten (Langston et al. 1983). MPTP wird in Gliazellen zu dem L-Methyl-Phenyl-Pyridinium-lon (MPP+) oxidiert und über den Dopamintransporter selektiv in dopaminerge Neurone aufgenommen (Javitch et al. 1985, Markey et al. 1984), wo es den Komplex I der mitochondrialen Atmungskette hemmt und die Aktivität der mitochondrialen NADH-Dehydrogenase mindert (Ramsay et al. 1986, Nicklas et al. 1985).

Auch Pestizide/Insektizide, wie bspw. Rotenon, in Obst und Gemüse können ein Parkinsonsyndrom hervorrufen (Pan-Montojo et al. 2012). Im Maus-Modell wurde gezeigt, dass durch Rotenon im Magen-Darmtrakt die Aggregation von $\alpha$-Syn in Nervenzellen induziert und über den Nervus vagus bis ins Gehirn übertragen werden kann. Dabei zerstört im Zellkörper angereichertes $\alpha$-Syn das Neuron (Pan-Montojo et al. 2012). In Frankreich wird das Parkinsonsyndrom seit 2012 als Berufskrankheit in der Landwirtschaft anerkannt, wenn Landwirte nachweislich mindestens 10 Jahre mit Pestiziden gearbeitet haben. 
Auch können Metalle, wie Mangan, ein Parkinsonsyndrom (Manganismus) auslösen, welches allerdings vorwiegend den Globus pallidus und nicht die Substantia nigra betrifft (Carmona et al. 2010). Des Weiteren gibt es beim IPS Hinweise auf eine gestörte Homöostase von Eisen und Kupfer (Morawski et al. 2005). Es konnte bspw. gezeigt werden, dass diese Metalle zu einer vermehrten Fibrillisation von $\alpha$-Syn führen (Uversky et al. 2001) und so pathogenetisch an der Ausbildung eines Parkinsonsyndroms beteiligt sein können (Carboni und Lingor 2015).

Obwohl Lösungsmittel als potentielle Risikofaktoren für ein Parkinsonsyndrom schon lange diskutiert werden und an vielen Arbeitsplätzen vorkommen, haben diese nicht die Aufmerksamkeit erlangt wie Pestizide oder Metalle (Caudle et al. 2012). In einer amerikanischen Zwillingsstudie mit 99 Zwillingspaaren standen Trichlorethen, Tetrachlorethen und Tetrachlormethan (Carbontetrachlorid) im Verdacht ein Parkinsonsyndrom auszulösen (Goldman et al. 2012), wobei bedacht werden muss, dass diese Studie nur eine geringe Anzahl an Probanden aufwies. Epidemiologische Studien zeigten eine erhöhte Inzidenzrate eines IPS insbesondere bei Frauen, welche eine erhöhte, bspw. beruflichbedingte Exposition zu polychlorierten Biphenylen hatten (Steenland et al. 2006).

Geographische Gegebenheiten und die ethnische Herkunft spielen bei der Häufigkeit eines IPS ebenfalls eine Rolle. Das IPS häuft sich besonders im mittleren Westen und den nordöstlichen Regionen der USA. Dabei haben Weiße eine nahezu doppelte Prävalenz im Vergleich zu Nicht-Weißen oder Asiaten (Wright Willis et al. 2010)

\subsubsection{Das sekundäre Parkinsonsyndrom}

Bei den sekundären Formen des Parkinsonsyndroms finden sich im Gegensatz zum IPS ursächliche Schädigungen, die strukturelle Läsionen des zentralen Nervensystems nach sich ziehen können. Sichere epidemiologische Daten liegen nicht vor. Am häufigsten scheinen vaskuläre, toxische und medikamentös-induzierte Parkinsonsyndrome (Parkinsonoid bei Neuroleptika) zu sein. Ein Unterscheidungsmerkmal zwischen sekundären und IPS kann ein akutes Auftreten von typischen primär motorischen Symptomen, welche zudem bilateral auftreten und nicht oder nur kaum auf L-Dopa ansprechen, sein. Außerdem können nichtmotorische Symptome fehlen und es treten dafür andere neurologische Beschwerden auf, welche nicht der typischen Symptomtrias angehören (Klebe 2014). Hierbei handelt es sich aber nur um Hilfen zur Diagnosefindung, die nicht immer zutreffen, da die Übergänge schleichend und nicht stets klar voneinander zu trennen sind. Apparative Diagnostik, bspw. mittels Dopamintransporter-SPECT (single photon emission computed tomography), kann bei der Differenzierung helfen (Pirker und Brücke 2004).

Beim vaskulären Parkinsonsyndrom werden rasch einsetzende Symptome durch akute lakunäre oder territoriale Infarkte in den Basalganglien von langsam progredienten 
Beschwerden aufgrund einer schleichenden, diffusen mikroangiopathischen Marklagerschädigung in Grenzzonengebieten der weissen Substanz und/oder der Baslaganglien unterschieden (Thompson und Marsden 1987). Die Verbindung zwischen zerebralen vaskulären Läsionen und dem Erscheinungsbild eines Parkinsonsyndroms wurde bereits 1929 beschrieben (Critchley 1929).

Daneben gibt es viele andere sekundär induzierte Parkinsonsyndrome, wie z. B. mechanische/posttraumatische (Boxer-Encephalopathie), inflammatorische (Encephalitis lethargica, HIV-Encephalopathie), durch Gehirntumore bedingte und auch metabolischassoziierte (Morbus Wilson) Parkinsonsyndrome.

\subsubsection{Potentiell protektive Faktoren}

Harnsäure als Endprodukt des Purinstoffwechsels und natürlich vorkommendes Antioxidans reduziert oxidativen Stress. Hohe Serum-Konzentrationen schützen vor der Ausbildung einer neurodegenerativen Erkrankung - insbesondere eines IPS bei Männern - und/oder reduzieren dessen Progression (Shen und Ji 2013, Kutzing und Firestein 2008, Schlesinger und Schlesinger 2008, Schwarzschild et al. 2008).

Auch ein erhöhter Cholesterinspiegel senkt die Wahrscheinlichkeit an einem IPS zu erkranken (Huang et al. 2008, Simon et al. 2007, de Lau et al. 2006).

Außerdem konnte überproportional häufig ein Vitamin-D-Mangel bei Parkinsonpatienten ermittelt werden, sodass normale Vitamin-D-Serumspiegel als protektiv anzusehen sind (LV et al. 2014, van den Bos et al. 2013, Zhao et al. 2013).

Außerdem wurde eine um $15 \%$ reduzierte Inzidenzrate eines IPS unter der Gabe von nichtsteroidalen Antirheumatika (ausgenommen Acetylsalicylsäure) beobachtet (Gagne und Power 2010).

Rauchen senkt laut einer Meta-Analyse das relative Risiko einer IPS-Erkrankung. Im Vergleich zu Nicht-Rauchern zeigten Langzeit-Raucher ein relatives Risiko von 0,59, ehemalige Raucher ein relatives Risiko von 0,80 sowie gegenwärtige Raucher ein Risiko von 0,39 . Kaffee trinken hatte dabei einen vergleichbaren Effekt mit einem relativen Risiko von 0,69 im Vergleich zu Nicht-Kaffee-Trinkern (Hernán et al. 2002).

Neuere Studien belegen zudem, dass es einen Zusammenhang zwischen dem Erkrankungsrisiko und dem Einfluss von körperlicher Aktivität zu geben scheint. Der Studie zufolge sei das Erkrankungsrisiko schon bei sechs Stunden moderater Bewegung pro Woche um bis zu 45 \% gesenkt worden (Yang et al. 2015, Xu Q et al. 2010). 


\subsubsection{Pathophysiologie und Histopathologie}

\subsubsection{Histopathologie: Lewy-Körperchen und Lewy-Neuriten}

Für das IPS charakteristisch und histopathologisches Korrelat sind intraneuronale, zytoplasmatische eosinophile Einschlusskörperchen, die sogenannten Lewy-Körperchen (LK) (Spillantini et al. 1998 und 1997). Hauptbestandteil ist a-Syn, welches zwar in allen neuronalen Zellen vorkommt, jedoch allein aufgrund des kausalen Zusammenhanges mutanter Formen dieses Proteins mit der Ausbildung eines IPS in den dopaminergen Neuronen eine besondere Bedeutung hat. Entdeckt wurden diese Einschlusskörperchen durch F. H. Lewy im Jahre 1912 zunächst außerhalb der Substantia nigra pars compacta (SNpc) im dorsalen Vagus-Kern, Globus pallidus, Nucleus lateralis und Nucleus periventrikularis des Thalamus sowie im Nucleus basalis Meynert von Parkinsonkranken (Lewy 1912). Tretiakoff beschrieb die Einschlusskörperchen erstmalig in der SNpc und benannte sie 1919 nach ihrem Entdecker als "corps de Lewy" (Tretiakoff 1919). Interessanterweise wurden die LK nicht nur im Zellkörper (wie oben beschrieben), sondern auch in dystrophen Neuriten gefunden und als Lewy-Neuriten bezeichnet (Galvin et al. 1999). Die Lewy-Neuriten kommen sowohl spindel- als auch fadenförmig in Axonen oder Dendriten vor (Braak et al. 1994).

Histologisch besitzen LK einen dichten eosinophilen Kern und einen blassen Halo. Sie bestehen neben $\alpha$-Syn aus Ubiquitin, Neurofilamenten und anderen Proteinablagerungen. Elektronenmikroskopisch zeigen sich in LK (und Lewy-Neuriten, s.u.) unverzweigte a-SynFilamente, mit einer Länge von 200-600 nm und einer Breite von 5-10 nm (Spillantini et al. 1998). Der Innenteil der Filamente ist über 70 Aminosäuren lang und überragt die repetitive Region von a-Syn. Die Filamente besitzen - wie andere Amyloide auch - eine $\beta$ Faltblattstruktur (Serpell et al. 2000). Man unterscheidet zwei Formen von LK: den Hirnstamm-Typ und den corticalen Typ. Das Hirnstamm-LK hat ein azidophiles Kernstück und einen blass gefärbten Halo, welcher gegenüber $\alpha$-Syn stark immunreaktiv ist. Das corticale LK ist weniger gut beschrieben. Ihm fehlt dieser sogenannte Halo (Goedert et al. 2013).

Histopathologische Korrelate des IPS sind demnach insbesondere der Zellverlust in der SNpc sowie die LK und die Lewy-Neuriten (Braak et al. 2003).

Man findet diese Einschlusskörperchen ebenfalls bei anderen neurodegenerativen Erkrankungen, wie z. B. einer Form des Morbus Alzheimers mit LK-Variante (Lang und Lozano 1998, Lowe et al. 1990) oder der LK-Demenz, einer Form der primären Demenzen, zu denen auch der Morbus Alzheimer und die vaskuläre Demenz zählen. Bei der LKDemenz finden sich die LK diffus in corticalen und subcorticalen Hirnarealen. 


\subsubsection{Modell der pathologischen Ausbreitung: Braak-Stadien}

Das topographisch-anatomische Vorkommen der LK beim IPS wurde anhand von Autopsiegehirnen näher untersucht und später aufgrund der Ergebnisse in Stadien eingeteilt (Braak und Del Tredici 2009). Dabei wurde von Braak die Dichte der LK bestimmt. Es handelt sich um eine sehr sorgfältige Korrelation von Autopsiebefunden mit klinischen Schweregraden der Erkrankung. Demnach gibt es bei der Ausbreitung der Lewy-Pathologie (LK und LewyNeuriten) ein topographisch „aufsteigendes“ Fortschreiten vom Hirnstamm bis zum Neokortex. Die Braak-Stadien wurden als dynamischer, d. h. sich ausbreitender kontinuierlicher Prozess beim Menschen bislang nicht bewiesen. Dennoch beschreibt Braak insgesamt 6 Stadien basierend auf der Autopsie von gesunden (asymptomatischen) humanen Gehirnen und erkrankten IPS-Gehirnen. Stadium 1 und 2 sind Befunde von Gehirnen, bei denen noch keine klinische Erkrankung vorlag. Im Stadium 1 findet man meist die ersten $\alpha$-Syn-positiven Strukturen im Bulbus olfactorius und/oder im dorsalen Nucleus glossopharyngeus sowie Nervus vagus (Medulla oblongata, Hirnstamm), was einen initialen Riechverlust und gastrointestinale Symptome als sogenannte Frühsymptomatik erklären könnte. Das Stadium 2 beinhaltet ein Fortschreiten der Ausbreitung der LK-Pathologie von der Medulla oblongata bis zum pontinen Tegmentum. Die Dichte der LK nimmt demnach im vorangestellten Teil jeweils zu. Im dritten Stadium liegen zusätzlich zu den genannten betroffenen Arealen die pathognomonischen Veränderungen in der Substantia nigra (Mittelhirn) sowie Amygdala vor. In diesem Stadium beginnen die typischen motorischen Symptome des IPS. Von dort kommt es zur Ausbreitung im Prosenzepahlon, temporalen Mesokortex und Allokortex (Stadium 4). Erst im Stadium 5 kommt es zur Beteiligung des Neokortex im Bereich des sensorischen Assoziationskortex und im präfrontalen Kortexbereich sowie schlussendlich im sechsten Stadium im primären sensorischen und motorischen Bereich, welches die spät auftretenden kognitiven Symptome erklären könnte (Goedert et al. 2013, Braak und Del Tredici 2009).

Es wird deutlich, dass neben den (dopaminergen) Neuronen der Substantia nigra zusätzlich viele andere nicht-dopaminerge Hirnareale betroffen sind, zu denen unter anderem der Locus coeruleus (noradrenerg) oder der Nucleus raphe dorsalis (serotonerg) gehört. Ein weiteres bereits beschriebenes Hirnareal ist der dorsale motorische Vaguskern (cholinerg). Ferner kann es zu einem Verlust von Neuronen im Nucleus basalis Meynert (cholinerg) kommen und zu den besagten kognitiv-dementiellen Symptomen führen. Im terminalen Abschnitt der Pathogenese sind große Teile des gesamten ZNS inkl. des Neokortex betroffen, was sich bspw. auch in dementiellen Symptomen äußert. 


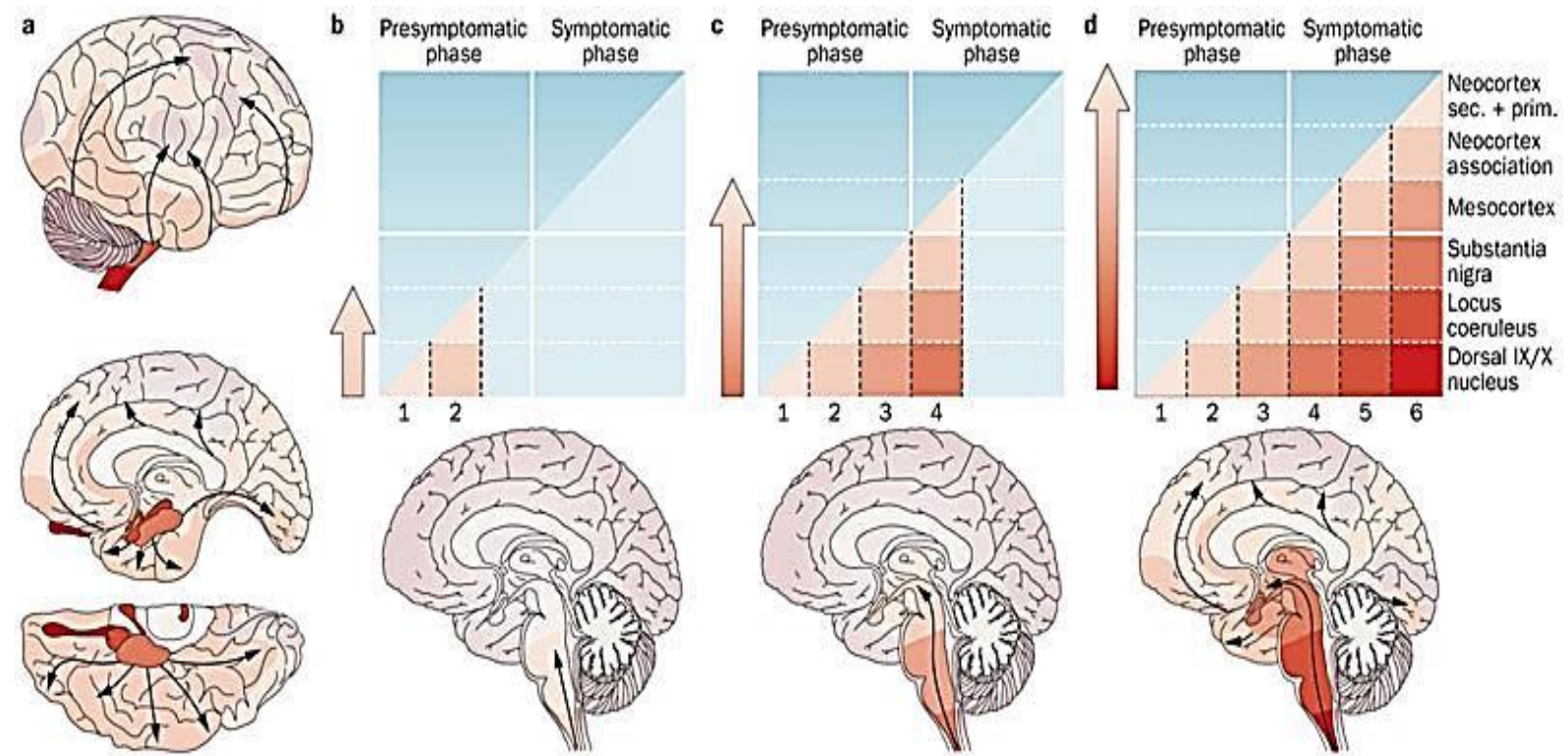

Abb. 1.1 Schematische Lokalisation der $\alpha$-Syn-Einschlusskörperchen im Gehirn eingeteilt in 6 Stadien. Eine Progression zwischen den Gruppen bedeutet ein Hinzukommen eines anderen Hirnareals bei gleichzeitiger Zunahme in dem vorangestellten Teil. (a) Die schwarzen Pfeile zeigen die scheinbar gerichtete, aufsteigende Ausbreitung der Pathologie von caudal nach cranial innerhalb des Gehirns in Abhängigkeit vom Krankheitsstadium. Die Intensität der Rotfärbung korreliert mit der Progression/dem Schweregrad der Pathologie/Dichte der LK. (b) Stadium 1: Läsionen treten im Bulbus olfactorius, dem anterioren Nucleus olfactorius und dem dorsalen, motorischen Vaguskern und den glossopharyngealen Nerven des Hirnstammes auf. Stadium 2: Läsionen im pontinen Tegmentum (Locus coeruleus, magnozelluläre Kerne der Formatio reticularis und Raphekerne). (c) Stadium 3 und 4: die Läsionen erreichen den Nucleus pedunculopontinus, den cholinergen Nucleus magnocellulares, die pars compacta der Substantia nigra (Stadium 3), den Hypothalamus, Teile des Thalamus und die erste kortikale Region, den anteromedialen temporalen Mesokortex (Stadium 4). Erste typische motorische Symptome treten im Stadium 3 und 4 auf. (d) Stadium 5 und 6: die Läsionen erreichen den Neokortex und Assoziationsareale höherer Ordnung (Stadium 5), gefolgt von Assoziationsarealen erster Ordnung und primären sensorischen und motorischen Bereichen (Stadium 6) (Goedert et al. 2013, doi: 10.1038/nrneurol.2012.242).

\subsubsection{Axonale Degeneration}

Es gibt zunehmend Hinweise darauf, dass der Verlust der striatalen axonalen Innervation (nigrostriatale Projektion) einen viel entscheidenderen Einfluss auf die Ausprägung der motorischen Symptomatik hat als der neuronale Zellverlust in der SNpc (Burke und O'Malley 2013). Hierunter wird vornehmlich die neuritische Degeneration der dopaminergen Neurone der Substantia nigra verstanden. Unterstützt wird diese Hypothese dadurch, dass die Anzahl der Lewy-Neuriten in Gehirnen von IPS-Patienten in frühen Stadien die Zahl der LK bei weitem übersteigt (Braak et al. 2003). Des Weiteren fand sich in drei unabhängigen morphologischen Studien lediglich ein 30 \%iger neuronaler Verlust in der Substantia nigra, demgegenüber ein knapp 70\%iger Verlust von striatalen Axonen beim Auftreten der ersten motorischen Symptome steht (Cheng et al.2010).

Es gibt mehrere unterschiedliche Arten der axonalen Degeneration bei neuronalen Verletzungen oder Erkrankungen (Luo und O'Leary 2005, Raff et al. 2002). Die am besten untersuchte Form der axonalen Degeneration ist die sogenannte Wallersche Degeneration und betrifft den distal der Läsion gelegenen Teil des Axons nach einer Läsion. Dieser Degenerationsprozess entspricht einem aktiven, molekularbiologisch gesteuerten Ablauf, bei dem morphologisch zuerst zytoskelettale Bestandteile zerfallen, es dann zu einem Anschwellen der Mitochondrien kommt, gefolgt von einer axonalen Fragmentation, meist in 
anterograder Richtung (Coleman und Freeman 2010). Die axonale Degeneration, wie sie bei neurodegenerativen Erkrankungen wie dem IPS oder anderen Neuropathien vorkommt, verläuft häufig retrograd von den distalen Axonterminalen bis zum Zellkörper (Luo und O'Leary 2005, Raff et al. 2002). Im letzten Stadium ähnelt diese Art morphologisch der axonalen Fragmentation der Wallerschen Degeneration, wobei die genauen molekularen Hintergründe noch unklar sind.

Axonale Degeneration findet sich auch bei der LK-Demenz (s. 1.2.4.1), bei der es sich um ein atypisches Parkinsonsyndrom mit hypokinetisch-rigider Symptomatik zusammen mit einer früh beginnenden Demenz und neuropsychiatrischen Auffälligkeiten handelt. In Gehirnen von Patienten, die an der LK-Demenz litten, fand man die höchste Menge an aggregiertem a-Syn im Neuropil bzw. in den präsynaptischen terminalen Nervenendigungen (Kramer und Schulz-Schaeffer 2007). Dies unterstreicht die besondere Vulnerabilität von Neuriten für die LK-Pathologie. Daraus erwächst die Annahme, dass die Pathogenese des IPS in den präsynaptischen Nervenendigungen und distal gelegenen Axonen beginnt und von hier aus retrograd zum Soma der Nervenzellen wandert (Burke und O'Malley 2013, Orimo et al. 2008).

\subsubsection{Genetische Pathophysiologie: Mutationen und Phänotypen}

Bei ca. 5 \% der Patienten mit einem „klassischen“ Parkinsonsyndrom, das klinisch als IPS zu klassifizieren ist, findet sich ursächlich ein monogenetisch vererbtes familiäres Parkinsonsyndrom, welches, trotz möglicher zusätzlicher atypischer Symptome (früherer Erkrankungsbeginn etc.), klinisch und histopathologisch kaum von einem IPS zu unterscheiden ist. Daher kann die nähere Untersuchung des ätiogenetisch klar definierten und somit einfacher zu untersuchenden familiären Parkinsonsyndroms möglicherweise auch wertvolle Erkenntnisse zum besseren Verständnis der Pathogenese des IPS im Allgemeinen liefern.

Das familiäre Parkinsonsyndrom wird monogen vererbt und es konnten bereits 18 Genorte (bezeichnet als PARK 1-18) identifiziert werden, von denen 15 Genprodukte bekannt sind (Spatola und Wider 2014).

Zu den autosomal dominant vererbten Formen zählen unter anderem PARK 1 und PARK 4, die sich beide auf das Gen SNCA mit dem Genprodukt $\alpha$-Syn beziehen (Singleton et al. 2003, Polymeropoulos et al. 1997). Mittlerweile wurden 5 Mutationen im SNCA-Gen identifiziert, die allesamt Punktmutationen mit jeweilig resultierendem Austausch einer Aminosäure sind: Alanin-30 zu Prolin (A30P), Glutaminsäure-46 zu Lysin (E46K), Histidin-50 zu Glutamin (H50Q), Glycin-51 zu Asparaginsäure (G51D) und Alanin-53 zu Threonin (A53T) (Appel-Cresswell et al. 2013, Lesage et al. 2013, Zarranz et al. 2004, Krüger et al.1998; Polymeropoulos et al. 1997). Zudem wurden Duplikationen und Triplikationen des SNCA- 
Wildtyp-Gens beschrieben, die zur Ausbildung eines autosomal dominant vererbten familiären Parkinsonsyndroms führen (Singleton et al. 2003). So spielen nicht nur defekte Formen von a-Syn, sondern auch hohe Dosen im Sinne eines Gen-Dosis-Effekts eine Rolle. Unterstützt wird diese These durch die Beobachtung, dass Polymorphismen in der PromotorRegion des SNCA-Gens mit resultierender gesteigerter Transkription ebenfalls einen Risikofaktor darstellen, an einem IPS zu erkranken (Tan et al. 2003).

Eine weitere autosomal dominant vererbte Form (PARK 5) weist eine Mutation im UCHL 1 Gen (Ubiquitin Carboxyl-Terminal Esterase L1) auf. Der Aminosäurenaustausch von Isoleucin-93 zu Methionin reduziert die enzymatische Aktivität des für die Ubiquitinvermittelte Proteindegradation benötigten Proteins Ubiquitin-Hydrolase und führt dadurch zu einer Störung im Ubiquitin-Proteasomensystem und einem L-Dopa-sensitiven Parkinsonsyndrom (Leroy et al. 1998).

Mutationen in beiden genannten Genen (SNCA und UCHL 1) führen zu einem früh beginnenden Parkinsonsyndrom mit einem mittleren Erkrankungsalter von 45 Jahren.

Zu den autosomal rezessiven Formen zählen PARK 2, 6 und 7 mit Mutationen in den Genen Parkin, PINK 1 und DJ-1. Sie führen neben einer Störung des Ubiquitin-vermittelten Proteinabbaus zu einer Beeinträchtigung der mitochondrialen Homöostase und der Mitophagie als weitere Ursachen für den dopaminergen Zellverlust (Kitada et al. 1998, Bonifati et al. 2003).

Neben den monogenen Formen wird aktuell intensiv an Kombinationen von Risiko-Genen geforscht, z. B. in Form von SNP (single nucleotid polymorphism)-Variationen, die zur Parkinsonerkrankung führen (Sotiriou et al. 2009, Edwards et al. 2010).

\subsubsection{Andere Synucleinopathien}

Neurodegenerative Erkrankungen, wie bspw. das IPS, unabhängig einer sporadischen oder erblichen Genese, vereinen als grundlegende Eigenschaft den langsamen, fortschreitenden Verlust von Neuronen und deren Neuriten mit unterschiedlicher Symptomatik je nach Ausmaß und Lokalisation der neuronalen Schädigung (Jellinger 2005). Unterschieden werden neurodegenerative Erkrankungen z. B. nach dem pathophysiologisch führend beteiligten Protein oder nach dem dominierenden pathohistologischen Korrelat.

Zu den typischen neurodegenerativen Erkrankungen gehören die Tauopathien (z. B. Morbus Alzheimer), Trinukleotid-/Polyglutamin-Erkrankungen (z. B. Chorea Huntington), motorische Systemerkrankungen (wie die Amyotrophe Lateralsklerose) oder die Prionenerkrankungen (z. B. Creutzfeldt-Jakob-Krankheit) (Jellinger 2005). Auch die Synucleinopathien gehören zum Formenkreis der neurodegenerativen Erkrankungen und haben als gemeinsames Merkmal intrazelluläre Ablagerungen von fehlgefaltetem und unlöslichem $\alpha$-Syn. Hierzu 
zählen neben dem IPS die LK-Demenz, die MSA und die Neurodegeneration mit Eisenablagerungen (Galpern und Lang 2006).

Bei der LK-Demenz kommt es zu einer ubiquitären frühen und vermehrten Ausbreitung der LK-Pathologien im Kortex, Hirnstamm und im limbischen System. Dadurch entwickeln sich dementielle, kognitive Einbußen sowie ein Parkinson-ähnliches Syndrom (Beyer et al. 2009). Die MSA ist eine schnell fortschreitende, neurodegenerative Erkrankung verschiedener neurologischer Systeme und ist bereits initial nicht auf das Mittelhirn beschränkt. Das histopathologische Korrelat sind oligodendrogliale Einschlusskörperchen, deren Hauptkomponente $\alpha$-Syn ist (Arima et al. 1998). Man unterscheidet die MSA vom Parkinson-Typ, die MSA vom zerebellären Typ und die progressive supranukleäre Ophthalmoplegie (SteeleRichardson-Olszewski-Syndrom).

Die Neurodegeneration mit Eisenablagerung im Gehirn ist eine seltene autosomal-rezessiv vererbte und letal verlaufende Erkrankung mit exzessiven Ablagerungen von Eisen und Neuromelanin im Gehirn (insbesondere den Basalganglien), wobei es bereits in der Kindheit zu extrapyramidalen Symptomen kommt (Zhou B et al. 2001). Ätiologisch liegt eine bspw. PANK2-Gen-Mutation vor, welche für die Pantothenkinase 2 codiert, die an der Biosynthese von Co-Enzym A beteiligt ist und eine entscheidende Rolle im Energiestoffwechsel spielt.

\subsection{Das extrapyramidale System: Basalganglien}

Das IPS zählt zu den neurodegenerativen Erkrankungen des extrapyramidal-motorischen Systems (EPS). Hierunter versteht man Bahnen von motorischen Steuerungsvorgängen, die nicht durch die Pyramidenbahn verlaufen (Trepel 1999). Allerdings darf man beide Systeme (pyramidal und extrapyramidal) nicht als völlig voneinander getrennt betrachten, sondern als zwei Untereinheiten des motorischen Systems, welche eng miteinander verbunden sind (Bähr und Frotscher 2003).

Das spinal verlaufende extrapyramidale System nimmt seinen Ursprung in erster Linie im Hirnstamm, insbesondere dem Nucleus ruber, den Ncll. vestibulares und der Formatio reticularis. Demnach werden die extrapyramidalen Bahnen entsprechend Tractus vestibulospinalis sowie medialer und lateraler Tractus reticulospinalis genannt. Der Tractus vestibulospinalis verläuft ungekreuzt vom Nucleus vestibularis lateralis in das Rückenmark. $\mathrm{Er}$ hat auf die Motoneurone der Extensoren eine aktivierende und auf die Flexoren eine hemmende Wirkung. Der mediale Tractus reticulospinalis verläuft ebenfalls ungekreuzt und wirkt wie der Tractus reticulospinalis auf die Motoneurone. Der laterale Reticulospinaltrakt verläuft gekreuzt und ungekreuzt von der Medulla oblongata in das Rückenmark und aktiviert Flexoren und hemmt die Extensoren. Das EPS wird über Kollateralen der Pyramidenbahn und von dem prämotorischen und supplementär-motorischen Kortexarealen aktiviert (Trepel 1999). 
Über das EPS werden vornehmlich grobe, unbewusste Bewegungsabläufe der Halte- und Stützmotorik ausgeführt. Außerdem wird über das EPS der Muskeltonus reguliert. Das EPS hat zahlreiche cerebrale Kerngebiete, wobei der wichtigste Teil die Basalganglien sind.

Die Basalganglien bestehen aus dem Nucleus caudatus und dem Putamen [bilden zusammen das Striatum: größte subcorticale Struktur des humanen Gehirns mit einem Volumen von $10 \mathrm{~cm}^{3}$ (Schröder et al. 1975)], dem Globus pallidus (Diencephalon) sowie den assoziierten Kerngebieten: dem Nucleus subthalamicus (Diencephalon), der Substantia nigra (Mesencephalon) und dem Nucleus ruber (Bähr und Frotscher 2003). Es ist ein akzessorisches Zentrum, das modulierend auf den Thalamus wirkt und sowohl motorische als auch mentale Aktionen beeinflusst. Die Großhirnrinde wiederum wird über den Thalamus beeinflusst. Die Substantia nigra („schwarze Substanz“ = pigmentiert), als Teil der modulierenden Instanz, wird eingeteilt in die pars compacta, die die Neuromelanin(pigmentiert) und Tyrosinhydroxylase-enthaltenden Neurone (= $\mathrm{TH}+$, dopaminerg) aufweist, und die pars reticulares, die zytologisch dem Globus pallidus gleicht (Trepel 1999). Die Basalganglienschleife beschreibt die Interaktionen zwischen den einzelnen Komponenten, um Motorik-modulierend auf den Thalamus einzuwirken. Störungen in diesem Gleichgewicht führen zu motorischen Beeinträchtigungen.

\subsubsection{Der direkte und indirekte Weg}

Es gibt einen direkten, bewegungsfördernden und einen indirekten, bewegungshemmenden Weg, welche beide modulierend auf den Thalamus wirken. Über den direkten Weg bewirkt corticale Aktivität eine glutamaterge (aktivierende) Anregung von GABAergen Neuronen (inhibierend) des Striatums, welche die GABAergen Neurone der Substantia nigra pars reticularis und des Globus pallidus internus hemmen. Dadurch wird der ventrolaterale Thalamus disinhibiert und kann den Kortex glutamaterg aktivieren (bewegungsfördernd) (s. Abb. 1.2 A). Andersherum wird über den indirekten Weg der Globus pallidus externus durch GABAerge Neurone des Striatums gehemmt, welcher nun nicht mehr hemmend (GABAerg) auf den Nucleus subthalamicus wirkt, der folgend aktivierend (glutamaterg) auf den Globus pallidus internus einwirkt, welcher über seine GABAergen Neurone den Thalamus inhibiert (bewegungshemmend) (Calabresi et al. 2014) (s. Abb. 1.2 A). Des Weiteren werden verschiedene Dopamin-Rezeptoren innerhalb der Basalganglienschleife exprimiert, wobei die Wichtigsten der D1-Rezeptor (direkter Weg) und der D2-Rezeptor (indirekter Weg) sind. Die Aktivierung des D1-Rezeptors bewirkt eine Verstärkung des direkten Weges. Passend dazu bewirkt der D2-Rezeptor eine Inhibition des indirekten Weges. Beide bewirken somit eine Bewegungsförderung. Dopamin nimmt demnach eine weitere modulierende Instanz in der Basalganglienschleife ein (Bravo et al. 2014) und hat als Neurotransmitter im synaptischen Spalt eine aktivitätsfördernde motorische Komponente im EPS. Fehlt der 
dopaminerge Transmitter, wie beim IPS (s. Abb. 1.2 B), fehlt folglich die aktivierende Komponente, der indirekte Weg überwiegt und der Thalamus wird ungehindert gehemmt (Trepel 1999). Im Gegenzug dazu überwiegt bei der L-DOPA induzierten Dyskinesie der direkte Weg, was zu unkontrollierten Bewegungen führt (s. Abb. 1.2 C).

A

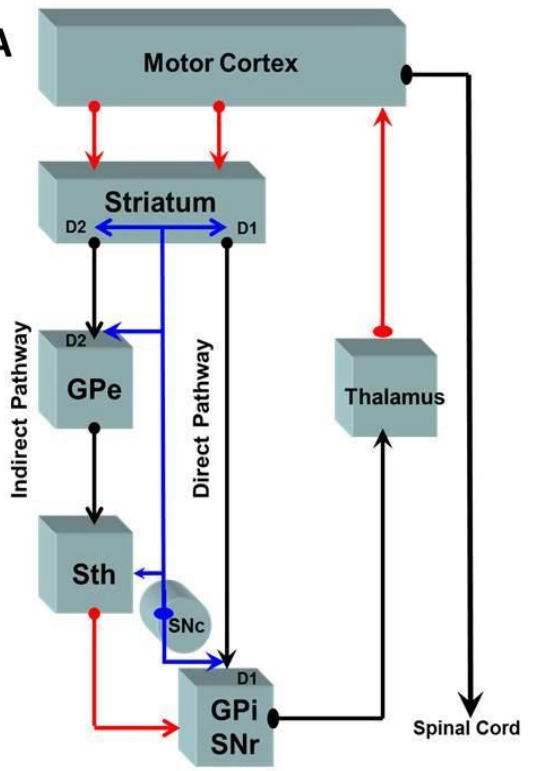

B

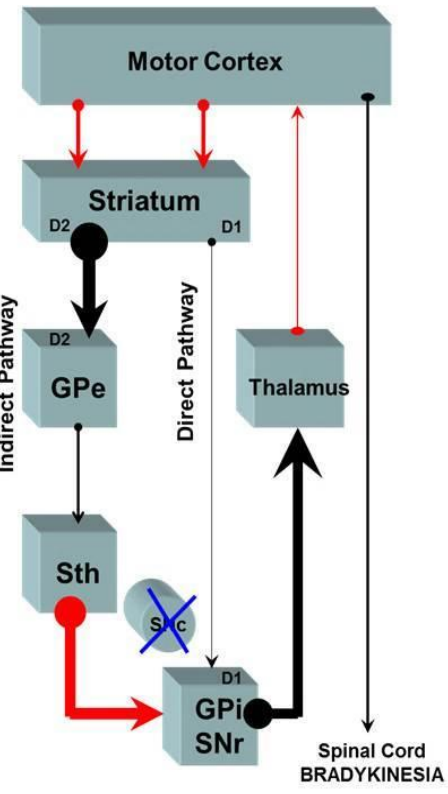

C

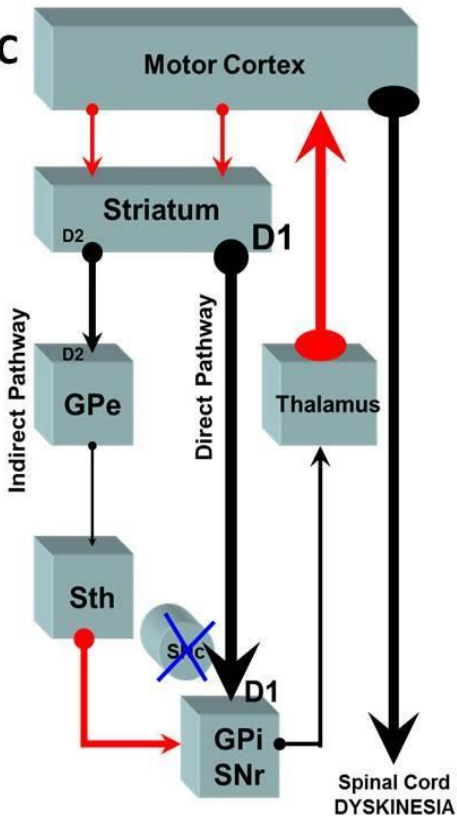

Abb. 1.2 Schematische Darstellung der Basalganglienschleife. (A) Physiologische Verschaltung, (B) Parkinson, (C) LDOPA-induzierte Dyskinesie. GPe: Globus pallidus externus; Sth: Nucleus subthalamicus; GPi: Globus pallidus internus; SNr: substantia nigra pars reticulata; SNc: substantia nigra pars compacta, D1: Dopamin D1-Rezeptor; D2: Dopamin D2Rezeptor (Bravo et al. 2014, doi: 10.5772/57102).

\subsubsection{Dopaminerge Neurone und ihre Projektionen}

Dopaminerge Neurone gehören zu den Projektionsneuronen mit langen, dünnen und nur schwach myelinisierten Axonen, welche sehr vulnerabel sind (Braak et al. 2004).

Eine weitere Eigenschaft dieser Neurone ist eine ausgeprägte striatal-terminale Verzweigung, welche über eine sehr große Anzahl von Axonterminalen eine sehr hohe Innervation des Striatums erreichen (Matsuda et al. 2009). Es wurde gezeigt, dass ein einzelnes dopaminerges Neuron in der Substantia nigra mehr als 245000 Synapsen aufweist, wohingegen bspw. ein Neuron aus dem Globus pallidus externus nur 2000 Synapsen hat (Bolam und Pissadaki 2012). Die dopaminergen Neurone enthalten spezifisch Tyrosinhydroxylase (TH), ein Enzym der Dopaminsynthese (s. Abb. 1.3 links), und Neuromelanin, welches zu einer makroskopisch sichtbaren Dunkelfärbung des jeweiligen Kerngebietes führt (Lüllmann-Rauch 2009). Dopaminerge Neurone sind mit einer Anzahl von 400000 im humanen Gehirn relativ wenig vertreten (Schultz 2007). Ihre Zellkörper findet man als Gruppen in relativ klein abgrenzbaren Gehirnarealen angeordnet (Björklund und Dunnett 2007). Diese dopaminergen Zellgruppen wurden erstmals im Jahre 1964 abgebildet. Die jeweiligen Areale wurden mit dem Anfangsbuchstaben A (=aminergic) nummeriert 
(Dahlstroem und Fuxe1964). Insgesamt konnten 7 Areale mit dopaminergen Neuronen identifiziert werden (A8-14; A1-7 noradrenerge Neurone), zu denen u. a. die Substantia nigra (A8 und A9), das ventrale tegmentale Areal (A10) oder auch der Nucleus periventricularis (A14) gehören (Dubach 1994, Smeets und Reiner 1994, Felten und Sladek 1983).

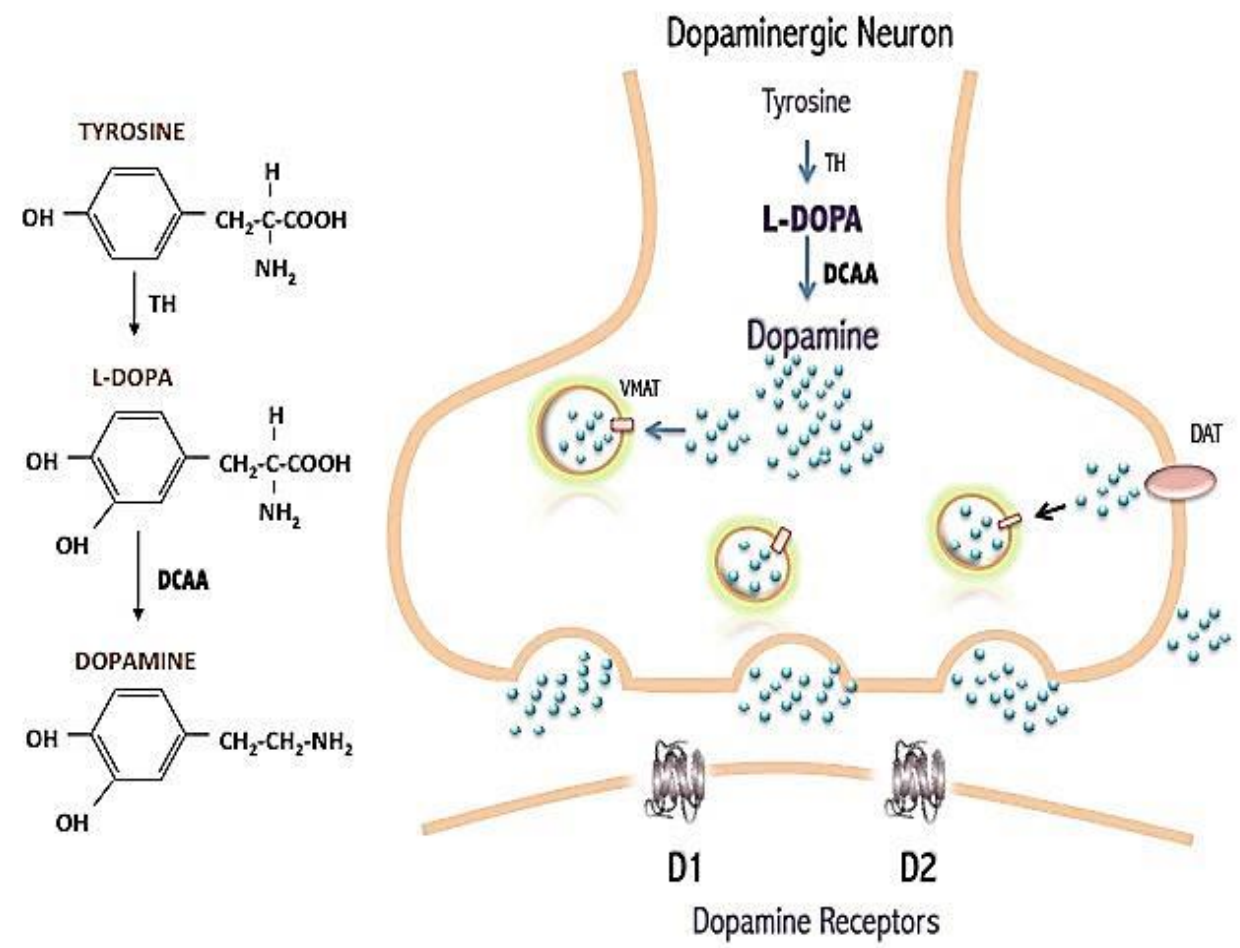

Abb. 1.3 Darstellung der Dopaminsynthese in den dopaminergen Nervenendigungen. Links) Chemische Darstellung, Rechts) Schematische Darstellung als Zeichnung einer Nervenendigung/Synapse. Relevante Abkürzungen: TH: Tyrosinhydroxylase, DCAA: Dopa-Decarboxylase (Bravo et al. 2014, doi: 10.5772/57102).

Es gibt vier verschiedene dopaminerge Systeme, zu denen das nigrostriatale, das mesokortikale, das mesolimbische und das tuberoinfundibuläre gehören.

Der nigrostriatale Trakt projiziert von den neuromelaninhaltigen Neuronen der SNpc (Mesencephalon) zum Striatum (Diencephalon). Diese Bahn hat einen modulierenden Einfluss auf die akzessorische motorische Funktion der Basalganglien und führt zu einer Disinhibiton des Thalamus, sodass er letztlich bewegungsfördernd wirkt (s. auch 1.3.1).

Der mesokortikale Trakt zieht vom ventralen mesenzephalen Tegmentum in den anteromedialen Frontalkortex. Störungen führen möglicherweise zu kognitiven Defiziten (Bidwell et al. 2011, Nestler et al. 2008).

Die mesolimbischen Projektionen reichen ebenfalls vom ventralen, mesenzephalen Tegmentum in das limbische System (Burda et al. 2014). Stimmung, Affekt und Antrieb werden hierüber beeinflusst und können bei Störungen zu Halluzinationen und Schizophrenien führen (Rey 2011).

Die tuberoinfundibulären Bahnen projizieren vom Nucleus infundibularis zur Hypophyse und können die Prolaktin-Freisetzung beeinflussen (Burda et al. 2014). Hierüber können 
Dopaminantagonisten, wie bspw. Bromocriptin, die Prolaktin-Freisetzung inhibieren und darüber therapeutisch - z. B. - zum Abstillen, genutzt werden.

\section{$1.4 \quad \alpha-S y n u c l e i n$}

\subsubsection{Struktur und physiologische Funktionen}

$\alpha$-Syn ist ein relativ kleines, zytoplasmatisch und nukleär vorkommendes Protein, das der Familie der Synucleine angehört, zu denen auch das $\beta$ - und das $\gamma$-Synuclein gehören (Lavedan 1998). Sein kalkuliertes molekulares Gewicht von $14 \mathrm{kDa}$, erscheint unter reduzierten Konditionen [durch DTT-Behandlung (Dithiothreitol) im Western Blot zur Disulfidbrücken-Reduktion (Proteindenaturierung) mit besserer Separation der Proteine nach ihrer Größe] in der SDS-PAGE bei $19 \mathrm{kDa}$. Das Gen für $\alpha$-Syn (SNCA) ist lokalisiert auf dem Chromosom 4q21.3-q22 (Campion et al. 1995).

a-Syn ist 140 Aminosäuren (AS) lang und besteht aus 3 Regionen: einem $\mathrm{COOH}$-terminalen saurem Ende (AS 96-140), einem Mittelteil und einem $\mathrm{NH}_{2}$-Terminus (amphipathisch, $\alpha$ helikal) (AS 1-60). Im Mittelteil befindet sich die hydrophobe NAC (non-AmyloidßKomponente)-Region (AS 61-95), welche an Proteinaggregationen beteiligt ist (Uéda et al. 1993). Die COOH-terminale Region (C-Terminus) ist sauer und sehr Prolin-reich (Bisaglia et al. 2009). Sie ist verantwortlich für die ungeordneten strukturellen Eigenschaften von a-Syn, das heißt, sie hat keine Tendenz eine regelmäßige Sekundärstruktur zu bilden. Der CTerminus supprimiert die Aggregation von $\alpha$-Syn ( $\mathrm{Li}$ et al. 2005). Außerdem enthält es den AS-Rest Serin an der Stelle 129, welcher in den LK zu $90 \%$ phosphoryliert, allerdings in Gehirnen von Gesunden posttranslational nur zu $4 \%$ phoshoryliert ist (Sato et al. 2013). Außerdem kann Dopamin mit den C-terminalen sauren Resten unspezifisch interagieren, was die Dopamin-Homöostase beeinflussen kann und in Gehirnen von Parkinsonpatienten beobachtet werden konnte (Bellucci et al. 2012, Bisaglia et al. 2009). Der N-terminale Teil hat eine charakteristische Sequenz von elf Aminosäuren, welche viermal wiederholt wird und jeweils die Konsensussequenz KTKEGV aufweist. Diese Sequenz ist verantwortlich für die Sekundärstruktur einer $\alpha$-Helix und ähnelt damit Domänen, die an Apolipoproteine binden (Deleersnijder et al. 2013, Bellucci et al. 2012). In dieser Region sind auch die mit monogenetischen hereditären Formen der Parkinsonerkrankung verbundenen Mutationen A30P, E46K, H50Q, G51D und A53T lokalisiert (Bisaglia et al. 2009). Der hydrophobe Mittelteil kann eine Konformationsänderung seiner Primärstruktur in eine B-Faltblattstruktur durchlaufen und eine zylindrische B-Faltblattstruktur sowie B-Amyloid-ähnliche Fibrillen bilden (Bellucci et al. 2012, Deleersnijder et al. 2013). Fehlgefaltete Proteine sind reich an BFaltblattstrukturen und haben darüber eine hohe Tendenz lange fibrilläre Aggregate zu bilden (Soto 2012). 


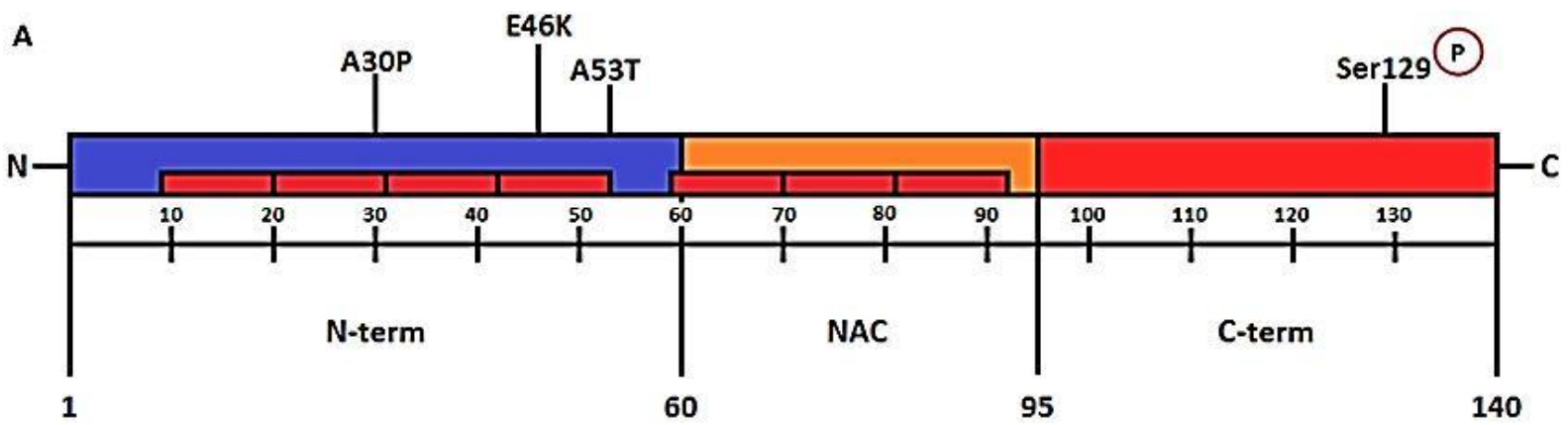

B

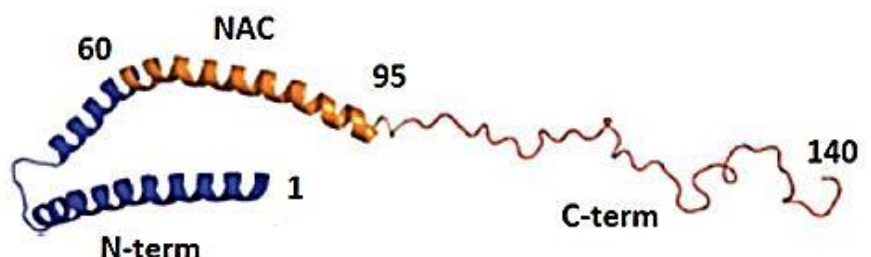

Abb. 1.4 A) Schematische Darstellung der a-Syn-Genregion. Der N-terminale Teil (Aminosäuren 1-60) ist amphiphatisch und für Membraninteraktionen verantwortlich. Er enthält 4 hexamere Wiederholungen, welche in rot dargestellt sind. Hier befinden sich die Punktmutationen A30P, E46K, H50Q (nicht eingezeichnet), G51D (nicht eingezeichnet) und A53T. Die zentrale NAC-Region (AS 61-95) ist hydrophob und am Aggregationsprozess beteiligt. Sie kann eine B-Faltblattstruktur und Amyloidfibrillen bilden. Der C-terminale Teil (AS 96-140) enthält saure Reste und zahlreiche negative Ladungen. Es enthält Serin an der Stelle 129, welche in phophorylierter Form vermehrt in Lewy-Körperchen zu finden ist. B) Schematische Darstellung der $\alpha$-Syn-Sekundärstruktur (Micellen-gebunden). N-Terminal-Region mit antiparalleler $\alpha$-Helix (blau), NAC Region als a-Helix (orange) und die C-terminale Region ohne spezifiche Struktur (rot) (Gallegos et al. 2015, doi: 10.3389/fnins.2015.00059).

a-Syn liegt zytosolisch als Monomer, ungefaltet und in löslicher Form vor (Conway et al. 1998). Andere Untersuchungen haben aber auch das Vorhandensein von $\alpha$-Syn-Tetrameren unter physiologischen Bedingungen gezeigt (Bartels et al. 2011). Welche Quartärstruktur von a-Syn überwiegt, wird aktuell weiter kontrovers diskutiert. Zudem wurde $\alpha$-Syn auch membrangebunden in a-helikaler Form vorgefunden und zeigte in dieser Form unter Ausbildung einer B-Faltblattstruktur eine Neigung zur Oligomerisierung (Cooksen 2009).

\subsubsection{Funktionen an der Synapse, Membranen und Vesikeln}

a-Syn findet sich aufgrund einer Lokalisationspräferenz für gekrümmte Membranen (Middleton und Rhoades 2011), wie bspw. synaptische Vesikel, vorwiegend in den terminalen Nervenendigungen, also den kleinen Synapsen-Endknöpfchen (Iwai et al. 1995). Es ist in der Lage Membrankanäle zu bilden, indem es aus großen Lipidvesikeln Kanäle formt und bei negativ geladenen Vesikeln zu einer Verformung der Membran führt (Varkey et al. 2010). Es konnte mehrfach gezeigt werden, dass multimeres a-Syn Poren in artifiziellen Membranen in-vitro induziert (Tsigelny et al. 2007, Rochet et al. 2004, Volles et al. 2001). Es bindet über seinen N-Terminus vornehmlich an negativ geladene Phospholipide der Lipidmembranen (Burré et al. 2010) und verändert die Doppelschicht, sodass sich Vesikel formen (Madine et al. 2006). Der C-Terminus interagiert mit Synaptobrevin 2, was besonders während synaptischer Aktivitäten eine wichtige Rolle spielt (Burré et al. 2010). 
a-Syn spielt eine Rolle in der synaptischen Plastizität und beim Aufbau des SNAREKomplexes (soluble $\mathrm{N}$-ethylmaleimide-sensitive-factor attachement proteinreceptor) als Chaperon, welches für Membranfusionen notwendig ist (Chandra et al. 2005, Bonini und Giasson 2005). Dagegen spielt $\alpha$-Syn bei der initialen Synapsenformation keine Rolle, wie an primären hippocampalen Neuronen gezeigt werden konnte (Murphy et al. 2000), und es ist eines der letzten sich an der neubildenden Synapse lokalisierenden Proteine (Withers et al.1997). Entgegen der Annahme, dass a-Syn mit synaptischen Vesikeln assoziert ist, konnte bei einer Fraktionierung von Gehirnextrakten a-Syn-transgener Mäuse nur eine sehr geringe Verbindung mit diesen gesehen werden (Fortin et al. 2004, Kahle et al. 2000). Dabei findet man a-Syn überwiegend in löslicher Form ohne statische Vesikelassoziation (Fortin et al. 2004). Eine Überexpression des $\alpha$-Syn-WTs als Simulation pathologischer Bedingungen führte zu einer Inhibition der Exozytose synaptischer Vesikel in Zellkulturen hippocampaler Neurone und dopaminerger Mittelhirnneuronen, was in transgenen Mäusen reproduziert werden konnte (Nemani et al. 2010). Dennoch impliziert die präsynaptische Lokalisation und die Eigenschaft der Membraninteraktion eine Rolle bei der Transmitterfreisetzung, insbesondere der Induktion der Transmitterfreisetzung (Cabin et al. 2002, Murphy et al. 2000). An a-Syn-Knockout-Mäusen konnte nach repetitiven Stimulationen gezeigt werden, dass gegenüber $\alpha$-Syn-WT-Mäusen eine erhöhte Transmitterfreisetzung mit einem konsekutiv reduzierten Dopaminspeicher zu finden war (Abeliovich et al. 2000). Die Dopamin- sowie Norepinephrin-Freisetzung in Knockout-Mäusen zeigte ebenfalls eine schnellere Verfügbarkeit und reduzierte Depression nach repetitiven Stimulationen (Yavich et al. 2006 und 2004), sodass $\alpha$-Syn als negativer Regulator der Dopaminfreisetzung fungiert. Weiterhin wird postuliert, dass a-Syn die Aktivität des Dopamin-Transporter (DAT) herunterreguliert und dadurch eine verminderte Wiederaufnahme des Dopamins in die Zelle nach sich zieht (Wersinger und Sidhu 2003).

\subsubsection{Lokalisation und Gewebeexpression}

a-Syn wird in vielen Zelltypen - u. a. in roten Blutkörperchen (Barbour et al. 2008) vornehmlich jedoch in neuronalen Strukturen exprimiert und macht hier ca. $1 \%$ aller zytosolischen Proteine aus (Iwai et al. 1995). Insbesondere wird es im Neokortex, Hippocampus, Striatum, Thalamus und Cerebellum exprimiert (George 2002).

Wie der Name "Synuclein“ impliziert, findet es sich vornehmlich (prä-) synaptisch und nukleär (Maroteaux et al. 1988). Hohe Konzentrationen finden sich dabei im Bereich des Nucleus der Neurone von Säugetieren (Yu et al. 2007) und speziell in den terminalen Nervenendigungen, jedoch nicht im Zellkörper, den Dendriten oder extrasynaptisch entlang der Axone (George et al. 1995, Iwai et al. 1995). In der Präsynapse liegt es sowohl frei als auch $15 \%$ der Gesamtmenge von $\alpha$-Syn in membrangebundener Form vor (Leeet al. 2002, McLean et al. 2000). Eine weitere Lokalisation findet sich nach neueren Erkenntnissen außerdem in den 
Mitochondrien der Nervenzellen (Zhang L et al. 2008, Liu et al. 2009). Dabei differiert seine Expression je nach Hirnregion und beeinflusst hierdurch unterschiedlich die mitochondrialen Funktionen (Liu et al. 2009).

\subsubsection{Aggregate und Toxizität}

a-Syn neigt zur Aggregation, welche über eine Konformationsänderung vermittelt wird und zur Ausbildung unlöslicher Fibrillen führt, welche wiederum toxische Effekte haben. Dabei kommt es entweder aus der löslichen Form oder der a-helikalen Form heraus zur Ausbildung einer B-Faltblattstruktur (Fehlfaltung), die als Monomer nicht stabil ist und reversibel, über die Zuhilfenahme von Chaperonen, in die ursprüngliche Form gebracht wird (Dohm et al. 2008, Goldberg und Lansbury 2000). Allerdings können aus der B-Faltblattstruktur (Sekundärstruktur) heraus, durch Zusammenlagerung, auch stabilere Oligomere gebildet werden (Conway et al. 1998).

Die Fibrillen ordnen sich aus einer sphärischen Anordnung heraus durch eine vermehrte BFaltblattstruktur linear an und bilden Protofibrillen. In einem weiteren Schritt kommt es zur Konversion zu wasserunlöslichen Fibrillen, die am Ende der Kaskade zur Ausbildung von LK oder Lewy-Neuriten führen. Dabei stellt die Ausbildung der LK mutmaßlich einen Schutzmechanismus der Zellen dar, um die Toxizität der Zwischenprodukte (Oligomere und Protofibrillen) zu vermindern (Goldburg und Lansbury 2000). Die direkte Neurotoxizität der präfibrillären Strukturen konnte bereits nachgewiesen werden (Karpinar et al. 2009). Die physiologische Expression von humanem a-Syn-WT führt in transgenen Mäusen nicht zu klinischen oder histopathologischen Veränderungen (Giasson et al. 2002, Leeet al. 2002), wohingegen dessen Überexpression und somit eine Dosissteigerung, bspw. über adenoassoziierte Virus-Vektoren, zu neurodegenerativen Veränderungen führt (St Martin et al. 2007).

Protofibrillen führen zur Ausbildung von Membranporen, die Vesikel zerstören und z. B. deren Inhalt wie oxidationsanfälliges Dopamin freisetzen (Kim HY et al. 2009, Volles und Lansbury 2002). Weiterhin führen die vermehrten Oligomere bei der A30P- und A53TMutation zur Blockierung der proteasomalen Funktion und somit zum verminderten Abbau von a-Syn und anderen Proteinen (Xilouri et al. 2009). Auch die schützende Funktion der Chaperone, die fehlgefaltete Proteine in ihre normale Form bringen, wird durch Oligomere beeinträchtigt (Martinez-Vicente et al. 2008). Oligomere führen weiterhin zu Dysfunktionen der Chaperon-vermittelten Autophagie sowie zu Funktionsstörungen im Golgi-Apparat (Xilouri et al. 2009, Cooper et al. 2006).

Eine erhöhte Konzentration von a-Syn-WT sowie die Expression von a-Syn-A53T zeigte eine beschleunigte Ausbildung von wasserunlöslichen Fibrillen, wohingegen A30P die 
Fibrillenbildung (Konversion von Protofibrillen zu Fibrillen) inhibiert und folglich zu einer vermehrten Bildung von toxischen Oligomeren führt (Conway et al. 2000).

\subsection{5 Überexpression, reduzierte Expression und Knockout}

In dieser Arbeit wurden die Effekte einer Überexpression des a-Syn-WTs auf die Neuritenmorphologie von primären Mittelhirnneuronen untersucht und mit den Mutationen A53T und A30P sowie einer unbehandelten Kontrolle verglichen. Vorarbeiten anderer Arbeitsgruppen in unterschiedlichen neuronalen Zelllinien hatten zum Teil widersprüchliche Ergebnisse bezüglich der Effekte einer Überexpression von a-Syn auf das Neuritenwachstum und die Neuritenintegrität erbracht.

Eine Überexpression von humanem $\alpha$-Syn führte in der Ratten-Neuroblastom-Zelllinie B103 zu einer signifikanten Reduktion der Neuritenlänge, was als Resultat einer reduzierten Adhäsion der auswachsenden Neuriten mit der umgebendenden Zellmatrix diskutiert wurde (Takenouchi et al. 2001). Dass jedoch nicht allein eine Erhöhung der Zelladhäsion zu einem besseren Auswachsen der Neuriten führt, konnte in dieser Arbeit anhand $\beta$-Synucleinüberexprimierender B103-Neuroblastomzellen gezeigt werden. Diese zeigten zwar eine signifikant erhöhte Zelladhäsion, jedoch blieb die durchschnittliche Neuritenlänge im Vergleich zur Kontrollgruppe reduziert, weshalb bereits 1985 durch Joshi et al. ein kritisches Zusammenspiel von Zelladhäsion und Neuritenwachstum diskutiert wurde. Demgegenüber konnte in primären corticalen Neuronen der Ratte gezeigt werden, dass eine Überexpression des a-Syn-WTs, im Gegensatz zu den Mutationen A30P und A53T, zu einer Zunahme der Durchschnittslänge der Neuriten führte. Es wurde postuliert, dass der WT über eine vermehrte Polymerisation von Tubulin zu Mikrotubuli das Neuritenwachstum fördert (Liu et al. 2013). Des Weiteren führt eine Überexpression des a-Syn-WTs und A30P zu einer erhöhten Instabilität von Aktin in hippocampalen Neuronen der Maus (Sousa et al. 2009).

Bei Mäusen, die humanes a-Syn-WT überexprimieren, konnte überdies gezeigt werden, dass diese IPS-ähnliche Symptome aufweisen und neuronale, jedoch afibrilläre Einschlusskörperchen ausbilden (Masliah et al. 2000). Zudem wurde ein Dosis-abhängiger Effekt bspw. auf den Verlust dopaminerger Neurone durch eine Adeno-assoziierterVirus(AAV)-vermittelte Überexpression von a-Syn gezeigt (St Martin et al. 2007, Zhou W et al. 2000).

Ferner führt eine mittels antisense-Oligonukleotiden reduzierte Expression von $\alpha$-Syn zu einer verminderten Anzahl distal lokalisierter synaptischer Vesikel, sodass von einer Regulierung der Größe des Vesikelpools durch a-Syn auszugehen ist (Murphy et al. 2000). a-Syn spielt ferner eine Rolle in der Ausbildung von kognitiven Lernvorgängen. So konnte gezeigt werden, dass a-Syn-Knockout-Mäuse ein vermindertes Lernverhalten und Arbeitsgedächtnis besaßen (Kokhan et al. 2012) und a-Syn als negativer Regulator der 
dopaminergen Neurotransmission fungiert, wobei sich erstaunlicherweise der primäre Phenotyp der $\alpha$-Syn-defizienten Mäuse nur unwesentlich verändert zeigte, was durch eine Kompensation mittels $\beta$ - und $y$-Synuclein erklärt wird (Abeliovich et al. 2000).

\subsubsection{Proteininteraktionen}

Das neuronale Zytoskelett besteht aus Mikrofilamenten (Aktin), Intermediärfilamenten und Mikrotubuli, welche neben der Stabilisierung der Zelle auch dem intrazellulären Transport sowie der Zellbewegung (Lokomotion) während der Embryonalentwicklung dienen. Das Zytoskelett ist ein molekularer Angriffspunkt oligomeren oder überexprimierten $\alpha$-Syns, $d . h$. unter pathologischen Bedingungen. Es interagiert mit Tubulin, wie durch Ko-LokalisationsStudien von a-Syn und Tubulin in LK und Lewy-Neuriten gezeigt wurde (Alim et al. 2002). In einer weiteren Studie wurde dargestellt, dass es als Mikrotubuli-assoziertes Protein (MAP) physiologisch ähnliche Eigenschaften wie das Tau-Protein hat und das Wachstum von Mikrotubuli fördert (Alim et al. 2004). Mikrotubuli sind für die Form (Stützapparat) und Bewegung des Neurons sowie den intrazellulären energieabhängigen Transport mittels Motorproteine (Kinesin und Dynein) verantwortlich (Millecamps und Julien 2013). Es sind kurzlebige Hohlzylinder, die sich aus Dimeren des Proteins Tubulin zusammensetzen. Wichtige Funktionen und Eigenschaften der verschiedenen Mikrotubuli werden über die MAPs vermittelt. Multimere Formen von a-Syn beeinträchtigen in-vitro die Polymerisation von Tubulin und darüber die Bildung von Mikrotubuli (Prots et al. 2013, Lee et al. 2006). Zusätzlich interagiert es auch mit dem Tau-Protein und stimuliert über die Bindung an Tau die Proteinkinase A, was zu einer vermehrten Phosphorylierung von Tubulin führt (Giasson et al. 2003, Jensen et al. 1999a). Über diese Zusammenhänge beeinflusst $\alpha$-Syn das Neuritenwachstum in primären Neuronen (Tsaneva-Atanasova et al. 2009, Gordon-Weeks 1991).

Aktin-Filamente sind formgebend und stabilisieren die Zelle, insbesondere an Ausbuchtungen (Dendriten) des Neurons. Des Weiteren dienen sie dem Kurzstreckentransport von Vesikeln mittels Myosin sowie der Neuronadhäsion und Zellmotilität. In einer Studie an hippocampalen Zellkulturen konnte gezeigt werden, dass eine Überexpression von $\alpha$-Syn eine erhöhte Instabilität von Aktin sowie dessen Bündelung induziert (Sousa et al. 2009).

\subsubsection{Intrazellulärer Abbau}

Der intrazelluäre Abbau zytosolischer Proteinen, wie a-Syn, erfolgt unter Energieverbrauch über das Ubiquitin-Proteasom-System. Aggregiertes (inbesondere Protofibrillen) aber auch monomeres $\alpha$-Syn hemmt in-vitro seinen eigenen Abbau und den anderer Proteine durch die Inhibition der proteasomalen Funktion (Zhang NY et al. 2008, Snyder et al. 2003). Passend 
dazu führt eine proteasomale Hemmung zur vermehrten Bildung von $\alpha$-Syn- sowie Ubiquitinpositiver Einschlusskörperchen (Rideout et al. 2001). Eine direkte Hemmung des Proteasoms durch $\alpha$-Syn-Filamente/Oligomere konnte in Kulturen von humanen Fibroblasten nachgewiesen werden. Dabei konnte die proteasomale Toxizität durch die $\alpha$-Syn-Filamente durch eine Überexpression von Hitzeschockprotein 70 (Hsp70) reduziert werden. Hsp 70 ist ein endogener Ligand von aggregiertem $\alpha$-Syn, welcher an Filamente bindet und dessen hemmende Auswirkung auf die Proteasomen inhibiert (Lindersson et al. 2004).

Allerdings erfolgt der Abbau von anormalem a-Syn größtenteils über Autophagie und nur zu einem kleinen Teil über das proteasomale System (Vogiatzi et al. 2008). Proteine mit langen Halbwertzeiten, wie a-Syn, werden über den Autophagie-Weg in den Lysosomen abgebaut (Cuervo et al. 2004). Es konnte in zahlreichen Studien gezeigt werden, dass eine verminderte Autophagie zu einer vermehrten Akkumulation und Toxizität von $\alpha$-SynProdukten führt und andersherum die Aktivierung der Autophagie einen therapeutischen Ansatz darstellt (Friedman et al. 2012, Spencer et al. 2009, Xilouri et al. 2009). Bei der Autophagie unterscheidet man zwischen der Makro- und Mikroautophagie sowie der Chaperon-vermittelten Autophagie (chaperone-mediated-autophagy, CMA). Bei der Makroautophagie werden Teile des Zytosols oder ganze Organellen von einem doppelmembranösen, sog. Autophagosom umschlossen, welches dann mit Lysosomen verschmilzt und die darin enthaltenen Proteine degradiert. Die CMA ist eine Autophagie-Form, welche ebenfalls über den lysosomalen Weg spezifisch Proteine degradiert. Hierbei erfolgt die Einschleusung der zu degradierenden Proteine in die lysosomalen Strukturen der Neurone Rezeptor-vermittelt nach Bindung an zytosolisch gelegenes Hsc 70 (heat shock cognate protein of $70 \mathrm{kDa}$ ) (Cuervo et al. 2004, Dice 1990). 


\section{$1.5 \quad$ Fragestellung und Zielsetzung der Arbeit}

Das IPS ist eine chronisch progrediente neurodegenerative Erkrankung mit großer sozioökonomischer Bedeutung und fatalen persönlichen Folgen für die betroffenen Patienten. Trotz aller Forschungsbemühungen gibt es bis heute nur symptomatische Therapiemöglichkeiten und keine krankheitsmodifizierenden oder neuroprotektiven Therapieansätze. Dies liegt zu einem großen Teil darin begründet, dass die Pathogenese noch nicht komplett verstanden ist. Insbesondere das bessere Verständnis der frühen pathogenetischen Veränderungen könnte dazu beitragen, Therapien zu entwickeln, die die Neurodegeneration zu einem Zeitpunkt stoppen, zu dem noch viel intaktes neuronales Gewebe erhalten ist und der Patient eine akzeptable Lebensqualität besitzt, wenn die Erkrankung nicht voranschreitet.

Wie oben ausführlich dargelegt, ist die Degeneration der Neuriten ein initialer Prozess in der Pathogenese des IPS, der erst später vom Untergang der zugehörigen neuronalen Somata gefolgt wird. Zum Zeitpunkt der ersten Diagnosestellung findet sich entsprechend ein ausgeprägter Verlust von dopaminergen Axonen, wohingegen der Großteil der Somata noch intakt ist. Daher ist es wichtig, die Prozesse besser zu verstehen, die der Degeneration von Neuriten zugrunde liegen, um diese in einem möglichen therapeutischen Ansatz zu stoppen und das Fortschreiten der Pathologie auf das Zellsoma zu verhindern. Während eine zentrale Rolle des Proteins a-Syn in der Pathogenese des IPS durch zahlreiche Studien belegt werden konnte, ist unklar, ob und wie $\alpha$-Syn zur Degeneration von Neuriten beiträgt. Ziel dieser Arbeit war es daher, die Effekte von a-Syn und zwei seiner pathogenen Mutanten auf die Morphologie von Neuriten zu analysieren. Insbesondere sollten Effekte einer vermehrten intraneuronalen Proteinmenge des $\alpha$-Syn-WTs, wie sie auch in der Pathogenese des IPS angenommen wird, mit Effekten der Mutationen A53T und A30P und der unbehandelten Kontrolle verglichen werden. Als Grundlage für die hierfür benötigten Experimente wurde zunächst ein Verfahren für einen effizienten Gentransfer zur konsekutiven Überexpression von $\alpha$-Syn in primären dopaminergen Mittelhirnneuronen etabliert. Die Neuritenmorphologie wurde dann in den einzelnen Versuchsgruppen anhand diverser quantitativer Parameter detailliert analysiert. Es fanden sich signifikante Effekte der a-Syn-Expression auf die Neuriten-Morphologie, die interessante Erklärungsansätze für die frühe Pathogenese des IPS liefern. 


\section{$2 \quad$ Material und Methoden}

\section{$2.1 \quad$ Material}

\subsubsection{Chemikalien, Reagenzien und Kits}

\section{Chemikalien, Reagenzien und Kits}

Agarose

Ammoniumperoxidisulfat

Ampicillin

Ampuwa- $\mathrm{H}_{2} \mathrm{O}$

BCA (Bicinchonininsäure)-Assay

Borsäure

Bromphenolblau

BSA (Bovines Serumalbumin)-Standardprotein

BSA (Bovines Serumalbumin)-Mediumzusatz

CPI (complete proteinase inhibitor)

DAKO® Antibody Diluent

DAPI (4',6-Diamidin-2'Phenylindoldihydrochlorid)

DMEM IF-12 (Dulbecco's modified eagle medium)

DNase(Desoxyribonulease)

DTT (Dithiothreitol)

Dual ${ }^{\circledR}$ Color Marker

EGTA (Ethylenglycol-bis(aminoethylether)-

$\mathrm{N}, \mathrm{N}, \mathrm{N}^{\prime}, \mathrm{N}^{\prime}$-tetraessigsäure)

Enzym Bgl2

Enzym Not1

Enzym Sma1

Ethanol absolut

Ethidiumbromid

FCS (Fötales Rinderserum)

Glucoselösung $45 \%$

Glycin

Glycerol/Glycerin

HBSS (Hank's balanced salt solution)

HEPES (2-(4-(2-Hydroxyethyl)-1-Piperazinyl)-

Ethansulfonsäure)

Igepal

Insulin

Isopropanol

$\mathrm{KCl}$ (Kaliumchlorid)

Laminin
Hersteller

AppliChem, Darmstadt, Deutschland

Roth, Karlsruhe, Deutschland

Roth, Karlsruhe, Deutschland

Fresenius Kabi, Bad Homburg, Deutschland

Thermo Scientific, Rockford, IL USA

AppliChem, Darmstadt, Deutschland

SERVA, Heidelberg, Deutschland

Sigma-Aldrich, Taufkirchen, Deutschland

Sigma-Aldrich, Taufkirchen, Deutschland

Roche, Mannheim, Deutschland

Dako, Hamburg, Deutschland

AppliChem, Darmstadt, Deutschland

Gibco, Karlsruhe, Deutschland

Roche, Mannheim, Deutschland

Sigma-Aldrich, Taufkirchen, Deutschland

Bio-Rad, München, Deutschland

Sigma-Aldrich, Taufkirchen, Deutschland

New England Biolabs, Frankfurt am Main, Deutschland

New England Biolabs, Frankfurt am Main, Deutschland

New England Biolabs, Frankfurt am Main, Deutschland

AppliChem, Darmstadt, Deutschland

Sigma-Aldrich, Taufkirchen, Deutschland

PAA, Pasching, Österreich

Sigma-Aldrich, Taufkirchen, Deutschland

AppliChem, Darmstadt, Deutschland

Roth, Karlsruhe, Deutschland

Gibco, Karlsruhe, Deutschland

AppliChem, Darmstadt, Deutschland

Sigma-Aldrich, Taufkirchen, Deutschland

Sigma-Aldrich, Taufkirchen, Deutschland

AppliChem, Darmstadt, Deutschland

AppliChem, Darmstadt, Deutschland

Sigma-Aldrich, Taufkirchen, Deutsch 


\section{LB-Agar}

LB-Pulver

L-Glutamin (200 mM)

Luminol

Methanol

$\mathrm{MgCl}_{2}$ (Magnesiumchlorid)

Milchpulver

Mowiol® 4-88 Reagent, Calbiochem ${ }^{\circledR}$

N1 Medium Supplement 100x

Natriumacetat

Natriumhydrogenkarbonat

Natriumchlorid

Nucleofectionslösung

[Basic Nucleofector Kit for primary mammalian neurons/Basic Primary Neurons Nucleofector ${ }^{\circledR} K i t$ (VPI-1003)]

PBS (Phosphat-gepufferte physiologische Kochsalzlösung)-Pulver

p-Coumarsäure

PFA (Paraformaldehyd)

Poly-L-Ornithin-Hydrobromid

Propylgallat

PSN (Penicillin, Streptomycin, Neomycin)

Antibiotic Mixture 100x

QIAprep Spin Miniprep Kit

Qiagen Plasmid Maga Kit

Rotiphorese (30\%)

SDS (Natriumdodecylsulfat)

Sucrose $(D(+)$ Saccharose)

TEMED (Tetramethylethylendiamin)

Tris

Trypsin

Tween

Wasserstoffperoxid $30 \%$

Xylenxyanol

\subsubsection{Geräte und Software}

\section{Geräte und Software}

Autoklav, Systec 5075 ELV

AxioCam HRM (Kamera)

AxioVision 4.8 Software Paket

Binokularmikroskop

CoralDRAW X3, Graphics Suite, Version 13
AppliChem, Darmstadt, Deutschland

AppliChem, Darmstadt, Deutschland

PAA, Pasching, Österreich

Sigma, Taufkirchen, Deutschland

AppliChem, Darmstadt, Deutschland

AppliChem, Darmstadt, Deutschland

Roth, Karlsruhe, Deutschland

Merck Millipore, Darmstadt, Deutschland

Sigma-Aldrich, Taufkirchen, Deutschland

Roth, Karlsruhe, Deutschland

Gibco, Karlsruhe, Deutschland

AppliChem, Darmstadt, Deutschland

Lonza, Basel, Schweiz

AppliChem, Darmstadt, Deutschland

Sigma-Aldrich, Taufkirchen, Deutschland

AppliChem, Darmstadt, Deutschland

Sigma-Aldrich, Taufkirchen, Deutschland

Sigma-Aldrich, Taufkirchen, Deutschland

Gibco, Karlsruhe, Deutschland

Qiagen, Hilden, Deutschland

Qiagen, Hilden, Deutschland

Roth, Karlsruhe, Deutschland

AppliChem, Darmstadt, Deutschland

Roth, Karlsruhe, Deutschland

Sigma-Aldrich, Taufkirchen, Deutschland

AppliChem, Darmstadt, Deutschland

Sigma-Aldrich, Taufkirchen, Deutschland

AppliChem, Darmstadt, Deutschland

Roth, Karlsruhe, Deutschland

Merck, Darmstadt, Deutschland

\section{Hersteller}

Systec, Wettenberg, Deutschland

Zeiss, Jena, Deutschland

Zeiss, Jena, Deutschland

Zeiss, Jena, Deutschland

Coral Corporation, Ottawa, Ontario, Canada 
Eismaschine, Scotsman®

Elektrophoresekammer für Western Blots

(Mini-PROTEAN® 3 Cell-System)

Elektrophoresekammer für DNA-Auftrennung

(Mini-Sub-Cell GT)

Entwicklungsmaschine für Röntgenfilme Curix 60

Feinwaage, BL210S

Fluoreszenzlichtquelle HXP 120 (KüblerCodix)

Fluoreszenz Mikroskop Axioplan

Fluoreszenz Mikroskop Axiovert

Fluor-S ${ }^{\mathrm{TM}}$-Multilmager (UV-Gerät)

Gefrierschrank $-20^{\circ} \mathrm{C}$

Gefrierschrank $-80^{\circ} \mathrm{C}$

Heizblock ThermoStat plus

Inkubator für Bakterienkulturen $37^{\circ} \mathrm{C}$

Inkubator für Zellkulturen $\left(37^{\circ} \mathrm{C}, 5 \% \mathrm{CO}_{2}\right)$

Kühlschränke

Magellan 3

Messzylinder

Microsoft Office Excel 2007

Microsoft Office PowerPoint 2007

Microsoft Office Word 2007

Mikrowelle silver edition

Motor-Pipettierhelfer accu-jet ${ }^{\circledR}$ pro

Neubauer-Zählkammer

Nucleofector ${ }^{\mathrm{TM}}$ II Device

$\mathrm{pH}-$ Meter

Photometer (Biophotometer)

Photometer

Photometer, ELISA-Photometer Tecan RainBow

Petrischalen (Durchmesser $10 \mathrm{~cm}$ und $20 \mathrm{~cm}$ )

Pipetten

Präparationsbesteck

Cohan-Vannas Spring Scissors $(5,7 \mathrm{~cm})$

Dumont \#5-Mirror Finish Forceps $(11 \mathrm{~cm})$

Quantity One 4.2.1

Rollmixer

Sauger

Schüttler Gyro rocker Stuart SSM3 3D mini

Schüttler (Amplifikation Mini-Präp)

Schüttler (Amplifikation Mega-Präp)
Frimont, Mailand, Italien

Bio-Rad, München, Deutschland

Bio-Rad, München, Deutschland

AGFA, Düsseldorf, Deutschland

Sartorius, Göttingen, Deutschland

Zeiss, Jena, Deutschland

Zeiss, Jena, Deutschland

Zeiss, Jena, Deutschland

Bio-Rad, München, Deutschland

Liebherr, Biberach, Deutschland

Heraeus, Hanau, Deutschland

Eppendorf, Hamburg, Deutschland

Gesellschaft für Labortechnik,Burgwedel, Deutschland

Heraeus, Hanau, Deutschland

Liebherr, Biberach, Deutschland

Tecan, Crailsheim, Deutschland

Duran, Wertheim, Deutschland

Microsoft, Unterschleißheim, Deutschland

Microsoft, Unterschleißheim, Deutschland

Microsoft, Unterschleißheim, Deutschland

Bosch, Stuttgart, Deutschland

Brand, Wertheim, Deutschland

Roth, Karlsruhe, Deutschland

Lonza, Basel, Schweiz

Sartorius, Göttingen, Deutschland

Eppendorf, Hamburg, Deutschland

Bio-Rad, München, Deutschland

Tecan, Crailsheim, Deutschland

Roth, Karlsruhe, Deutschland

Gilson, Villiers le Bel, Frankreich

FST (Fine Science Tools), Heidelberg, Deutschland

Bio-Rad, München, Deutschland

Dynalab Corp., Rochester, NY USA

Schütt Labortechnik, Göttingen, Deutschland

Dynalab Corp., Rochester, NY USA

Heidolph Instruments, Schwabach, Deutschland

New Brunswick Scientific, Enfield, USA 
Sonificator

Stereoskop Stemi 2000

Sterilbank mit Abschirmung, LaminAir HB 2448

Sterilbank ohne Abschirmung, Hera guard

Spannungsquelle, EPS 301

Transferkammer, Mini-PROTEAN®

Elektrophorese-System

Vortex-Mixer 7-2020

Waage, LE 6202S

Wasserbad

Wasserreiniger, PureLab plus

Wippe

Zellschaber

Zentrifugen Centrifuge 5415R, 5810R, 5415D

Zentrifuge Biofuge fresco

\subsubsection{Puffer und Lösungen}

\section{Puffer/Lösungen}

Agarosegel

BCA-Farblösung

Boratpuffer

BSA-Standardprotein

CPI $(25 x)$

DAPI-Lösung

DNA-Ladepuffer 6-fach

ECL (enhanced chemiluminiscence)

Elektrophoresepuffer (10x)
Bandelin, Berlin, Deutschland

Zeiss, Jena, Deutschland

Heraeus, Hanau, Deutschland

Heraeus, Hanau, Deutschland

Amersham Pharmacia Biotech, Freiburg,

Deutschland

Bio-Rad, München, Deutschland

NeoLab, Heidelberg, Deutschland

Sartorius, Göttingen, Deutschland

Gesellschaft für Labortechnik, Burgwedel, Deutschland

Elga Labwaters, Ransbach-Baumbach, Deutschland

NeoLab, Heidelberg, Deutschland

Sarstedt, Nümbrecht, Deutschland

Eppendorf, Hamburg, Deutschland

Heraeus, Hanau, Deutschland

\section{Herstellung}

$1 \%$ Agarose $(1,5 \mathrm{~g}), 1,3 \%$ Ethidiumbromid $(2 \mu \mathrm{l})$ in $150 \mathrm{ml}$ TBE-Puffer

$2 \%$ Reagenz B in Reagenz A

150 mM Borsäurein $\mathrm{H}_{2} \mathrm{O}_{\text {dest. }}$; $\mathrm{pH} 8,4$ steril filtrieren

$10 \mu \mathrm{g} / \mu \mathrm{l}$ BSA in Lysepuffer

1 Tablette $\mathrm{CPI}$ in $2000 \mathrm{ml}$ Ampuwa- $\mathrm{H}_{2} \mathrm{O}$

$20 \mu \mathrm{g} \mathrm{DAPI}+180 \mu \mathrm{l} \mathrm{CH}{ }_{3} \mathrm{OH}+39800 \mu \mathrm{l}$ PBS

0,15 \% Bromphenolblau, 0,15\%

Xylenxyanol, $40 \%$ Saccharose in $\mathrm{H}_{2} \mathrm{O}_{\text {dest. }}$.

DNase-Lösung DNase in CMF lösen,

Endkonzentration $5 \mathrm{mg} / \mathrm{ml}$

Lösung 1:

2,5 mM (100 $\mu \mathrm{l})$ Luminol

0,4 mM (44 $\mu \mathrm{l})$ P-Coumarsäure

$0,1 \mathrm{M}(1 \mathrm{ml})$ Tris-Chlorid

in $(8,85 \mathrm{ml}) \mathrm{H}_{2} \mathrm{O}_{\text {dest. }}$; $\mathrm{pH} 8,5$

Lösung 2:

$6 \mu \mathrm{l} 30 \%$ iges $\mathrm{H}_{2} \mathrm{O}_{2}$

$0,1 \mathrm{M}(1 \mathrm{ml})$ Tris-Chlorid

in $(9 \mathrm{ml}) \mathrm{H}_{2} \mathrm{O}_{\text {dest. }}$; $\mathrm{pH} 8,0$

Direkt vor dem Gebrauch werden beide Lösungen im Verhältnis 1:1 gemischt.

$250 \mathrm{mM}$ Tris

1,9 M Glycin

$1 \%$ SDS 
Glucoselösung $5 \%$

HKME-Puffer

Lysepuffer für Zelllysate

Milchlösung $5 \%$

Mowiol $\circledast$ (coverslip mounting solution)

Paraformaldehyd-Lösung (4 \%)

PBS

$\mathrm{H}_{2} \mathrm{O}_{\text {dest. }}$

Sammelgel für Western-Blots $5 \%$ (Angaben für 2 Gele)

TBE (Tris-Borsäure-EDTA-Puffer)

TBS (Tris-gepufferte Salzlösung)

TBS-T (TBS mit Tween)

Transferpuffer

Trenngel für Western-Blots (15\%) (Angaben für 2 Gele)

Tris/SDS-Puffer $4 \times \mathrm{pH} 6,8$ in $\mathrm{H}_{2} \mathrm{O}_{\text {dest. }}$.

zur Gelelektrophorese 1:10 mit

$\mathrm{H}_{2} \mathrm{O}_{\text {dest. }}$ mischen $(=1 \mathrm{x}$

Elektrophoresepuffer)

$5 \mathrm{ml} 45 \%$ ige Glucoselösung, $45 \mathrm{ml} \mathrm{H}_{2} \mathrm{O}$ Ampuwa

10 mM HEPES, $\mathrm{pH}$ 7,2,

$142 \mathrm{mM} \mathrm{KCl}$,

$5 \mathrm{mM} \mathrm{MgCl}_{2}$,

$1 \mathrm{mM}$ EDTA,

in $\mathrm{H}_{2} \mathrm{O}_{\text {dest. }}$

$940 \mu$ l HKME-Puffer,

$40 \mu \mathrm{l} \mathrm{CPI} \mathrm{(25x),}$

$10 \mu \mathrm{l} 100 \mathrm{mM}$ DTT,

$10 \mu \mathrm{l}$ Igepal

$5 \mathrm{~g}$ Milchpulver in $100 \mathrm{ml}$ TBS-T

$5 \mathrm{~g}$ Mowiol $\Theta+20 \mathrm{ml}$ PBS ( $1 \mathrm{~h}$ bei $40^{\circ}$ Crühren)

$+10 \mathrm{ml}$ Glycerin ( $1 \mathrm{~h}$ bei RT rühren),

Zentrifugation bei $500 \mathrm{rpm} 15 \mathrm{~min}, \mathrm{pH} 8,0+$ $0,3 \mathrm{ml} \%$ iges $\mathrm{NaN}_{3}+$ Propylgallat

(1 Spatelspitze auf $10 \mathrm{ml}$ ), rühren bei RT über Nacht, 4000 rpm 20 min

$40 \mathrm{~g}$ Paraformaldehyd in $1000 \mathrm{ml}$ PBS $(1 \mathrm{~h}$ bei $60^{\circ} \mathrm{C}$ rühren; filtriert, $\mathrm{pH} 7,4$ (mit $1 \mathrm{M}$ $\mathrm{NaOH})$

9,55 g PBS-Pulver in $1000 \mathrm{ml} \mathrm{H}_{2} \mathrm{O}_{\text {dest.; }}$; steril filtriert

mittels Wasserreiniger PureLab Plus gereinigtes $\mathrm{H}_{2} \mathrm{O}$

$3,05 \mathrm{ml} \mathrm{H}_{2} \mathrm{O}_{\text {dest. }}$

$1,25 \mathrm{ml}$ Tris/SDS-Puffer 4x pH 6,8

$0,65 \mathrm{ml} 30 \%$ iges Rotiphorese-Gel

$0,025 \mathrm{ml} \mathrm{10 \% iges} \mathrm{Ammoniumperoxidsulfat}$

$0,005 \mathrm{ml}$ TEMED

$84 \mathrm{mM}$ Tris-Chlorid, $89 \mathrm{mM}$ Borsäure, $2 \mathrm{mM}$ $\mathrm{Na}_{2}$-EDTA in $\mathrm{H}_{2} \mathrm{O}$

$150 \mathrm{mM} \mathrm{NaCl}$

$50 \mathrm{mM}$ Tris

in $\mathrm{H}_{2} \mathrm{O}_{\text {dest. }}$.

$0,1 \%$ Tween in TBS; $\mathrm{pH} 7,6$

$25 \mathrm{mM}$ Tris-Chlorid

$192 \mathrm{mM}$ Glycin

$20 \% \mathrm{H}_{2} \mathrm{O}$

in $\mathrm{H}_{2} \mathrm{O}_{\text {dest. }}$; $\mathrm{pH} 8,3$

$4,25 \mathrm{ml} \mathrm{H}_{2} \mathrm{O}_{\text {dest. }}$

$4,25 \mathrm{ml}$ Tris/SDS-Puffer $4 \times \mathrm{pH} 8,8$

$8,5 \mathrm{ml} 30 \%$ iges Rotiphorese-Gel

$85 \mu \mathrm{l}$ 10\%ige Ammoniumperoxidsulfat-

Lösung

$8,5 \mu$ I TEMED

$0,5 \mathrm{M}$ Tris

$0,4 \%$ SDS

in $\mathrm{H}_{2} \mathrm{O}_{\text {dest. }}$; $\mathrm{pH} 6,8$ 
Tris/SDS-Puffer 4x pH 8,8

Trypsin-Lösung

\subsubsection{Kulturmedien}

\section{Kulturmedium}

CMF-Ampuwa ( $\mathrm{Ca}^{2+}, \mathrm{Mg}^{2+}$-frei)

CMF-Medium $\left(\mathrm{Ca}^{2+}, \mathrm{Mg}^{2+}\right.$-frei)

LB-Medium

LB-Agar

MDN-Medium

(midbrain dopaminergic neuron)

MDN-Medium mit FCS

\subsubsection{Gebrauchsmaterialien}

\section{Material}

Blotting-Filterpapiere

Blotting-Schwämme

Glasplatten

Glasspaltplatten

Kämme

\subsubsection{Verbrauchsmaterialien}

\section{Material}

Auslaufpipetten ( $5 \mathrm{ml}, 10 \mathrm{ml}, 25 \mathrm{ml}$ )

Chemiluminiszenzfilme

(Amersham Hyperfilm ${ }^{\mathrm{TM}}$ ECL)

Deckgläser rund (Coverslips)

Filter, steril (Filtropur S 0.2)

Nukleofektions-Kit

(Nukleofektionslösung, sterile Küvetten und

Transferpipetten)

Objektträger
1,5 M Tris, 0,4 \% SDS

in $\mathrm{H}_{2} \mathrm{O}_{\text {dest. }}$; $\mathrm{pH} 8,8$

0,25 \% Trypsin in CMF; pH 7,4

\section{Herstellung}

$10 \%$ HBSS (10x) in Ampuwa- $\mathrm{H}_{2} \mathrm{O}$;

$\mathrm{pH} 7,4$ mittelsNatriumhydrogenkarbonat einstellen

50 ml HBSS 10x in sterilem $\mathrm{H}_{2} \mathrm{O}_{\text {dest.; }}$; $\mathrm{pH} 7,4$ mittels Natriumhydrogenkarbonat einstellen

$25 \mathrm{~g}$ LB-Pulver in $1000 \mathrm{ml} \mathrm{H} \mathrm{H}_{2} \mathrm{O}_{\text {dest. }}, \mathrm{pH}$ 7,0; autoklaviert und versetzt mit Antibiotikum Ampicillin 100 \%g/m

$11,2 \mathrm{~g} \mathrm{LB}-A g a r$ in $350 \mathrm{ml} \mathrm{H} \mathrm{O}_{\text {dest.; }}$; autoklaviert und auf ca. $60^{\circ} \mathrm{C}$ abgekühlt, versetzt mit Antibiotikum Ampicillin 100 $\mathrm{g} / \mathrm{ml}$

94,09 ml DMEM IF-12

$2 \mathrm{ml}$ Glucose

$0,71 \mathrm{ml} \mathrm{BSA}$ für Zellkultur

$1 \mathrm{mI} P S N$

$1 \mathrm{ml} \mathrm{N} 1$

$1 \mathrm{ml}$ Glutamin

$200 \mu$ Insulin

MDN-Medium + $10 \%$ FCS

\section{Hersteller}

Roth, Karlsruhe, Deutschland

Bio-Rad, München, Deutschland

Bio-Rad, München, Deutschland

Bio-Rad, München, Deutschland

Bio-Rad, München, Deutschland

\section{Hersteller}

Sarstedt, Nümbrecht, Deutschland

GE Healthcare, München, Deutschland

R. Langenbrinck, Emmendingen, Deutschland

Sarstedt, Nümbrecht, Deutschland

Lonza, Rockland, ME USA

Knittel Glass, Braunschweig, Deutschland 
Parafilm

Pipettenspitzen mit Filter (div. Größen) Biosphere

Pipettenspitzen (div. Größen)

Nitrocellulosemembran PROTAN®

Reaktionsgefäße $(0,5 \mathrm{ml}, 1,5 \mathrm{ml}, 2 \mathrm{ml})$ (Epicup)

Reaktionsgefäße (10 ml, $15 \mathrm{ml}, 50 \mathrm{ml})$ (Falcon-Röhre)

Spritze $20 \mathrm{ml}$ (Discardit $\left.{ }^{\mathrm{TM}} \mathrm{II}\right)$

Zellkulturplatten (6 Well, 24 Well, 96 Well)

\subsubsection{Antikörper}

\section{Antikörper}

Anti-human- $\alpha$-Synuclein-Maus-Antikörper

Anti-rat\&human- $\alpha$-Synuclein-Maus-Antikörper

Anti-TH-Kaninchen-Antikörper

Anti-Tubulin-Maus-Antikörper

Anti-Maus-IgG-Cy3-Ziegen-Antikörper

Anti-Kaninchen-IgG-Cy3-Ziegen-Antikörper

Anti-Maus-IgG-Cy5-Ziegen-Antikörper

Anti-Maus-IgG-HRP-Ziegen-Antikörper

Anti-Ratten-IgG-HRP-Ziegen-Antikörper
Pechiney Plastic Packaging, Menesha, WI USA

Sarstedt, Nümbrecht, Deutschland

Sarstedt, Nümbrecht, Deutschland

Schleicher \& Schuell Bioscience $\mathrm{GmbH}$,

Dassel, Deutschland

Eppendorf, Hamburg, Deutschland

Sarstedt, Nümbrecht, Deutschland

BD, Heidelberg, Deutschland

Sarstedt, Nümbrecht, Deutschland

\section{Hersteller}

Invitrogen, Karlsruhe, Deutschland

BD Biosciences, Heidelberg, Deutschland

Zytomed, Berlin, Deutschland

Sigma-Aldrich, Taufkirchen, Deutschland

Dianova, Hamburg, Deutschland

Dianova, Hamburg, Deutschland

Invitrogen, Karlsruhe, Deutschland

Santa Cruz Biotechnology, Santa Cruz, CA USA

Santa Cruz Biotechnology, Santa Cruz, CA USA

\subsubsection{Plasmide}

\section{Plasmid}

eGFP

S. 2.3 .1

a-Syn-WT

s. 2.3 .2

a-Syn-A30P

s. 2.3 .2

a-Syn-A53T

s. 2.3 .2

\subsubsection{Versuchstiere}

Die Rattenembryonen wurden am Embryonaltag 14 (E14) aus weiblichen verpaarten WistarRatten entnommen. Sämtliche Versuche erfolgten in Einklang mit den Tierschutzrichtlinien des Landes Niedersachsen (AZ T10/28). 


\subsection{Primäre Mittelhirnneuronenzellkultur}

Die Präparation der primären Mittelhirnneurone erfolgte modifiziert nach dem Protokoll von Shimoda (Shimoda et al. 1992). Primäre Zellen werden direkt aus dem entsprechenden Gewebe entnommen und zeichnen sich durch die Eigenschaften, postmitotisch zu sein, sich nur noch begrenzt teilen zu können und unter Kulturbedingungen eine begrenzte Lebensdauer zu besitzen, aus (Schmitz 2011). Der Vorteil dieser Zellkultur ist, dass sie bezüglich ihrer Aktivität und Funktion ein physiologischeres Bild im Vergleich zu immortalisierten Zelllinien aufweist.

Es wurde eine primäre neuronale Zellkultur mit einem möglichst hohen Anteil dopaminerger Neurone $(8,28 \%$, s. 3.1) gewonnen. Es konnte gezeigt werden, dass die Zellkultur keine Gliazellen im Rahmen der angewandten Präparation aufweist (Saal et al. 2015). Die Arbeitsvorgänge untergliedern sich in die folgenden Schritte: Plattenvorbereitung, Präparation der Zellen, Lösung des Zellverbandes, Zellaussaat und Kultivierung.

\subsubsection{Plattenvorbereitung}

Zur Erzeugung eines optimalen Wachstumsmilieus der primären neuronalen Zellkultur wurden die Wachstumsplatten mit einem Untergrund (Matrix) beschichtet, auf dem die Neurone gut adhärieren können. Zu diesem Zweck wurde eine Poly-L-OrnithinHydrobromid/Laminin-Matrix verwendet, wie sie für zahlreiche Kulturen gut etabliert ist (Gstraunthaler und Lindl 2013). Poly-L-Ornithin-Hydrobromid ist eine synthetische Aminosäure, die eine künstliche positive Ladung erzeugt und zusammen mit Laminin, ein Bestandteil der Basallamina, für ein verbessertes Anhaften sowie Wachstum und verbesserte Migration der Zellen auf der Kulturplatte sorgt (Flanagan et al. 2006).

Zur Herstellung von Zelllysaten wurden 6-Kavitäten-Zellkulturplatten (6-well-plates) mit einer Wachstumsoberfläche von $9,5 \mathrm{~cm}^{2} /$ Kavität verwendet. Für die Immunzytochemie wurden kleinere 24-Kavitäten-Zellkulturplatten (24-well-plates) mit einer Wachstumsoberfläche von $2 \mathrm{~cm}^{2} /$ Kavität ausgewählt.

Die Kavitätenplatten wurden unter möglichst sterilen Bedingungen mit Ampuwa gewaschen und anschließend in Ampuwa 1:10 verdünntem Poly-L-Ornithin-Hydrobromid (50 mg in $50 \mathrm{ml}$ Boratpuffer gelöst) mindestens 4 Stunden bei Raumtemperatur und anschließend mehrere Tage bei $4^{\circ} \mathrm{C}$ inkubiert. Die Lamininbeschichtung erfolgte am Tag vor der Präparation durch erneutes Waschen der Platten mit Ampuwa und Benetzung mit in $\mathrm{CMF}\left(\mathrm{Ca}^{2+}\right.$, $\mathrm{Mg}^{2+}$-free Hank's balanced salt solution) gelöstem Laminin (1:1000) mit $500 \mu \mathrm{l} /$ Kavität bei einer 24Kavitätenplatte oder $2 \mathrm{ml} /$ Kavität in eine 6-Kavitätenplatte und anschließender Inkubation im Inkubator bei $37^{\circ} \mathrm{C}$ über Nacht.

Unmittelbar vor der Präparation wurden die Platten abermals mit CMF gewaschen und für die spätere Aussaat mit jeweils $400 \mu \mathrm{l} /$ Kavität bei einer 24-Kavitäten-Platte oder bei einer 6- 
Kavitätenplatte mit $2000 \mu \mathrm{l} /$ Kavität MDN-Medium (midbrain dopaminergic neuron-Medium) gefüllt und im Inkubator bis zur Ausplattierung (100 $\mu$ Zellsuspension bei einer 24-KavitätenZellkulturplatte oder $500 \mu$ l bei einer 6-Kavitätenplatte) gelagert.

\subsubsection{Herstellung der Zellkultur (MDN-Präparation)}

Ziel der Präparation war die Isolierung der primären Mittelhirnneurone aus dem rostral (zum vorderen Ende des Körpers hin) gelegenen Mittelhirn, dem $1 \mathrm{~mm}^{3}$ großen Tegmentum, das $90 \%$ aller im Rattengehirn vorhandener dopaminergen Mittelhirnneurone, d. $\mathrm{h}$. Tyrosinhydroxylase-positive Neurone (TH-positive), enthält (Shimoda et al. 1992). Hierzu wurden Mittelhirne aus Rattenembryonen von trächtigen Wistar-Ratten am 14ten Embryonaltag (E14) entnommen.

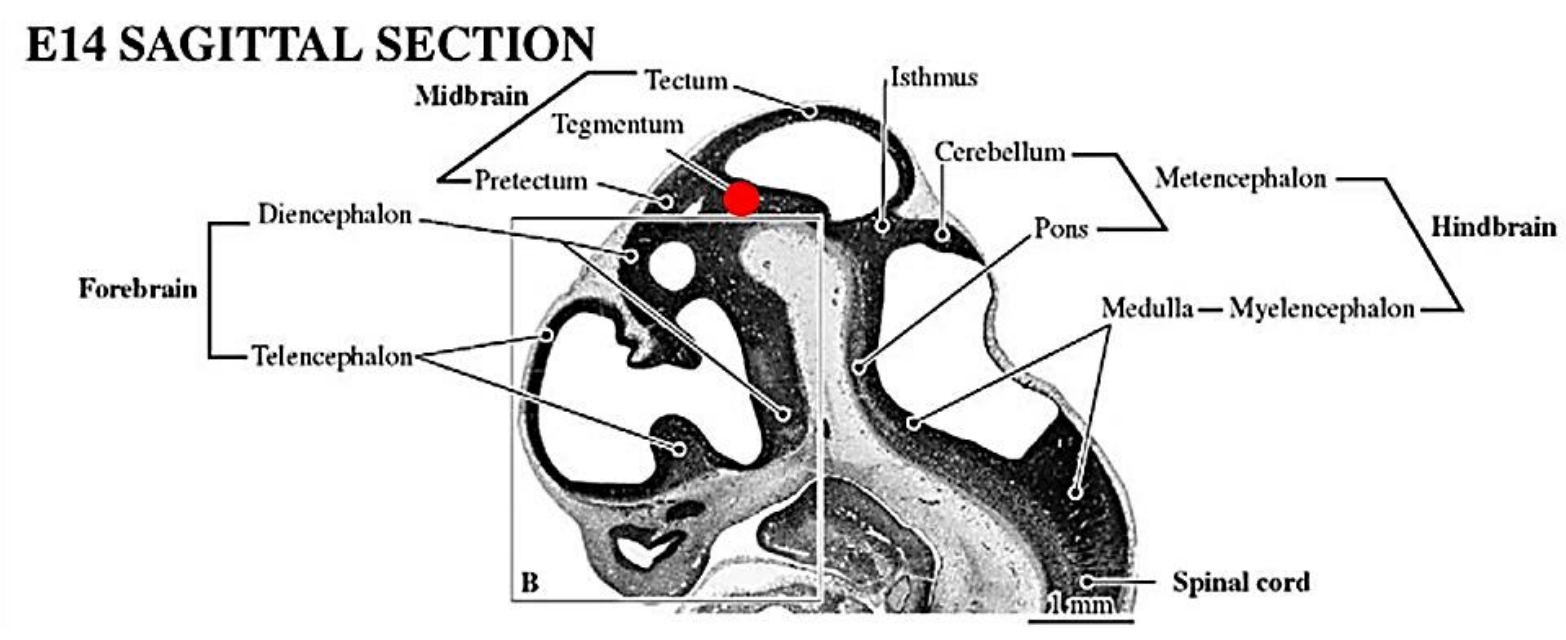

Abb. 2.1 Rattenembryo-Gehirn (E14). Sagittaler, $10 \mu \mathrm{m}$ dicker Paraffinschnitt, Nisselfärbung. Die dopaminergen Neurone liegen im Tegmentum $\left(1 \mathrm{~mm}^{3}\right)$ des Mesencephalons, roter Markierungspunkt (modifiziert aus "The Rat Nervous System“, Paxinos 2004, mit Erlaubnis von ELSEVIER).

Das Vorgehen der Präparation der Mittelhirnneurone basierte mit Abweichungen auf dem Protokoll von Shimoda et al. 1992.

Die trächtigen Ratten werden in einem luftdicht geschlossenen Käfig mittels langsamer, kontinuierlicher Einleitung von $\mathrm{CO}_{2}$ narkotisiert. Die Hyperkapnie führt zum Atemstillstand und Hypoxie, an welcher die Ratte verstirbt. Rasch nachdem der Tod sicher eingetreten ist, folgt die Desinfektion der ventralen Rumpfseite mit $70 \%$ Ethanol. Anschließend erfolgt die Eröffnung des Abdomens durch einen medianen Längsschnitt. Der Uterus mit den darin enthaltenen Embryonen (E14) wird mit einer chirurgischen Pinzette gefasst und an der Uterusbasis mit einem Schnitt gelöst.

Unter einer offenen Sterilbank (ohne Abschirmung) werden die Embryonen samt Uterus in eine Petrischale $(20 \mathrm{~cm})$ mit $4^{\circ} \mathrm{Ckaltem}$ CMF gelegt und von Fettgewebe und Blut befreit. Nach der Reinigung werden sie in eine neue Petrischale mit $\mathrm{CMF}\left(4^{\circ} \mathrm{C}\right)$ überführt und dort aus dem Uterusgewebe und der Fruchtblase mit einem Schnitt gelöst. Anschließend werden 
die Embryonen mit einer kleineren chirurgischen Pinzette im Rumpfbereich gefasst, in eine kleinere Petrischale überführt und auf Eis gestellt.

Zur Präparation der Mittelhirnneurone wird das Mittelhirn unter stereoskopischer Sicht (Stereoskop, Zeiss) identifiziert, keilförmig im 90-Winkel (s. Abb. 2.2 und Abb. 2.3 (a)) herausgeschnitten, an der geschlossenen konvexen Seite entlang der Medianlinie mit einem Schnitt geöffnet (s. Abb. 2.3 (a)) und aufgeklappt, sodass die linke und rechte Mittelhirnhälfte nun von ihrer medialen Seite zu sehen ist und sich als eine Schmetterlingsfigur darstellt (s. Abb. 2.3(b)). Die lateralen Enden mit dem meningealen Gewebe werden entfernt (s. Abb. 2.3(b)). Sodann wird das restliche Hirnhautmaterial mit einer Pinzette fixiert gehalten. Mit der geschlossenen Spitze der Schere wird das Mittelhirngewebe unterminiert und die Hirnhäute in einer gegensinnigen Bewegung abgestreift (s. Abb. 2.3 (c)). Das separierte Mittelhirngewebe wird in eine vorbereitete Falcon-Röhre (Reaktionsgefäß $10 \mathrm{ml}$ ) mit CMFAmpuwa auf Eis überführt. Anschließend wird die Glasplatte, die in einem Petrischalendeckel (unter dem Objektiv) liegt, mit CMF gewaschen, um meningeales Restgewebe und Erythrozyten zu entfernen. Diese Schritte wurden so oft wiederholt, bis alle Embryonen verarbeitet waren. Ein Muttertier lieferte eine maximale Anzahl von 20 Embryonen. Das Mittelhirngewebe musste in weiteren Schritten bearbeitet werden, um einzelne Mittelhirnneurone zu gewinnen.

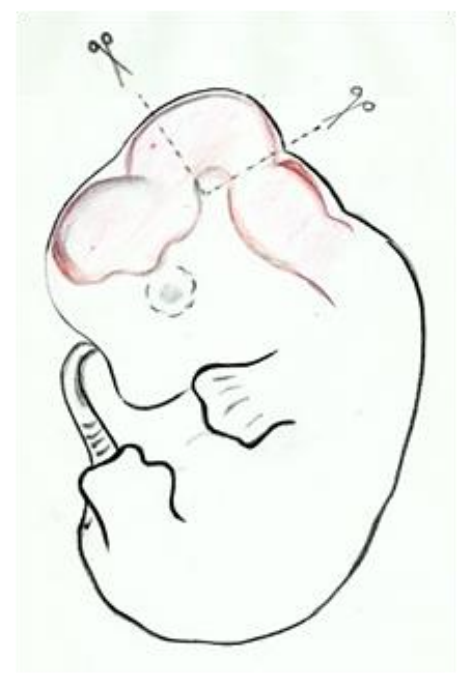

Abb. 2.2 Schematische Darstellung eines Rattenembryos (E14). Eingezeichnet ist die Schnittführung im $90^{\circ}$-Winkel (Keil) zur Entnahme der Mittelhirnregion, welche die dopaminergen Neurone enthält. 


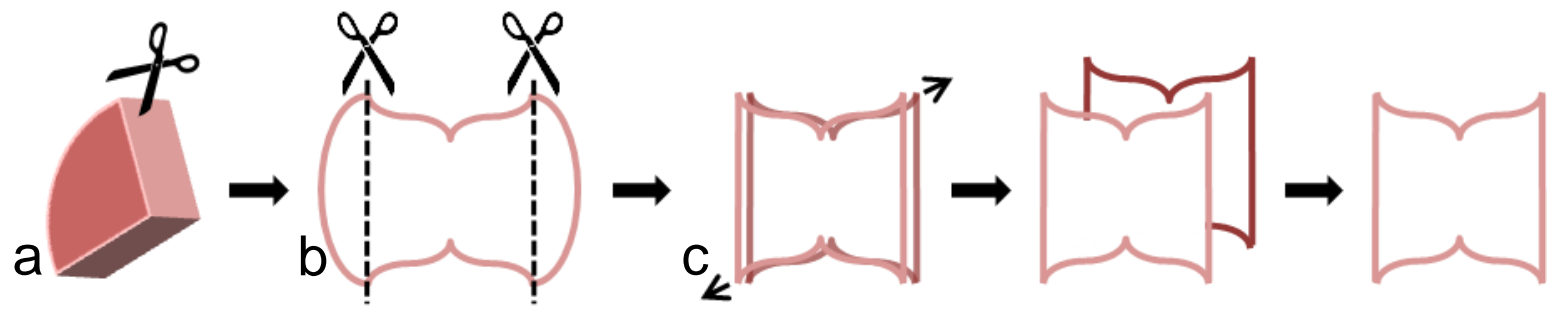

Abb. 2.3 Schritte der Präparation des Mittelhirns. a) Keilförmig exzidierte Mittelhirnregion mit Eröffnung der konvexen, ehemals äußeren Schicht. b) Aufklappen des Mittelhirn-Keils (Schmetterlingsfigur) und Entfernung der lateralen Enden entlang der gestrichelt dargestellten Schnittführung. c) Separation des menigealen Gewebes vom restlichen Mittelhirngewebe.

\subsubsection{Lösung des Zellverbandes}

In mehreren Teilschritten wurde unter einer Sterilbank (mit Abschirmung) das gewonnene Mittelhirngewebe mit dem Ziel behandelt, die einzelnen Neurone möglichst schonend aus ihrem Verband zu lösen, um diese anschließend im Nährmedium zu kultivieren.

Dazu wurden die Zellen in einem Falcon-Röhrchen 1 Minute bei $20^{\circ} \mathrm{C}$ und $800 \mathrm{rpm}$ zentrifugiert und der Überstand (CMF) mit der Pasteurpipette und dem Sauger entfernt,das gewonnene Zellpellet mit $1 \mathrm{ml}$ Trypsin resuspendiert und für 11 Minuten in ein37 ${ }^{\circ} \mathrm{C}$ warmes Wasserbad gestellt. Anschließend wurden $60 \mu \mathrm{l}$ DNAse in das Falcon-Röhrchen hinzugefügt und für 1 Minute bei $20^{\circ} \mathrm{C} / 800 \mathrm{rpm}$ zentrifugiert. Der Überstand (Trypsin und DNAse) wurde entfernt und das Zellpellet mit $900 \mu$ FCS resuspendiert, mit einer $1000 \mu$ l-Pipettenspitze 4mal trituriert und für 1 Minute stehen gelassen, damit die Zellen sedimentieren. Der Überstand wurdeanschließend in ein frisches, $12 \mathrm{ml}$ fassendes Falcon-Röhrchen überführt. Das Zellsediment wurde erneut mit $900 \mu$ l Nährmedium resuspendiert und mit einer speziell angefertigten Glaspasteurpipette (kleine Öffnung ca. $100 \mu \mathrm{m}$ ) 4-5x trituriert und homogenisiert bis die Flüssigkeit milchig-trüb geworden ist. Die homogenisierte Flüssigkeit (aus ihrem Verband gelöste Zellen) wurde in das neue Falcon-Röhrchen mit FCS-Überstand überführt und für 4 Minuten bei $20^{\circ} \mathrm{C} / 800 \mathrm{rpm}$ zentrifugiert, der Überstand wiederum entfernt und verworfen und das Pellet mit genau $1000 \mu$ l Nährmedium resuspendiert und noch 1-2x trituriert bis das Pellet sich vollständig homogenisierte ( $=1000 \mu$ Z Zellsuspension). Die Zellsuspension konnte in weiteren Schritten als Zellkultur ausplattiert werden.

\subsubsection{Zellaussaat}

Für die nach einer Transfektion kultivierten primären Mittelhirnneurone wurde eine Zelldichte von ca. $4 \times 10^{5}$ Neurone $/ \mathrm{cm}^{2}$ ausplattiert und kultiviert (z. B. $800.000 /$ Kavität in einer 24Kavitätenplatte).

Die Bestimmung der Zellkonzentration erfolgte in einer Neubauer Zählkammer. 
Die Zellen wurden mit jeweils $100 \mu \mathrm{l}$ pro Kavität in kreisender Bewegung langsam ausplattiert und zusätzlich im Anschluss die gesamte Kavitätenplatte im und gegen den Uhrzeigersinn gekreist.

\subsubsection{Kultivierung}

Die Zellen wurden in einer 24- oder 6-Lochkulturplatte bei $37^{\circ} \mathrm{C}, 5 \% \mathrm{CO}_{2}$ und in mit Wasserdampf-gesättigter Atmosphäre in $500 \mu \mathrm{l}$ respektive $2500 \mu \mathrm{l}$ Medium/Kavität kultiviert. Bei Konditionen, die ohne Nukleofektion angelegt wurden, erfolgte ein Mediumwechsel von $250 \mu \mathrm{l}$ am ersten und dritten Tag nach der Präparation.

Nach einer Transfektion durch Anwendung des Nukleofektionsverfahrens wurden 2/3 des Mediums bereits nach ca. 3 Stunden ausgetauscht [Zellkulturtage = days in-vitro 0 (DIV0)], um die adhärenten Zellen möglichst schnell von Rückständen der Nukleofektionslösung und avitalen Zellen bzw. Zelldetritus zu befreien. 24 Stunden später (DIV1) erfolgte der Austausch der Hälfte des Mediums und nach weiteren 24 Stunden (DIV2) ein erneuter Wechsel der Hälfte des Mediums. Der letzte Mediumwechsel erfolgte weitere 24 Stunden später (DIV3) vor der am fünften Tag durchgeführten Zellfixierung bzw. Lysatherstellung (DIV5).

\subsubsection{Nukleofektionsverfahren}

Die Transfektion durch die Nukleofektionsmethode dient dem Zweck, dass die eingebrachte DNA mittels Plasmid direkt in den Zellkern der Zelle gelangt, dort transkribiert wird und zur transienten Expression der Proteine $\alpha$-Syn (WT), seiner Mutanten A30P und A53T und dem Kontrollprotein eGFP führt. Die Transfektion der a-Syn-Plasmide erfolgte immer als CoTransfektion mit dem eGFP-Plasmid, welches als Indikator für den Transfektionserfolg diente. Die Kontrollgruppe wurde ausschließlich mit dem eGFP-Plasmid in einer äquivalenten Dosis transfiziert. Die isolierte eGFP-Expression hat keinen Effekt auf den Zellstoffwechsel und ist nicht zytotoxisch (Chalfie et al. 1994).

Die Transfektion der Zellen mit den Plasmiden mittels Nukleofektion wurde durch einen Nukleofektor (Nucleofector ${ }^{\mathrm{TM}}$ II Device, Lonza), der ein elektrische Feld erzeugt, erzielt. Zur Herstellung eines elektrischen Kontaktes besitzt die zugehörige Küvette Elektroden aus Alluminium. Die Zellsuspension wird in die Küvette pipettiert, welche in den Nukleofektor platziert wird (s. Abb. 2.4).

Bei der Nukleofektion handelt es sich um eine spezielle Form der Elektropration, bei der durch ein elektrisch erzeugtes Feld die Permeabilität der Zellmembran, durch eine lokale Zerstörung der Membranintegrität, transient erhöht wird und mittels einer speziellen Nukleofektionslösung (Pufferlösung) die Plasmid-DNA direkt in den Nukleus gelangt (Zeitelhofer et al. 2009, Maasho et al. 2004). Durch mögliche toxische Effekte des 
Verfahrens kann die Zellviabilität je nach Zelltyp stark beeinträchtigt werden. Aus diesem Grund musste die Elektroporationsmethode der vulnerablen primären Mittelhirnneurone zunächst optimiert werden.

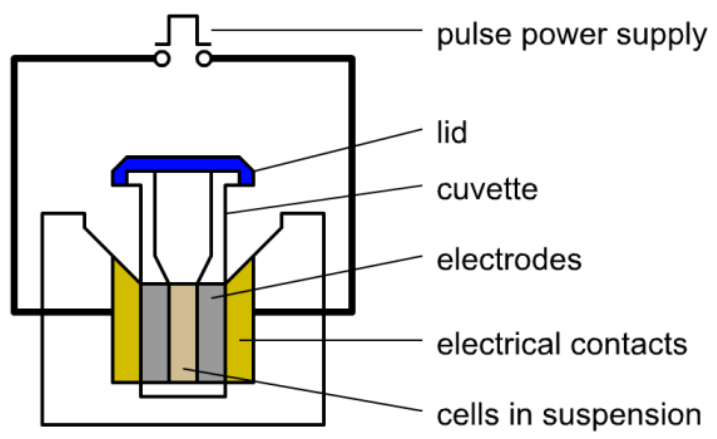

Abb. 2.4 Schematische Darstellung eines Elektroporators mit Küvette (Abbildung unverändert aus Wheeler 2007). Die Küvette besteht an zwei Seiten aus Aluminiumelektroden, über die der elektrische Fluss gewährleistet wird.

Als Transfektionszubehör wurde das Basic Nucleofector Kit for primary mammalian neurons/ Basic Primary Neurons Nucleofector ${ }^{\circledR}$ Kit (VPI-1003), bestehend aus der Basic Neuron Nucleofector ${ }^{\mathrm{TM}}$ Solution 2,25 ml (Nukleofektionslösung), dem Supplement 0,5 ml (Zusatz), den Küvetten und sterilen Plastikpipetten, genutzt. Der Nukleofektor (Nucleofector ${ }^{\mathrm{TM}}$ II Device, Lonza) verfügt über mehrere Programme, die mit unterschiedlicher Intensität und Dauer das elektrische Feld erzeugen. Für die primären mesencephalen Mittelhirnneurone wurden von der Firma Lonza vier verschiedene Programme zur Auswahl gestellt: A-033, C013, G-013 und O-005. Alle vier Programme wurden für die Transfektion gestestet (s. 3.2.1). Das Programm G-013 zeigte hierbei die besten Ergebnisse und wurde für alle weiteren Versuche verwendet.

\subsubsection{Nukleofektionsprotokoll}

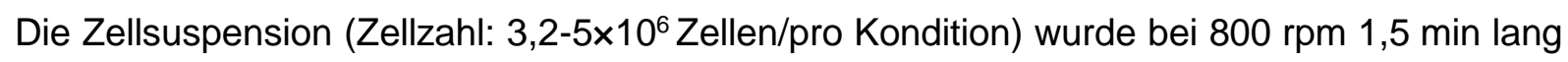
zentrifugiert und der Überstand vollständig verworfen, um Interaktionen mit der Nukleofektionslösung zu vermeiden. Die Resuspension des Zellpellets erfolgte mit $90 \mu \mathrm{l}$ Nukleofektionslösung [plus dessen Zusatzkomponente (Supplement)] und $10 \mu$ l einer Lösung des jeweiligen Plasmids (z. B. $3 \mu \mathrm{g}$ a-Syn-Plasmid $+2 \mu \mathrm{g}$ eGFP-Plasmid verdünnt in Ampuwa). Die resultierende Mischung wurde in die Transfektionsküvette überführt und die Nukleofektion erfolgte mit dem Programm G-013 (s. 3.2.1). Nachkommend wurde die Zellsuspension mit einer sterilen Plastikpipette auf das errechnete Zielvolumen mit Nährmedium (+ $10 \%$ FCS) aufgefüllt [z. B. für 4 Konditionen:400 $\mu$ l-100 $\mu$ l (Zellsuspension) $=300 \mu \mathrm{l}$ (Nährmedium)] und in ein vorbereitetes Epicup überführt. Anschließend erfolgte die Aussaat und Kultivierung der Zellen nach bereits beschriebener Methodik. 


\subsection{Plasmide}

\subsection{1 eGFP-Plasmid}

Das eGFP-Plasmid exprimiert unter der Kontrolle eines hSYN-Promotors (humaner Synapsin-Promotor) und eines H1 RNA-Promotors das enhanced green fluorescent protein (eGFP.), welches eine grüne Autofluoreszenz besitzt und bei allen Experimenten als Kontrollprotein diente. Zur weiteren Steigerung der Transkription wurde ein Simian Virus 40Promotor (= SV40) in die Plasmide eingebaut (Koch et al. 2011). Das Plasmid wurde freundlicherweise von Prof. Uwe Michel zur Verfügung gestellt (Koch et al. 2011).

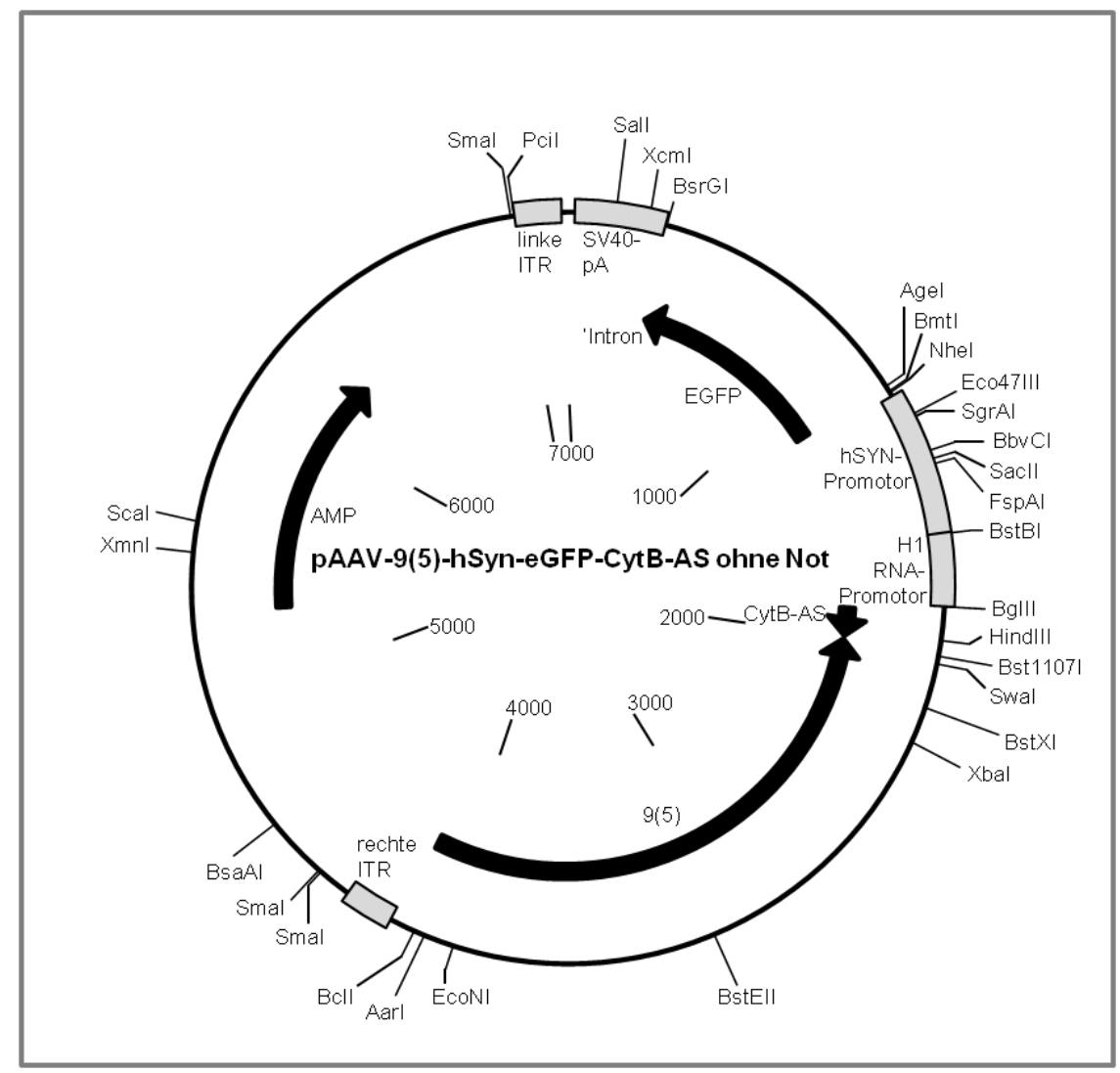

Abb. 2.5 Schematische Darstellung des eGFP-Plasmids. Zahlen entsprechen Basenpaaren (bp); AMP: AmpicillinResistenz; hSYN: humaner Synapsinpromotor; ITR: umgekehrte endständige Wiederholung (inverted terminal repeat); SV40 pA: Simian Virus 40 Polyadenylat-Sequenz; H1 RNA-Promotor: Polymerase III H1 RNA-Promotor-Sequenz; CytbAS: partielle Sequenz von Cytochrom B. In die Plasmidkarte sind die Schnittstellen verschiedener Restriktionsenzyme eingezeichnet.

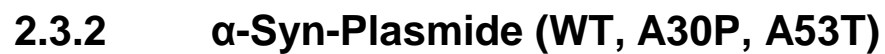

Diese Plasmide wurden freundlicherweise von der Arbeitsgruppe um Dr. S. Kügler (AG Bähr, Göttingen, Deutschland) bereitgestellt und exprimieren humanes $\alpha$-Syn in seiner WildtypForm sowie in zwei Parkinson-relevanten Mutationen (A30P und A53T). Sämtliche Plasmide sind in ihrer Grundstruktur (s. Abb. 2.6) gleich aufgebaut. 


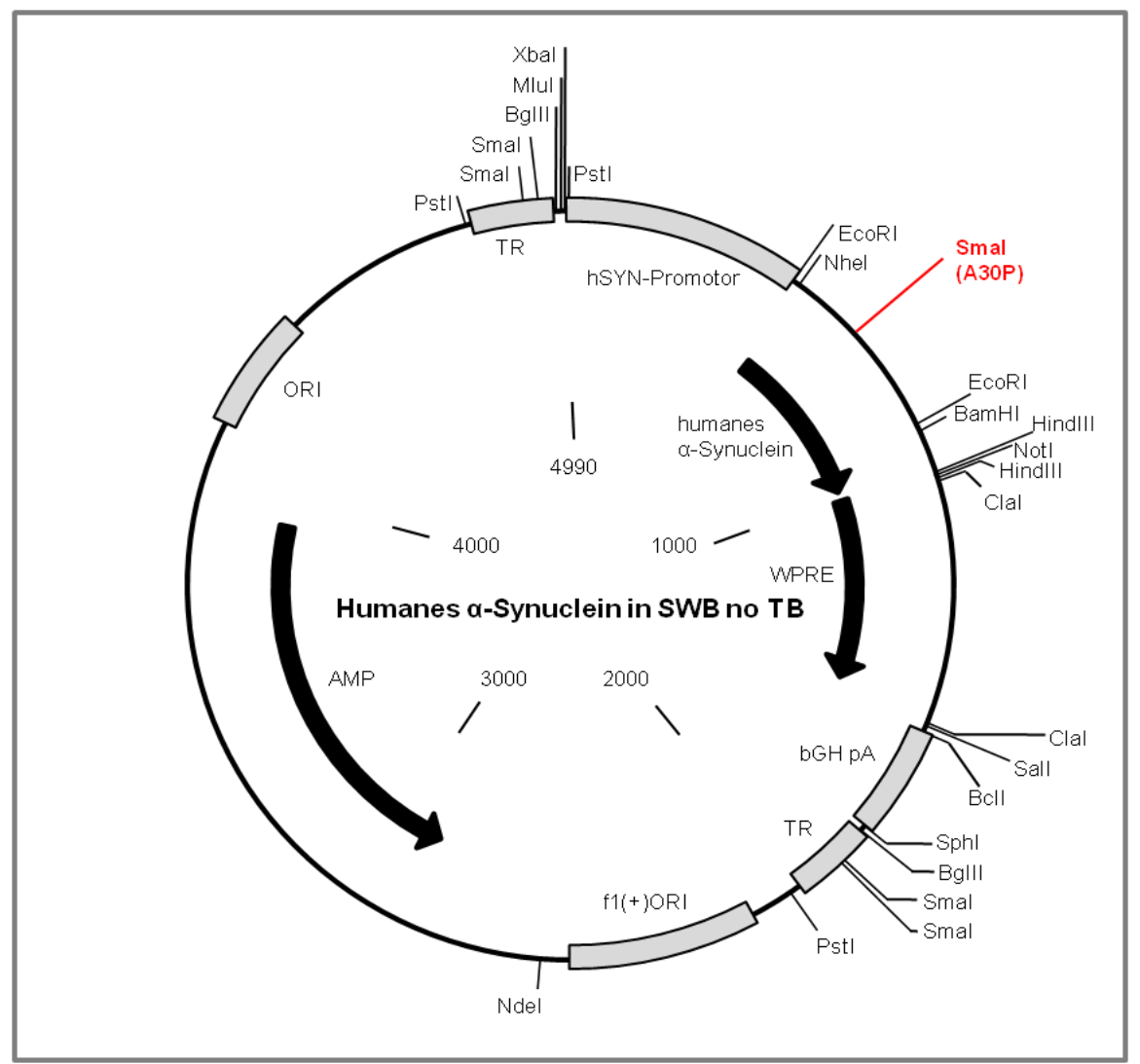

Abb. 2.6 Humanes a-Syn-exprimierendes Plasmid. Zahlen entsprechen Basenpaaren (bp); AMP: Ampicillin-Resistenz; WPRE: Woodchuck Hepatitis Virus posttranskriptionelles Regulationselement (Woodchuck hepatitis virus posttranscriptional regulatory element); ORI: Replikationsursprung (origin of replication); f1(+) ORI: Replikationsursprung zur einzelsträngigen Replikation von f1-Phagen; TR: endständige Wiederholung (terminal repeat); bGH pA: bovines Wachstumshormon (bovine growth hormone) mit Polyadenylat-Sequenz; hSYN: humaner Synapsin-Promotor. In die Plasmidkarte sind die Schnittstellen verschiedener Restriktionsenzyme eingezeichnet. Die durch die A30P-Mutation neu entstehende Sma1-Schnittstelle ist rot hervorgehoben.

Sie beinhalten einen humanen Synapsin-Promotor (hSYN-Promotor), der die Expression der Proteine reguliert. Zusätzlich ist auf allen Plasmiden eine Ampicillin-Resistenz codiert (AMP), um im Rahmen der bakteriellen Vervielfältigung eine Selektion der korrekten Plasmide mittels Antibiotika-Behandlung zu ermöglichen. Lediglich die zu transkribierenden Proteine unterscheiden sich zum einen durch die Mutationen (WT, A30P oder A53T) und zum anderen durch ein UA-Tag bei der A53T-Mutation, welches jedoch die Funktionalität des Proteins nicht beeinflusst und bei einem etwas größeren Plasmid ein leicht erhöhtes Molekulargewicht zur Folge hat. Durch die A30P-Mutation entsteht eine neue Schnittstelle für das Restriktionsenzym Sma1, sodass das Vorhandensein dieser Mutation in der restriktionsenzymatischen Verdauung nachgewiesen werden kann (s. Abb. 2.7). Die Plasmide wurden nach Amplifikation mittels Restriktionsenzymverdau (s. auch 2.3.7) auf ihre Korrektheit untersucht.

\subsubsection{Plasmidamplifikation in E.coli}

E.coli hat, wie einige andere Bakterien auch, die Eigenschaft, ringförmige DNA (sog. Plasmide) unabhängig von ihrem eigenen Genom vervielfältigen zu können. Deshalb wurden 
Plasmide in kompetente E.coli Bakterien eingebracht, um anschließend von den Bakterien das gewünschte Plasmid vervielfältigen zu lassen (Transformation). Kompetenz ist die Eigenschaft von Zellen extrazelluläre DNA aufnehmen zu können (Palchevskiy und Finkel 2006). Für alle $\alpha$-Syn-Plasmide wurde Ampicillin als Antibiotikum zur Selektion der richtigen Klone verwendet (s. 2.3.2).

Nach Impfung einer Agar-Platte wurden je 4 Bakterien-Kolonien pro Plasmid gepickt, in Falcon-Röhrchen (Reaktionsgefäß $10 \mathrm{ml}$ ) mit je 2,5 ml Antibiotika-haltigem (Ampicillin 1:1000) LB-Medium (Luria Bertani) überführt und bei $37^{\circ} \mathrm{C}$, schräg stehend und schüttelnd bei 180 rpm für ca. 14 Stunden inkubiert. Anschließend wurde die Hälfte jedes Ansatzes zur Plasmid-DNA-Extraktion mittels Mini-Präparation genutzt, um nach erfolgtem Nachweis der korrekten Plasmid-Amplifikation mittels Restriktionsenzymverdau die übrige Hälfte für das Bakterienwachstum zur Plasmidgewinnung durch eine Mega-Präparation zu nutzen.

\subsubsection{Mini-Präparation}

Plasmid-Präparationen dienen dazu, die in den transformierten Bakterien amplifizierte Plasmid-DNA zu gewinnen und aufzureinigen. Dies kann je nach Bedarf in verschiedenen Größendimensionen erfolgen. Über eine Mini-Präparation können etwa $20 \mu \mathrm{g}$ Plasmid-DNA, in einer Maxi-Präparation bis zu $500 \mu \mathrm{g}$ und in einer Mega-Präparation bis zu $2500 \mu \mathrm{g}$ (laut QIAGEN-Herstellerangaben) gewonnen werden.

Die Mini-Präparation wurde mit Hilfe des QIAprep Spin Miniprep Kit und den mitgelieferten Puffern (P1, P2, N3, PB und PE), entsprechend dem beiliegenden Protokoll, durchgeführt.

Aus den Röhrchen der Plasmidamplifikation wurden $2 \mathrm{ml}$ abpipettiert, in ein Epicup überführt und zentrifugiert. Nach einer Zentrifugation bei 13000 rpm für 1 Minute wurde das Bakterienenthaltende Pellet mit $250 \mu \mathrm{l}$ Puffer P1 resuspendiert und dann mit $250 \mu \mathrm{l} \mathrm{Puffer} \mathrm{P2} \mathrm{für}$ maximal fünf Minuten bei Raumtemperatur inkubiert, während das Epicup per Hand geschwenkt wurde. Dies diente der Lysierung der Bakterien. Anschließend wurden $350 \mu \mathrm{l}$ Puffer N3 zur Präzipitation der DNA zugefügt, geschwenkt und 10 Minuten bei 13000 rpm zentrifugiert. Im Pellet war nun der Bakteriendetritus, genomische DNA und Proteine gesammelt, im Überstand lagen die Plasmide in isolierter Form vor. Der Überstand wurde auf die QIA spin column® (ff. Säule) überführt und die Säule bei 13000 rpm für eine Minute zentrifugiert. Dabei verblieb die DNA in der Säule und der Durchfluss wurde verworfen. Mit Hilfe von $500 \mu \mathrm{l}$ Puffer PB, der auf die Säule pipettiert wurde, und anschließender Zentrifugation bei 13000 rpm für 1 Minute wurde die DNA gewaschen, vorhandene Nukleasen inaktiviert und der Durchfluss wieder verworfen. Anschließend wurde abermals mittels $750 \mu$ l Puffer PE gewaschen, für eine Minute zentrifugiert und der Durchfluss verworfen. Um letzte Restbestände zu entfernen und die DNA zu trocknen wurde nochmals für eine Minute zentrifugiert. Zuletzt wurde die Säule in ein neues Epicup (1,5 ml) überführt 
und die DNA mittels $50 \mu \mathrm{l}$ Puffer $\mathrm{AE}$, einer einminütigen Inkubation und erneuter Zentrifugation eluiert.

Nach der Mini-Präparation wurden die aufgereinigten Plasmide mittels Restriktionsenzymverdau (s. 2.3.5) und anschließender Agarosegelelektrophorese (s. 2.3.5.1) auf Korrektheit geprüft. Sowohl die Reinheit als auch die Konzentration der gewonnenen Plasmid-DNA wurde mit einem Bio-Photometer bestimmt (s. 2.3.6).

\subsubsection{Mega-Präparation}

Über eine Mega-Präparation können etwa $2500 \mu \mathrm{g}$ Plasmid gewonnen werden. Ausgangspunkt für eine Mega-Präparation war ein auf genomische Korrektheit geprüfter Mini-Präparationsansatz. Die Bakterien aus der Amplifikation wurden hierzu in jeweils $500 \mathrm{ml}$ Antibiotika-haltiges LB-Medium, welches sich in Kolbenflaschen befand, überführt und über Nacht bei $37^{\circ} \mathrm{C}$ geschüttelt bei 180 rpm inkubiert. Die Mega-Präparation wurde mit Hilfe des Qiagen Plasmid Mega Kits, entsprechend den Herstellerangaben, durchgeführt. Die Durchführung der Mega-Präparation ist der Durchführung der Mini-Präparation bis auf einige zusätzliche Reinigungsschritte mittels 70\%igem Ethanol und der Präzipitation der DNA mittels Isopropanol nahezu identisch, sodass hier auf die ausführliche Darstellung in 2.3.4 verwiesen wird. Auch nach der Mega-Präparation erfolgte die Kontrolle der Plasmide über einen Restriktionsenzymverdau und anschließender Agarose-Gelelektrophorese. Die DNAKonzentration und Reinheit wurden ebenfalls mit dem Bio-Photometer bestimmt (s. 2.3.6). Die entstandenen Plasmid-Ansätze wurden für alle nachfolgenden Experimente verwendet.

\subsubsection{Bestimmung der DNA-Konzentration und Reinheit (OD-Bestimmung)}

Die Bestimmung der optischen Dichte der Plasmidlösung diente der Reinheitskontrolle und Konzentrationsbestimmung.

Zum einen musste, damit bei der Elektroporation identische Plasmidmengen transfiziert werden, die DNA-Menge in der Plasmidlösung bestimmt werden und zum anderen hängt die Erfolgsrate der Elektroporation stark von der Reinheit der Plasmide ab. Eine unreine Lösung würde zu einem vermehrten Zelltod durch die Transfektion führen. Die Reinheit der Plasmidlösung konnte durch Bestimmung der optischen Dichte evaluiert werden.

Die Konzentration einer DNA-Lösung wurde photometrisch bei einer Wellenlänge von $260 \mathrm{~nm}$ in einer Quarzküvette bestimmt. Aus der Extinktion der Lösung kann die Konzentration berechnet werden. Das Verhältnis der Nukleinsäure-Absorption zur ProteinAbsorption gibt zusätzlich Auskunft über die Reinheit einer Nukleinsäure-Lösung. Das Absorptionsmaximum für Proteine liegt, basierend auf der Absorption der aromatischen Aminosäurereste, bei $280 \mathrm{~nm}$. Das Verhältnis der OD 260 (Optische Dichte) zur OD 280 zeigt somit an, wie stark eine DNA-Lösung durch Ethanol-Rückstände, Kontaminationen und 
Reste von Proteinen verunreinigt ist (Sambrook und Russell 2001, Wilfinger et al. 1997). Ein Verhältnis von 1,8 spricht für eine reine DNA-Isolierung. Ist die Nukleinsäure-Lösung kontaminiert, so ist der Wert deutlich kleiner.

Der Mittelwert aus 2 unabhängigen Einzelmessungen lag für den $\alpha$-Syn-WT bei 1,80 $\pm 0,01$ (OD260/280), für das $\alpha$-Syn-A30P-Plasmid bei 1,75 $\pm 0,01$ (OD260/280), für das $\alpha$-SynA53T-Plasmid bei 1,69 $\pm 0,01$ (OD260/280) und für die eGFP-Plasmid-Lösung bei $1,80 \pm 0,01$ (OD260/280).

Die gute Reinheit der DNA-Lösungen konnte hiermit bestätigt und die einzelnen Konzentrationen berechnet werden.

\subsubsection{Restriktionsenzymverdau}

Der Restriktionsenzymverdau dient der Kontrolle der Plasmidamplifikation. Hiermit wurde vornehmlich ausgeschlossen, dass es während einer Amplifikation zu Fehlern in der DNALänge und damit zu einem anderen Genprodukt gekommen ist.

Restriktionsenzyme sind Restriktionsendonukleasen, die DNA an bestimmten Stellen (sog. Palindrome) erkennen, „schneiden“ können und folglich verschieden lange DNA-Stücke entstehen lassen, je nachdem an welcher Stelle sie die DNA trennen (Mülhardt 2008). Über die spezifische Länge und somit der Anzahl der Basenpaare (bp) der DNA-Abschnitte können diese durch den Vergleich mit einer Restriktionskarte (Plasmidkarte) identifiziert werden.

Aus der Plasmidkarte (s. Abb. 2.5 und 2.6) sind die verschiedenen Schnittstellen für unterschiedliche Restriktionsenzyme zu entnehmen. Es wurden die Enzyme SMA1, Bgl2 und Not1 ausgewählt.

Der erste Restriktionsverdau wurde mit dem Enzym SMA1 durchgeführt. Es wurden 0,5 $\mu \mathrm{l}$ Enzym, $1 \mu$ l von Puffer 4 sowie 200 ng DNA-Menge zusammengefügt und mit Ampuwa auf ein Gesamtvolumen von $10 \mu \mathrm{l}$ aufgefüllt. Die Mischung wurde für 30 Minuten bei $25^{\circ} \mathrm{C}$ Raumtemperatur inkubiert. Danach wurden 2,5 $\mu$ l 5x-DNA-Puffer hinzugefügt und auf ein Agarose-Gel (s. 2.3.7.1) auftragen. Für den zweiten enzymatischen Verdau mit den Restriktionsenzymen Bgl2 und Not 1 erfolgte die Hinzugabe des Enzympuffers 3 und die Inkubation bei $37^{\circ} \mathrm{C}$. Die übrigen Angaben blieben gleich zum Verdau mit SMA1.

\subsubsection{Agarose-Gelelektrophorese}

Die Agarose-Gelelektrophorese dient der Auftrennung der im Restriktionsverdau entstandenen DNA-Fragmente nach ihrer Größe. Die negativ-geladenen Fragmente wandern durch das elektrisch erzeugte Feld zum positiven Pol und werden dabei nach ihrer Größe aufgetrennt. 
Für die Agarose-Gelelektrophorese wurde ein 1\%iges Agarose-Gel für eine große Elektrophoresekammer mit $1 \mu \mathrm{l}$ Ethidiumbromid-Zusatz gegossen. Für jede Probe wurden $10 \mu \mathrm{l}$ in die Taschen des Gels pipettiert. Außerdem wurden $5 \mu$ DNA-Marker in eine Tasche pipettiert, damit die Größe der einzelnen Fragmente am Ende semiquantitativ abgelesen werden konnte. Die Auftrennung der Fragmente erfolgte bei $100 \mathrm{~V}$ für maximal 2 Stunden. Nach Erreichen der gewünschten Trennungsabstände konnten die DNA-Fragmente mit Hilfe des DNA-interkalierenden und nach Anregung durch UV-Licht (ultraviolettes Licht) fluoreszierenden Ethidiumbromids mit Hilfe des Fluor-S $S^{T M}$-Multilmagerssowie den Softwares Quantity One 4.2.1 und Magellan 3 dargestellt werden.

\subsubsection{Ergebnisse des Restriktionsenzymverdaus}

Durch den Verdau der a-Syn-WT- und a-Syn-A53T-Plasmide mit dem Enzym SMA1 ergeben sich zwei Fragmente, ein Fragment mit einer Größe von 3013 bp und ein weiteres von 1955 bp Größe. Dahingegen führt der Verdau des a-Syn-A30P-Plasmids zu drei Fragmenten, da die Punktmutation zur Bildung einer weiteren Schnittstelle für SMA1 führt. Es entstehen hier Fragmente der Größen 3013 bp, 1265 bp und 690 bp.

Der zweite Restriktionsverdau wurde zusammen mit den Enzymen Bgl2 und Not1 durchgeführt. Für alle drei $\alpha$-Syn-Plasmide ( $\alpha$-Syn-WT, -A30P und -A53T) ergeben sich beim Verdau mit diesen jeweils 3 Fragmente in den Größen 3173 bp, 959 bp und 858 bp (s. Abb. 2.7).

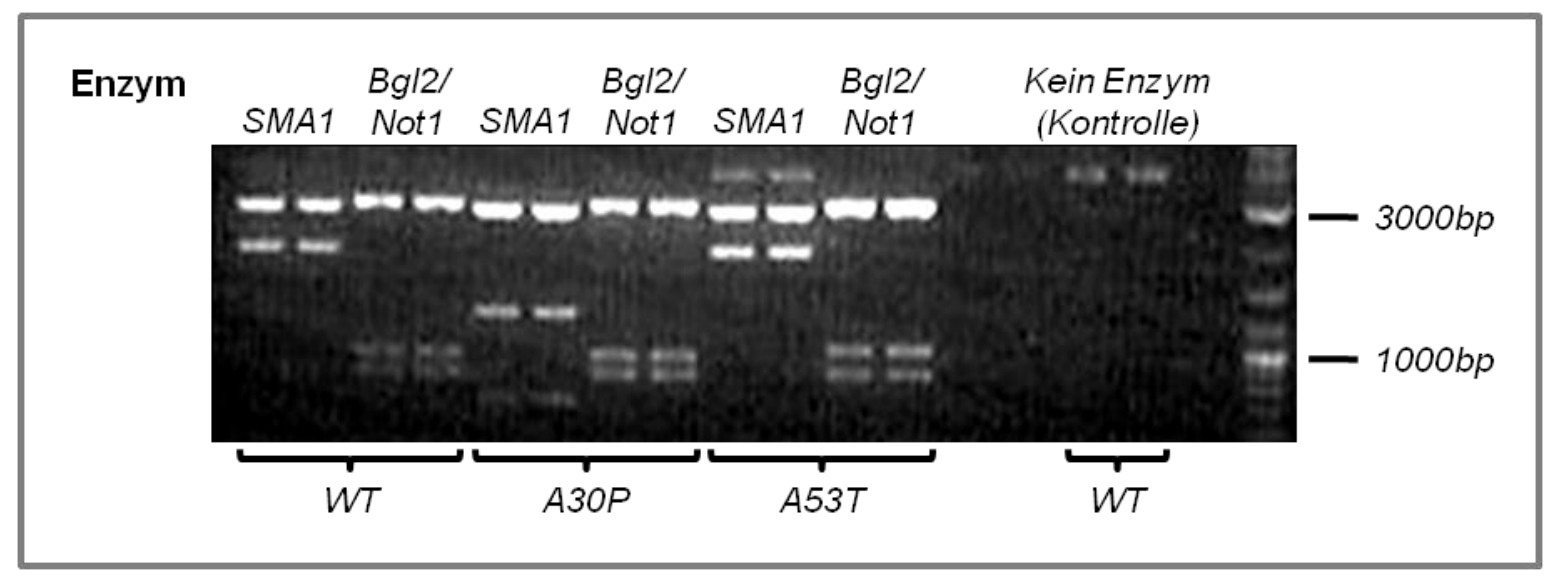

Abb. 2.7 Restriktionsenzymverdau der a-Syn-Plasmide in zweifacher Ausführung. Der Restriktionsenzymverdau zeigt eine korrekte Amplifikation der a-Syn Plasmide (WT, A30P und A53T). Als Kontrolle diente ein Ansatz des a-Syn-WTPlasmids ohne Restriktionsenzym. Basenpaare (bp).

Der Restriktionsenzymverdau für das Kontrollplasmid eGFP wurde mit dem Enzym SMA1 durchgeführt, was zu Fragmenten der Größen 4406 bp, 2861 bp und 11 bp führt,wobei letzteres aufgrund der geringen Größe auf dem Gel nicht eindeutig zu erkennen ist. 


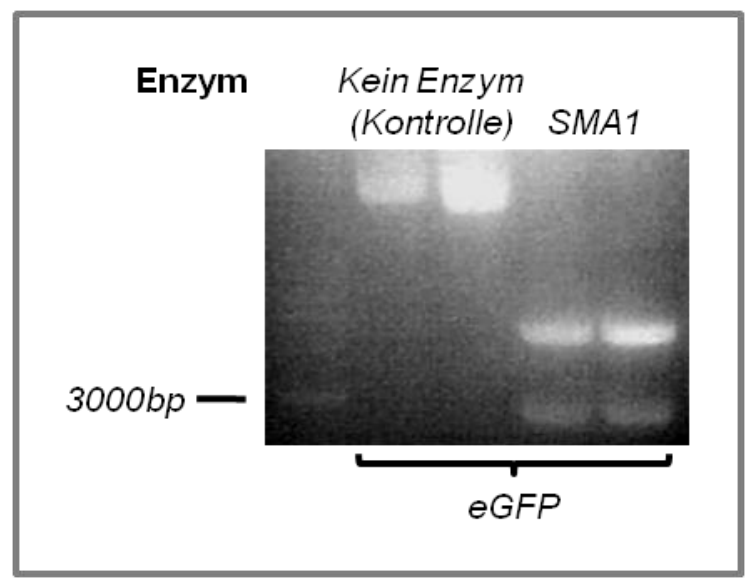

Abb. 2.8 Restriktionsenzymverdau des eGFP-Plasmids in zweifacher Ausführung. Der Restriktionsenzymverdau zeigt eine korrekte Amplifikation von eGFP. Basenpaare (bp).

\subsection{Immunzytochemie der primären Mittelhirnneurone}

Hierzu wurden die Mittelhirnneurone auf zuvor mit Poly-L-Ornithin und Laminin beschichtete, runde Deckgläser (Coverslips) in einer 24-Kavitätenplatte ausgesät.

\subsubsection{Zellfixierung}

Die Zellfixierung erfolgte an DIV5, indem das Medium vorsichtig mittels einer PlastikPasteurpipette aus den Kavitäten der Kulturplatte entfernt und durch $37^{\circ} \mathrm{C}$ warmes PBS ersetzt wurde. Dann wurde das PBS in gleicher Art und Weise entfernt und durch $4 \%$ iges Paraformaldehyd (PFA) ersetzt und die Zellen damit bei $4{ }^{\circ} \mathrm{C}$ für 10 Minuten inkubiert. Anschließend wurde das PFA entfernt und die Zellen dreimal mit PBS gewaschen.

\subsubsection{Zellfärbung}

Nach dem Waschvorgang wurden die Deckgläser mit den darauf befindlichen Neuronen mit höchster Vorsicht aus den Kavitäten geholt und auf eine mit Paraffin abgedeckte, umgekehrte Kulturplatte überführt, die zum Schutz vor Austrocknung mit Wasser gefüllt war. Nach dem vollständigen Entfernen der PBS-Reste mittelsPlastikpipette wurden die Zellen mit Aceton schockgefroren und bei $-20^{\circ} \mathrm{C}$ für 10 Minuten inkubiert. Es folgte der Blockvorgang mit der Block-Lösung $D A K O{ }^{\circledR}$ diluent für 20 Minuten, um unspezifische Bindungen der verwendeten Antikörper zu inhibieren. Nach dem Blocken wurden die Neurone mit dem ersten Antikörper (in entsprechender Verdünnung gelöst in DAKO diluent) bei $4{ }^{\circ} \mathrm{C}$ über Nacht inkubiert (Anti- $\alpha$-Syn-Maus-AK 1:250, Anti-TH-Kaninchen-AK 1:200). Vor der Inkubation mit dem Zweitantikörper wurden die Deckgläser erneut in PBS gewaschen und bei $37^{\circ} \mathrm{C}$ für eine halbe Stunde inkubiert (Cy3-anti-Kaninchen-Ziegen-AK 1:1000, Cy5-antiMaus-Ziegen-AK 1:1000), abermals in PBS gewaschen und dann für 5 Minuten mit DAPI für die Zellkernfärbung inkubiert. Der letzte Waschvorgang erfolgte wiederum in PBS, bevor die 
runden Deckgläser auf Objektträgern in $20 \mu \mathrm{l}$ Mowiol®/Deckglas (erwärmt auf $37^{\circ} \mathrm{C}$ ) eingebettet und bei $4^{\circ} \mathrm{C}$ im Dunkeln getrocknet wurden.

\subsubsection{Fluoreszenzmikroskopie}

Die gefärbten Präparate wurden am Axioplan Fluoreszenzmikroskop mit einem 10-fach- und einem 20-fach-Objektiv mikroskopiert, digital fotografiert (Kamera AxioCam) und über das Programm AxioVision Rel. 4.8 (Carl Zeiss Vision) bearbeitet.

Bei der Fluoreszenzmikroskopie werden Fluoreszenzfarbstoffe (Fluorochrome) mit Licht einer bestimmten Wellenlänge angeregt (Absorbtion) und strahlen nur wenige Nanosekunden später Licht einer anderen Wellenlänge zurück (Emmission).

Das rot-fluoreszierende Indocarbocyanin 3 (Сy3) ist sehr leuchtintensiv und hat ein Exzitationsmaximum (Absorbtion) bei $550 \mathrm{~nm}$ und ein Emissionsmaximum bei $570 \mathrm{~nm}$. Das infrarot-leuchtende Fluorochrom Indodicarbocyanin 5 (Cy5) ist bei $650 \mathrm{~nm}$ maximal angeregt und hat ein Emmisionsmaximum von $670 \mathrm{~nm}$. Das Fluorochrom Cy5 ist für das menschliche Auge kaum sichtbar und kann nur mittels Aufnahme dargestellt und nicht direkt mikroskopiert werden.

Das vom Kontroll-Plasmid exprimierte eGFP diente der Kontrolle der Transfektionseffizienz und Identifikation von transfizierten Neuronen, da es bei erfolgreicher Expression durch seine Eigenfluoreszenz (Autofluoreszenz) bei Anregung grün leuchtet und folglich keiner Färbung bedarf. Es hat ein Exzitationsmaximum bei $490 \mathrm{~nm}$ und ein Emissionsmaximum bei $508 \mathrm{~nm}$.

4',6-Diamidin-2-phenylindol (DAPI) wurde für die Kernfärbung genutzt und ist ein blauer Fluoreszenzfarbstoff, welcher der Markierung von DNA dient und ein Absorbtionsmaximum von $358 \mathrm{~nm}$ und ein Emissionsmaximum von $461 \mathrm{~nm}$ besitzt.

Die digitalen Aufnahmen der Mikroskopie erfolgten über die Kamera AxioCam und mit dem Programm AxioVision Rel. 4.8 (Carl Zeiss Vision). Bei den Standardaufnahmen der Mittelhirnneurone wurden die Bilder in einem definierten Bereich aufgenommen. Dabei wurden die Aufnahmen quer durch die Mitte der runden Deckplatte (Coverslip) gemacht (s. Abb. 2.9), um mögliche systematische Ungleichheiten der Zellverteilung entlang des Durchmessers des Deckgläschens in allen Gruppen gleichermaßen abzubilden (häufig findet sich in der Mitte des Deckgläschens eine etwas höhere Zelldichte als am Rand). So entstanden pro Coverslip 10 Bilder. Die Aufnahmen wurden dann zur statistischen Auswertung genutzt. 


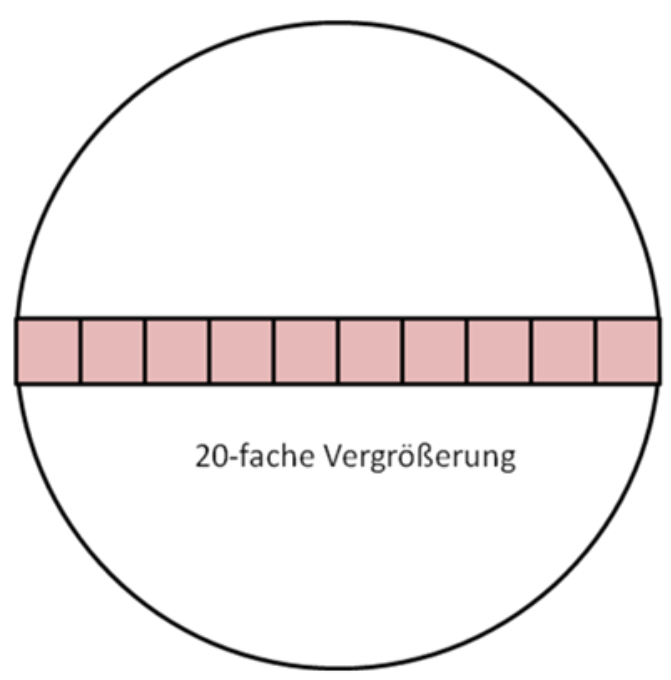

Abb. 2.9 Schematische Darstellung der systematischen Bildaufnahmen eines Deckglases. Dargestellt ist ein Deckglas mit 10 Aufnahmen (rosa Quadrate), dabei entspricht ein kleines Quadrat in etwa einem Gesichtsfeld in 20-facher Vergrößerung.

Bei spezifischer Betrachtung der TH-positiven transfizierten Neurone erfolgten die Aufnahmen, aufgrund der relativ geringen Zelldichte von $8,28 \%$ (s. 3.1), vornehmlich in zelldichten Bereichen, umanschließend zur statistischen Auswertung genutzt zu werden.

\subsubsection{Quantifizierung}

Um die Objektivität der Auswertung zu gewährleisten, erfolgten die Messungen unter verblindeten Voraussetzungen, indem die Versuchsgruppen von einer anderen Person unsystematisch nummeriert wurden. Erst nach Abschluss der quantitativen Auswertung erfolgte die korrekte Zuordnung.

Die Vermessung und Auswertung der Zellmorphologie erfolgte über die Programme ImageJ, CoralDraw und Microsoft-Excel.

\subsubsection{Neuritenlänge}

Bei der Vermessung der Neuritenlängen wurden die Neuriten, d. h. die Dendriten und das Axon der Neurone, um den Einfluss von a-Syn-WT und den pathogenen Mutationsformen auf die Neuritenlänge der mesencephalen primären Neurone beurteilen zu können, einzeln markiert bzw. vermessen.

Es wurden 3 verschiedene Parameter beurteilt. Hierzu wurden sowohl die Anzahl der Neuriten pro Zelle, die durchschnittliche Neuritenlänge eines Neurons, als auch die Neuritengesamtlänge einer Zelle betrachtet.

Die Neuritenlänge wurde mit Hilfe des Programmes ImageJ und dem Plug-In NeuronJ gemessen (Meijerding et al. 2004). Hierfür wurden die Neuriten durch den Kontrastunterschied zum Hintergrund automatisch vom manuell festgelegten Anfangs- und Endpunkt 
markiert, offensichtliche Fehler durch z. B. andere kreuzende Neuriten manuell korrigiert und im Anschluss ihre Gesamtlänge, durchschnittliche Länge und Anzahl ermittelt.
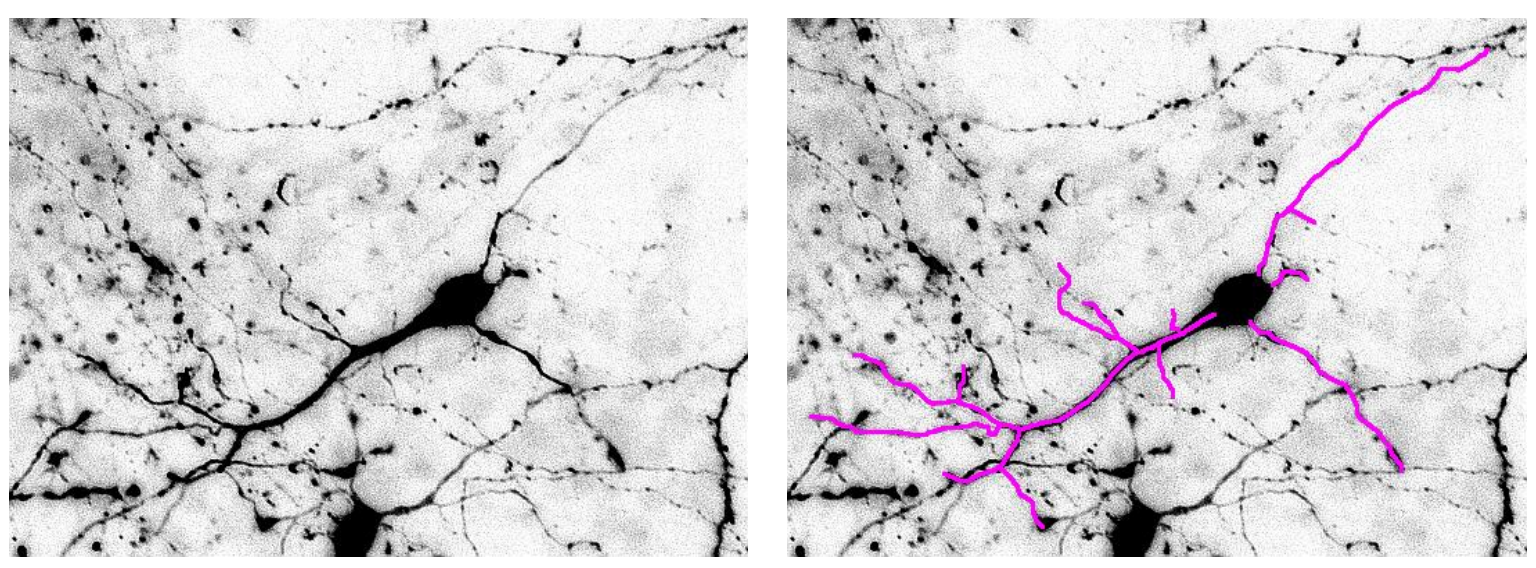

Abb. 2.10 Beispielhafte Darstellung der Neuritenmarkierung zur Analyse der einzelnen Parameter der Neuritenmorphologie. Links: Neuron (TH-Färbung) ohne Markierung. Rechts: Neuron nach teilautomatisierter Neuritenmarkierung mit ImageJ (lila).

\subsubsection{Sholl-Analyse}

Die Sholl-Analyse ist eine quantitative Methode, die von dem Erstbeschreiber Sholl 1953 zur Beschreibung der Dendriten von Neuronen des motorischen und visuellen Kortex erstmals bei der Katze genutzt wurde (Sholl et al. 1953). Dabei wird die Anzahl der Kreuzungen der Dendriten mit einer im Zentrum des Zellkörpers platzierten konzentrisch-zirkulären Schablone an unterschiedlichen Abstandsradien gezählt.

Das Verzweigungsverhalten (branching) wurde in dieser Arbeit durch eine quantitative Analyse aller Neuriten, d. h. des Axons und der Dendriten der Mittlehirnneurone, untersucht. Die Darstellung der markierten Neuriten wurde aus der Neuritenlängenmessung genutzt und als .jpg-Datei in ImageJ geöffnet. Die konzentrisch-zirkulär angeordnete Schablone wurde in CoralDraw erstellt und bei jeder Analyse das Zentrum der Schablone mittig auf den Zellkörper platziert (s. Abb. 2.11). Die konzentrisch angeordneten Kreise hatten Abstände von jeweils $12,5 \mu \mathrm{m}$ zueinander. Für jeden Kreis wurde manuell die Anzahl der Intersektionen, $d$. h. wie oft ein einzelner Kreis von verschiedenen Neuriten gekreuzt wurde, notiert.

Die Ergebnisse der Zählungen wurden in einer Excel-Tabelle notiert und anschließend graphisch dargestellt bzw. die Graphen in PowerPoint weiter bearbeitet. Zur Interpretation wurde die direkte lineareMethode angewandt.

Die lineare Methode ist die Analyse der Funktion $\mathrm{N}(\mathrm{r})$, wobei $\mathrm{N}$ die Anzahl der kreuzenden Neuriten eines Kreises mit dem Radius ( $r$ ) ist. Die direkte Analyse erlaubt dadurch eine Aussage über den kritischen Wert (critical value), das Neuritenmaximum und den Verzweigungsindex (Schoenen-Ramifikationsindex). 
Der kritische Wert ist der Radius an dem es zu einem Maximum an Kreuzungen (Verzweigungen) von Neuriten kommt. Dieser Wert ist eng mit dem Neuritenmaximum verknüpft.

Das Neuritenmaximum ist der Maximalwert der Funktion $\mathrm{N}(\mathrm{r})$, welcher durch den kritischen Wert, also dem entsprechenden Radius mit der höchsten Kreuzungsdichte, spezifiziert wird.

Der Schoenen-Ramifikationsindex dient der Darstellung des Verzweigungsverhaltens einer neuronalen Zelle. Er wird berechnet, indem das Neuritenmaximum durch die Anzahl der primären Neuriten, d. h. den Neuriten, die direkt dem Perikaryon entspringen, dividiert wird.

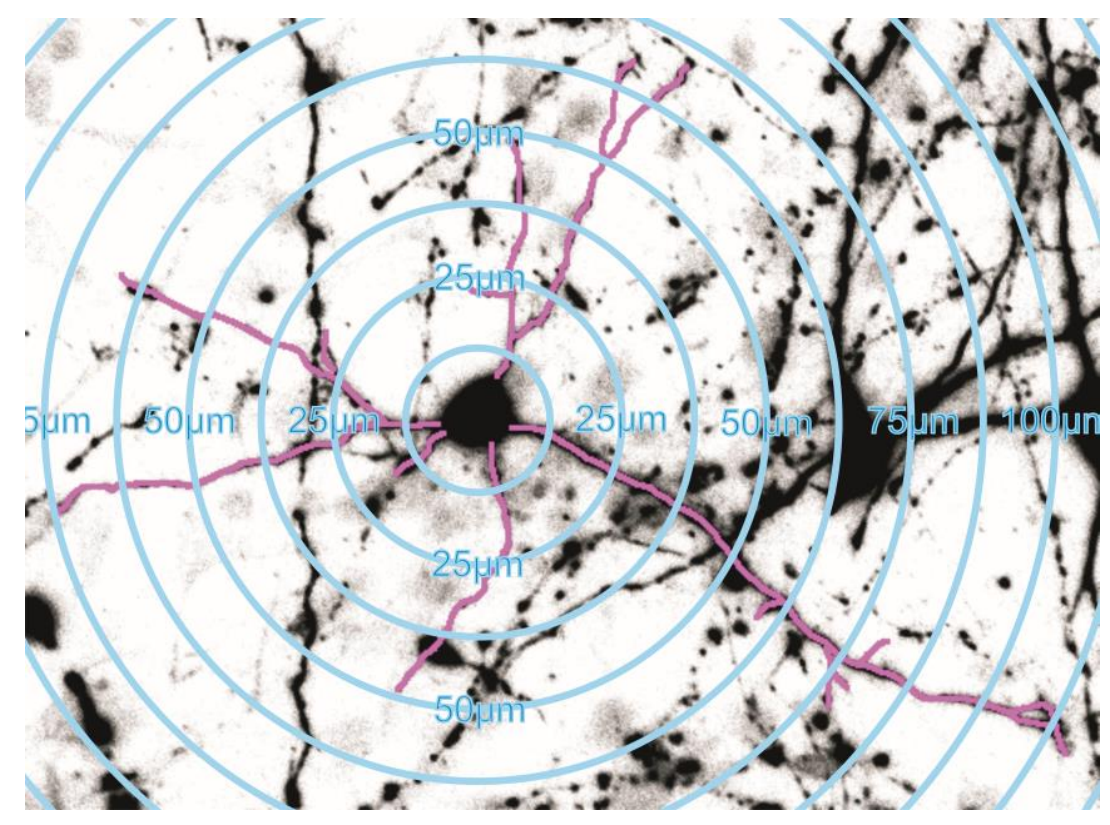

Abb. 2.11 Beispielhafte Darstellung der Sholl-Analyse. Mit Hilfe der Radienschablone erfolgte die Messung der Neuritenkreuzungen je Abstand (12,5 $\mu \mathrm{m}$ je Radius) zur Analyse der einzelnen Sholl-Parameter.

\subsubsection{Zellkörpergröße}

Die Zellkörpergröße wurde vermessen, indem das Perikaryon manuell im Programm ImageJ umfahren und anschließend die Fläche automatisiert berechnet wurde. Die Werte wurden in eine Microsoft Office Excel-Tabelle übertragen und graphisch als Balkendiagramme in Microsoft Office PowerPoint weiter dargestellt.

Zur Umrechnung der Pixelanzahl in $\mu \mathrm{m}$ wurde eine Neubauerkammer mikroskopisch bei gleicher Vergrößerung fotographiert und als Maßstab genutzt.

\subsubsection{Zellzahl}

Die Gesamtzellzahl an TH-positiven Neuronen bzw. die dopaminerge Neuronendichte nach den verschiedenen Plasmid-Transfektionen wurde durch die manuelle Zählung der Zellen mittels Zellzähler (CellCounter) in ImageJ durchgeführt. 


\section{$2.5 \quad$ Western Blot}

\subsubsection{Proteinlysatgewinnung}

Das Lysieren der Zellen dient der Freisetzung (und Isolierung) der enthaltenen Proteine, um diese für den nachfolgenden Western Blot mittels Antikörperdetektion zugänglich zu machen. Der verwendete Lysepuffer permeabilisiert die Zellmembranen, macht die Proteine löslich und verhindert Proteinaggregationen ohne die Konformation und biologischen Funktionen der Proteine zu beeinträchtigen. Außerdem wird die Degradation von Proteinen durch freigesetzte Enzyme verhindert.

Die Lysatgewinnnung aus den primären Zellkulturen erfolgte am DIV5, indem das gesamte Nährmedium mit einem Sauger aus der 6-Lochplatte entfernt und unmittelbar danach ein- bis zweimal mit jeweils $2 \mathrm{ml} 5 \%$ iger Glukoselösung pro Well gewaschen wurde. Nach vollständiger Entfernung der Glukose-Lösung wurden die Zellen mit $60 \mu \mathrm{l}$ Lyse-Puffer versetzt und mit einem Zellschaber vom Boden der Well-Platte gelöst. Die Zellen samt Lysepuffer wurden in einem 1,5 ml Reaktionsgefäß gesammelt und sofort auf Eis gestellt.

\subsubsection{Ultraschallbehandlung (Sonifizierung)}

Die Behandlung des Zellmaterials mit Ultraschall dient der Zelldesintegration, d. h. es ist eine Methode um Zellstrukturen mechanisch aufzubrechen und intrazelluläres Material (z. B. Proteine) zu extrahieren. Durch Hoch-und Niederdruckphasen entstehen Vakuumblasen, welche implodieren und dadurch Scherkräfte auslösen. Die mechanischen Kräfte helfen Zellbestandteile zu zerkleinern und Zellmembranen zu lysieren (Suslick 1989).

Jede Lysatprobe wurde insgesamt 30 Sekunden (Einstellung: Power: 40, Cycle: -) mit dem Ultraschallgerät behandelt. Anschließend wurden die Proben für 30 Minuten bei13000 rpm und $4^{\circ} \mathrm{C}$ zentrifugiert, um den Protein-haltigen Überstand von anderen Bestandteilen zu trennen und diesen in ein neues Reaktionsgefäß zu überführen. Die Proben wurden bis zur weiteren Verarbeitung (BCA-Assay) bei $-20^{\circ} \mathrm{C}$ aufbewahrt.

\subsubsection{BCA-Reaktion/Proteingehalt Quantifizierung}

Die BCA-Reaktion (Bicinchoninsäure, bicinchoninic acid = BCA) wird zur quantitativen photometrischen Bestimmung von Proteinen genutzt. Bei diesem Vorgang reagieren zweiwertige Kupferionen quantitativ mit Proteinen zu einwertigen Kupferionen. Diese Reaktion ergibt mit der Bicinchoninsäure einen violetten Farbstoff, dessen Absorption bei einer Wellenlänge von 562 nm photometrisch ausgewertet werden kann (Smith et al. 1985).

Zur Bestimmung der Proteinkonzentration im Lysat wurden diese mit einer Standardproteinkonzentrationsgeraden verglichen. Die Standardreihe wurde dabei in einer 96-Well-Platte mit verschiedenen BSA-Konzentrationen pipettiert $(40 \mu \mathrm{g}, 20 \mu \mathrm{g}, 10 \mu \mathrm{g}, 5 \mu \mathrm{g}$, $2,5 \mu \mathrm{g}, 1,25 \mu \mathrm{g}, 0,625 \mu \mathrm{g})$. Zusätzlich wurde $1 \mu \mathrm{l}$ aus jeder Lysatprobe mit je $199 \mu \mathrm{l}$ BCA- 
Lösung (50 Teile Reagent $A$ und 1 Teil Reagent $B \rightarrow 50: 1 A: B$ ) vermengt und bei $37^{\circ} \mathrm{C}$ für 30 Minuten inkubiert. Nach der Inkubationszeit wurde die Mikroplatte (96-well-plate) bis auf Raumtemperatur abgekühlt und anschließend die Absorbanz (Extinktion) mittels eines Photometers bei einer Wellenlänge von $562 \mathrm{~nm}$ bestimmt. Die Konzentrationsberechnung erfolgte anhand der oben aufgeführten BSA-Standardreihe.

\subsubsection{SDS-Polyacrylamid-Gelelektrophorese}

Die Natriumdodecylsulfat-Polyacrylamid-Gelelektrophorese (SDS-PAGE = sodium dodecyl sulfate polyacrylamide gel electrophoresis) ist eine Variante der PolyacrylamidGelelektrophorese, bei der die Eigenladung der Proteine durch Natriumdodecylsulfat vereinheitlicht (negativ) und so die Auftrennung allein nach dem Molekulargewicht der Proteine im elektrischen Feld ermöglicht wird.

Hierzu wurden zunächst SDS-Polyacryamid-Gele aus einem 15\%igem Trenngel (separating gel) mit 1,5 mm Binnenraum/ Dicke (spaces) und einem 5\%igem Sammelgel (stacking gel) mit 10 Taschen (Kammern zur Befüllung) hergestellt.

Die hergestellten Proteinsamples wurden mit einer Proteinmenge von $20 \mu \mathrm{g}$ pro12 $\mu$ Probe hergestellt. Hierzu wurde die Proteinmenge mit $2 \mu \mathrm{l} 6 \mathrm{x}$-SDS-Puffer (Lysepuffer mit Bromphenolblau = Leammli-Puffer) vermischt und bei $95^{\circ} \mathrm{C}$ für $5 \mathrm{~min}$ erhitzt. Die Proteinproben wurden mit Lysepuffer so verdünnt, dass sie im Verhältnis 5:1 mit dem Western-Blot Ladepuffer (6x konzentriert) eine Proteinkonzentration von $20 \mu \mathrm{g} / 12 \mu \mathrm{l}$ ergaben.

Der Elektrophoresetank wurde mit 1x-Elektrophoresepuffer befült. Danach wurde in die erste Geltasche des Sammelgels zunächst eine Proteinleiter als Größenmarker ( $5 \mu$ l Dual-ColorMarker/Rainbow-Proteinmarker) geladen und die anderen Taschen mit jeweils $12 \mu \mathrm{l}$ der o. g. Proteinlösung befüllt. Die Auftrennung der Proteine im Gel in Richtung Basis wurde bei einer Umgebungstemperatur von $4^{\circ} \mathrm{C}$ im Kühlraum zunächst mit einer Spannung von $75 \mathrm{~V}$ für $15 \mathrm{~min}$ und dann ca. $1,5 \mathrm{~h}$ bei $100 \mathrm{~V}$ vollzogen.

\subsubsection{Proteintransfer (Blotten)}

Nach der erfolgten Auftrennung der Proteine im Polyacrylamid-Gel müssen diese auf eine Nitrozellulosemembran (Whatman 6x9 cm) mittels Elektrophorese transferiert werden. Die Nitrozellulosemembran muss hierzu vorerst für $10 \mathrm{~min}$ in Ampuwa und weitere $10 \mathrm{~min}$ in Transferpuffer einweichen. Dann müssen die Gele aus dem Elektrophorese-Aggregat und den Glaskammern vorsichtig entnommen, das Sammelgel samt Kammern entfernt und das Trenngel auf die Nitrozellulosemembran gelegt werden. Das ganze wird mitsamt von Whatman-Papieren und Schwämmen in einer Gitterzwinge verschlossen und in die Transferkammer gestellt. Diese wird mit Transferpuffer gefüllt und schließlich bei $4{ }^{\circ} \mathrm{C}$ der 
Proteintransfer mit einer Spannung von $100 \mathrm{~V}$ durchgeführt. Zur erstmaligen Kontrolle, ob der Transfer erfolgreich war, wurde Ponceau-Rot genutzt, um Proteine unspezifisch auf der Membran sichtbar zu machen.

\subsubsection{Immundetektion spezifischer Proteine}

Zur Detektion von bestimmten Proteinen werden primäre und sekundäre Antikörper genutzt, um das Protein, welches von Interesse ist, spezifisch sichtbar zu machen.

Nach dem Transfer der Proteine auf die Membran müssen zunächst unspezifische Bindungsstellen der Antikörper blockiert werden. Dazu wird die Nitrozellulose-Membran 5 Minuten in TBS-T gewaschen, um Rückstände vom Transferpuffer zu entfernen und danach in 5\%iger Milchlösung für eine Stunde bei Raumtemperatur inkubiert.

Die Verdünnung der benötigten Antikörper erfolgte in allen Fällen in 5\%iger Milch.

Die Inkubation im primären Antikörper erfolgte über Nacht bei $4{ }^{\circ} \mathrm{C}$. Zur Detektion von

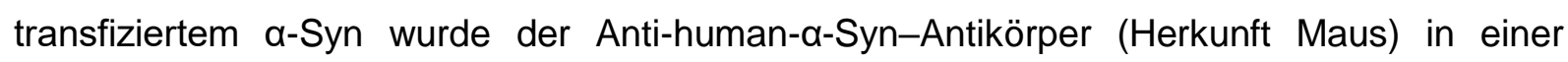
Konzentration von 1:500 benutzt. Zum Nachweis der $\alpha$-Syn-Gesamtmenge (Ratte und transfiziertes humanes $\alpha$-Syn) wurde der Anti- $\alpha$-Syn-Antikörper verwendet, welcher sowohl $\alpha$-Syn der Ratte als auch $\alpha$-Syn des Menschen bindet. Für den Nachweis von B-Tubulin als Ladekontrolle wurde der Anti-ß-Tubulin-Antikörper (Herkunft Maus) in einer Konzentration von 1: 1000 genutzt.

Nach $24 \mathrm{~h}$ Inkubationszeit wurden die Membranen dreimal in TBS-T für 15 Minuten gewaschen, um nicht gebundene Antikörperrückstände zu entfernen. Danach wurde das gewünschte Protein mittels eines sekundären Antikörpers detektiert. Als zweiter Antikörper wurde ein Anti-Maus-IgG gekoppelt mit einer horseradish-Peroxidase (HRP) (= Anti-MausHRP) verwendet. Er wurde für den Nachweis von $\alpha$-Syn in einer Konzentration von 1:1000 und für den Nachweis von B-Tubulin in einer Konzentration von 1:5000 eingesetzt. Die Inkubationszeit erfolgte bei Raumtemperatur für 1 Stunde. Nach dreimaligem Waschen in TBS-T (15 Minuten) erfolgte die Detektion des Proteins mittels ECL-Lösung (enhanced chemiluminescence). Die ECL-Lösung wurde hierzu auf die Membran pipettiert und 1 Minute darauf belassen. Die HRP reagiert als Enzym, welches die Chemolumineszenz-Reaktion des Luminols in der ECL-Lösung beschleunigt und das Protein in einem weiteren Schritt mittels Entwicklungsmaschine auf Chemoluminiszenzfilmen dargestellt. Die letztgenannten Schritte erfolgten in einer Dunkelkammer.

\subsubsection{Quantifizierung des Western Blots}

Zur statistischen Quantifizierung der Western-Blot-Bilder wurde die optometrische Dichte (Densiometrie) der einzelnen Banden gemessen. 
Die gewonnenen Bilder wurden dazu eingescannt und in ImageJ als .jpeg-Datei geöffnet. Jede einzelne Bande wurde markiert und die Intensität der Pixel als Graph durch ImageJ dargestellt (Gassmann et al. 2009). Auf jedem Graphen wurde manuell eine Linie gezogen (line too), um den Hintergrundbereich der Banden zu markieren, und anschließend wurde die Pixel-Intensität als Zahlenwert von ImageJ berechnet (magic wand). Es wurde immer die eGFP-Versuchsgruppe als Referenz (=1) markiert, und die Quantifizierung der Banden erfolgte, indem jede Proteinprobe als Bande mit der Referenz in Relation gesetzt wurde.

Die ImageJ Ergebnisse wurden in eine Microsoft Office Excel-Tabelle kopiert, weiter berechnet und graphisch in Microsoft Office PowerPoint dargestellt.

\subsection{Statistische Auswertung}

Zur statistischen Auswertung der einzelnen Versuchsergebnisse wurde das Programm KyPlot genutzt. Bei allen Versuchen wurde zunächst eine einfache ANOVA durchgeführt, um zu prüfen, ob es zwischen den Versuchsgruppen einen signifikanten Unterschied bzgl. des Mittelwertes gab, ohne dabei eine Aussage zu machen, zwischen welchen Gruppen der Unterschied bestand. Ergab sich bei der einfachen ANOVA ein signifikanter Unterschied, wurden anschließend die Versuchsgruppen untereinander mittels Tukey-Kramer oder Dunnett Post-hoc-Test auf Signifikanz geprüft, um herauszufinden, welche Gruppen zueinander signifikante Unterschiede der jeweiligen Messgrößen aufwiesen. Ein $p<0,05$ wurde dabei als statistisch signifikant gewertet. Wann welcher Test eingesetzt wurde, ist den Ausführungen und den graphischen Darstellungen im Ergebnisteil zu entnehmen. Sofern nur 2 Versuchsgruppen miteinander verglichen wurden, erfolgte dies mittels Student`s t-Test. 


\title{
3.1 Charakterisierung der primären Mittelhirnneuronenkultur
}

Zu den Mittelhirnneuronen zählen die dopaminergen und nicht-dopaminergen Neurone. Da in dieser Arbeit die Untersuchung des Einflusses von humanem a-Syn-WT und seiner Mutanten A30P und A53T sowohl auf nicht-dopaminerge Mittelhirnneurone als auch auf dopaminerge und somit Tyrosinhydroxylase-positive (TH-positive) Mittelhirnneurone erfolgte, wurde zunächst untersucht, in welcher Quantität diese Neurone in der verwendeten primären Neuronenkultur vorhanden waren. Dies erfolgte mittels immunzytochemischer Färbung dieser Neurone gegen die Tyrosinhydroxylase der Ratte, ein Enzym im Dopaminstoffwechsel dopaminerger Neurone. Shimoda et al. beschrieben1992 in ihrem Präparationsprotokoll eine dopaminerge Zelldichte von 17-21\%, wohingegen Krieglstein et al. 1995 die dopaminerge Zelldichte mit $8 \%$ angaben.

Zur Sicherung der Präparationsqualität wurden die TH-positiven Neurone in der THImmunzytochemie (s. auch 2.4) gezählt und gemessen an der Gesamtzahl aller Mittelhirnneurone (Zellkerne/DAPI) quantifiziert. Es wurde im Rahmen von 60 Einzelbildern in 20-facher Vergrößerung eine durchschnittliche dopaminerge Neuronenzahl von $8,28 \pm 1,17 \%$ erreicht (s. Abb. 3.1). Hiervon konnten später lediglich $6,47 \%$ über das Nukleofektionsverfahren transfiziert werden (s. 3.2.1). Daher musste der Anteil der THpositiven Neurone so hoch wie möglich gehalten werden, um die Auswirkungen der Überexpression in diesem Zelltyp untersuchen zu können.
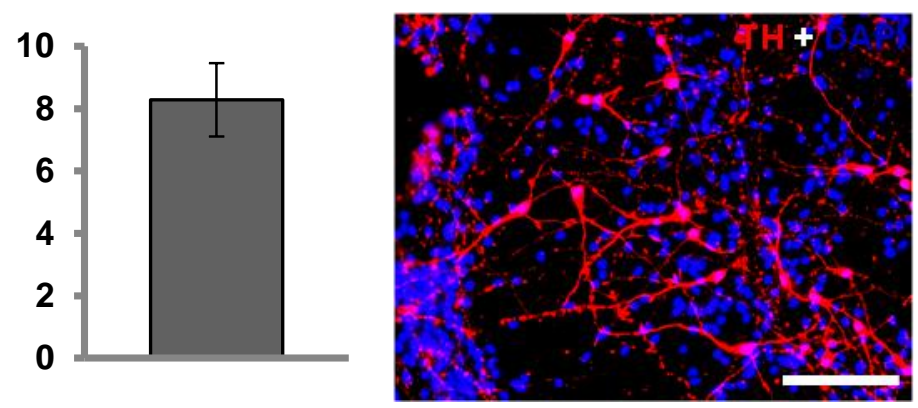

\begin{abstract}
Abb. 3.1 Prozentualer Anteil dopaminerger Neurone an der Gesamtzellkultur. Graph: Durchschnittlich wurde ein Anteil von $8,28 \%$ dopaminerger Neurone an der Gesamtzellkultur erreicht. Bild: repräsentative Abbildung des prozentualen Anteils dopaminerger Neurone an der Gesamtzellkultur, blau: Zellkernfärbung mittels DAPI (Gesamtzellzahl), rot: dopaminerge Neurone (mittels Immunzytochemie gegen Tyrosinhydroxylase). Primäre Mittelhirnneurone, DIV5, $\mathrm{n}=60$ Einzelmessungen aus 3 unabhängigen Zellkulturen, Maßbalken: $100 \mu \mathrm{m}, 20 x-O b j e k t i v$.
\end{abstract}

\subsection{Transfektionsetablierung primärer Mittelhirnneurone}

Für den DNA-Transfer wurde das Nukleofektionsprinzip ausgewählt (s. auch 2.2.3). Da es bei dieser Methode zu einer elektrisch getriggerten kurzfristig gesteigerten Permeabilität durch eine Porenbildung in der Zellmembran der vulnerablen Mittelhirnneurone kommt und dies einen negativen Effekt auf das Überleben einzelner Neurone haben kann, mussten die 
Transfektionsschritte zunächst optimiert werden. Da die biologischen Eigenschaften von unterschiedlichen Nervenzellen differieren, stehen je nach Nervenzelltyp unterschiedliche Transfektionsprotokolle und -kits zur Verfügung. Es gab allerdings bislang keine Erfahrungen oder Berichte über die DNA-Transfektion von primären Mittelhirnneuronen. Die Nukleofektion von mesencephalen Neuronen wurde lediglich an deren Vorläuferzellen (Progenitorzellen E11,5) untersucht (Cesnulevicius et al. 2006). Cesnulevicius et al. verwendeten ebenso das Basic Nucleofector Kit for primary mammalian neurons, verglichen die Programme A-033 und 0-005 in Vorläuferzellen von Mittelhirnneuronen und erreichten mit dem Programm A033 die höchste Transfektionsrate von $47 \%$ bei einer Überlebensrate von $40 \%$. Von der Firma Lonza wurden vier Programme empfohlen (A-033, C-013, G-013 und O-005), die für die Transfektion (s. auch 2.2.3.1) von primären Neuronen geeignet sind, wobei die unterschiedlichen Buchstaben einer bestimmten Stromstärke und die Zahlen der Zeitdauer des Transfektionspulses entsprechen. Es mussten folglich ein geeignetes Programm, die optimale zu transfizierende Plasmidmenge und der optimale Transfektionsablauf gefunden werden. Ziel war aufgrund der insgesamt geringen Anzahl dopaminerger Neurone in der Zellkultur eine möglichst hohe Transfektionsrate unter niedrigem Neuronenverlust und optimale Wachstumsbedingungen zu erreichen.

Das ursprünglich in dem Transfektions-Kit enthaltene pmaxGFPTM-Plasmid als Positivkontrolle hatte einen toxischen Effekt auf die primären mesencephalen Neurone. Somit erfolgte die Transfektion mittels eines eGFP-Plasmids, welches freundlicherweise von U. Michel bereitgestellt wurde (Koch et al. 2011, s. auch 2.3.1).

Um herauszufinden, über welches Programm die effektivste Transfektionsrate bei möglichst geringer Toxizität erzielt wird, wurden zuerst die vier von der Herstellerfirma Lonza vorgeschlagenen Programme inklusive der Programme von Cesnulevicius et al. miteinander verglichen.

\subsubsection{Vergleich unterschiedlicher Transfektionsprogramme}

Die primären Mittelhirnneurone wurden mit den entsprechenden Nukleofektionsprogrammen und jeweils $3 \mu \mathrm{g}$ eGFP-Kontrollplasmid transfiziert. Nachdem sie 5 Tage kultiviert wurden (DIV5), erfolgte die Fixierung und Immunzytochemie gegen TH (s. Abb. 3.3). In der folgenden quantitativen Auswertung der Transfektionseffizienz an 3 unabhängigen Zellkulturen wurde sowohl die Rate aller transfizierten (eGFP-positiven) Mittelhirnneurone im Vergleich zur Gesamtzellzahl aller (DAPI-positiven) Neurone als auch die Rate der transfizierten dopaminergen (TH-positiven) Neurone in Relation zur dopaminergen Gesamtzellzahl bestimmt.

Dabei erbrachte das Programm G-013 in 62 Einzelmessungen in 20-facher Vergrößerung die beste Transfektionsrate von durchschnittlich $14,73 \pm 0,87 \%$ aller Mittelhirnneurone, 
während sich für die anderen getesteten Programme ein signifikant geringerer Anteil transfizierter Neurone zeigte. Beim Programm A-033 waren 11,00 $\pm 0,52 \%\left(p=9,82 * 10^{-5}\right.$ zu G-013, in One-Way ANOVA gefolgt von Tukey-Kramer-Post-hoc-Test, $n=73$ ), bei C-013 $10,34 \pm 0,52 \%\left(p=1,19 * 10^{-5}, \quad n=59\right)$ und bei $0-00510,42 \pm 0,47 \% \quad\left(p=6,87 * 10^{-6}\right.$, $\mathrm{n}=71$ ) der gesamten Mittelhirnneurone transfiziert (s. Abb. $3.2(\mathrm{a})$ ).

Auch bei den dopaminergen Neuronen konnte die signifikant höchste Transfektionsrate mit dem Programm G-013 erreicht werden [6,47 $\pm 0,91 \%$ im Vergleich zu 1,92 $\pm 0,39 \%$ $\left(p=1,67 * 10^{-6}\right)$ bei $A-033,0,75 \pm 0,23 \%\left(p=1,64 * 10^{-6}\right)$ bei $C-013$ und $2,42 \pm 0,40 \%(p=$ $\left.2,71 * 10^{-6}\right)$, s. Abb. $\left.3.2(b)\right]$.

Ergänzend wurde die Absolutzahl der transfizierten dopaminergen Neurone pro Gesichtsfeld in 20-facher Vergrößerung $\left(\sim 0,147 \mathrm{~mm}^{2}\right)$ betrachtet. Auch hierbei konnte eine signifikant höhere absolute Transfektionsrate bei G-013 [1,12 $\pm 0,15 \mathrm{im}$ Vergleich zu 0,54 $\pm 0,10$ $(p=0,0012)$ bei A-033, $0,22 \pm 0,07\left(p=2,25^{*} 10^{-6}\right)$ bei C-013 und 0,69 $\pm 0,11 \quad(p=0,030)$ bei O-005] ermittelt werden. Darüber hinaus ergab sich zusätzlich ein signifikanter Unterschied zwischen O-005 und C-013 ( $p=0,018)$ (siehe Abb. $3.2(c)$ ).
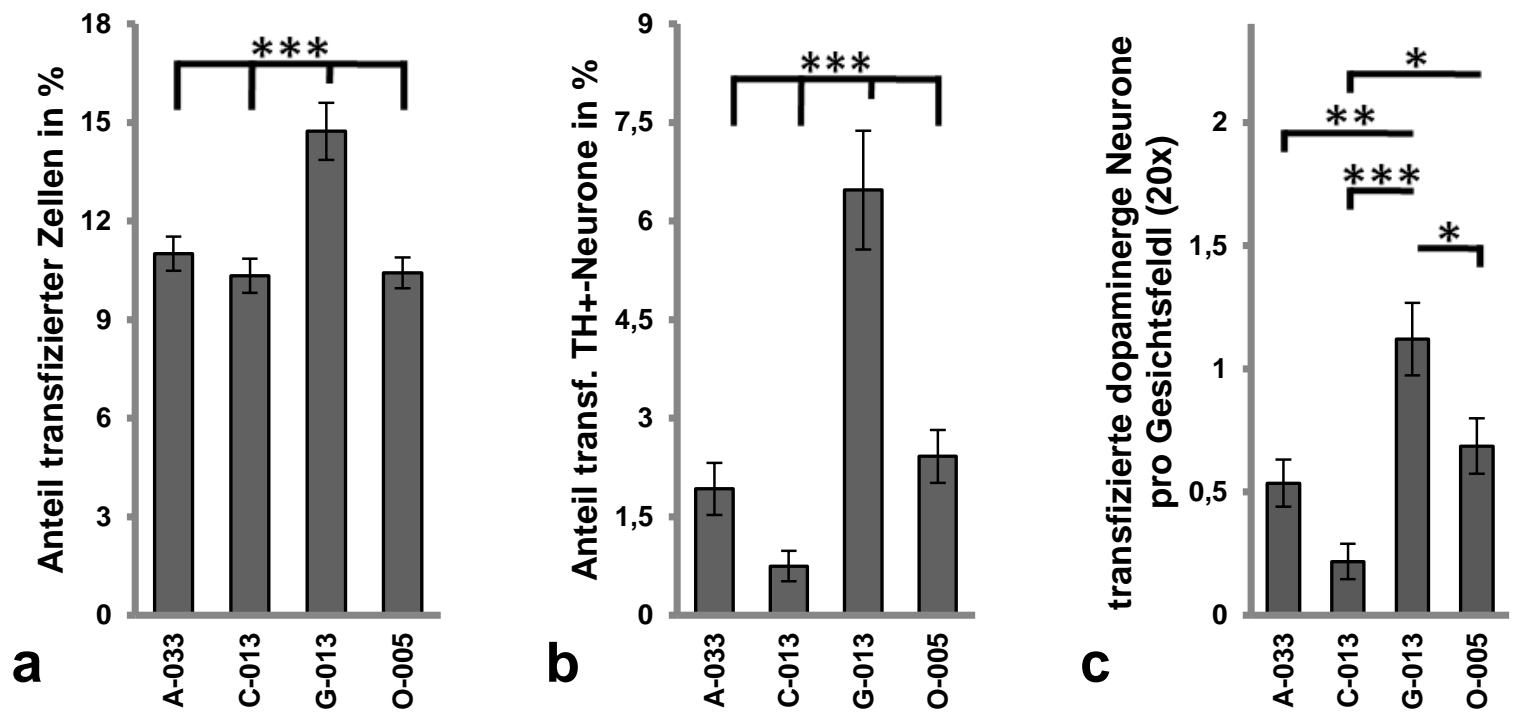

Abb. 3.2 Darstellung der Transfektionseffizienz der unterschiedlichen Programmtypen nach Nukleofektion. Die beste Transfektionsrate konnte mit dem Transfektionsprogramm G-013 erzielt werden. a) Anteil transfizierter Mittelhirnneurone an der Gesamtzellzahl. b) Anteil transfizierter dopaminerger ( $\mathrm{TH}+$ )Neurone an allen dopaminergen Neuronen. c) absolute Anzahl transfizierter dopaminerger Neurone/Gesichtsfeld (20x). Primäre Mittelhirnneurone, DIV5, A033: $n=73, C-013: n=59, G-013: n=62,0-005: n=71$ Gesichtsfelder in 20-facher Vergrößerung aus 3 unabhängigen Zellkulturen, DIV5, ${ }^{*}: p<0,05 ;{ }^{* *}: p<0,01 ;{ }^{* * *}: p<0,001$ in One-Way ANOVA gefolgt von Tukey-Kramer-Post-hoc-Test, Fehlerbalken: Standardfehler des Mittelwertes. 

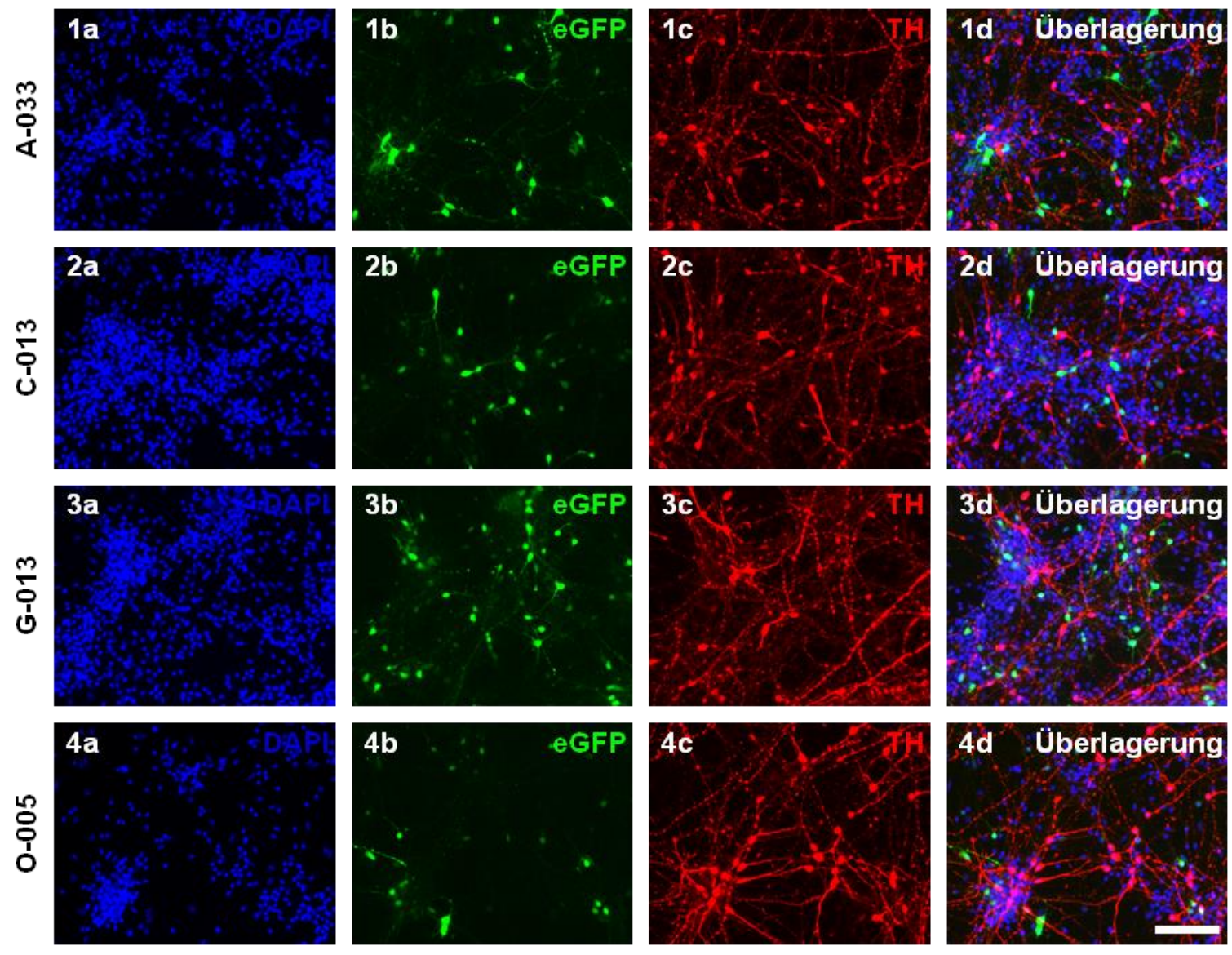

Abb 3.3 Repräsentative Darstellung der TH-Immunzytochemie zur Bestimmung der Transfektionseffizienz der unterschiedlichen Programmtypen. Es zeigt sich eine deutlich höhere Transfektionsrate bei den mit G-013 transfizierten Mittelhirnneuronen. a) DAPI Zellkernfärbung, b) eGFP-Fluoreszenz, c) TH-Färbung, d) Überlagerung von a bis c. 1(a-d) A033, 2(a-d) C-013, 3(a-d) G-013, 4(a-d) O-005. Primäre Mittelhirnneurone, DIV5,Maßbalken: 100 m, 20x-Objektiv.

Zur Bestimmung der Toxizität der verschiedenen Transfektionsprogramme erfolgte die Quantifizierung der Gesamtzellzahl und der Zahl der dopaminergen Neurone. Es zeigte sich hierbei, dass G-013 mit einer durchschnittlichen Gesamtzellzahl von $223 \pm 9$ und signifikant erniedrigter Anzahl dopaminerger Neurone das toxischste und C-013 insgesamt das schonendste Programm war (s. Tab. 3.1).

Zusammenfassend zeigte sich eine signifikant höhere Transfektionsrate für G-013 bei zwar relevanter, aber tolerierbarer Toxizität im Vergleich zu den übrigen Programmen, weshalb sich insbesondere auf Grundlage der erhöhten Absolutzahl transfizierter dopaminerger Neurone für das Programm G-013 zur weiteren Analyse der optimalen Plasmidmenge, sowie den Untersuchungen zur Neuritenlänge, Neuritenverzweigung, dem Zellüberleben der THpositiven Neurone und zur Vermessung der Zellkörpergröße nach Transfektion mit $\alpha$-Synexprimierenden Plasmiden entschieden wurde. 


\begin{tabular}{|c|c|c|c|c|c|c|c|c|}
\hline \multirow[b]{3}{*}{ Programm } & \multicolumn{4}{|c|}{ Gesamtzellkultur } & \multicolumn{4}{|c|}{ dopaminerge Neurone } \\
\hline & \multirow[t]{2}{*}{ Zellzahl } & \multicolumn{3}{|c|}{ Signifikanzlevel ( $p$-Wert) } & \multirow[t]{2}{*}{ Zellzahl } & \multicolumn{3}{|c|}{ Signifikanzlevel (p-Wert) } \\
\hline & & C-013 & G-013 & 0-005 & & C-013 & G-013 & 0-005 \\
\hline A-033 & $250 \pm 10$ & 0,026 & 0,23 & 0,21 & $32 \pm 2$ & 1,00 & $1,86 * 10^{-6}$ & 0,37 \\
\hline C-013 & $291 \pm 12$ & & $6,02 * 10^{-5}$ & 0,76 & $31 \pm 2$ & & $3,98 * 10^{-6}$ & 0,53 \\
\hline G-013 & $223 \pm 9$ & & & 0,0013 & $18 \pm 1$ & & & $3,3 * 10^{-4}$ \\
\hline 0-005 & $277 \pm 11$ & & & & $28 \pm 2$ & & & \\
\hline
\end{tabular}

Tab. 3.1 Gesamtzellzahl und Anzahl dopaminerger Neurone nach Transfektion mit verschiedenen Transfektionsprogrammen. Signifikante Unterschiede kursiv und fett hervorgehoben. Es zeigt sich, dass G-013 das toxischste Programm ist.

\subsubsection{Optimierung der Plasmidmenge}

Ziel der Optimierung der Plasmidmenge war, die beste Expression des auf dem Plasmid kodierten Proteins zu ermitteln.

\subsubsection{Quantifizierung der Transfektionsrate in Abhängigkeit von der Plasmidmenge}

Die Ermittlung der Plasmidmenge für die höchstmögliche Transfektionsrate erfolgte über eine TH-Immunzytochemie primärer Mittelhirnneurone (s. auch 2.4) nach Transfektion mit zwei unterschiedlichen Plasmidmengen des Kontrollplasmids eGFP ( $2 \mu \mathrm{g}$ und $5 \mu \mathrm{g})$ mit dem Programm G-013 (s. Abb. 3.4).
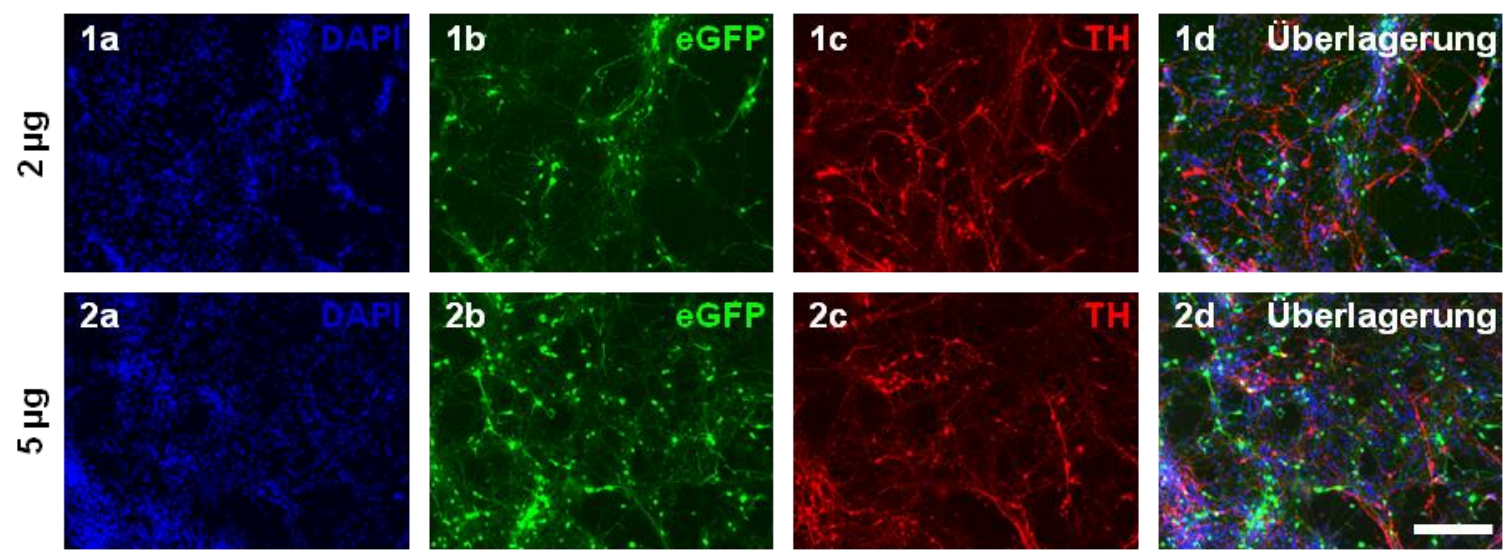

Abb. 3.4 Beispielhafte immunzytochemische Darstellung der Transfektionseffizienz bei Transfektion mit zwei unterschiedlichen Plasmidmengen. Es zeigt sich eine deutliche Steigerung der Transfektion durch den Einsatz von $5 \mu \mathrm{g}$ Plasmid zur Transfektion im Vergleich zu $2 \mu \mathrm{g}$. a) DAPI Zellkernfärbung, b) eGFP-Fluoreszenz, c) TH-Färbung, d)

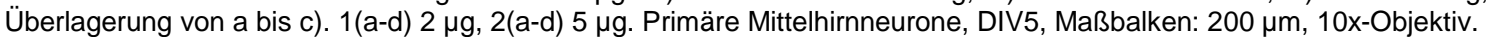



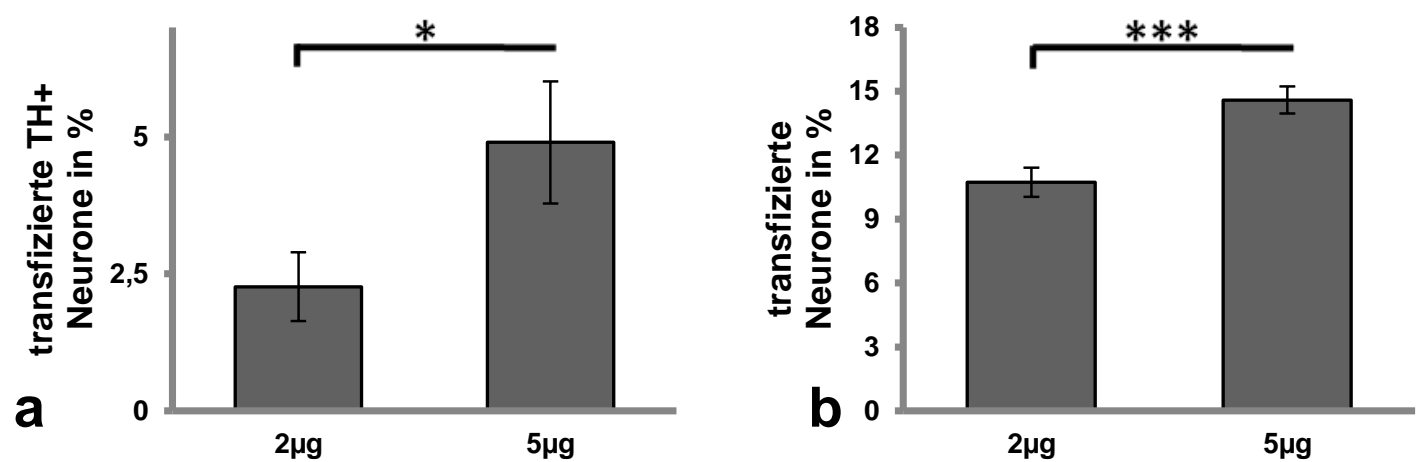

Abb. 3.5 Darstellung der Transfektionsraten mit dem Programm G-013 bei $2 \mu \mathrm{g}$ und $5 \mu \mathrm{g}$ eingesetzter Plasmidmenge (eGFP). a) Anteil transfizierter dopaminerger ( $\mathrm{TH}_{+}$) Neurone an der Gesamtzahl dopaminerger Neurone. b) Anteil transfizierter Mittelhirnneurone an der Gesamtzellzahl. Die Ergebnisse zeigen eine höhere Transfektionsrate bei einer Plasmidmenge von $5 \mu \mathrm{g}$ im Vergleich zu $2 \mu \mathrm{g}$ in beiden Zellgruppen. Primäre Mittelhirnneurone, DIV5, $2 \mu \mathrm{g}: \mathrm{n}=11,5 \mu \mathrm{g}$ : $\mathrm{n}=13$ Gesichtsfelder in 20-facher Vergrößerung, *: $\mathrm{p}<0,05, * * * \mathrm{p}<0,001$ in One-Way ANOVA gefolgt von Students $\mathrm{t}-$ Test, Fehlerbalken: Standardfehler des Mittelwertes.

Die quantitative Auswertung von $11(2 \mu \mathrm{g})$ bzw. $13(5 \mu \mathrm{g})$ Einzelbildern in 20-facher Vergrößerung ergab einen Anteil mittels Transfektionsprogramm G-013 transfizierter Neurone im Vergleich zur Gesamtzellzahl von 10,73 $\pm 0,69 \%$ bei $2 \mu \mathrm{g}$ und 14,59 $\pm 0,60 \%$ bei $5 \mu \mathrm{g}$ eingesetzter Plasmidmenge. Dieser Unterschied war signifikant mit einem $\mathrm{p}$-Wert von 0,00044 (One-Way ANOVA gefolgt von Student's t-Test). Speziell bei den dopaminergen Neuronen konnte ebenfalls ein signifikanter Unterschied in der transfizierten Neuronenzahl ermittelt werden. Bei $2 \mu \mathrm{g}$ waren lediglich 2,27 $\pm 0,63 \% \mathrm{TH}$-positive Neurone transfiziert, wohingegen bei $5 \mu \mathrm{g} 4,90 \pm 1,11 \%$ dopaminerge Neurone eGFP exprimierten $(p=0,037)$ (s. Abb. 3.5).

\subsubsection{Quantifizierung der exprimierten Proteinmenge in Abhängigkeit von der transfizierten Plasmidmenge}

Um quantitativ zu beurteilen, ob nicht nur die Anzahl der transfizierten Neurone, sondern auch die Menge des in der Gesamtkultur exprimierten Proteins in Abhängigkeit zur eingesetzten Plasmidmenge steht, wurden Western Blot-Analysen von Zelllysaten der transfizierten primären Mittelhirnneurone durchgeführt. Es wurden hierbei die Plasmidmengen 2 und $4 \mu \mathrm{g}$ verglichen. Verwendet wurde ein $\alpha$-Syn-Antikörper, der sowohl das transfizierte humane $\alpha$-Syn als auch das endogene Ratten- $\alpha$-Syn detektiert, um eine Aussage zur Gesamtexpression von a-Syn treffen zu können.

Die Transfektion mit $2 \mu \mathrm{g}$ des $\alpha$-Syn-WT-exprimierenden Plasmids in 2 unabhängigen Zellkulturen führte zu einer durchschnittlichen Steigerung der $\alpha$-Syn-Gesamtproteinmenge im Vergleich zur Kontrollgruppe auf das 1,39 $\pm 0,024$-fache $(p=0,039$ zur eGFPKontrollgruppe, One-Way ANOVA gefolgt von Tukey-Kramer-Post-hoc-Test). Bei $4 \mu \mathrm{g}$ eingesetzter $\alpha$-Syn Plasmidmenge konnte eine weitere Steigerung auf das 1,70 $\pm 0,00054$ fache erzielt werden $(p=0,000496)$. Die Differenz zur Kontrollgruppe entspricht dem exprimierten humanen $\alpha$-Syn, welches durch die Transfektion der Neurone mit dem Plasmid 
exprimiert werden konnte. Zwischen $2 \mu \mathrm{g}$ und $4 \mu \mathrm{g}$ zeigte sich eine ebenfalls signifikante Steigerung der Proteinexpression ( $p=0,0011)$ (s. Abb. 3.6).

a

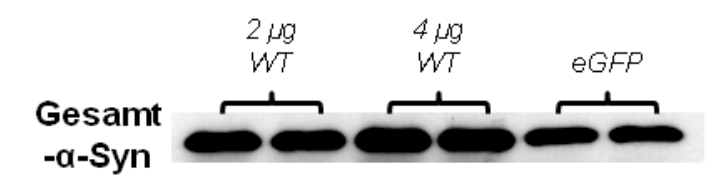

$\beta-T$ ubulin b

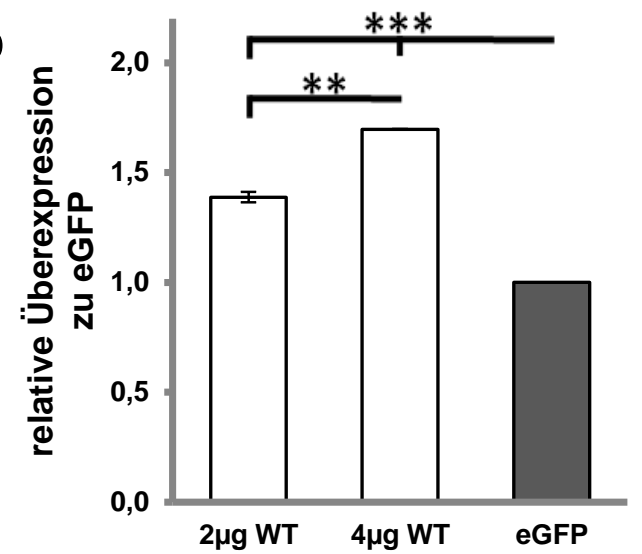

Abb. 3.6 Plasmidmengen-abhängige Gesamt- $\alpha$-Syn-Expression. a) Exemplarischer Western Blot der Gesamt- $\alpha$-SynExpression in Abhängigkeit der transfizierten Plasmidmenge. Es ist ersichtlich, dass die Transfektion mit $\alpha$-Synexprimierenden Plasmiden zu einer erhöhten Expression des Gesamt- $\alpha$-Syns führt und hierbei eine höhere Plasmidmenge auch eine weitere Proteinzunahme bewirkt. b) Quantifizierung der Plasmidmengen-abhängigen Expression der Gesamt- $\alpha$ Syn-Proteinmenge. Es zeigt sich eine signifikante Steigerung der Gesamtproteinmenge von $\alpha$-Syn durch Expression von humanem $\alpha$-Syn nach Transfektion mit 2 oder $4 \mu \mathrm{g} \alpha$-Syn-WT-Plasmid. Primäre Mittelhirnneurone, DIV5, $\mathrm{n}=2$ unabhängige Mittelhirnzellkulturen, ${ }^{* *}: p<0,01,{ }^{* * *}: p<0,001$ in One-Way ANOVA gefolgt von Tukey-Kramer-Post-hoc-Test, Fehlerbalken: Standardfehler des Mittelwertes.

Für alle weiteren Versuche wurde eine Plasmid-Gesamtmenge von $5 \mu \mathrm{g}$ gewählt. Dabei wurden stets insgesamt $3 \mu \mathrm{g}$ a-Syn-Plasmid zusammen mit $2 \mu \mathrm{g}$ eGFP-Plasmid als Positivkontrolle (Transfektionsmarker) transfiziert und $5 \mu \mathrm{g}$ eGFP-Plasmid als Kontrollgruppe verwendet.

\subsubsection{Nachweis des transfizierten humanen $\alpha-S y n$}

Zur eindeutigen Identifikation des transfizierten humanen $\alpha$-Syns wurde sowohl beim Western Blot (s. auch 2.5.5) als auch in der Immunzytochemie (s. auch 2.4) ein Antikörper verwendet, der ausschließlich das humane a-Syn und seine pathogenen Isoformen A30P und A53T, aber nicht das endogene a-Syn der Ratte detektiert. Auf der folgenden Abbildung ist daher erwartungsgemäß keine Detektion einer $\alpha$-Syn-Bande in der nur mit eGFPtransfizierten Gruppe zu verzeichnen, da hier nur das endogene $\alpha$-Syn der Ratte vorhanden ist, während die anderen drei Gruppen mit humanen $\alpha$-Syn-Varianten transfiziert wurden (s. Abb. 3.7 (a)). Es fanden sich keine signifikanten Unterschiede zwischen den mit humanem aSyn transfizierten Gruppen. Diese spezifische Expression konnte mittels Immunzytochemie qualitativ bestätigt werden (Abb. 3.10) und weiterhin erkennt man die nahezu 100\%ige CoTransfektion in der Überlagerungsdarstellung (Abb. 3.8 (c)) (s. 3.2.2.4). 
a

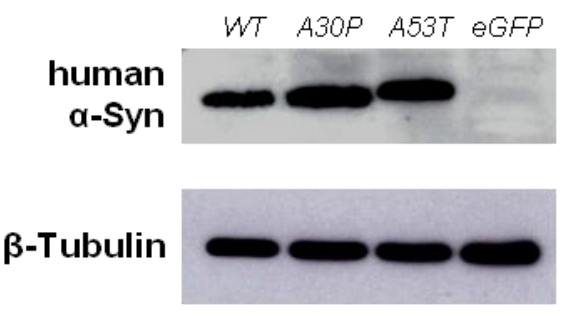

b

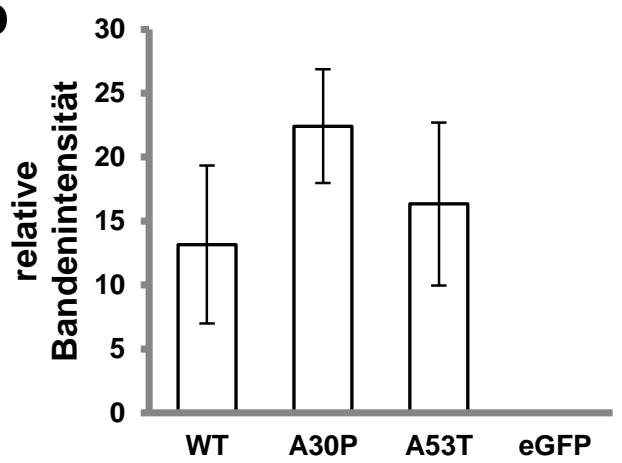

Abb. 3.7 Expression des humanen a-Syns nach Transfektion. a) Repräsentativer Western Blot der Expression des transfizierten humanen $\alpha$-Syns. Erwartungsgemäß ist bei deutlicher Darstellung in den mit $\alpha$-Syn-Plasmid-transfizierten Versuchsgruppen in der Kontrollgruppe keine Expression von humanem a-Syn zu verzeichnen. b) Quantifizierung der relativen Bandenintensität des exprimierten $\alpha$-Syns. Es ergaben sich keine signifikanten Unterschiede der Expression zwischen den $\alpha$-Syn-transfizierten Populationen.Primäre Mittelhirnneurone, DIV5, $\mathrm{n}=3$ unabhängige Mittelhirnzellkulturen, Fehlerbalken: Standardfehler des Mittelwertes.
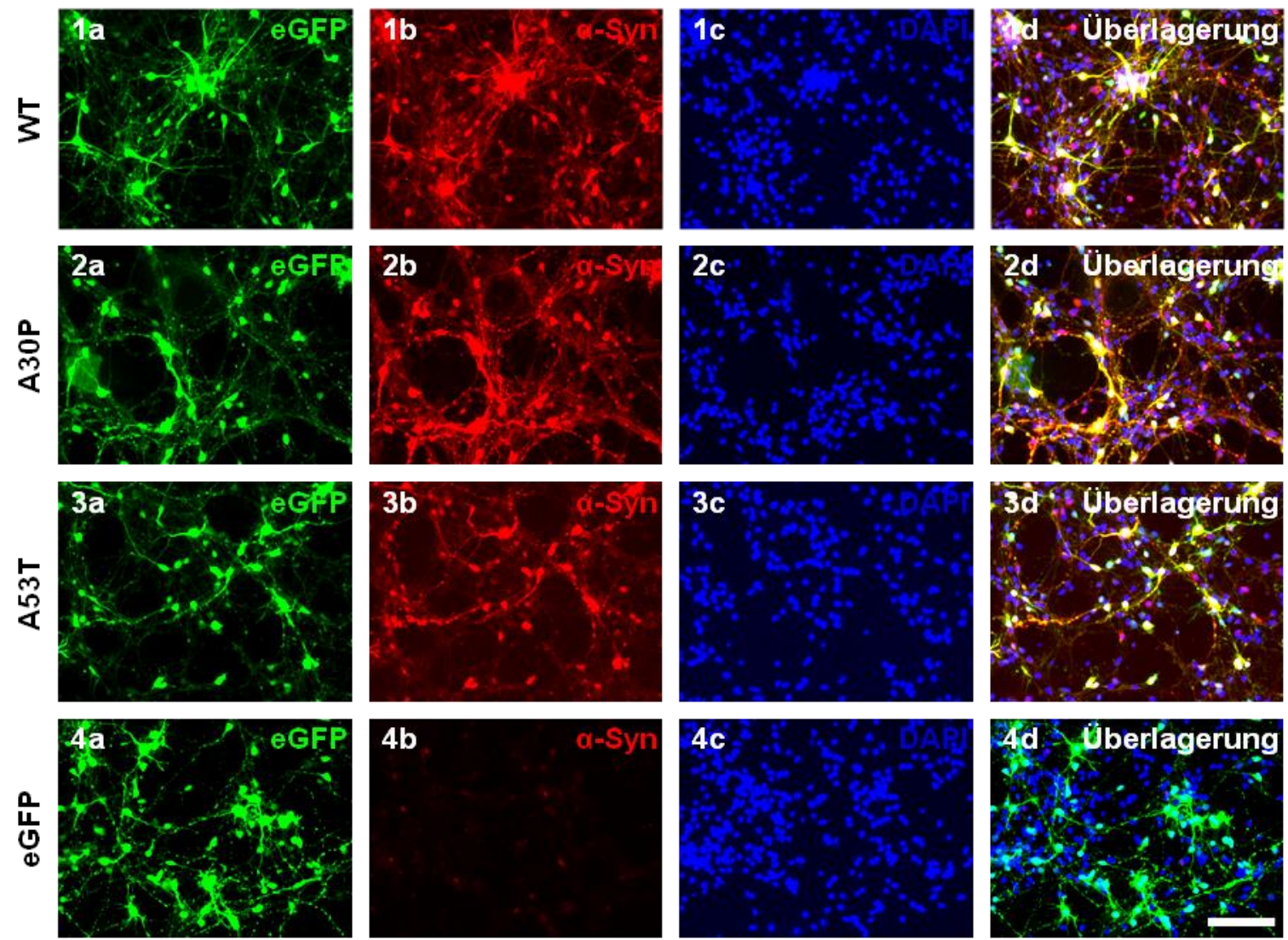

Abb. 3.8 Beispielhafte immunzytochemische Darstellung der Expression von humanem $\alpha$-Syn nach Transfektion primärer Mittelhirnneurone mit den verschiedenen $\alpha$-Syn-Plasmiden im Vergleich zur Kontrolle. Erwartungsgemäß ist bei deutlicher Darstellung in den mit $\alpha$-Syn-Plasmid-transfizierten Versuchsgruppen in der Kontrollgruppe keine Expression von humanem $\alpha$-Syn zu verzeichnen. a) eGFP-Fluoreszenz, b) Färbung mit humanspezifischem $\alpha$-SynAntikörper, c) DAPI Zellkernfärbung, d) Überlagerung von a bis c. 1(a-d) $\alpha$-Syn-WT, 2(a-d) $\alpha$-Syn-A30P, 3(a-d) $\alpha$-Syn-A53T, 4(a-d) eGFP-Kontrollgruppe.Pfeile: beispielhafte $\alpha$-Syn und eGFP co-exprimierende Neurone nach Co-Transfektion mit $\alpha$ Syn- und eGFP-Plasmiden, Doppelkonturpfeile: Zellen ohne a-Syn-Expression bei alleiniger eGFP-Plasmid-Transfektion. Primäre Mittel-hirnneurone, DIV5, Maßbalken: $100 \mu \mathrm{m}, 20 x-O b j e k t i v$.

\subsubsection{Nachweis der Co-Transfektion}

Die in dieser Arbeit zur Transfektion verwendeten Plasmide exprimieren allesamt die

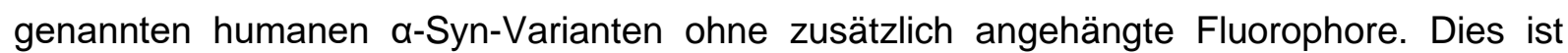


wichtig, da die kovalente Addition weiterer Moleküle die biologischen Proteineigenschaften der jeweiligen a-Syn-Variante verändern und die Ergebnisse verfälschen könnte.

Um trotzdem die erfolgreich transfizierten Neurone eindeutig erkennen und von der Mehrzahl der nicht-transfizierten Neurone sicher unterscheiden zu können, wurde stets eine CoTransfektion mit $2 \mu \mathrm{g}$ des eGFP-Plasmids und $3 \mu \mathrm{g}$ des Plasmids mit der jeweiligen $\alpha$-SynVariante durchgeführt. Laut Angabe des Herstellers Lonza führt die gleichzeitige Nukleofektion zweier Plasmide zu einer nahezu 100\%igen Co-Transfektion respektive Protein-CoExpression in den Neuronen. Somit ist die alleinige Darstellung der eGFP-Fluoreszenz eines Neurons ein sicherer Marker für den erfolgreichen Transfer beider Plasmide.

Zur Überprüfung dieser Herstellerangabe wurde eine Immunzytochemie der co-transfizierten Mittelhirnneurone mit dem humanspezifischen $\alpha$-Syn-Antikörper durchgeführt und die Färbung mit dem eGFP-Signal verglichen. Wie in Abb. $3.10 \mathrm{zu}$ erkennen ist, fand sich tatsächlich eine annähernd perfekte Co-Lokalistation der Expressionsprodukte des eGFPund der jeweiligen $\alpha$-Syn-Plasmide (s. ebenfalls Abb. 3.8).

Die Co-Transfektionsraten von eGFP und $\alpha$-Syn betrugen 98,34 $\pm 0,54 \%$ für den WT $99,18 \pm 0,26 \%$ für A30P und 98,92 $\pm 0,38 \%$ für A53T (s. Abb. 3.9). Es wurden insgesamt 18 Gesichtsfelder (je 6 pro Coverslip einer Zellkultur) in 20-facher Vergrößerung quantifiziert.

Infolgedessen konnte eGFP allein als Transfektionsmarker für das $\alpha$-Syn-Plasmid genutzt werden und auf eine zusätzliche Färbung von $\alpha$-Syn in weiteren immunzytochemischen Versuchen verzichtet werden.

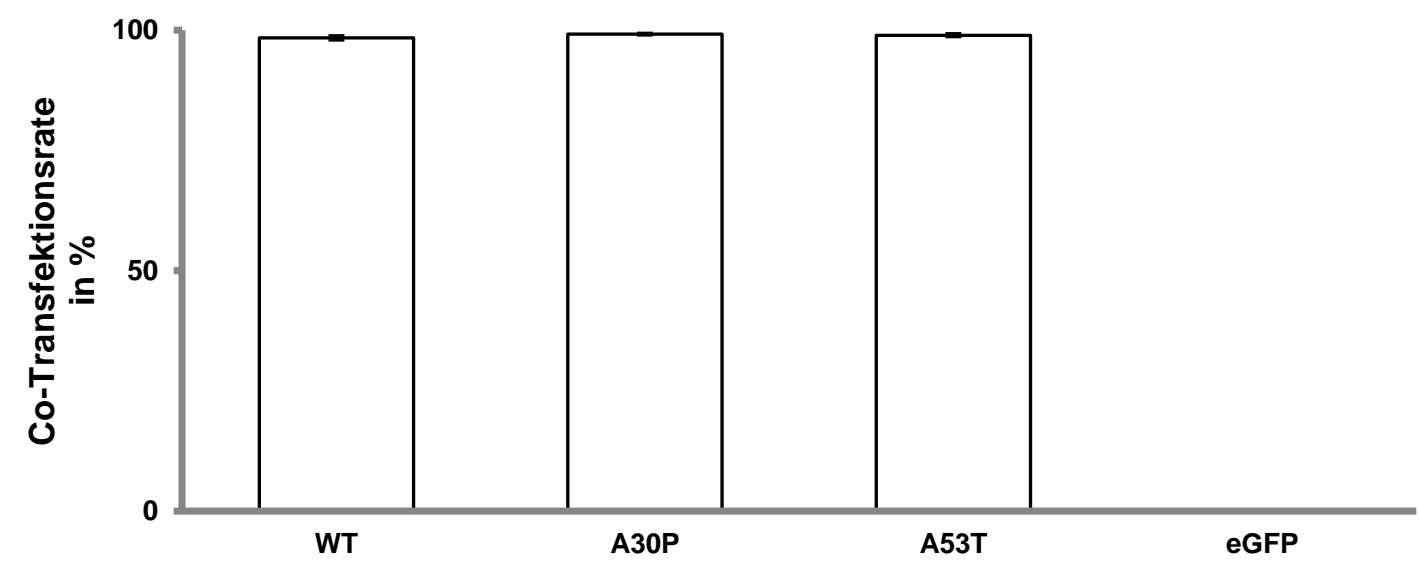

Abb. 3.9 Quantifizierung der Co-Transfektion von $\alpha$-Syn und eGFP in der Immunzytochemie. Es zeigt sich eine nahezu 100\%ige Co-Transfektion von eGFP und $\alpha$-Syn durch die vermittelte simultane Expression beider Proteine in primären Mittelhirnneuronen. DIV5, $\mathrm{n}=18$ Gesichtsfelder in 20-facher Vergrößerung (je 6 pro Coverslip einer Mittelhirnzellkultur), Fehlerbalken: Standardfehler des Mittelwertes. 

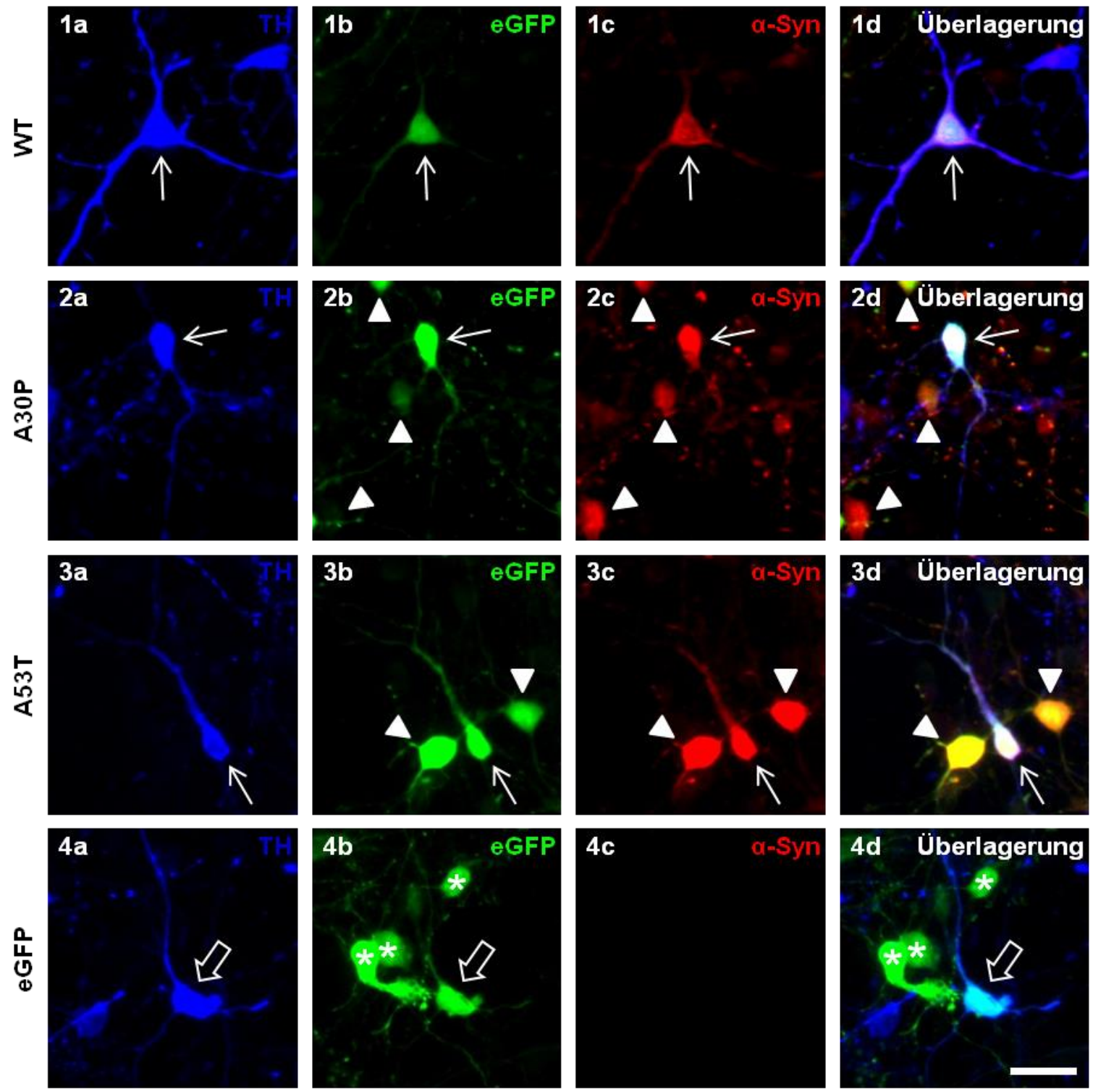

Abb. 3.10 Beispielhafte immunzytochemische Darstellung der Co-Transfektion und Expression von humanema-Syn und eGFP in dopaminergen und nicht-dopaminergen Neuronen. a) TH-Färbung, b) eGFP-Fluoreszenz, c) $\alpha$-SynFärbung, d) Überlagerung von a bis c. 1(a-d) a-Syn-WT, 2(a-d) a-Syn-A30P, 3(a-d) a-Syn-A53T, 4(a-d) eGFP-Kontrollgruppe.Pfeile: dopaminerge (TH-positive), co-transfizierte Mittelhirnneurone, Pfeilspitze: nicht-dopaminerge (TH-negative), co-transfizierte Mittelhirnneurone, ungefüllter Blockpfeil: dopaminerges, eGFP-transfiziertes Mittelhirnneuron ohne $\alpha$-SynExpression, Stern: nicht-dopaminerge, eGFP-transfizierte Mittelhirnneurone ohne a-Syn-Expression. Primäre Mittelhirnneurone, DIV5, Maßbalken: $25 \mu \mathrm{m}, 20 x$-Objektiv.

\subsubsection{Quantifizierung der Überexpression}

Nach Evaluation des optimalen Nukleofektionsprogramms und der adäquaten Plasmidmenge erfolgte die quantitative Bestimmung der resultierenden GesamtÜberexpression von a-Syn-WT und seinen pathogenen Isoformen A30P und A53T mittels Western Blot (s. auch 2.5.5).

Zur Quantifizierung wurde ein Antikörper verwendet (BD Biosciences), der sowohl das humane als auch das endogene Ratten- $\alpha-S y n$ erkennt (Gesamt- $\alpha-S y n)$. Das exprimierte Protein konnte mit der eGFP-Kontrolle, die ausschließlich das endogene Ratten- $\alpha-S y n$ enthält, verglichen werden (s. Abb. 3.13). Die Differenz spiegelt somit das exprimierte 
humane $\alpha$-Syn wider. Es zeigte sich nach Quantifizierung von 3 unabhängigen Zellkulturen für den $\alpha$-Syn-WT eine 1,88 \pm 0,2-fache $(p$ zu eGFP $=0,012$, One-Way ANOVA gefolgt von Tukey-Kramer-Post-hoc-Test), für die A30P-Mutation eine 2,38 \pm 0,36-fache ( $p$ zu eGFP = 0,0019) und für die A53T-Mutation eine 2,08 \pm 0,09-fache ( $\mathrm{p}$ zu eGFP = 0,0038) Überexpression im Vergleich zur eGFP-Kontrolle (s. Abb. 3.11). Zwischen den einzelnen aSyn-transfizierten Versuchsgruppen ergaben sich keine signifikanten Unterschiede.

a

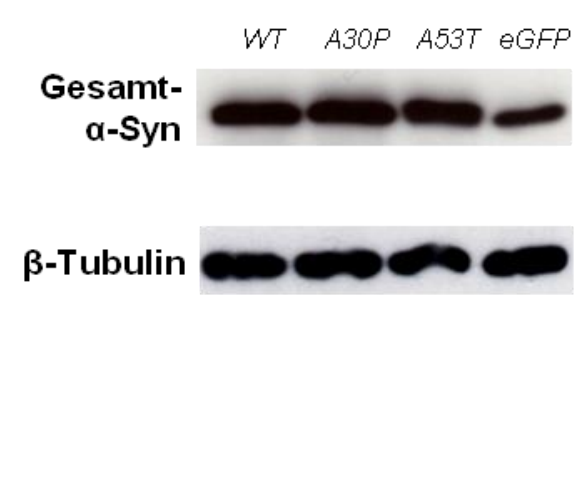

b

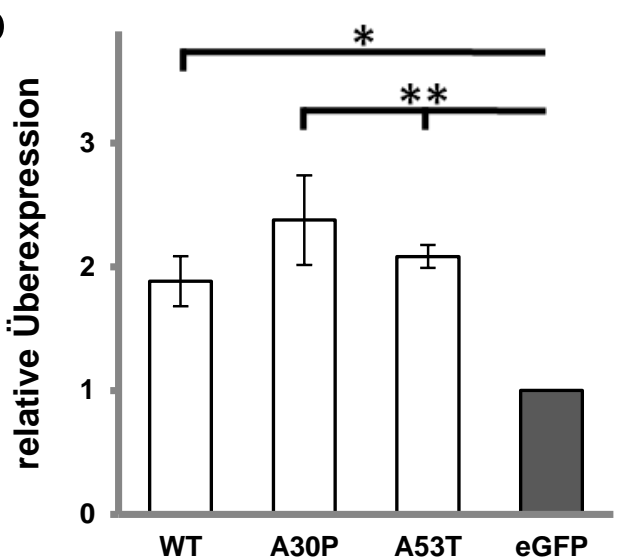

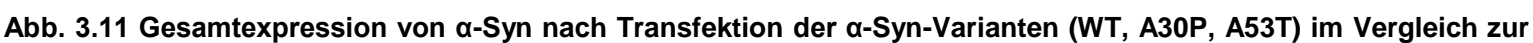
eGFP-Kontrollgruppe. a) Exemplarischer Western Blot.Bereits hier ist visuell eine ungefähre Verdopplung der Proteinmenge in den a-Syn-transfizierten Versuchsgruppen im Vergleich zur Kontrollgruppe zu erkennen. b) Quantifizierung der Gesamt-a-Syn-Expression im Vergleich zur eGFP-Kontrollgruppe. Es zeigt sich durchschnittlicheine 2,11-fache Überexpression der $\alpha$-Syn-transfizierten Gruppen im Vergleich zur eGFP-Kontrollgruppe. Primäre Mittelhirnneurone, DIV5, $\mathrm{n}=3$ unabhängige Mittelhirnzellkulturen, ${ }^{*}: \mathrm{p}<0,05,{ }^{* *}: \mathrm{p}<0,01$ in One-Way ANOVA gefolgt vomTukey-Kramer-Post-hocTest, Fehlerbalken: Standardfehler des Mittelwertes.

\subsection{Einfluss von $\alpha-S y n$ auf das Überleben von}

\section{Mittelhirnneuronen}

\subsection{1 Überleben dopaminerger Mittelhirnneurone nach Transfektion}

Beim IPS kommt es zum kontinuierlichen Absterben von Neuronen. Zu Beginn der klinischen Symptome steht dabei eine Degeneration des dopaminergen nigrostriatalen Systems. Eine pro-apoptotische Wirkung veränderter a-Syn-Mengen in Neuronen ist daher wahrscheinlich, zudem könnte es eine besondere Suszeptibilität von dopaminergen Neuronen geben.

Dies wurde in der verwendeten Mittelhirnneuronenkultur untersucht. Hierzu wurde die Anzahl der TH-positiven Neurone der jeweiligen transfizierten Versuchsgruppe mit der der eGFPKontrollgruppe verglichen (s. auch 2.4.4.4). Die quantitative Auswertung von 167 Gesichtsfeldern in 20-facher Vergrößerung ergab in der Kontrollgruppe einen Mittelwert von $19 \pm 1$ dopaminerge Neurone / 0,147 $\mathrm{mm}^{2}$ (entspr. 1 Gesichtsfeld in 20x-Vergrößerung). Die Auswertung für die mit $\alpha$-Syn-WT transfizierte Gruppe $(n=133)$ ergab einen Mittelwert von $16 \pm 1$ dopaminerge Neurone / 0,147 $\mathrm{mm}^{2}$, einen Mittelwert von $15 \pm 1$ Neurone / 0,147 mm² für die mit $\alpha$-Syn-A30P transfizierte Gruppe $(n=115)$ und von $15 \pm 1$ Neurone / 0,147 mm² für die A53T-Mutation ( $n=133$ ). Hieraus ergaben sich signifikante Unterschiede für den WT 
$(p=0,0059$, One-Way ANOVA gefolgt von Tukey-Kramer-Post-hoc-Test), A30P $(p=0,00021)$ und A53T $\left(p=2,42 * 10^{-6}\right)$ im Vergleich zur Kontrolle (s. Abb 3.12 und 3.13).
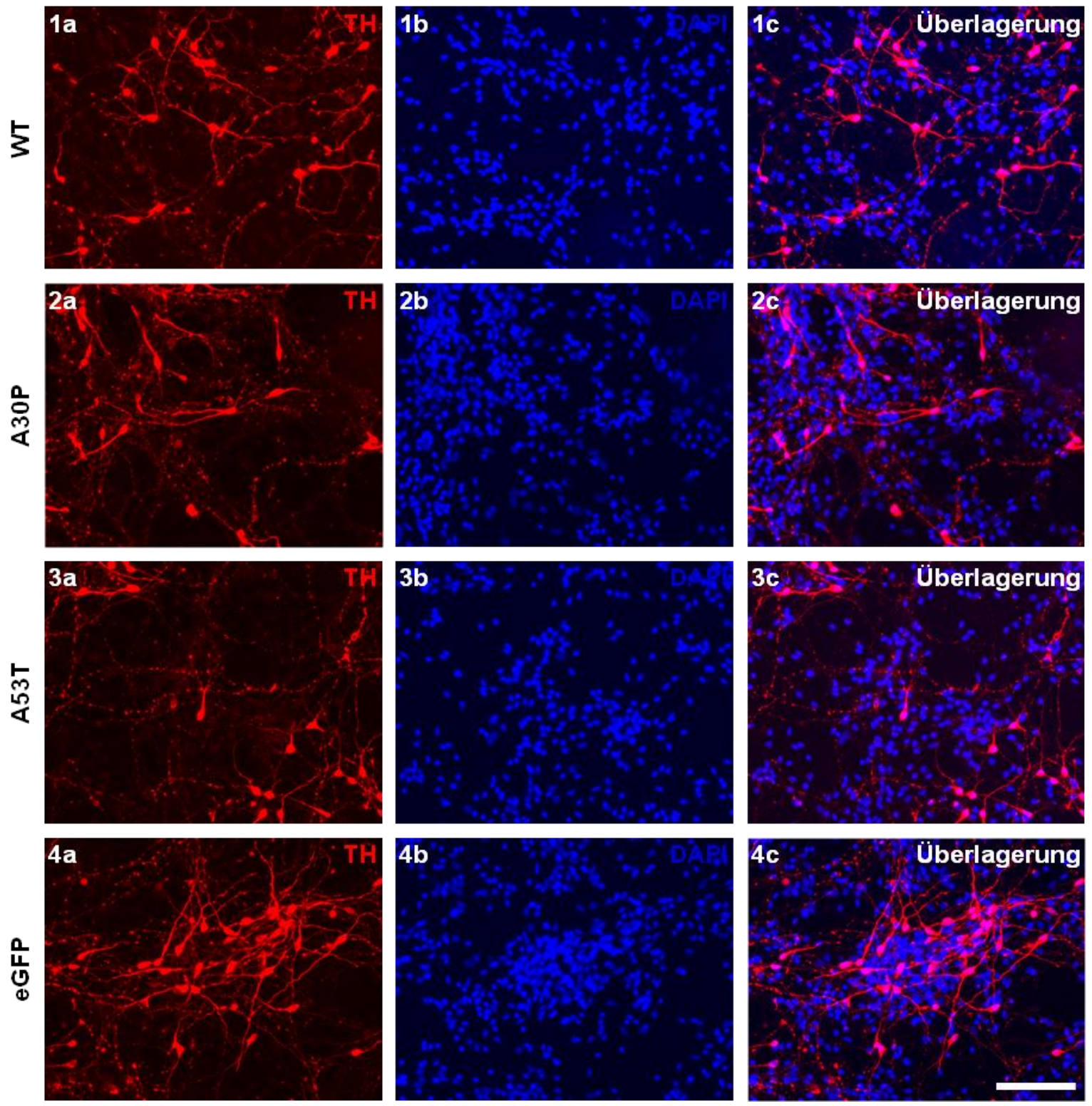

Abb. 3.12 Repräsentative immunzytochemische Darstellung des gesteigerten Zelluntergangs nach Transfektion mit a-Syn-Varianten im Vergleich zur eGFP-Kontrolle. Zu beachten ist die geringere Anzahl TH-positiver Neurone in den a-Syn-Gruppen. a) TH-Färbung, b) DAPI Zellkernfärbung, c) Überlagerung von a und b. 1(a-c) $\alpha$-Syn-WT, 2(a-c) $\alpha$-SynA30P, 3(a-c) a-Syn-A53T, 4(a-c) eGFP-Kontrollgruppe. Primäre Mittelhirnneurone, DIV5, Maßbalken: 100 4m, 20x-Objektiv. 


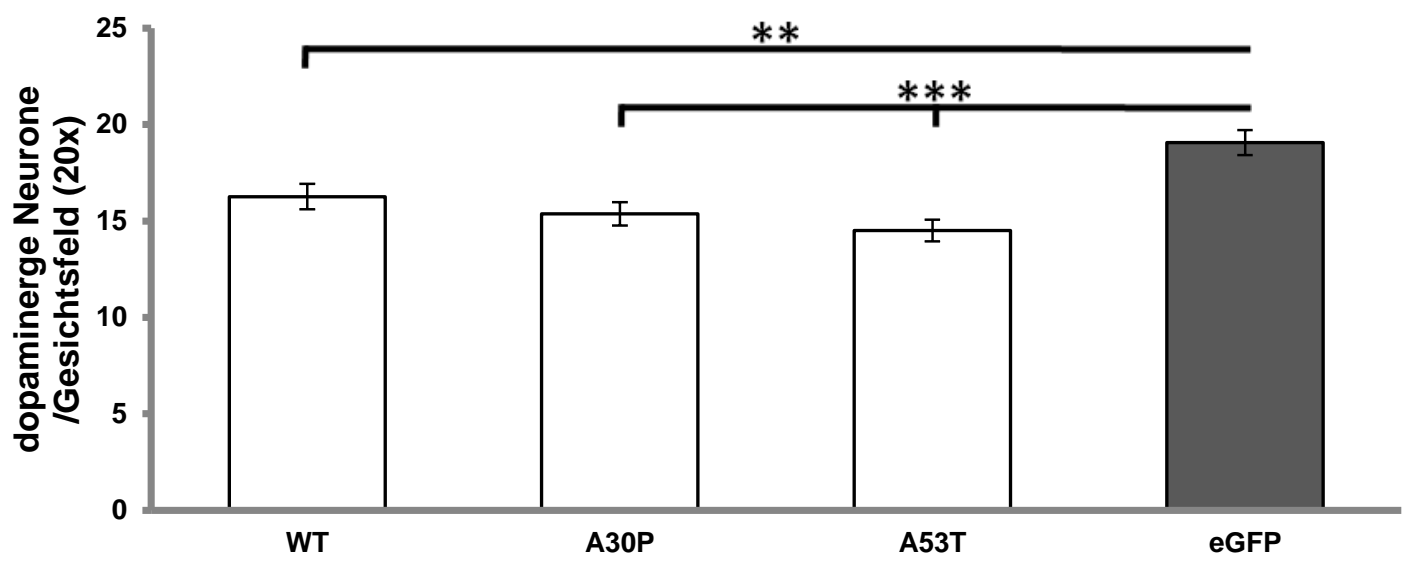

Abb. 3.13 Anzahl dopaminerger Mittelhirnneurone nach Transfektion mit $\alpha$-Syn-Varianten im Vergleich zur eGFP. Kontrolle. Die Darstellung zeigt eine signifikante Reduktion der dopaminergen Neuronein den a-Syn-transfizierten Populationen im Vergleich zur eGFP-Kontrolle in primären Mittelhirnneuronen. WT: $n=133$, A30P: $n=115$, A53T: $n=133$, eGFP: $n=167$ Gesichtsfelder in 20-facher Vergrößerung aus 3 unabhängigen Mittelhirnzellkulturen, **: $p<0,01$, $p<0,001$ in One-Way ANOVA gefolgt von Tukey-Kramer-Post-hoc-Test, Fehlerbalken: Standardfehler des Mittelwertes.

\subsection{2 Überleben nicht-dopaminerger Mittelhirnneurone nach Transfektion}

Ergänzend und vergleichend erfolgte die Analyse des Überlebens nicht-dopaminerger Neurone. Hierbei ergab sich nach Auswertung von 100 Gesichtsfeldern in 20-facher Vergrößerung je Versuchsgruppe aus 3 unabhängigen Zellkulturen ebenfalls eine signifikante Reduktion der Zellzahl nicht-dopaminerger Neurone in den a-Syn-transfizierten Versuchsgruppen im Vergleich zur lediglich mit eGFP transfizierten Kontrollgruppe. Im Detail konnten für den WT eine Zellzahl von $350 \pm 12$ / 0,147 mm² (entspr. 1 Gesichtsfeld in 20xVergrößerung) ( $p=3,56 * 10^{-5}$ zu eGFP, One-Way ANOVA gefolgt von Tukey-Kramer-Posthoc-Test), für A30P $385 \pm 13$ ( $p=0,041$ zu eGFP) und für A53T $334 \pm 11$ ( $p=2,10^{*} 10^{-6} z u$ eGFP) nicht-dopaminerge Neurone bei einer Zellzahl von $432 \pm 14$ in der Kontrollgruppe ermittelt werden. Zusätzlich ergab sich ein signifikanter Unterschied zwischen A30P und A53T $(p=0,0315)$ (s. Abb. 3.14).

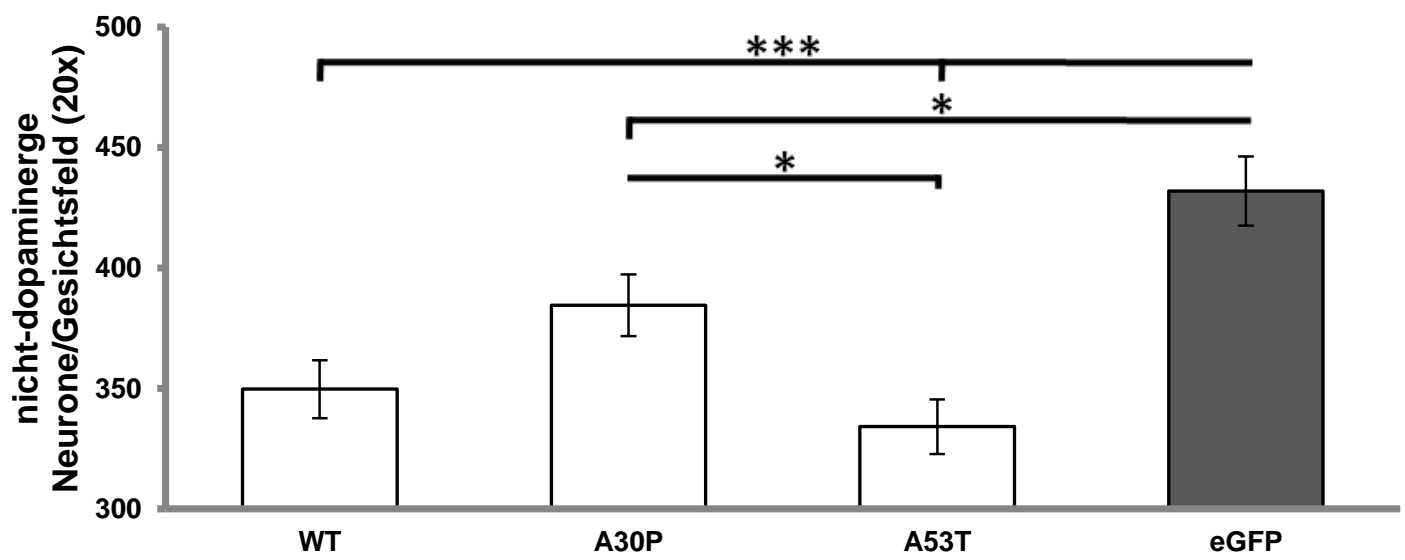

Abb. 3.14 Anzahl nicht-dopaminerger Mittelhirnneurone nach Transfektion mit $\alpha$-Syn im Vergleich zur eGFP. Kontrolle. Die Darstellung zeigt eine signifikante Reduktion der nicht-dopaminergen Neurone bei den $\alpha$-Syn-transfizierten Versuchsgruppen im Vergleich zur eGFP-Kontrolle. Primäre Mittelhirnneurone, DIV5, $\mathrm{n}=100$ Gesichtsfelder in 20 -facher Vergrößerung aus 3 unabhängigen Zellkulturen, *: $p<0,05 ;{ }^{* * *}$ : $p<0,001$ in One-Way ANOVA gefolgt von Tukey-KramerPost-hoc-Test, Fehlerbalken: Standardfehler des Mittelwertes. 
Somit fanden sich bereits nach wenigen Tagen in der Zellkultur signifikant negative Effekte einer Überexpression von $\alpha$-Syn auf das Überleben von Mittelhirnneuronen, wobei eine spezifische Vulnerabilität der dopaminergen Neurone nicht nachgewiesen werden konnte.

\subsection{Neuritenmorphologie}

Um den Einfluss von $\alpha$-Syn-WT und den pathogenen Mutationsformen auf die Neuritenmorphologie der primären mesencephalen Neurone beurteilen zu können, wurden die Neuriten der Nervenzellen nach immunzytochemischer Färbung einzeln markiert und vermessen (s. auch 2.4.4.1).

Zur Analyse der Neuritenmorphologie wurden die Anzahl der Neuriten pro Neuron (Neuritenanzahl), die durchschnittliche Länge einzelner Neuriten (Neuritenlänge) und die Gesamtlänge aller Neuriten pro Neuron (Gesamtneuritenlänge) bestimmt. Zudem wurde eine Sholl-Analyse (s. 3.5) zur Beurteilung des Verzweigungsverhaltens der Neuriten angefertigt. Diese Parameter wurden isoliert für die dopaminergen und nicht-dopaminergen Mittelhirnneurone erhoben. Die Mittelhirnneurone wurden zuvor mit dem a-Syn-WT-,-A30P-, -A53T- oder dem eGFP-Kontrollplasmid transfiziert, um spezifische Effekte der Überexpression des jeweiligen Proteins zu erfassen.

\subsubsection{Neuritenanzahl}

\subsubsection{Neuritenanzahl dopaminerger Mittelhirnneurone}

Zunächst wurden die TH-positiven Neurone nach immunzytochemischer Färbung vermessen (s. Abb. 3.16). Die untersuchte Zellgruppe bestand somit aus dopaminergen mesencephalen Neuronen, die co-transfiziert mit eGFP und $\alpha$-Syn waren. Die dopaminergen, nicht transfizierten Neurone (untrans) dienten neben der eGFP-Kontrolle als eine weitere Kontrollgruppe.

Die Transfektion mit $\alpha$-Syn-Plasmiden und die daraus resultierende Proteinüberexpression führten zu einer signifikanten Steigerung der Neuritenanzahl pro Neuron im Vergleich zu den Kontrollgruppen. Hierbei zeigten sich in der $\alpha$-Syn-WT-Gruppe 9,62 $\pm 0,32$, für die A30PMutation 10,53 $\pm 0,35$ und für die A53T-Mutation 10,98 $\pm 0,30$ Neuriten. Zwischen der lediglich mit eGFP transfizierten Gruppe (7,96 \pm 0,26 Neuriten) und der Gruppe bestehend aus untransfizierten dopaminergen Neuronen $(8,074 \pm 0,19)$ ergab sich kein signifikanter Unterschied. Dies spiegelt, wie zuvor bereits erwähnt, wider, dass die alleinige Transfektion mit eGFP-Plasmid und die daraus resultierende Expression von eGFP offensichtlich keinen toxischen Einfluss nehmen. Zusätzlich bestand ein signifikanter Unterschied zwischen dem a-Syn-WT und der A53T-Mutation. Die folgende Abbildung soll diesen Zusammenhang zeigen, und in der darauf folgenden Tabelle sind die einzelnen $\mathrm{p}$-Werte dargestellt (s. Abb. 3.15 und Tab. 3.2). 
Ergebnisse

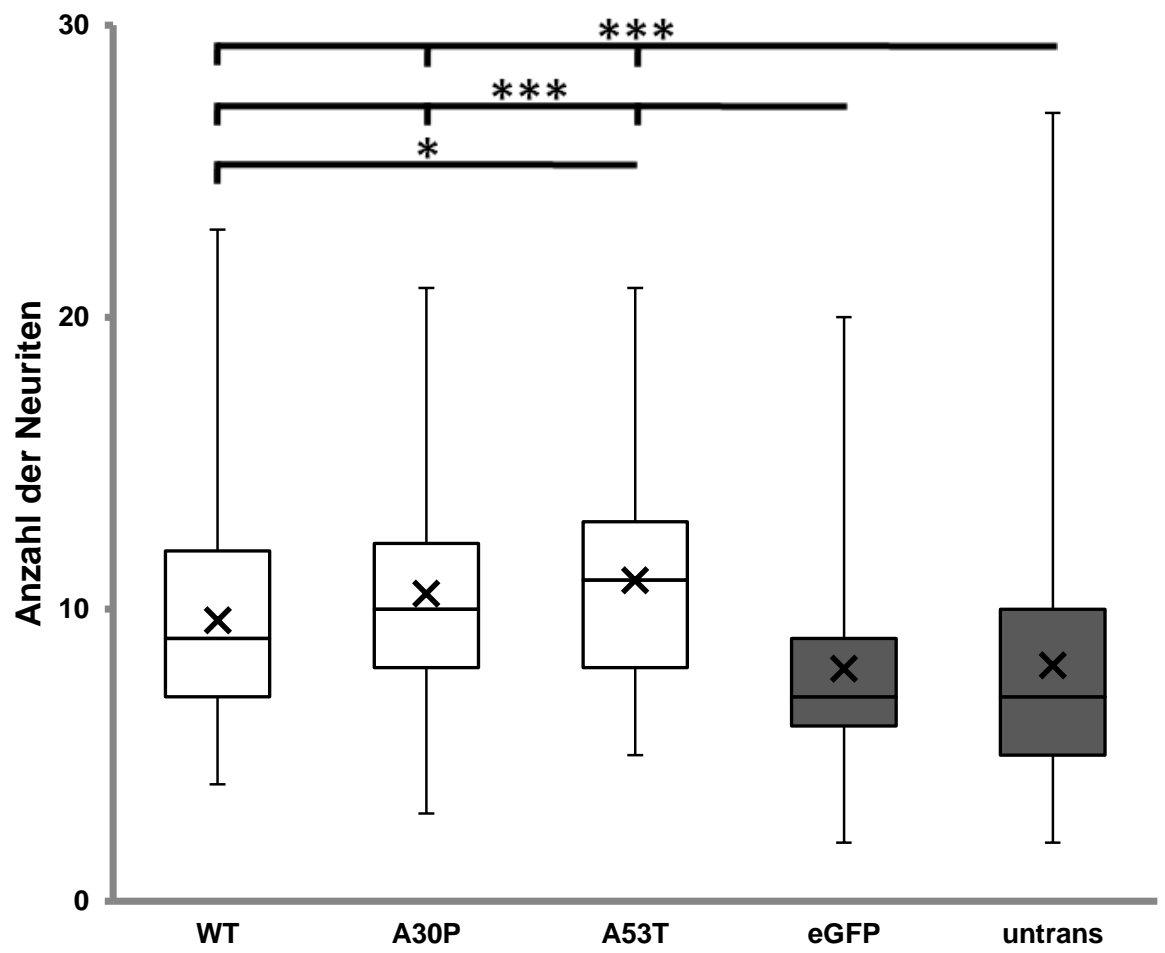

Abb. 3.15 Durchschnittliche Neuritenanzahl pro dopaminergem, mit $\alpha$-Syn (WT, A30P, A53T) transfiziertem Mittelhirnneuron im Vergleich zur eGFP-Kontrolle und nicht-transfizierter, TH-positiver Kontrollgruppe (untrans). Es zeigte sich in allen $\alpha$-Syn-transfizierten Populationen eine erhöhte Anzahl an Neuriten im Vergleich zu den Kontrollgruppen. WT: $n=133$, A30P: $n=120$, A53T: $n=130$, eGFP: $n=171$, untrans: $n=380$ aus 3 unabhängigen Mittelhirnzellkulturen, DIV5, *: $p<0,05,{ }^{* *}: p<0,001$ in One-Way ANOVA gefolgt von Tukey-Kramer-Post-hoc-Test. Darstellung als Box Plot: Box-Reichweite: von 1. bis 3. Quartile, innere Bande: Median (2. Quartile), Kreuz: arithmetischer Mittelwert, oberer Whisker: Maximum, unterer Whisker: Minimum.

\begin{tabular}{|c|c|c|c|c|}
\hline \multirow{2}{*}{} & \multicolumn{4}{|c|}{ Signifikanzlevel (p-Wert) } \\
\cline { 2 - 5 } & A30P & A53T & eGFP & untrans \\
\hline WT & 0,26 & 0,019 & 0,00079 & 0,00026 \\
\hline A30P & & 0,85 & $1,76 * 10^{-6}$ & $1,72 * 10^{-6}$ \\
\hline A53T & & & $1,72 * 10^{-6}$ & $1,72 * 10^{-6}$ \\
\hline eGFP & & & & 0,997 \\
\hline
\end{tabular}

Tab. 3.2 p-Werte der einzelnen Signifikanzvergleiche der Anzahl der Neuriten dopaminerger Neurone zwischen den Versuchsgruppen. Es zeigte sich in allen a-Syn transfizierten Populationen eine erhöhte Anzahl an Neuriten im Vergleich zu den Kontrollgruppen. Darüber hinaus ist der Unterschied zwischen A53T und WT ebenfalls signifikant. Kursiv und fett: signifikante Unterschiede in One-Way ANOVA gefolgt von Tukey-Kramer-Post-hoc-Test. 

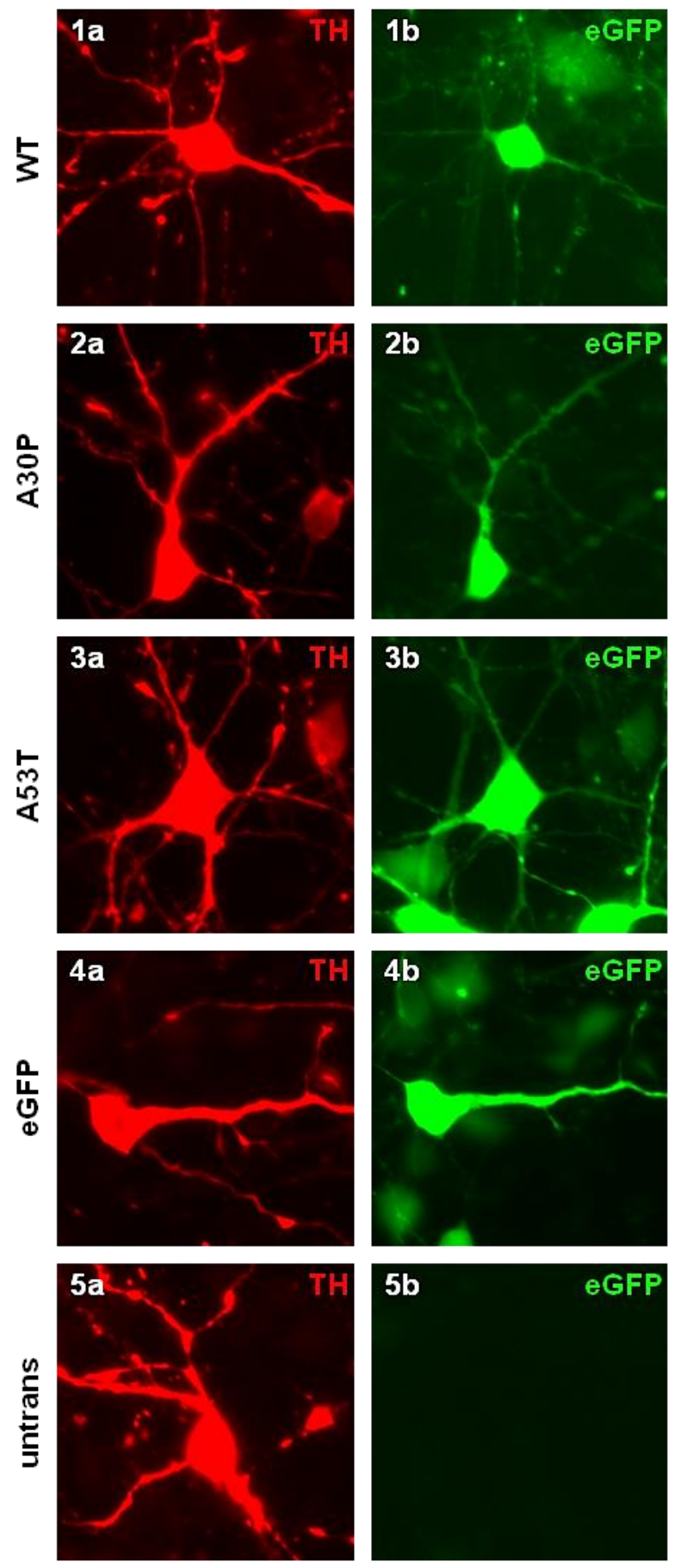
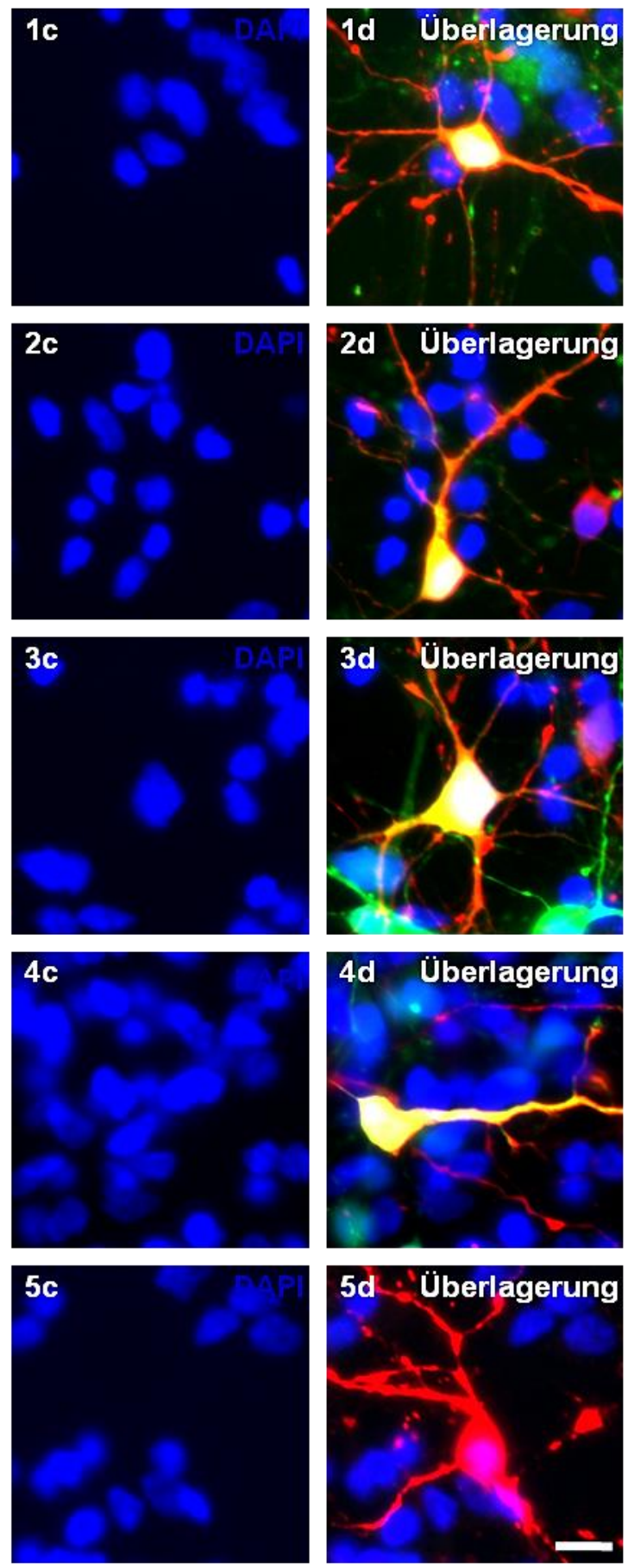

Abb. 3.16 Repräsentative immunzytochemische Darstellung der unterschiedlichen Neuritenanzahl pro dopaminergem Mittelhirnneuron in den verschiedenen Versuchsgruppen. Bereits visuell ist eine Erhöhung der Neuritenanzahl in den mit $\alpha$-Syn transfizierten Versuchsgruppen zu erkennen. a) TH-Färbung, b) eGFP-Fluoreszenz, c) DAPI-Zellkernfärbung, d) Überlagerung von a bis c. 1(a-d) $\alpha$-Syn-WT, 2(a-d) $\alpha$-Syn-A30P, 3(a-d) $\alpha$-Syn-A53T, 4(a-d) eGFPKontrollgruppe, $5(\mathrm{a}-\mathrm{d})$ untransfizierte dopaminerge Neurone. Primäre dopaminerge Mittelhirnneurone, DIV5, Maßbalken: $12,5 \mu \mathrm{m}, 40 x-O b j e k t i v$.

\subsubsection{Neuritenanzahl nicht-dopaminerger Mittelhirnneurone}

Des Weiteren wurden die Neuriten der nicht-dopaminergen Mittelhirnneurone vermessen. Es zeigte sich hierbei eine signifikante Steigerung der Neuritenanzahl nur bei der A30P Mutation. 
Pro Neuron fanden sich in der WT-Gruppe 8,85 \pm 0,36 Neuriten ( $p=0,99$ zu eGFP, OneWay ANOVA gefolgt von Tukey-Kramer-Post-hoc-Test, $n=89$ Neurone), für die A30PMutation eine signifikante Erhöhung der Neuritenanzahl auf 10,76 $\pm 0,54$ Neuriten $(p=0,0010 \mathrm{zu}$ eGFP, $n=93)$ und für die A53T-Mutation ebenfalls eine jedoch statistisch nicht-signifikante Erhöhung auf 10,05 $\pm 0,38$ Neuriten ( $p=0,078$ zu eGFP, $n=94$ ) bei einer durchschnittlichen Neuritenzahl von 8,84 $\pm 0,28$ in der eGFP-Kontrollgruppe $(n=208)$.

Zusätzlich bestand ein signifikanter Unterschied zwischen dem WT und der A30P-Mutation $(p=0,0092)$. Die folgende Abbildung soll diesen Zusammenhang graphisch zeigen (s. Abb. 3.17).

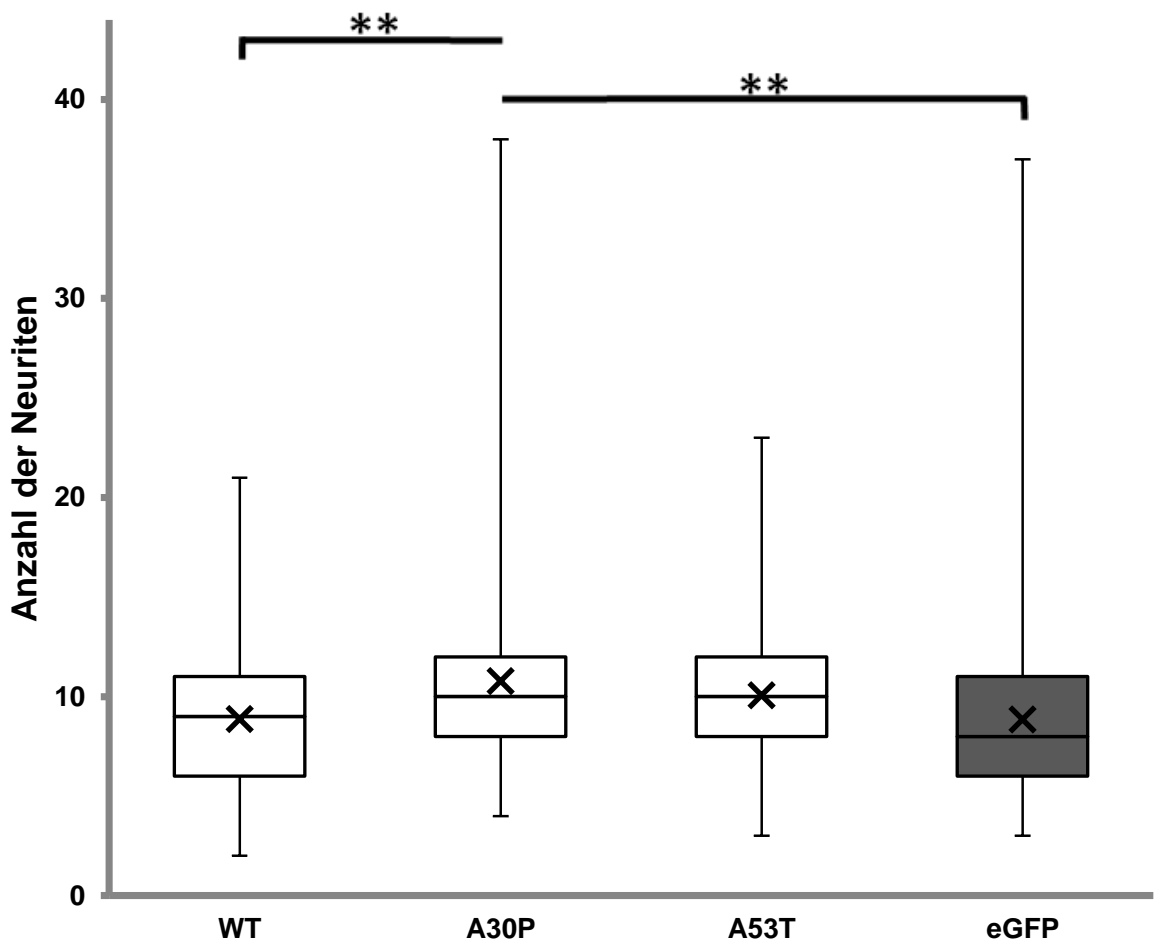

Abb. 3.17 Neuritenanzahl pro nicht-dopaminergem, mit $\alpha$-Syn (WT, A30P, A53T) transfiziertem Mittelhirnneuron im Vergleich zur eGFP-Kontrolle. Lediglich in der A30P-Versuchsgruppe war eine Steigerung der Neuritenzahl zu verzeichnen. WT: $n=89$, A30P: $n=93$, A53T: $n=94$, eGFP: $n=208$ aus 3 unabhängigen Mittelhirnzellkulturen, DIV5,**: $p<0,01$ in One-Way ANOVA gefolgt von Tukey-Kramer-Post-hoc-Test. Darstellung als Box Plot: Box-Reichweite: von 1. bis 3. Quartile, innere Bande: Median (2. Quartile), Kreuz: arithmetischer Mittelwert, oberer Whisker: Maximum, unterer Whisker: Minimum.

\subsubsection{Gesamtneuritenlänge}

Nachdem zunächst die Anzahl der Neuriten ermittelt worden war, erfolgte die Analyse der Gesamtlänge des Neuritenbaums der einzelnen Neurone.

\subsubsection{Gesamtneuritenlänge dopaminerger Mittelhirnneurone}

Die Gesamtneuritenlänge der dopaminergen Neurone, welche mit den einzelnen $\alpha$-SynVarianten transfiziert wurden, zeigte sich in Bezug auf die Kontrollgruppen nicht signifikant verändert. Zwar konnte beim WT mit einer Gesamtneuritenlänge von 
298,20 $\pm 11,32 \mu \mathrm{m}$ eine tendenzielle Erniedrigung und bei der A53T-Mutante mit $357,18 \pm 11,69 \mu \mathrm{m}$ eine leichte Erhöhung im Vergleich zu den Kontrollgruppen (eGFP: $329,08 \pm 9,47 \mu \mathrm{m}$, untrans: $334,72 \pm 7,08 \mu \mathrm{m})$ gesehen werden, diese waren jedoch nicht signifikant. Die A30P-Mutante zeigte eine Gesamtneuritenlänge, welche mit durchschnittlich 336,93 $\pm 12,81 \mu \mathrm{m}$ annähernd den Kontrollgruppen entsprach (s. Abb. 3.18 und 3.19).

So ergab sich lediglich zwischen der A53T-Mutante und dem WT ein signifikanter Unterschied ( $p=0,0033$, One-Way ANOVA gefolgt von Tukey-Kramer-Post-hoc-Test).

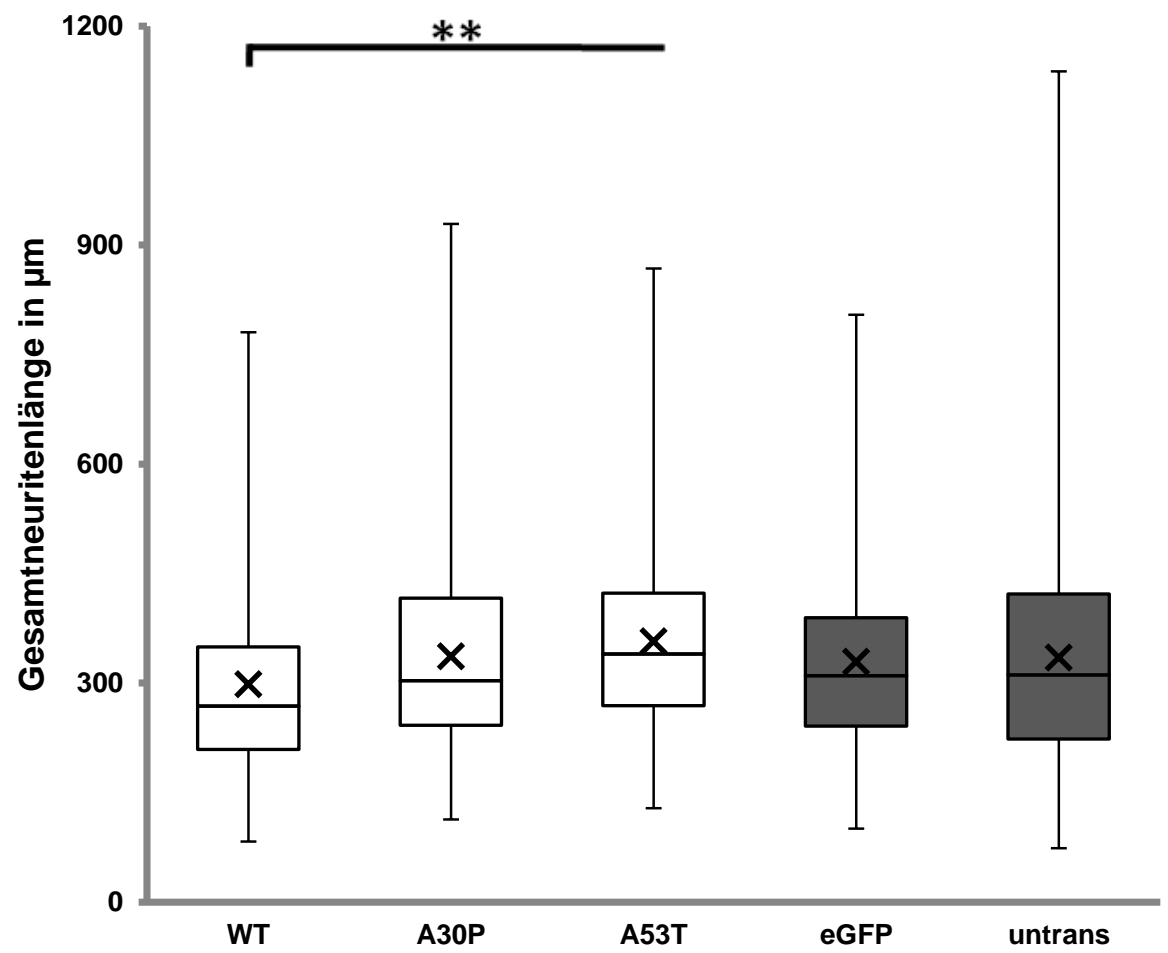

Abb. 3.18 Gesamtneuritenlänge eines dopaminergen Mittelhirnneurons nach Transfektion mit $\alpha$-Syn (WT, A30P, A53T) im Vergleich zu den Kontrollgruppen [alleinige eGFP-Transfektion bzw. nicht transfiziert (untrans)]. Die Gesamtneuritenlänge zeigte sich im Vergleich der $\alpha$-Syn-Versuchsgruppen mit den Kontrollen nicht verändert. Bei jedoch tendenzieller Erniedrigung des WTs und Erhöhung der A53T-Mutation war der Unterschied zwischen diesen Populationen signifikant. WT: $n=133$, A30P: $n=120$, A53T: $n=130$, eGFP: $n=171$, untrans: $n=380$ aus 3 unabhängigen Mittelhirnzellkulturen, DIV5, ${ }^{* *}: \mathrm{p}<0,01$ in One-Way ANOVA gefolgt von Tukey-Kramer-Post-hoc-Test. Darstellung als Box Plot: Box-Reichweite: von 1. bis 3. Quartile, innere Bande: Median (2. Quartile), Kreuz: arithmetischer Mittelwert, oberer Whisker: Maximum, unterer Whisker: Minimum. 

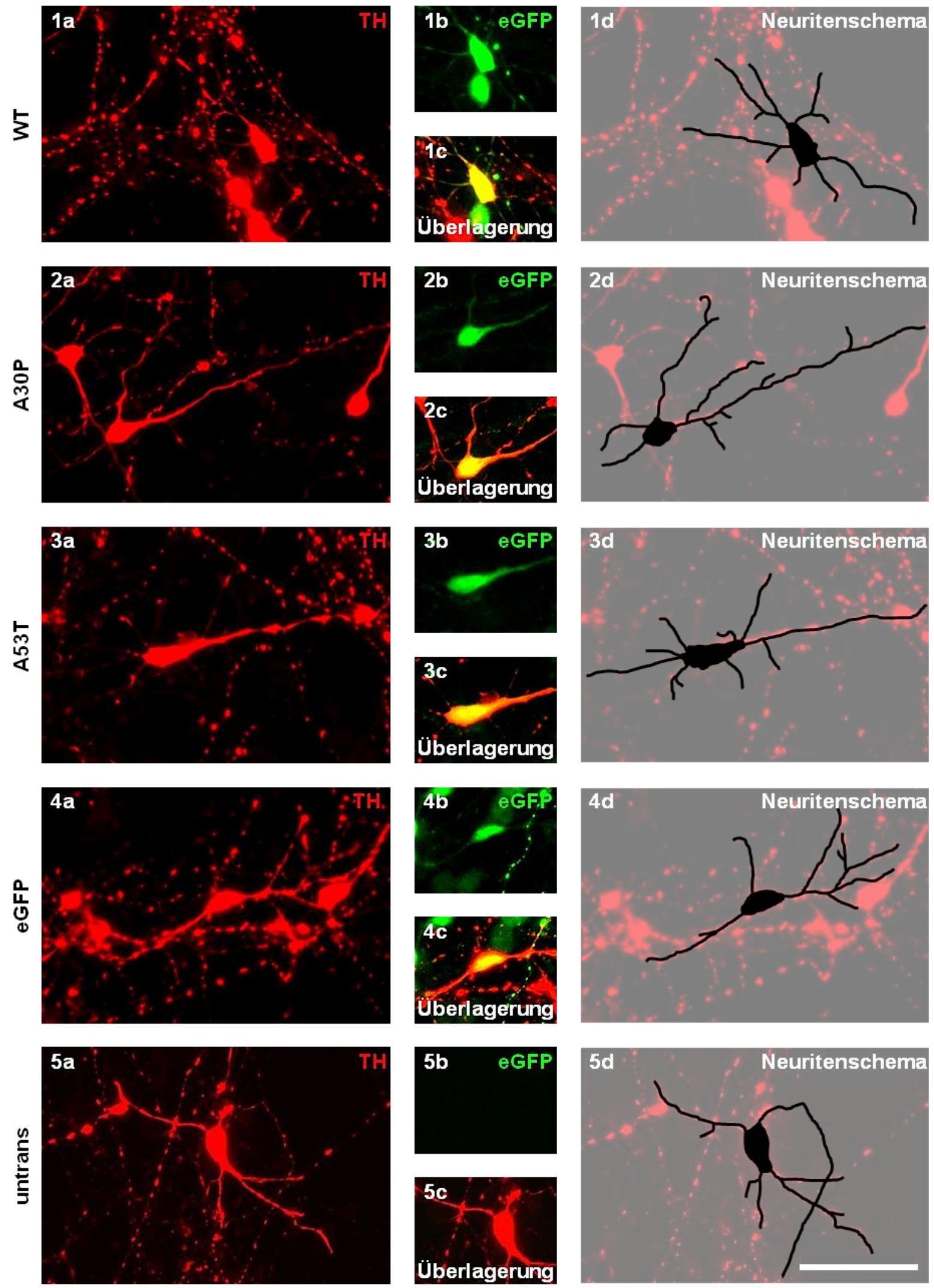

Abb. 3.19 Repräsentative immunzytochemische Darstellung der Gesamtneuritenlänge eines dopaminergen Mittelhirnneurons nach Transfektion mit $\alpha$-Syn (WT, A30P, A53T) im Vergleich zu den Kontrollgruppen [alleinige eGFP-Transfektion bzw. nicht transfiziert (untrans)]. a) TH-Färbung, b) eGFP-Fluoreszenz, c) Überlagerung von a und b (Ausschnitt des Zellkörpers), d) schematische Neuritenzeichnung.1(a-d) $\alpha$-Syn-WT, 2(a-d) $\alpha$-Syn-A30P, 3(a-d) $\alpha$-Syn-A53T, 4(a-d) eGFP-Kontrollgruppe, 5(a-d) untransfizierte dopaminerge Neurone. Primäre dopaminerge Mittelhirnneurone, DIV5, Maßbalken: $50 \mu \mathrm{m}, 20 x-O b j e k t i v$. 


\subsubsection{Gesamtneuritenlänge nicht-dopaminerger Mittelhirnneurone}

Es zeigte sich bei den Neuronen nach Transfektion mit dem a-Syn-WT eine Gesamtneuritenlänge von $358,31 \pm 17,93 \mu \mathrm{m}$, bei der A30P-Mutation von 455,87 $\pm 20,38 \mu \mathrm{m}$ und bei der A53T-Mutation von 414,34 $\pm 16,99 \mu \mathrm{m}$ im Vergleich zu 439,61 $\pm 12,16 \mu \mathrm{m}$ in der eGFP-Kontrollgruppe. Es fand sich dabei für den $\alpha$-Syn-WT eine signifikante Reduktion der Gesamtneuritenlänge im Vergleich zur A30P-Mutation ( $p=0,0012$, One-Way ANOVA gefolgt von Tukey-Kramer-Post-hoc-Test) und zur eGFP-Kontrollgruppe ( $p=0,0017)$. Die $\alpha-$ Syn-Mutanten wiesen keine signifikanten Veränderungen gegenüber der Kontrolle oder untereinander auf (s. Abb. 3.20).

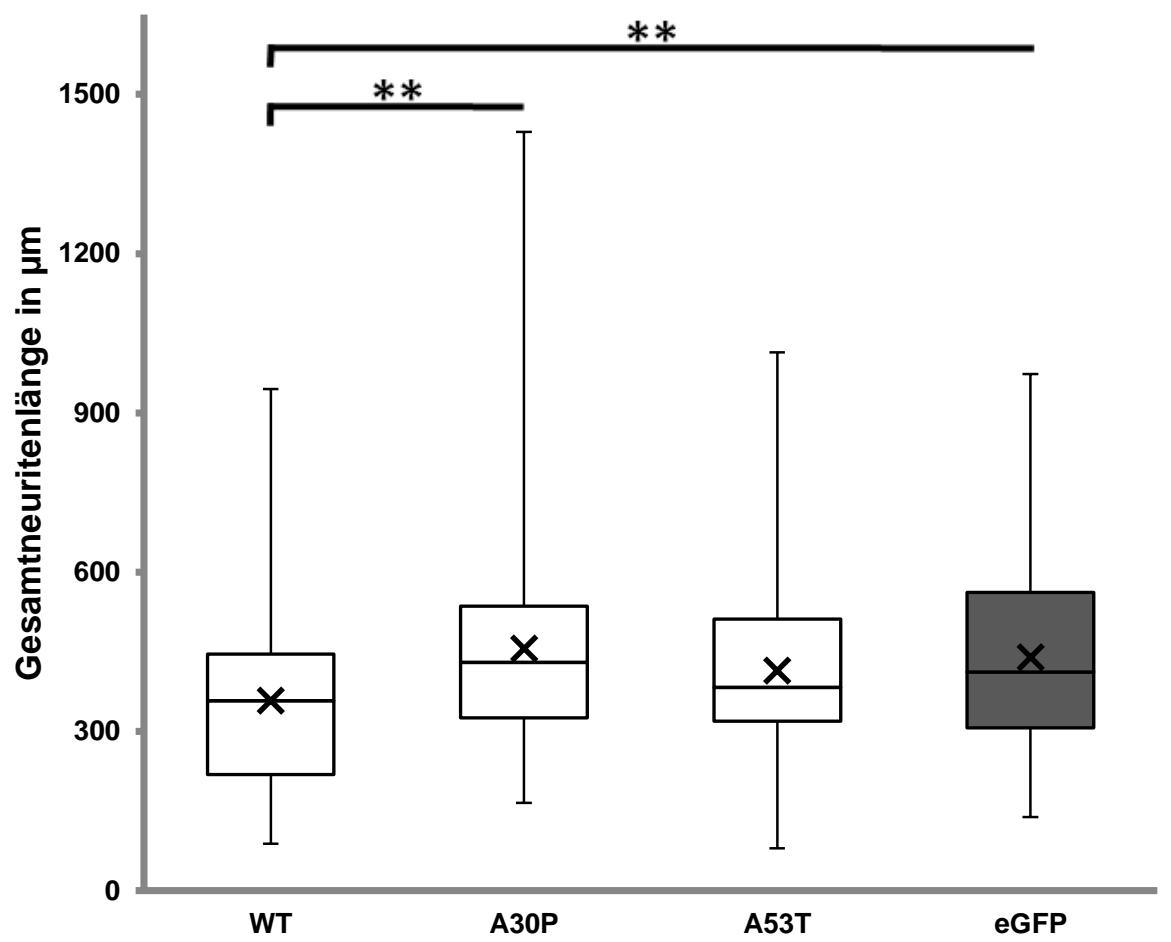

Abb. 3.20 Gesamtneuritenlänge pro nicht-dopaminergem, mit $\alpha$-Syn (WT, A30P, A53T) transfiziertem Mittelhirnneuron im Vergleich zur eGFP-Kontrolle. Lediglich der $\alpha$-Syn-WT zeigte eine signifikant reduzierte Gesamtneuritenlänge. WT: $n=89$, A30P: $n=93$, A53T: $n=94$, eGFP: $n=208$ aus 3 unabhängigen Mittelhirnzellkulturen, DIV5,**: $p<0,01$ in One-Way ANOVA gefolgt von Tukey-Kramer-Post-hoc-Test.Darstellung als Box Plot: Box-Reichweite: von 1. bis 3. Quartile, innere Bande: Median (2. Quartile), Kreuz: arithmetischer Mittelwert, oberer Whisker: Maximum, unterer Whisker: Minimum.

\subsubsection{Durchschnittliche Neuritenlänge}

Im Weiteren wurde die durchschnittliche Länge eines einzelnen Neuriten betrachtet.

\subsubsection{Durchschnittsneuritenlänge dopaminerger Mittelhirnneurone}

Die durchschnittliche Neuritenlänge bzw. mittlere Länge einzelner Neuriten war im Vergleich zu beiden Kontrollgruppen in allen drei $\alpha$-Syn-überexprimierenden Gruppen (WT, A30P, A53T) signifikant vermindert (s. Tab. 3.3). 
Neurone der a-Syn-WT-Versuchsgruppe hatten Neuriten einer durchschnittlichen Länge von 31,42 \pm 0,72 $\mu \mathrm{m}$, während die Durchschnittslänge der Einzelneuriten bei der A30P-Gruppe 33,15 $\pm 0,99 \mu \mathrm{m}$ und bei der A53T-Mutation 33,13 $\pm 0,80 \mu \mathrm{m}$ betrug.

Zwischen den beiden Kontrollgruppen ergab sich kein signifikanter Unterschied. In der eGFP-Gruppe wurde eine durchschnittliche Neuritenlänge von 44,97 $\pm 1,41 \mu \mathrm{m}$ und in den untransfizierten Zellen von 45,32 $\pm 0,91 \mu \mathrm{m}$ gemessen (s. Abb. 3.21). Zwischen den einzelnen $\alpha-S y n-G r u p p e n$ ergaben sich keine signifikanten Unterschiede.

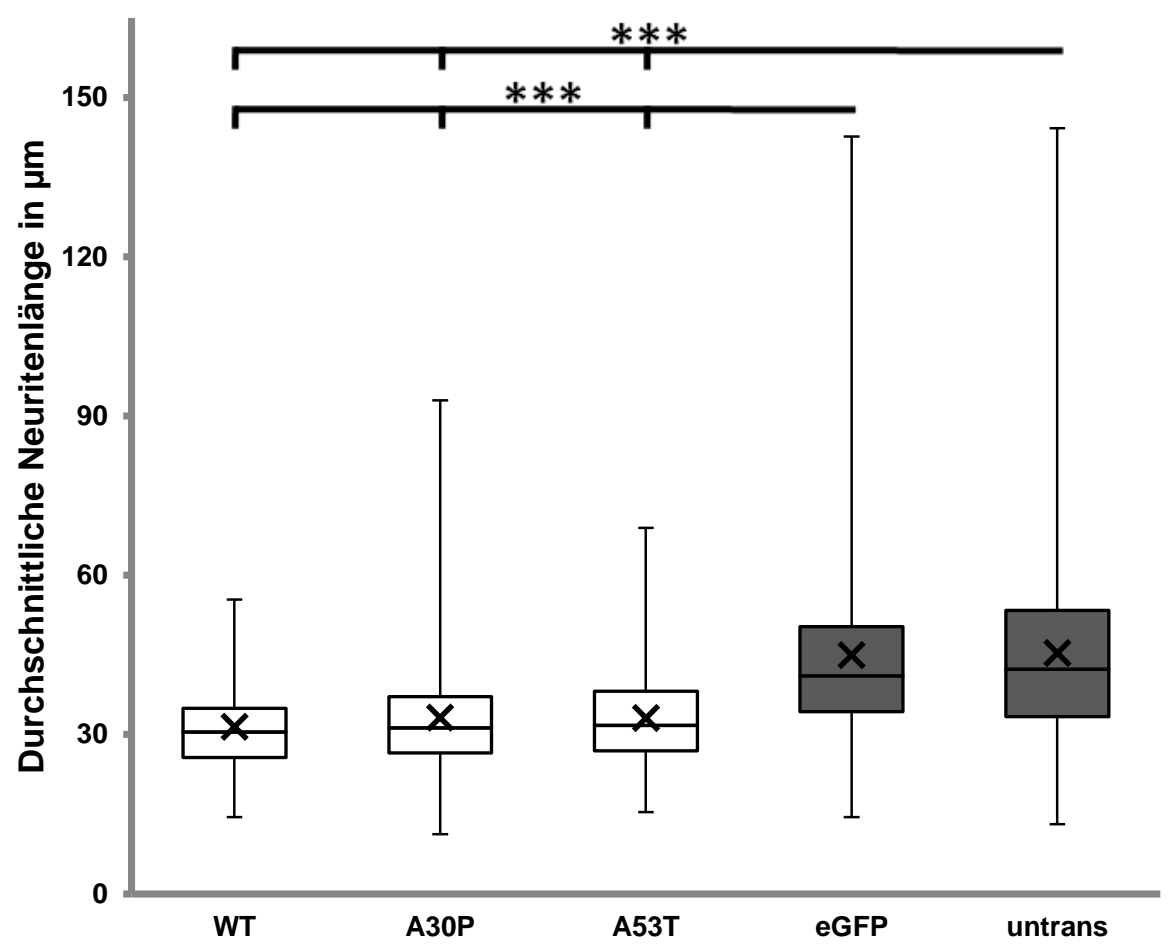

Abb. 3.21 Durchschnittliche Neuritenlänge eines dopaminergen Mittelhirnneurons nach Transfektion mit $\alpha-S y n$ (WT, A30P, A53T) im Vergleich zu den Kontrollgruppen. Die durchschnittliche Neuritenlänge war in allen $\alpha$-SynVersuchsgruppen im Vergleich zu den Kontrollen reduziert. WT: $n=133$, A30P: $n=120$, A53T: $n=130$, eGFP: $n=171$, untrans: $\mathrm{n}=380$ aus 3 unabhängigen Mittelhirnzellkulturen, $* * *: p<0,001$ in One-Way ANOVA gefolgt von Tukey-KramerPost-hoc-Test. Darstellung als Box Plot: Box-Reichweite: von 1. bis 3. Quartile, innere Bande: Median (2. Quartile), Kreuz: arithmetischer Mittelwert, oberer Whisker: Maximum, unterer Whisker: Minimum.

Die einzelnen $p$-Werte sind in der folgenden Tabelle zusammengefasst.

\begin{tabular}{|c|c|c|c|c|}
\hline & \multicolumn{4}{|c|}{ Signifikanzlevel (p-Wert) } \\
\hline & A30P & A53T & eGFP & untrans \\
\hline WT & 0,88 & 0,88 & $1,72 * 10^{-6}$ & $1,72 * 10^{-6}$ \\
\hline A30P & & 1,00 & $1,72 * 10^{-6}$ & $1,72 * 10^{-6}$ \\
\hline A53T & & & $1,72 * 10^{-6}$ & $1,72 * 10^{-6}$ \\
\hline eGFP & & & & 1,00 \\
\hline
\end{tabular}

Tab. 3.3 p-Werte der einzelnen Signifikanzvergleiche der durchschnittlichen Neuritenlänge dopaminerger Neurone zwischen den Versuchsgruppen. Die durchschnittliche Neuritenlänge war in allen $\alpha$-Syn-Versuchsgruppen im Vergleich zu den Kontrollen reduziert. kursiv und fett: signifikante Unterschiede in One-Way ANOVA gefolgt von Tukey-Kramer-Posthoc-Test. 


\subsubsection{Durchschnittsneuritenlänge nicht-dopaminerger Mittelhirnneurone}

Wie in der Zellpopulation dopaminerger Mittelhirnneurone zeigte sich auch hier eine signifikant verminderte durchschnittliche Neuritenlänge. Dabei zeigten sich bei den mit $\alpha$ Syn-WT transfizierten Neuronen Neuriten mit einer durchschnittlichen Länge von 42,17 $\pm 1,77 \mu \mathrm{m}$, bei der A30P-Mutation von 44,87 $\pm 1,44 \mu \mathrm{m}$ und bei der A53T-Mutante von $43,72 \pm 1,79 \mu \mathrm{m}$, wohingegen sich in der eGFP-Kontrollgruppe eine signifikant größere durchschnittliche Neuritenlänge von 52,61 $\pm 1,23 \mu \mathrm{m}$ fand (s. Abb. 3.22). Zwischen den verschiedenen $\alpha$-Syn-Formen ergaben sich keine signifikanten Unterschiede (s. Tab. 3.4).

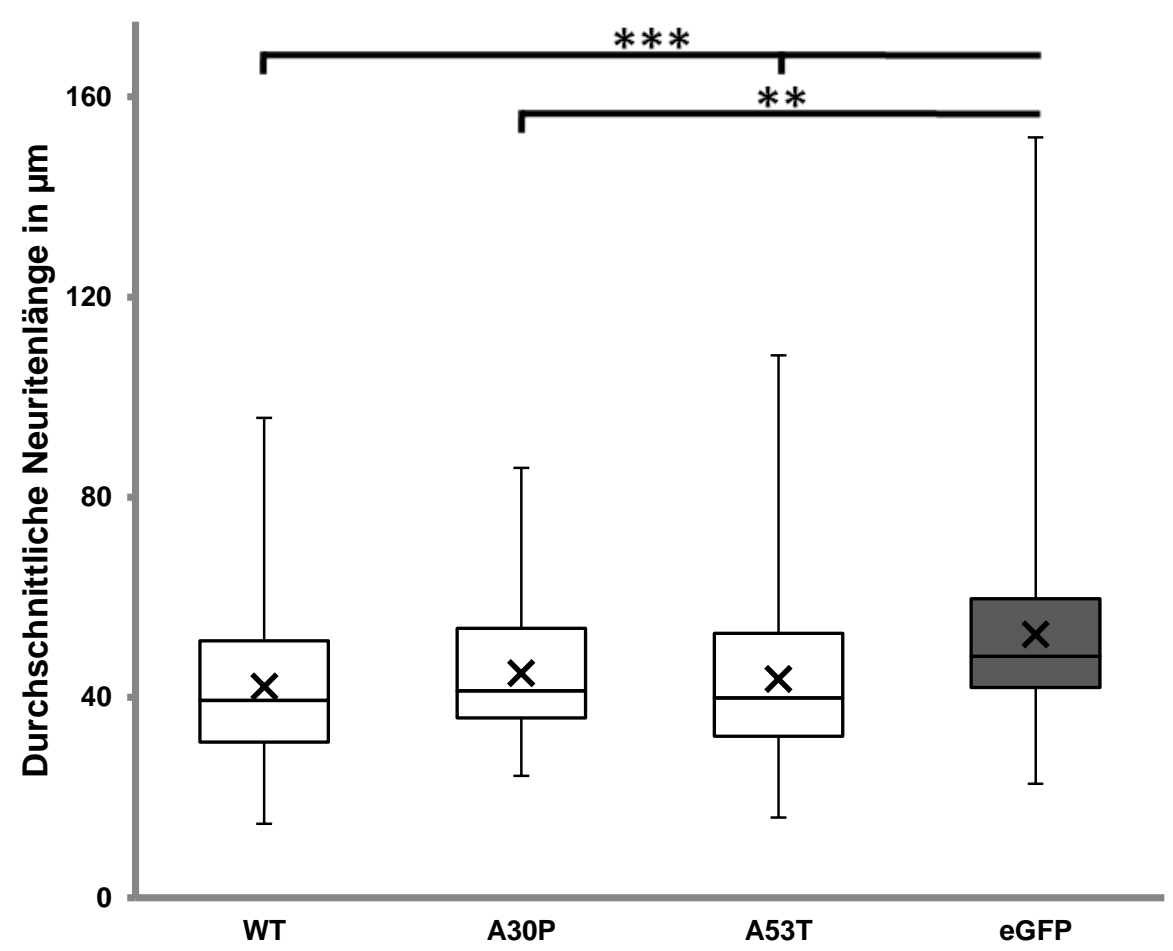

Abb. 3.22 Durchschnittliche Neuritenlänge pro nicht-dopaminergem, mit $\alpha-S y n$ (WT, A30P, A53T) transfiziertem Mittelhirnneuron im Vergleich zur eGFP-Kontrollgruppe. Die durchschnittliche Neuritenlänge war in allen $\alpha$-SynVersuchsgruppen reduziert. WT: $n=89$, A30P: $n=93$, A53T: $n=94$, eGFP: $n=208$ aus 3 unabhängigen Mittelhirnzellkulturen, DIV5,**: $p<0,01,{ }^{* * *}: \mathrm{p}<0,001$ in One-Way ANOVA gefolgt von Tukey-Kramer-Post-hocTest.Darstellung als Box Plot: Box-Reichweite: von 1. bis 3. Quartile, innere Bande: Median (2. Quartile), Kreuz: arithmetischer Mittelwert, oberer Whisker: Maximum, unterer Whisker: Minimum.

\begin{tabular}{|c|c|c|c|}
\hline & \multicolumn{3}{|c|}{ Signifikanzlevel (p-Wert) } \\
\hline & A30P & A53T & eGFP \\
\hline WT & 0,70 & 0,92 & ${ }^{*} 10^{-6}$ \\
\hline A30P & & 0,96 & 0,0014 \\
\hline A53T & & & 0.00015 \\
\hline
\end{tabular}

Tab. 3.4 p-Werte der einzelnen Signifikanzvergleiche der durchschnittlichen Neuritenlänge nicht-dopaminerger Mittelhirnneurone zwischen den Versuchsgruppen. Die durchschnittliche Neuritenlänge war in allen $\alpha$-SynVersuchsgruppen signifikant reduziert. Kursiv und fett: signifikante Unterschiede in One-Way ANOVA gefolgt von TukeyKramer-Post-hoc-Test. 
Zusammenfassend konnte bei den dopaminergen Neuronen nach der Transfektion mit $\alpha$ Syn eine signifikant erhöhte Neuritenanzahl mit einer reduzierten durchschnittlichen Neuritenlänge im Vergleich zu den Kontrollgruppen gezeigt werden, wohingegen die Gesamtneuritenlänge lediglich beim a-Syn-WT erniedrigt war.

Bei den nicht-dopaminergen Neuronen zeigte sich ein ähnliches Verhalten. Auch hier fand sich eine Erhöhung der Neuritenzahl bei den Mutationsformen, auch wenn diese lediglich für die A30P-Mutante signifikant war. Wie bei den dopaminergen Neuronen war die durchschnittliche Neuritenlänge reduziert, und lediglich beim $\alpha$-Syn-WT ergab sich eine signifikante Reduktion der Gesamtneuritenlänge.

\subsubsection{Perikaryongröße dopaminerger Mittelhirnneurone}

Des Weiteren wurde der Einfluss auf die Zellkörpergröße als Korrelat für die Zellmorphologie in einer immunzytochemischen Färbung (s. 2.4) untersucht (s. 2.4.4.3). Neurone, welche einen besonders ausgeprägten Neuritenbaum mit langen Projektionen ausbilden (sog. Projektionsneurone), haben in der Regel auch ein größeres Perikaryon im Vergleich zu sog. Interneuronen, die lediglich kurze Neuriten ausbilden (Lüllmann-Rauch 2009). Es ergab sich daher die Fragestellung, ob die durch die a-Syn-Überexpression induzierte, signifikant reduzierte durchschnittliche Neuritenlänge mit einer veränderten Soma-Größe korreliert.

Hierbei zeigten sich in 180 Einzelmessungen aus 3 unabhängigen Mittelhirnzellkulturen je Versuchsgruppe jedoch nahezu identische Zellkörpergrößen der dopaminergen Neurone, wie aus der folgenden Tabelle zu entnehmen ist, ohne signifikante Unterschiede $(p=0,10$ in One-Way ANOVA) zwischen den einzelnen Gruppen (s. Tab. 3.5).

\begin{tabular}{|c|c|c|c|c|}
\hline & WT & A30P & A53T & eGFP \\
\hline $\begin{array}{c}\text { Zellkörperfläche } \\
\text { in } \boldsymbol{\mu m}^{2}\end{array}$ & $112,19 \pm 2,40$ & $113,58 \pm 2,46$ & $107,45 \pm 1,92$ & $106,90 \pm 2,47$ \\
\hline
\end{tabular}

Tab. 3.5 Zellkörperfläche der transfizierten dopaminergen Mittelhirnneurone in $\mu^{2}$. Es zeigten sich keine signifikanten Unterschiede in der Zellkörperfläche zwischen den einzelnen Versuchsgruppen. $n=180$ je Versuchsgruppe aus 3 unabhängigen Mittelhirnzellkulturen. DIV5. 


\subsection{Sholl-Analyse}

Die Analysen der $\alpha$-Syn-induzierten Veränderungen der Neuritenmorphologie von Mittelhirnneuronen wurden erweitert durch eine Untersuchung des Verzweigungsverhaltens (sog. branching) der Neuriten mittels Sholl-Analyse (s. 2.4.4.2).

\subsubsection{Verzweigungsverhalten dopaminerger und nicht-dopaminerger Mittelhirnneurone}

Es wurde das Verzweigungsverhalten der dopaminergen und nicht-dopaminergen Neurone näher untersucht. Dabei wurden die maximale Anzahl an Neuritenkreuzungen (d. h. Neuritenverzweigungen) an einem beliebig vom Soma entfernten Messradius (Neuritenmaximum) pro Neuron und die durchschnittliche Distanz vom Soma, an der es zu diesem Maximum an Kreuzungen kommt (kritischer Wert), betrachtet. Der ebenfalls ermittelte Verzweigungsindex (Schoenen-Ramifikationsindex) ist ein Wert, der dieses Verzweigungsverhalten zusammenfasst. Zur Berechnung wurde hierfür der Quotient aus dem Neuritenmaximum und der Anzahl der dem Soma entspringenden Neuriten gebildet. Außerdem wurden die durchschnittlichen Neuritenkreuzungen an bestimmten Distanzpunkten vom Soma (verschiedene Radien) verglichen.

Die folgende Abbildung zeigt beispielhaft die Analyse der einzeln erhobenen ShollParameter. Hierbei hebt der rot-gestrichelte Kreis den kritischen Wert des dargestellten Neurons, also den Messradius, an welchem die meisten Neuritenkreuzungen (entsprechend dem Neuritenmaximum) auftreten, hervor (im Beispiel: kritischer Wert bei 37,5 $\mu \mathrm{m}$, Neuritenmaximum: 6, vom Soma entspringende Neurite: 5, daraus resultierend ein Schoenen-Ramifikationsindex von 1,2). Der Mittelwert verschiedener Einzelradien ergibt den kritischen Wert (= critical value), also den fiktiven Radius, an welchem das Neuritenmaximum einer Zellpopulation zu erwarten ist. Die roten Pfeile markieren die direkt dem Soma entspringenden Neuriten, woraus der Schoenen-Ramifikationsindex als Quotient aus Neuritenmaximums und der entspringenden Neuriten ermittelt werden kann (siehe Abb. 3.23). 


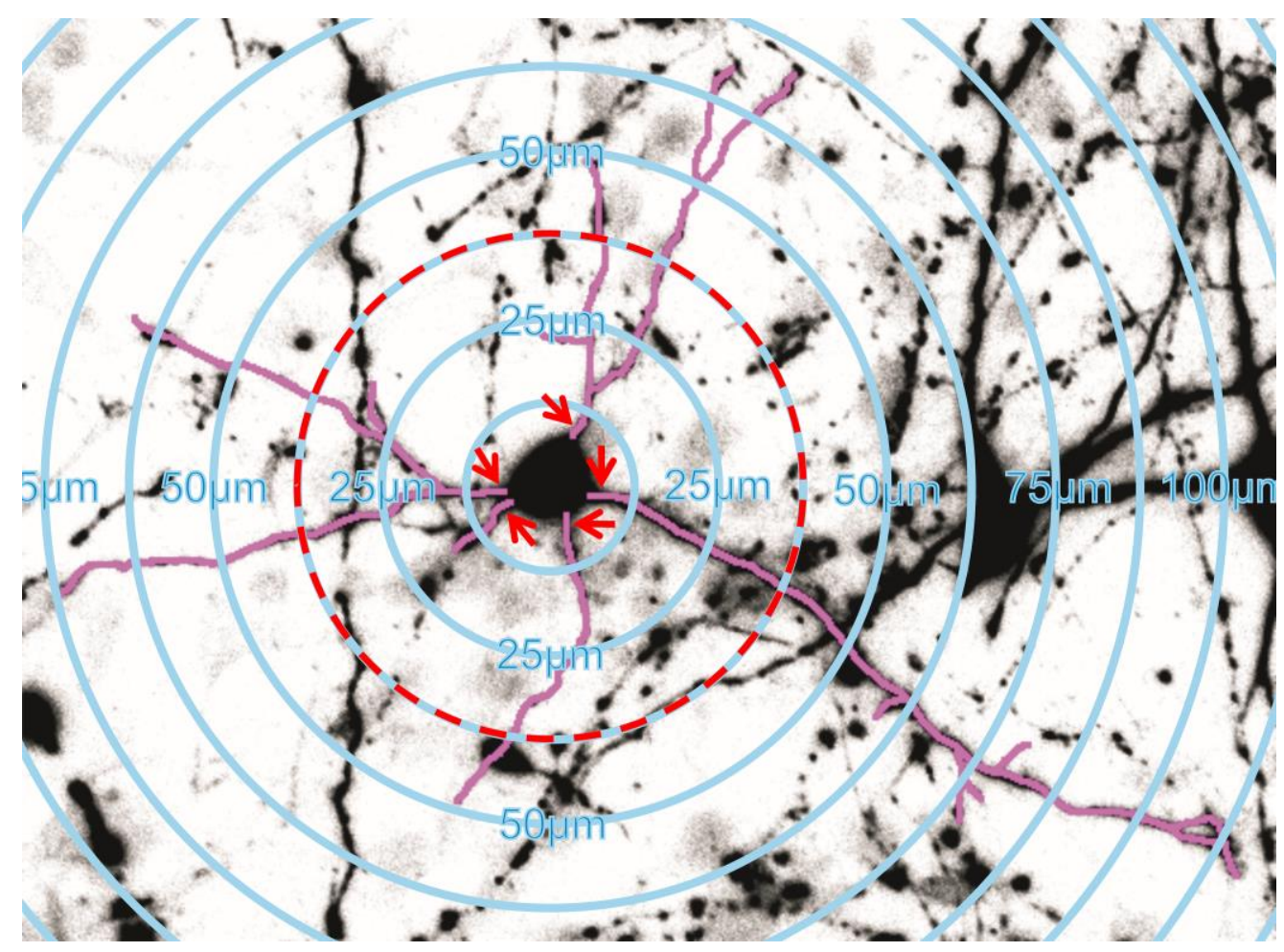

Abb. 3.23 Beispielhafte Darstellung der erhobenen Parameter der Sholl-Analyse eines dopaminergen Mittelhirnneurons. Färbung gegen TH, einzelne Neuriten des Neurons sind violett nachgezeichnet. Konzentrisch um das Zellzentrum angeordnete Kreise entsprechen den Radien, an welchen die Anzahl der Neuritenkreuzungen erhoben wurden (Abstand jeweils 12,5 $\mu \mathrm{m}$ ), rot gestrichelter Kreis: Radius des Neuritenmaximums (= kritischer Wert), rote Pfeile: vom Soma entspringende Neuriten.

\subsubsection{Neuritenmaximum dopaminerger Mittelhirnneurone}

Das Neuritenmaximum entspricht der maximalen Zahl an Neuritenkreuzungen eines Neurons an einem Messradius, welcher wiederum dem kritischen Wert entspricht.

Hierbei zeigte sich für den a-Syn-WT ein Neuritenmaximum von 5,61 $\pm 0,16$ ( $n=135$ Neurone), für die A30P-Mutation von 5,80 $\pm 0,18(n=119)$ und für die A53T-Mutante von $6,22 \pm 0,17(n=134)$. Im Vergleich hierzu waren die Neuritenmaxima in den Kontrollgruppen mit $5,04 \pm 0,14$ bei den eGFP-transfizierten Neuronen $(n=171)$ und $4,91 \pm 0,11$ bei den untransfizierten dopaminergen Neuronen $(n=373)$ kleiner (s. Abb. 3.24). 


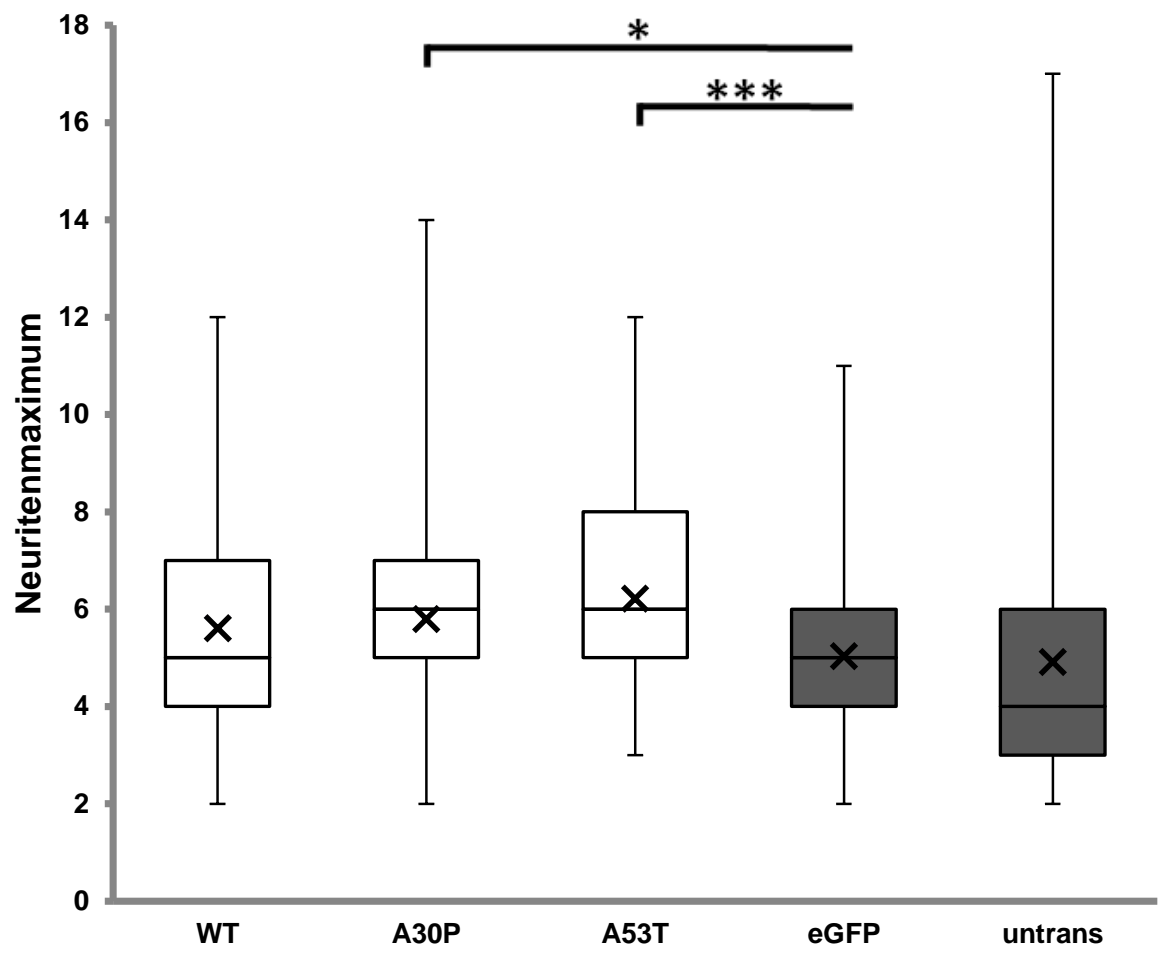

Abb. 3.24 Neuritenmaximum dopaminerger Mittelhirnneurone nach Transfektion mit $\alpha$-Syn (WT, A30P, A53T) im Vergleich zur eGFP-Kontrolle und nicht-transfizierten, TH-positiven Kontrollgruppe (untrans). Es zeigt sich eine signifikante Erhöhung der Neuritenmaxima in den a-Syn-Mutationsversuchsgruppen im Vergleich zur Kontrolle. WT: $n=135$, A30P: $n=119$, A53T: $n=134$, eGFP: $n=171$, untrans: $n=373$ aus 3 unabhängigen Mittelhirnzellkulturen, DIV5,*: $p<0,05,{ }^{* * *}: p<0,001$ in One-Way ANOVA gefolgt von Tukey-Kramer-Post-hoc-Test. Darstellung als Box Plot: Box-Reichweite: von 1. bis 3. Quartile, innere Bande: Median (2. Quartile), Kreuz: arithmetischer Mittelwert, oberer Whisker: Maximum, unterer Whisker: Minimum.

Während der Unterschied zwischen der eGFP-Gruppe und der nicht-transfizierten Kontrollgruppe nicht signifikant war $(p=0,97)$, waren die Neuritenmaxima der $\alpha$-SynMutanten A30P und A53T im Vergleich zu den Kontrollgruppen signifikant erhöht. Für den a-Syn-WT ist ein signifikanter Unterschied zur untrans-Kontrollgruppe und in der Tendenz auch für die eGFP-Kontrolle zu ermitteln. Ursächlich für den nicht bestehenden signifikanten Unterschied des a-Syn-WTs zur eGFP-Kontrolle, jedoch zur untrans-Versuchsgruppe, ist möglicherweise die deutlich höhere Anzahl ausgewerteter Zellen bei untrans $(n=373)$ gegenüber eGFP $(n=171)$. Die einzelnen $p$-Werte sind in der folgenden Tabelle zusammengefasst (s. Tab. 3.6).

Zu erwähnen ist hierbei jedoch, dass das Neuritenmaximum eine Abhängigkeit von den am Soma entspringenden Neuriten hat und dieser Sachverhalt erst bei der rechnerischen Ermittlung des Schoenen-Ramifikationsindex berücksichtigt und sinnvoll herausgerechnet wird. Hierfür sollte auch in Abb. 3.31 insbesondere der Abstand von 12,5 $\mu \mathrm{m}$, welcher bei einem Somadurchmesser der Neurone von ca. $10 \mu \mathrm{m}$ praktisch den am Zellkörper entspringenden Neuriten entspricht, betrachtet werden. 


\begin{tabular}{|c|c|c|c|c|}
\hline & \multicolumn{4}{|c|}{ Signifikanzlevel ( $p$-Wert) } \\
\hline & A30P & A53T & eGFP & untrans \\
\hline WT & 0,74 & 0,098 & 0,10 & 0,0062 \\
\hline A30P & & 0,46 & 0,014 & 0,00038 \\
\hline A53T & & & $7,60 * 10^{-6}$ & $1,72 * 10^{-6}$ \\
\hline eGFP & & & & 0,97 \\
\hline
\end{tabular}

Tab. 3.6 p-Werte der einzelnen Signifikanzvergleiche der Neuritenmaxima dopaminerger Neurone zwischen den Versuchsgruppen. kursiv und fett: signifikante Unterschiede in One-Way ANOVA gefolgt von Tukey-Kramer-Post-hocTest.

\subsubsection{Neuritenmaximum nicht-dopaminerger Mittelhirnneurone}

Das Neuritenmaximum zeigte sich bei den nicht-dopaminergen Neuronen lediglich für die Mutationen des $\alpha$-Syns signifikant erhöht im Vergleich zur eGFP-Kontrolle (A30P: $p=0,019$, A53T: $p=0,047$, One-Way ANOVA gefolgt von Dunnett-Post-hoc-Test). Der $a$-Syn-WT zeigte keine wesentliche Veränderung im Vergleich zur Kontrolle $(p=0,83)$.

Der $\alpha$-Syn-WT wies hierbei ein Neuritenmaximum von 5,89 $\pm 0,23(n=87)$, A30P von $6,47 \pm 0,25(n=93)$ und die A53T-Mutation von 6,37 $\pm 0,23(n=94)$ auf. Dagegen zeigte sich in der Kontrolle eine maximale Anzahl an Neuriten von 5,67 $\pm 0,17$ bei 146 ausgewerteten Neuronen (s. Abb. 3.25).

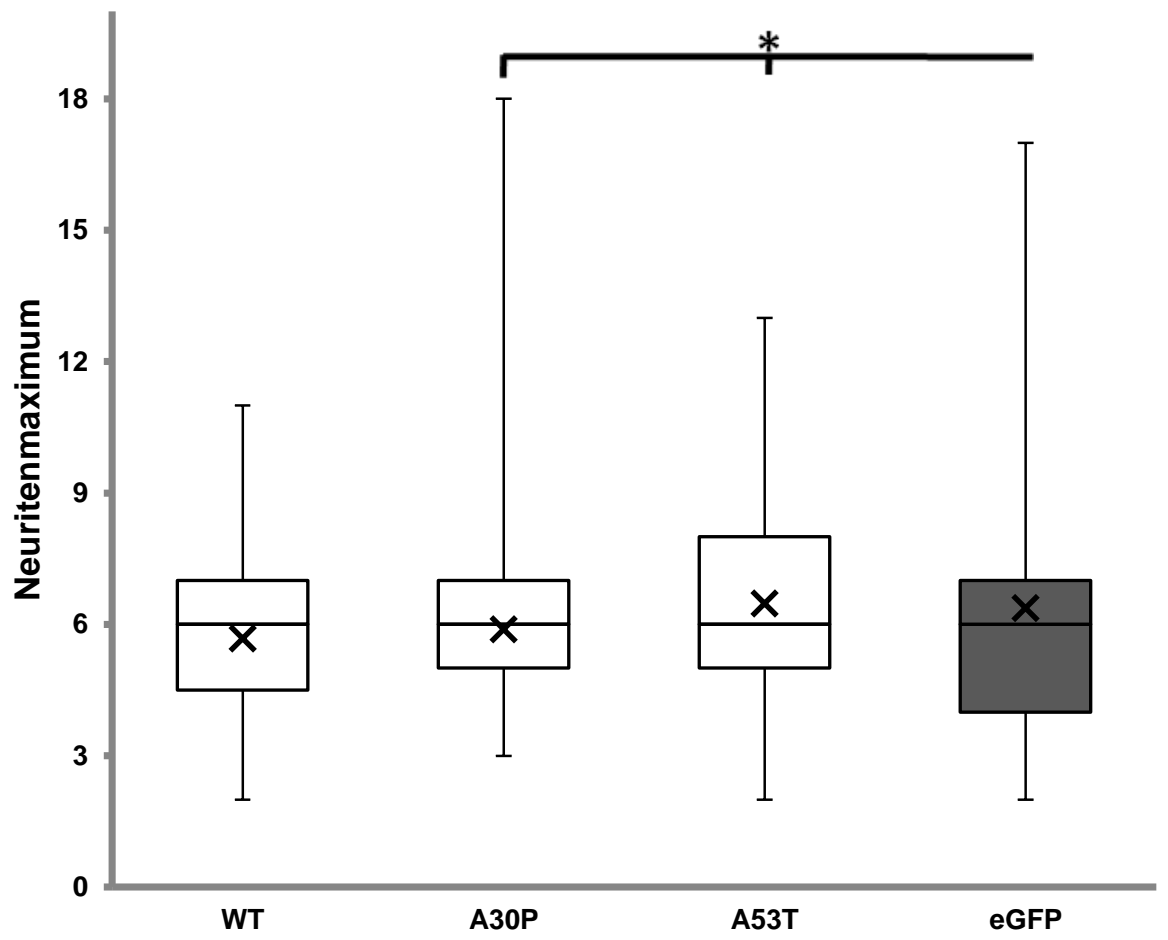

Abb. 3.25 Neuritenmaximum pro nicht-dopaminergem, mit $\alpha$-Syn (WT, A30P, A53T) transfiziertem Mittelhirnneuron im Vergleich zur eGFP-Kontrolle. Es zeigt sich eine signifikante Erhöhung der Neuritenmaxima in den $\alpha$-Syn-Mutationsversuchsgruppen im Vergleich zur Kontrolle. WT: $n=87$, A30P: $n=93$, A53T: $n=94$, eGFP: $n=146$ nicht-dopaminerge Mittelhirnneurone aus 3 unabhängigen Mittelhirnzellkulturen, DIV5, *: $p<0,05$ in One-Way ANOVA gefolgt von DunnettPost-hoc-Test. Darstellung als Box Plot: Box-Reichweite: von 1. bis 3. Quartile, innere Bande: Median (2. Quartile), Kreuz: arithmetischer Mittelwert, oberer Whisker: Maximum, unterer Whisker: Minimum. 


\subsubsection{Kritischer Wert dopaminerger Mittelhirnneuroneurone}

Der kritische Wert (critical value) entspricht dem Radius des konzentrischen Kreises um die fiktive Mitte des neuronalen Somas, an dem es zum Neuritenmaximum kommt. Er gibt somit an, in welchem Abstand von der Mitte des Somas eines Neurons die maximale Verzweigung der Neuriten zu erwarten ist. Für den a-Syn-WT lag dieser bei $22,13 \pm 1,40 \mu \mathrm{m}$, bei A30P bei $21,50 \pm 1,36 \mu \mathrm{m}$, bei A53T bei $23,41 \pm 1,21 \mu \mathrm{m}$ und in den Kontrollen bei $26,39 \pm 1,45 \mu \mathrm{m}$ in lediglich eGFP-transfizierten Zellen sowie bei 27,80 $\pm 1,02 \mu \mathrm{m}$ in der Population der nicht-transfizierten TH-positiven Neurone (s. Abb. 3.26). Ein signifikanter Unterschied zur eGFP Kontrollgruppe bestand nicht ( $p$-Wert zu $\alpha$-Syn-WT: 0,12, zu A30P: 0,073, zu A53T: 0,40, zu untrans: 0,81 in One-Way ANOVA gefolgt von Dunnett-Post-hocTest).

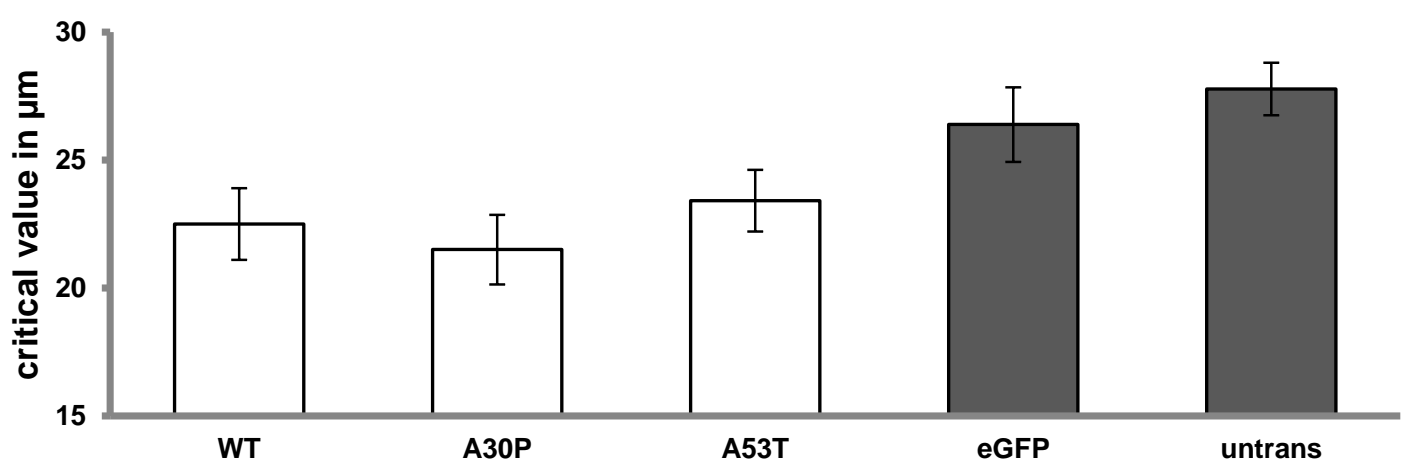

Abb. 3.26 Kritischer Wert pro dopaminergem, mit $\alpha$-Syn (WT, A30P, A53T) transfiziertem oder nicht-transfiziertem (untrans) Mittelhirnneuron im Vergleich zur eGFP-Kontrolle. Ein signifikanter Unterschied war nicht zu verzeichnen. WT: $n=135$, A30P: $n=119$, A53T: $n=134$, eGFP: $n=171$, untrans: $n=373$ aus 3 unabhängigen Mittelhirnzellkulturen, DIV5, Fehlerbalken: Standardfehler des Mittelwertes.

\subsubsection{Kritischer Wert nicht-dopaminerger Mittelhirnneurone}

In der eGFP-Kontrollgruppe wurde ein kritischer Wert von 29,79 $\pm 1,62 \mu \mathrm{m}$ ermittelt. Beim a-Syn-WT lag dieser bei 20,83 $\pm 1,51 \mu \mathrm{m}$, für A30P bei 25,40 $\pm 1,51 \mu \mathrm{m}$ und für A53T bei $24,73 \pm 1,64 \mu \mathrm{m}$. Hierbei ergab sich für den WT ein signifikanter Unterschied im Vergleich zur Kontrolle ( $p=0,00025$, One-Way ANOVA gefolgt von Dunnett-Post-hoc-Test) sowie in der Tendenz eine Reduktion der Mutationen verglichen mit der eGFP-Kontrollgruppe (s. Abb. 3.27). 


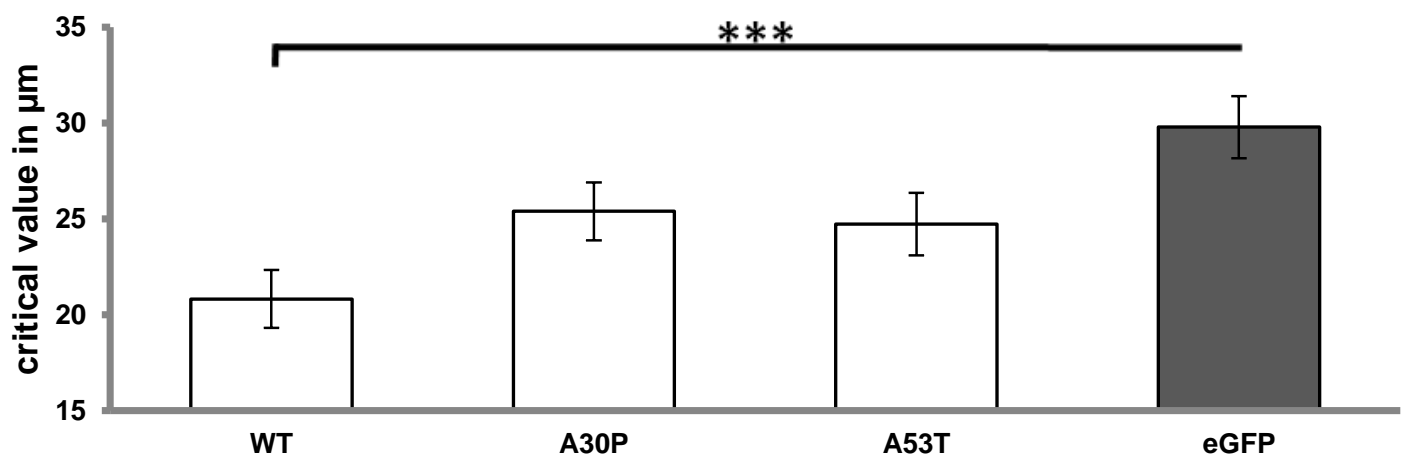

Abb. 3.27 Kritischer Wert der nicht-dopaminergen, mit a-Syn (WT, A30P, A53T) transfiziertem Mittelhirnneuron im Vergleich zur eGFP-Kontrolle. Es zeigt sich eine signifikante Reduktion des kritischen Wertes beim WT im Vergleich zur eGFP-Kontrolle. WT: $n=87$, A30P: $n=93$, A53T: $n=94$, eGFP: $n=146$ nicht-dopaminerge Neurone aus 3 unabhängigen Mittelhirnzellkulturen, DIV5,***: $p<0,001$ in One-Way ANOVA gefolgt von Dunnett-Post-hoc-Test, Fehlerbalken: Standardfehler des Mittelwertes.

\subsubsection{Verzweigungsindex dopaminerger Mittelhirnneurone}

Der Verzweigungsindex (Schoenen-Ramifikationsindex = Schoenen-RI) trifft eine Aussage darüber, wie ausgeprägt sich die dem Soma entspringenden Neuriten weiter aufzweigen und korreliert somit direkt mit dem Grad der Verzweigung des Neuritenbaums.

Bei den dopaminergen Neuronen zeigte sich, dass sich der a-Syn-WT (Schoenen-RI: $1,26 \pm 0,38)$ und die A30P-Mutation $(1,20 \pm 0,031)$ im Vergleich zu den Kontrollen (eGFP: $1,43 \pm 0,046$, untrans: $1,39 \pm 0,024)$ signifikant weniger verzweigen. Diese Tendenz war auch bei der A53T-Mutation $(1,31 \pm 0,036)$ zu sehen, wobei der Unterschied nicht signifikant war. Die einzelnen p-Werte sind in der folgenden Tabelle zusammengefasst (s. Tab. 3.7 und Abb. 3.28 sowie 3.29$)$.

\begin{tabular}{|c|c|c|c|c|c|}
\hline & & A30P & A53T & eGFP & untrans \\
\hline & Schoenen-RI & \multicolumn{4}{|c|}{ Signifikanzlevel ( $p$-Wert) } \\
\hline WT & $1,26 \pm 0,038$ & 0,82 & 0,91 & 0,016 & 0,044 \\
\hline A30P & $1,20 \pm 0,031$ & & 0,31 & 0,00039 & 0,00094 \\
\hline A53T & $1,31 \pm 0,036$ & & & 0,17 & 0,41 \\
\hline eGFP & $1,43 \pm 0,046$ & & & & 0,90 \\
\hline untrans & $1,39 \pm 0,024$ & & & & \\
\hline
\end{tabular}

Tab. 3.8 p-Werte der einzelnen Signifikanzvergleiche der Schoenen-RI dopaminerger Neurone zwischen den Versuchsgruppen. Kursiv und fett: signifikante Unterschiede in One-Way ANOVA gefolgt von Tukey-Kramer-Post-hocTest. 
eGFP
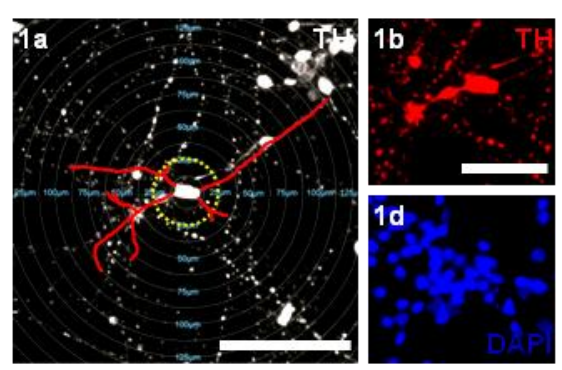

WT
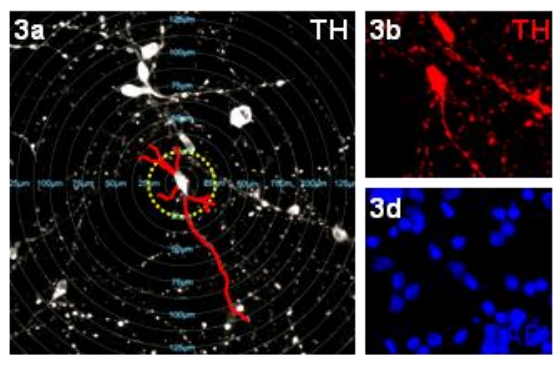

A53T
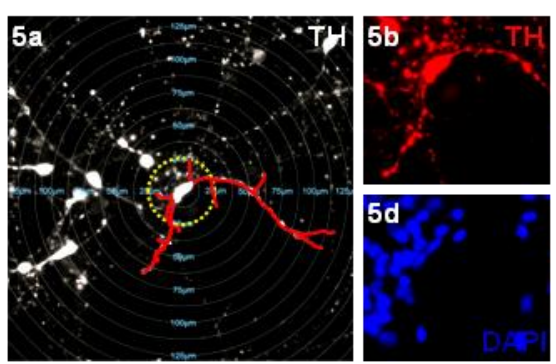

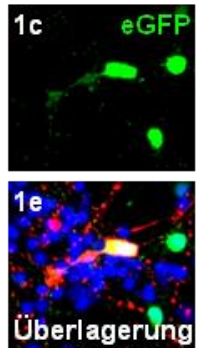

Überlagerung
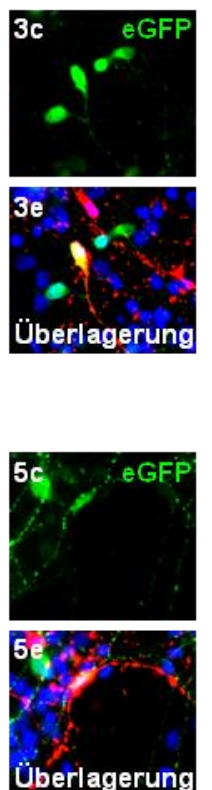

untrans
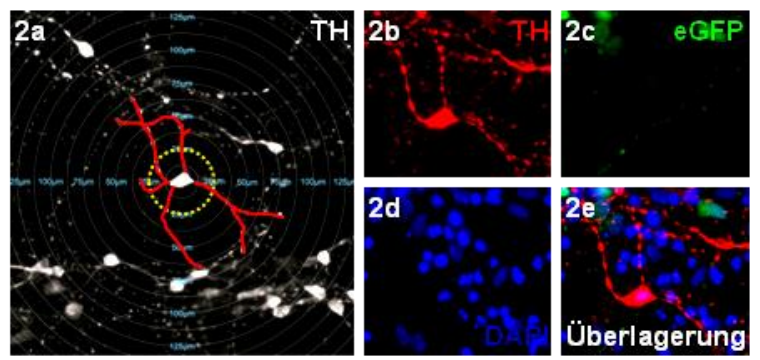

A30P
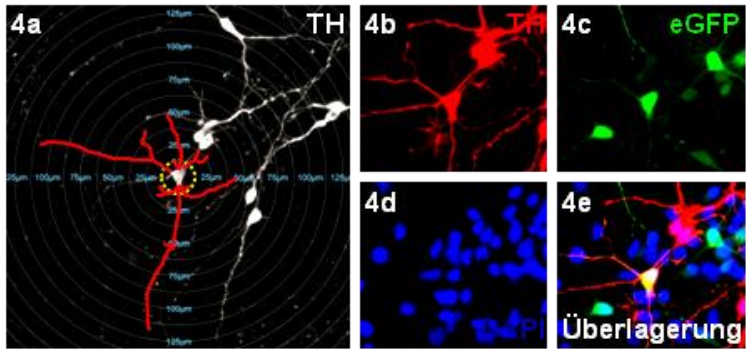

Abb. 3.28 RepräsentativeDarstellung der Sholl-Analyse dopaminerger, mit a-Syn-transfizierter (WT, A30P, A53T) Mittelhirnneurone im Vergleich zur eGFP-Kontrolle und nicht-transfizierten, TH-positiven Kontrollgruppe (untrans). a und b) TH-Färbung, c) eGFP-Fluoreszenz, d) DAPI-Zellkernfärbung, e) Überlagerung von b bis $d$. 1(a-e) eGFP-Kontrollgruppe, 2(a-e) untransfizierte dopaminere Neurone, 3(a-e) a-Syn-WT, 4(a-e) a-Syn-A30P, 5(a-e) aSyn-A53T. Maßbalken in 1a) (für a): $100 \mu \mathrm{m}$, Maßbalken in 1b) (für b-e): $50 \mu \mathrm{m}, 20 x-O b j e k t i v$. Die Neuriten wurden in a) schematisch nachgezeichnet (rot) und der zum Radius des Neuritenmaximums gehörende Kreis gelb-gestrichelt hervorgehoben.

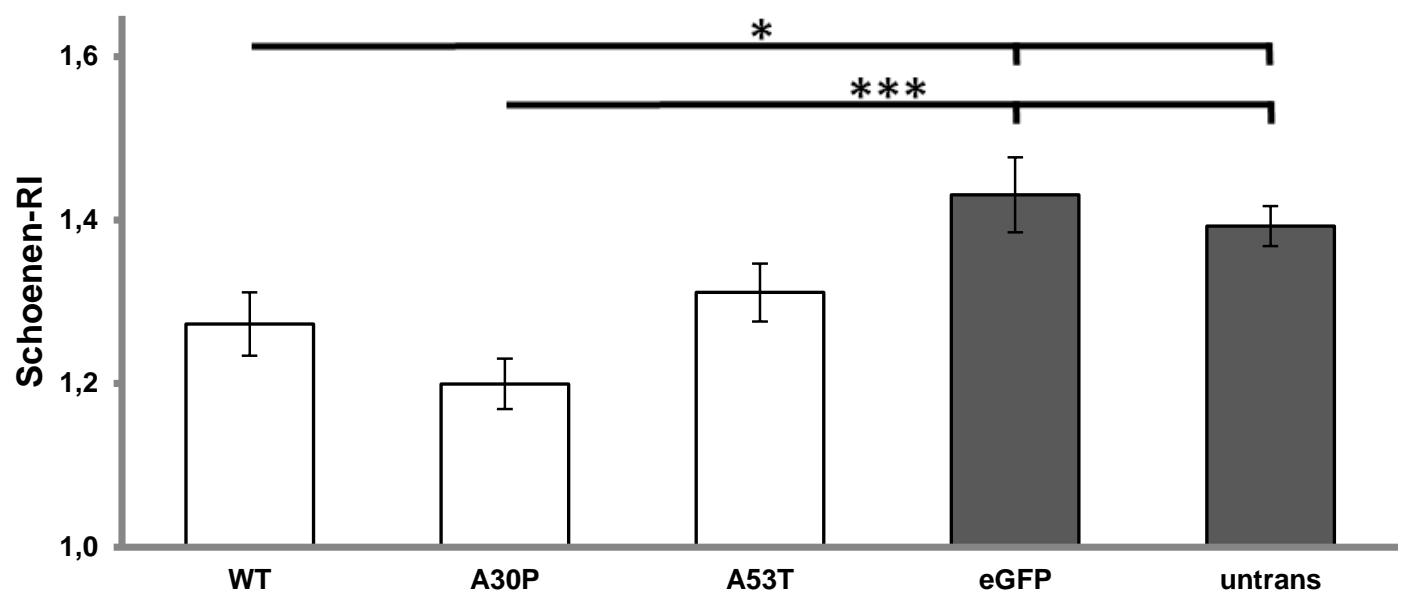

Abb. 3.29 Schoenen-Ramifikationsindex dopaminerger Mittelhirnneurone nach Transfektion mit $\alpha$-Syn (WT, A30P, A53T) im Vergleich zur eGFP-Kontrolle und nicht transfizierten, TH-positiven Kontrollgruppe (untrans). Lediglich der a-Syn-WT sowie die A30P-Mutation zeigen eine signifikante Reduktion. WT: $n=135$, A30P: $n=119$, A53T: $n=134$, eGFP: $n=171$, untrans: $n=373$ aus 3 unabhängigen Mittelhirnzellkulturen, DIV5, $: p<0,05,{ }^{* * *}: p<0,001$ in One-Way ANOVA gefolgt von Tukey-Kramer-Post-hoc-Test, Fehlerbalken: Standardfehler des Mittelwertes. 


\subsubsection{Verzweigungsindex nicht-dopaminerger Mittelhirnneurone}

Beim Verzweigungsindex der nicht-dopaminergen Neurone zeigte sich ähnlich wie bei den dopaminergen Neuronen eine signifikante Reduktion in allen Versuchsgruppen in Bezug auf die eGFP-Kontrolle.

Beim WT verzweigten sich die initial vom Soma abgehenden Neuriten durchschnittlich $1,31 \pm 0,053$-fach ( $p=0,0016$ zu eGFP, One-Way ANOVA gefolgt von Dunnett-Post-hocTest), in der A30P-Population 1,38 \pm 0,047-fach $(p=0,034)$ und bei der A53T-Mutation $1,35 \pm 0,048$-fach $(p=0,0077)$. Hingegen konnte in der eGFP-Gruppe ein Verzweigungsindex von 1,56 $\pm 0,053$ ermittelt werden (s. Abb. 3.30). Zwischen den einzelnen $\alpha$-SynVarianten ergaben sich keine signifikanten Unterschiede.

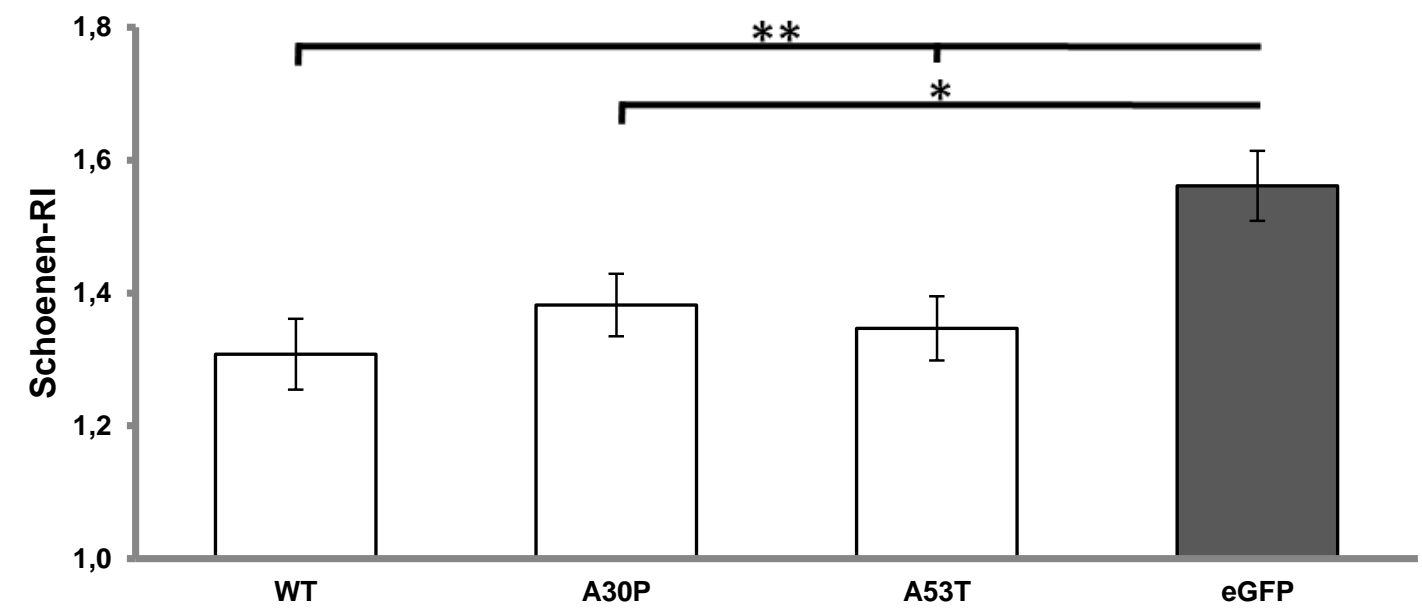

Abb. 3.30 Schoenen-Ramifikationsindex nicht-dopaminerger Mittelhirnneurone nach Transfektion mit $\alpha$-Syn (WT, A30P, A53T) im Vergleich zur eGFP-Kontrolle. Es zeigt sich eine signifikante Reduktion in allen $\alpha$-Syn-Versuchsgruppen gegenüber der eGFP-Kontrolle.WT: $n=87$, A30P: $n=93$, A53T: $n=94$, eGFP: $n=146$ nicht-dopaminerge Mittelhirnneurone aus 3 unabhängigen Mittelhirnzellkulturen, $: p<0,05,{ }^{* *}: p<0,01$ in One-Way ANOVA gefolgt von Dunnett-Posthoc-Test, Fehlerbalken: Standardfehler des Mittelwertes.

\subsubsection{Neuritenkreuzungen}

\subsubsection{Durchschnittliche Neuritenkreuzungen dopaminerger Mittelhirnneurone}

Der Durchschnitt/Mittelwert der Neuritenkreuzungen eines bestimmten Abstandes vom Soma der Mittelhirnneurone (Radius) wurde graphisch erfasst und die einzelnen Messpunkte trotz mathematischer Unkorrektheit zur besseren Visualisierung miteinander verbunden. Es zeigte sich hierbei, dass in Soma-nahen Abständen vor allem bei $12,5 \mu \mathrm{m}$ und $25 \mu \mathrm{m}$ die mit $\alpha$-Syn-transfizierten Neurone deutlich mehr Neuriten und somit Neuritenkreuzungen in diesem Bereich aufwiesen, wobei interessanterweise bei A53T - ähnlich wie bei den Kontrollgruppen - zunächst ein kleiner Anstieg (entsprechend einer Verzweigung der Neuriten) zu verzeichnen war. Dann jedoch kam es zu einem schnelleren Abfall der Anzahl an Neuritenkreuzungen in weiter distal gelegenen Abständen im Vergleich zur eGFPPopulation, sodass zunächst eine Angleichung zur Kontrollgruppe im Bereich von 37,5$50 \mu \mathrm{m}$ erfolgte, bevor im noch weiter distal gelegenen Abstandsbereich eine signifikante 
Reduktion der Neuritenkreuzungen zunächst beim WT und im Verlauf auch bei den Mutationsformen zu sehen war bzw. die Mutationsformen sogar keine Neuritenkreuzungen im Bereich über 212,5 $\mu \mathrm{m}$ Abstand zum Somazentrum, also auch keine Neuriten dieser Länge aufwiesen. Die einzelnen Messwerte sind in der folgenden Abbildung graphisch aufgezeichnet und anschließend tabellarisch mit den dazugehörigen Signifikanzleveln ( $p$ Werte) zur eGFP-Kontrollgruppe zusammengefasst (s. Abb. 3.31 und Tab. 3.8)

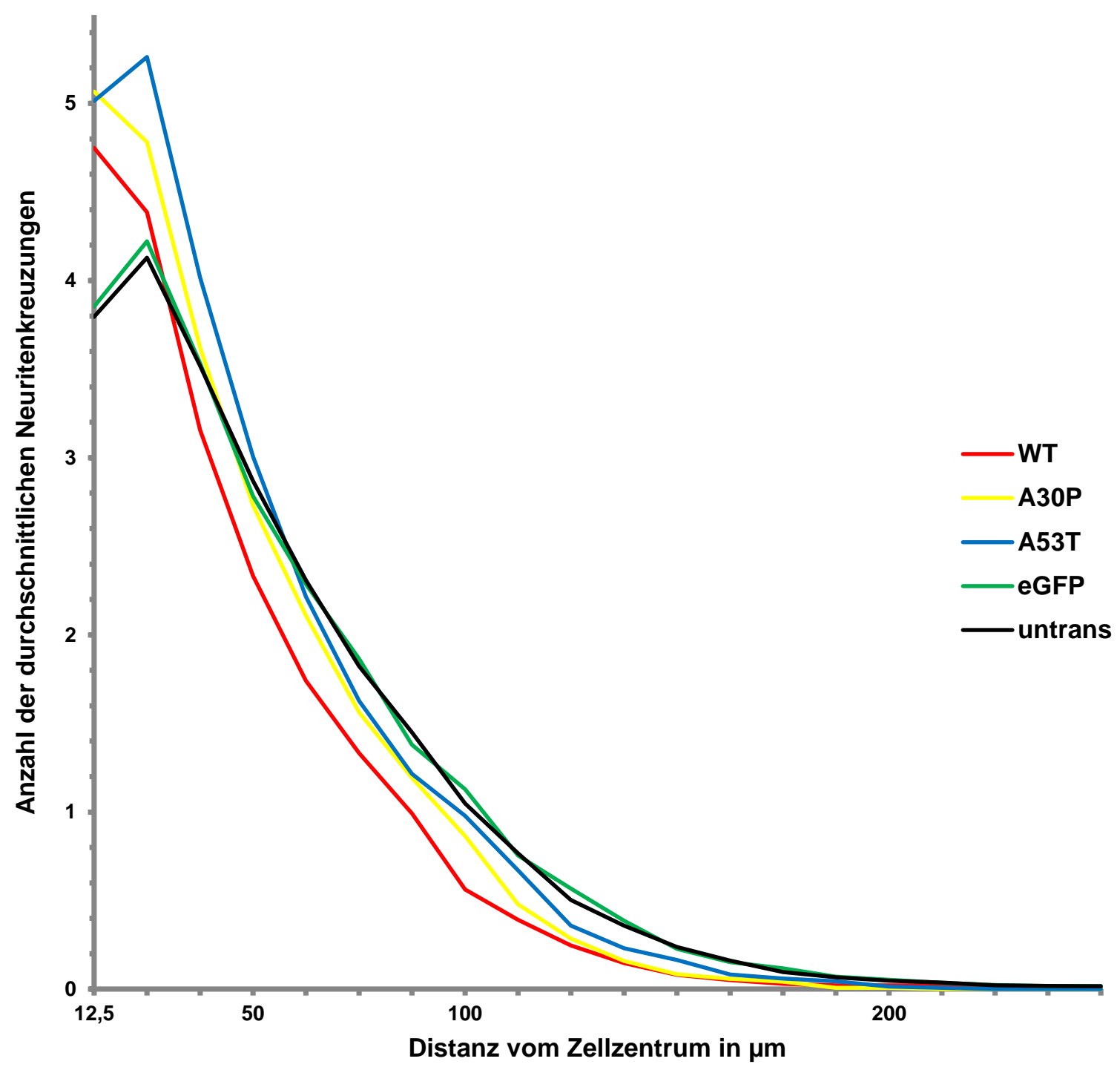

Abb. 3.31 Graphische Darstellung der durchschnittlichen Neuritenkreuzungen dopaminerger Mittelhirnneurone nach Transfektion mit a-Syn (WT, A30P, A53T) im Vergleich zur eGFP-Kontrolle und nicht transfizierten, THpositiven Kontrollgruppe (untrans) in Bezug auf die einzelnen Radien. Zusammenfassend zeigen sich Soma-nah deutlich mehr Neuritenkreuzungen bei distal reduzierter Anzahl (s. auch Text). WT: $n=135$, A30P: $n=119$, A53T: $n=134$, eGFP: $n=171$, untrans: $n=373$ dopaminerge Mittelhirnneurone aus 3 unabhängigen Mittelhirnzellkulturen, DIV5. Zur besseren Visualisierung erfolgte, wenn auch mathematisch nicht korrekt, die Verbindung der einzelnen Messpunkte und auf die Darstellung der Fehlerbalken wurde ebenso verzichtet. 


\begin{tabular}{|c|c|c|c|c|c|c|c|c|c|c|}
\hline \multirow[b]{2}{*}{$\begin{array}{l}\text { Radius } \\
\text { in } \mu \mathrm{m}\end{array}$} & \multicolumn{10}{|c|}{$\begin{array}{l}\text { Durchschnittliche Neuritenkreuzungen je Radius (oben) und Signifikanzlevel (p- } \\
\text { Wert) zur eGFP-Kontrolle (unten, kursiv) }\end{array}$} \\
\hline & 12,5 & 25 & 37,5 & 50 & 62,5 & 75 & 87,5 & 100 & 112,5 & 125 \\
\hline eGFP & 3,85 & 4,22 & 3,53 & 2,78 & 2,29 & 1,87 & 1,38 & 1,13 & 0,75 & 0,57 \\
\hline WT & $\begin{array}{c}4,75 \\
0,00015\end{array}$ & $\begin{array}{l}4,41 \\
0,88\end{array}$ & $\begin{array}{l}3,17 \\
0,27\end{array}$ & $\begin{array}{l}2,34 \\
0,067\end{array}$ & $\begin{array}{c}1,74 \\
0,0038\end{array}$ & $\begin{array}{c}1,34 \\
0,0017\end{array}$ & $\begin{array}{l}0,99 \\
0,021\end{array}$ & $\begin{array}{c}0,56 \\
1,7^{*} 10^{-5}\end{array}$ & $\begin{array}{c}0,39 \\
0,0014\end{array}$ & $\begin{array}{c}0,25 \\
0,00059\end{array}$ \\
\hline A30P & $\begin{array}{c}5,07 \\
1,7^{*} 10^{-6}\end{array}$ & $\begin{array}{l}4,78 \\
0,11\end{array}$ & $\begin{array}{l}3,62 \\
0,98\end{array}$ & $\begin{array}{l}2,73 \\
0,99\end{array}$ & $\begin{array}{l}2,11 \\
0,69\end{array}$ & $\begin{array}{l}1,56 \\
0,16\end{array}$ & $\begin{array}{l}1,19 \\
0,51\end{array}$ & $\begin{array}{l}0,87 \\
0,12\end{array}$ & $\begin{array}{c}0,48 \\
0,031\end{array}$ & $\begin{array}{c}0,29 \\
0,0049\end{array}$ \\
\hline A53T & $\begin{array}{c}5,01 \\
1,8^{*} 10^{-6}\end{array}$ & $\begin{array}{c}5,26 \\
0,00018\end{array}$ & $\begin{array}{l}4,01 \\
0,082\end{array}$ & $\begin{array}{l}3,01 \\
0,60\end{array}$ & $\begin{array}{l}2,22 \\
0,98\end{array}$ & $\begin{array}{l}1,63 \\
0,31\end{array}$ & $\begin{array}{l}1,22 \\
0,60\end{array}$ & $\begin{array}{l}0,98 \\
0,54\end{array}$ & $\begin{array}{l}0,67 \\
0,83\end{array}$ & $\begin{array}{l}0,36 \\
\mathbf{0 , 0 4 6}\end{array}$ \\
\hline untrans & $\begin{array}{l}3,80 \\
0,99\end{array}$ & $\begin{array}{l}4,19 \\
0,97\end{array}$ & $\begin{array}{l}3,52 \\
1,00\end{array}$ & $\begin{array}{l}2,87 \\
0,95\end{array}$ & $\begin{array}{l}2,31 \\
1,00\end{array}$ & $\begin{array}{l}1,82 \\
0,99\end{array}$ & $\begin{array}{l}1,45 \\
0,93\end{array}$ & $\begin{array}{l}1,05 \\
0,83\end{array}$ & $\begin{array}{l}0,77 \\
1,00\end{array}$ & $\begin{array}{l}0,50 \\
0,76\end{array}$ \\
\hline & \multicolumn{10}{|c|}{$\begin{array}{l}\text { Durchschnittliche Neuritenkreuzungen je Radius (oben) und Signifikanzlevel (p- } \\
\text { Wert) zur eGFP-Kontrolle (unten, kursiv) }\end{array}$} \\
\hline $\begin{array}{l}\text { Radius } \\
\text { in } \mu \mathrm{m}\end{array}$ & 137,5 & 150 & 162,5 & 175 & 187,5 & 200 & 212,5 & 225 & 237,5 & 250 \\
\hline eGFP & 0,36 & 0,23 & 0,15 & 0,12 & 0,070 & 0,053 & 0,035 & 0,023 & 0,018 & 0,018 \\
\hline WT & $\begin{array}{c}0,15 \\
0,0028\end{array}$ & $\begin{array}{l}0,081 \\
0,019\end{array}$ & $\begin{array}{l}0,052 \\
0,065\end{array}$ & $\begin{array}{l}0,030 \\
0,039\end{array}$ & $\begin{array}{c}0,022 \\
0,22\end{array}$ & $\begin{array}{c}0,022 \\
0,44\end{array}$ & $\begin{array}{c}0,022 \\
0,90\end{array}$ & $\begin{array}{c}0,0074 \\
0,58\end{array}$ & $\begin{array}{c}0,0074 \\
0,83\end{array}$ & $\begin{array}{c}0,0074 \\
0,81\end{array}$ \\
\hline A30P & $\begin{array}{c}0,16 \\
\mathbf{0 , 0 0 7 3}\end{array}$ & $\begin{array}{l}0,084 \\
0,029\end{array}$ & $\begin{array}{c}0,059 \\
0,12\end{array}$ & $\begin{array}{c}0,042 \\
0,11\end{array}$ & $\begin{array}{c}0,0084 \\
0,087\end{array}$ & $\begin{array}{c}0,0084 \\
0,16\end{array}$ & $\begin{array}{c}0 \\
0,22\end{array}$ & $\begin{array}{c}0 \\
0,28\end{array}$ & $\begin{array}{c}0 \\
0,46\end{array}$ & $\begin{array}{c}0 \\
0,42\end{array}$ \\
\hline A53T & $\begin{array}{l}0,23 \\
0,093\end{array}$ & $\begin{array}{l}0,16 \\
0,56\end{array}$ & $\begin{array}{c}0,082 \\
0,30\end{array}$ & $\begin{array}{c}0,060 \\
0,28\end{array}$ & $\begin{array}{c}0,045 \\
0,75\end{array}$ & $\begin{array}{c}0,015 \\
0,25\end{array}$ & $\begin{array}{c}0,0075 \\
0,40\end{array}$ & $\begin{array}{c}0 \\
0,25\end{array}$ & $\begin{array}{c}0 \\
0,43\end{array}$ & $\begin{array}{c}0 \\
0,36\end{array}$ \\
\hline untrans & $\begin{array}{l}0,36 \\
0,97\end{array}$ & $\begin{array}{l}0,24 \\
1,00\end{array}$ & $\begin{array}{l}0,16 \\
1,00\end{array}$ & $\begin{array}{c}0,097 \\
0,87\end{array}$ & $\begin{array}{r}0,067 \\
1,00\end{array}$ & $\begin{array}{c}0,048 \\
1,00\end{array}$ & $\begin{array}{r}0,038 \\
1,00\end{array}$ & $\begin{array}{c}0,021 \\
1,00\end{array}$ & $\begin{array}{r}0,019 \\
1,00\end{array}$ & $\begin{array}{c}0,016 \\
1,00\end{array}$ \\
\hline
\end{tabular}

Tab. 3.8 Durchschnittliche Anzahl der Neuritenkreuzungen sowie die p-Werte der einzelnen Signifikanzvergleiche zur eGFP-Kontrolle dopaminerger Neurone nach Transfektion. Fett: signifikante Unterschiede $(p-W e r t<0,05)$ in OneWay ANOVA gefolgt von Dunnett Post-hoc-Testhervorgehoben. WT: $n=135$, A30P: $n=119$, A53T: $n=134$, eGFP: $n=171$, untrans: $n=373$ dopaminerge Mittelhirnneurone aus 3 unabhängigen Mittelhirnzellkulturen, DIV5.

\subsubsection{Durchschnittliche Neuritenkreuzung nicht-dopaminerger Mittelhirn- neurone}

Auch bei den nicht-dopaminergen Neuronen zeigte sich ein ähnliches Verhalten der Neuritenverzweigung wie bei den dopaminergen Mittelhirnneuronen. Letztlich konnte auch hier zunächst eine Soma-nahe Erhöhung der Neuritenkreuzungen im Sinne einer zunächst zunehmenden Verzweigung beobachtet werden. Es zeigte sich jedoch im Unterschied zu den dopaminergen Neuronen auch ein kurzer Anstieg der Neuritenkreuzungszahl bei der A30P-Mutation (minimal auch beim a-Syn-WT) und nicht nur bei A53T. Im weiteren Verlauf kam es zunächst zu einem stärker ausgeprägten Abfall in den $\alpha$-Syn-transfizierten Zellpopulationen mit im mittleren Abstandsbereich von ca. 50-175 $\mu \mathrm{m}$ signifikant weniger Neuritenkreuzungen bevor noch weiter distal der a-Syn-WT sowie die A53T-Mutation sich wieder der Kontrollgruppe anglichen, jedoch die A30P Mutation weiter weniger Neuritenkreuzungen aufwies, auch wenn dieser Unterschied aufgrund der insgesamt 
geringen Anzahl von Neuritenkreuzungen in allen Versuchsgruppen sich nicht mehr signifikant darstellte. Letztlich fanden sich jedoch bei den nicht-dopaminergen Neuronen im Gegensatz zu den dopaminergen Neuronen auch nach Transfektion mit den beiden aSynMutationsformen bis weit nach distal reichende Neuriten (s. Abb. 3.32 und Tab. 3.9). Dies entspricht dem oben beschriebenen, weniger stark ausgeprägten Effekt der $\alpha$-SynÜberexpression auf die durchschnittliche Neuritenlänge bei nicht-dopaminergen im Vergleich zu dopaminergen Neuronen.

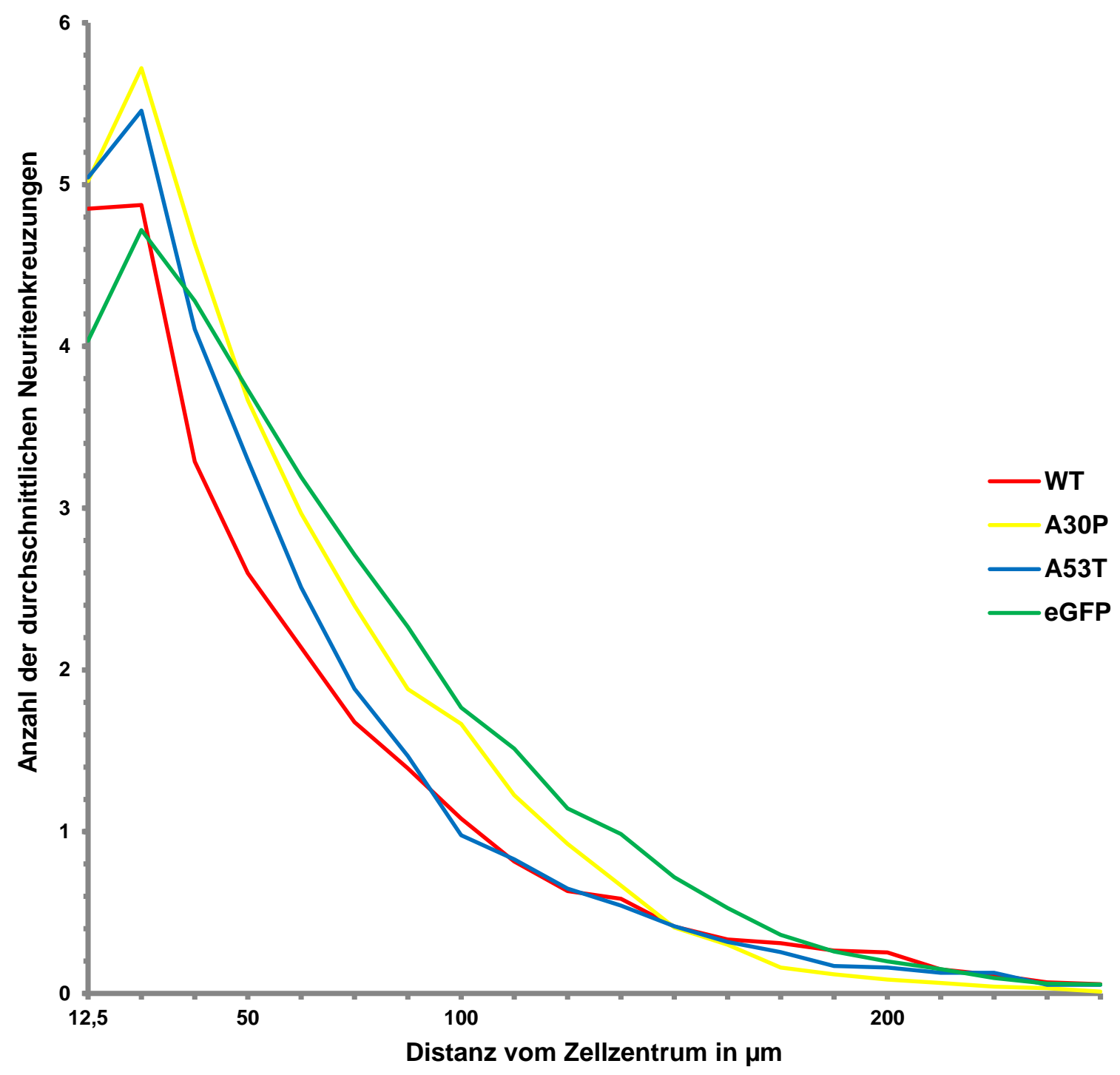

Abb. 3.32 Graphische Darstellung der durchschnittlichen Neuritenkreuzungen nicht-dopaminerger Mittelhirnneurone nach Transfektion mit $\alpha$-Syn (WT, A30P, A53T) im Vergleich zur eGFP-Kontrolle in Bezug auf die einzelnen Radien. Zusammenfassend zeigen sich Soma-nah deutlich mehr Neuritenkreuzungen bei distal reduzierter Anzahl (s. auch Text).WT: $n=87$, A30P: $n=93$, A53T: $n=94$, eGFP: $n=146$ nicht-dopaminerge Mittelhirnneurone aus 3 unabhängigen Mittelhirnzellkulturen, DIV5.Zur besseren Visualisierung erfolgte, wenn auch mathematisch nicht korrekt, die Verbindung der einzelnen Messpunkte und auf die Darstellung der Fehlerbalken wurde ebenso verzichtet. 


\begin{tabular}{|c|c|c|c|c|c|c|c|c|c|c|}
\hline \multirow[b]{2}{*}{$\begin{array}{l}\text { Radius } \\
\text { in } \mu \mathrm{m}\end{array}$} & \multicolumn{10}{|c|}{$\begin{array}{l}\text { Durchschnittliche Neuritenkreuzungen je Radius (oben) und Signifikanzlevel (p- } \\
\text { Wert) zur eGFP-Kontrolle (unten, kursiv) }\end{array}$} \\
\hline & 12,5 & 25 & 37,5 & 50 & 62,5 & 75 & 87,5 & 100 & 112,5 & 125 \\
\hline eGFP & 4,03 & 4,72 & 4,28 & 3,73 & 3,19 & 2,71 & 2,27 & 1,77 & 1,51 & 1,14 \\
\hline WT & $\begin{array}{c}4,85 \\
0,0067\end{array}$ & $\begin{array}{l}4,87 \\
0,94\end{array}$ & $\begin{array}{c}3,29 \\
0,00084\end{array}$ & $\begin{array}{c}2,60 \\
7,4^{*} 10^{-5}\end{array}$ & $\begin{array}{c}2,14 \\
0,00015\end{array}$ & $\begin{array}{c}1,68 \\
4,4^{*} 10^{-6}\end{array}$ & $\begin{array}{c}1,39 \\
8,3^{*} 10^{-6}\end{array}$ & $\begin{array}{c}1,08 \\
6,4^{*} 10^{-5}\end{array}$ & $\begin{array}{c}0,82 \\
5,3^{*} 10^{-6}\end{array}$ & $\begin{array}{c}0,63 \\
6,0^{*} 10^{-5}\end{array}$ \\
\hline A30P & $\begin{array}{c}5,02 \\
0,00052\end{array}$ & $\begin{array}{c}5,72 \\
\mathbf{0 , 0 0 4 2}\end{array}$ & $\begin{array}{l}4,63 \\
0,42\end{array}$ & $\begin{array}{l}3,67 \\
0,99\end{array}$ & $\begin{array}{l}2,97 \\
0,72\end{array}$ & $\begin{array}{l}2,40 \\
0,30\end{array}$ & $\begin{array}{c}1,88 \\
0,087\end{array}$ & $\begin{array}{l}1,67 \\
0,87\end{array}$ & $\begin{array}{l}1,23 \\
0,10\end{array}$ & $\begin{array}{l}0,92 \\
0,16\end{array}$ \\
\hline A53T & $\begin{array}{c}5,04 \\
0,00036\end{array}$ & $\begin{array}{l}5,46 \\
0,050\end{array}$ & $\begin{array}{l}4,11 \\
0,86\end{array}$ & $\begin{array}{l}, 30 \\
0,24\end{array}$ & $\begin{array}{l}2,51 \\
0,020\end{array}$ & $\begin{array}{c}1,88 \\
0,00016\end{array}$ & $\begin{array}{c}1,47 \\
3,1 * 10^{-5}\end{array}$ & $\begin{array}{c}0,98 \\
3,3^{*} 10^{-6}\end{array}$ & $\begin{array}{c}0,83 \\
4,9^{*} 10^{-6}\end{array}$ & $\begin{array}{c}0,65 \\
7,1^{*} 10^{-5}\end{array}$ \\
\hline & \multicolumn{10}{|c|}{$\begin{array}{l}\text { Durchschnittliche Neuritenkreuzungen je Radius (oben) und Signifikanzlevel (p- } \\
\text { Wert) zur eGFP-Kontrolle (unten, kursiv) }\end{array}$} \\
\hline $\begin{array}{l}\text { Radius } \\
\text { in } \mu \mathrm{m}\end{array}$ & 137,5 & 150 & 162,5 & 175 & 187,5 & 200 & 212,5 & 225 & 237,5 & 250 \\
\hline eGFP & 0,99 & 0,72 & 0,53 & 0,36 & 0,26 & 0,20 & 0,15 & 0,096 & 0,062 & 0,055 \\
\hline WT & $\begin{array}{c}0,59 \\
0,0014\end{array}$ & $\begin{array}{c}0,41 \\
0,0060\end{array}$ & $\begin{array}{c}0,33 \\
0,061\end{array}$ & $\begin{array}{l}0,31 \\
0,83\end{array}$ & $\begin{array}{r}0,26 \\
1,00\end{array}$ & $\begin{array}{l}0,25 \\
0,73\end{array}$ & $\begin{array}{l}0,15 \\
1,00\end{array}$ & $\begin{array}{l}0,11 \\
0,95\end{array}$ & $\begin{array}{c}0,069 \\
0,99\end{array}$ & $\begin{array}{r}0,057 \\
0,99\end{array}$ \\
\hline A30P & $\begin{array}{l}0,67 \\
\mathbf{0 , 0 1 2}\end{array}$ & $\begin{array}{c}0,41 \\
\mathbf{0 , 0 0 4 0}\end{array}$ & $\begin{array}{c}0,30 \\
\mathbf{0 , 0 1 9}\end{array}$ & $\begin{array}{c}0,16 \\
0,015\end{array}$ & $\begin{array}{c}0,12 \\
0,076\end{array}$ & $\begin{array}{c}0,086 \\
0,16\end{array}$ & $\begin{array}{c}0,065 \\
0,18\end{array}$ & $\begin{array}{c}0,043 \\
0,49\end{array}$ & $\begin{array}{c}0,032 \\
0,70\end{array}$ & $\begin{array}{c}0,010 \\
0,27\end{array}$ \\
\hline A53T & $\begin{array}{c}0,54 \\
0,00022\end{array}$ & $\begin{array}{c}0,41 \\
0,0049\end{array}$ & $\begin{array}{c}0,32 \\
\mathbf{0 , 0 3 4}\end{array}$ & $\begin{array}{l}0,26 \\
0,33\end{array}$ & $\begin{array}{l}0,17 \\
0,38\end{array}$ & $\begin{array}{l}0,16 \\
0,87\end{array}$ & $\begin{array}{l}0,13 \\
0,94\end{array}$ & $\begin{array}{l}0,13 \\
0,82\end{array}$ & $\begin{array}{c}0,053 \\
0,99\end{array}$ & $\begin{array}{c}0,053 \\
0,99\end{array}$ \\
\hline
\end{tabular}

Tab. 3.9 Durchschnittliche Anzahl der Neuritenkreuzungen sowie die p-Werte der einzelnen Signifikanzvergleiche zur eGFP-Kontrolle nicht-dopaminerger Neurone nach Transfektion. Fett: signifikante Unterschiede $(p-W e r t<0,05)$ in One-Way ANOVA gefolgt von Dunnett Post-hoc-Testhervorgehoben. WT: $n=87$, A30P: $n=93$, A53T: $n=94$, eGFP: $\mathrm{n}=146$ aus 3 unabhängigen Mittelhirnzellkulturen, DIV5. 


\section{$4 \quad$ Diskussion}

Um ein weiteres Verständnis der pathomechanistischen Veränderungen im Rahmen des idiopathischen Parkinsonsyndroms zu erlangen, wurden in dieser Arbeit die Auswirkungen einer leichten $\alpha$-Syn-Überexpression auf das Neuritenwachstum sowie die Neuritenverzweigungen grundlegend untersucht. Zusammengefasst konnte dabei gezeigt werden, dass in den $\alpha$-Syn-überexprimierenden Versuchsgruppen durchschnittlich kürzere Neuriten auswachsen. Durch jedoch deutlich mehr am Zellkörper entspringende Neuriten unterscheidet sich die Gesamtneuritenlänge der einzelnen Neurone nicht signifikant von der Kontrollgruppe. Daneben zeigten die $\alpha$-Syn-überexprimierenden Neurone deutlich weniger Verzweigungen.

Bei der Therapie des IPS muss grundsätzlich zwischen kausaler und symptomatischer Therapie unterschieden werden. Als kausale Therapie bezeichnet man die Behandlung der Krankheitsgenese, mit deren Hilfe der fortschreitende Krankheitsprozess inhibiert, gestoppt oder sogar rückgängig gemacht werden kann. Eine solche Therapie steht bislang jedoch weder für das IPS noch für die seltenen genetischen Parkinson-Formen zur Verfügung. Es fehlen weiterhin kausale, kurative und neuroprotektive Therapiestrategien, sodass rein symptomatisch bspw. mit den Medikamenten L-Dopa, DOPA-Decarboxylase-Hemmern oder Dopaminagonisten behandelt wird. Die Substitution des Neurotransmitters L-Dopa ist bereits seit Ende der sechziger Jahre des 20. Jh. Hauptprinzip der gängigen, klassischen symptomatischen Therapie beim IPS (Barbeau 1969).

Lange Zeit konzentrierte sich das Verständnis der Erkrankung darauf, dass das IPS durch einen fortschreitenden, lokal begrenzten Verlust von ausschließlich dopaminergen, pigmentierten Neuronen im ventrolateralen Teil der SNpc mit konsekutivem Dopaminmangel geprägt ist. Inzwischen weiß man, dass im Verlauf der Erkrankung multilokulär diverse Teile des Nervensystems und unterschiedliche Zellarten betroffen sind, sodass das IPS vielmehr als eine Multisystemerkrankung verstanden werden muss (Goedert et al. 2013).

Die Sichtweise änderte sich unter anderem durch die Erkenntnisse des Neuroanatomen Braak. Seine klinisch-pathologische Studie zerebraler Querschnitte zeigte eine Degeneration verschiedener auch nicht-dopaminerger Transmittersysteme, wie bspw. die serotonergen Raphekerne oder des noradrenergen Coeruleus-Komplexes. Dabei finden sich zudem LK, als pathognomonisches Korrelat, nicht nur in den dopaminergen Neuronen der SNpc, sondern ebenso in den Ganglien des Meissner- und Auerbach-Plexus des gastrointestinalen Traktes (Pouclet et al. 2012, Wakabayashi et al. 1990), in den sympathischen Ganglien und dem Grenzstrang (Braak et al. 2007, Wakabayashi und Takahashi 1997), in der Glandula submandibularis (Del Tredici et al. 2010) sowie im Herz (Orimo et al. 2005, Iwanaga et al. 1999) und dessen Reizleitungssystem (Ghebremedhin et al. 2009). Dabei wird eine systematische Ausbreitung der LK-Pathologie über das zentrale Nervensystem abhängig 
vom Krankheitsstadium beobachtet, wie in der Einleitung bereits ausführlich beschrieben (s. 1.2.4.2).

Nicht nur unterschiedliche neuronale Zellarten sind betroffen, sondern ebenso unterschiedliche Zellkompartimente, insbesondere die neuronalen Zellfortsätze (Axone und Dendriten) (Braak et al. 2003). Da sich der Verlust von nigrostriatalen Neuriten bereits in frühen Phasen der Pathogenese des IPS ereignet, könnte eine Unterbindung bzw. Reduktion dieses Neuritenverlustes ein potentiell kurativer Ansatz sein, vor allem da zu diesem Zeitpunkt das neuronale Soma noch intakt ist. Chronologisch ist der Neuritenverlust als eine retrograde axonale Degeneration charakterisiert, welche peripher an den Synapsen und Terminalen der Neuriten beginnt und erst im Verlauf zu einer Apoptose der neuronalen Perikaya führt (Tagliaferro und Burke 2016). Als molekulare Mechanismen der axonalen Degeneration werden unter anderem eine mitochondriale Dysfunktion, eine verminderte Autophagie, inflammatorische Veränderungen oder gestörte apoptotische Prozesse diskutiert (Tagliaferro und Burke 2016).

Multiple unterschiedliche Untersuchungsergebnisse zeigen, dass das Protein $\alpha$-Syn eine bedeutende Rolle in der Pathogenese des IPS spielt. Die Entdeckung des ersten Gens für eine seltene erbliche Form - genannt PARK1 - definiert eine gestörte Produktion des Proteins a-Syn. Kurz danach konnte gezeigt werden, dass die LK vornehmlich aus aggregiertem $\alpha$-Syn bestehen. Hierauf beruht letztlich auch die Stadien-Einteilung von Braak. LK finden sich allerdings nicht nur im Zellkörper, sondern ebenso in den Neuriten (Duda et al. 2002, Galvin et al. 1999). Zudem weisen aktuelle Studien daraufhin, dass $\alpha$-Syn an den Pathomechanismen eines gestörten Neuritenwachstums beteiligt ist (Liu et al. 2013, Sousa et al. 2009, Takenouchi et al. 2001) und insbesondere stark verzweigte Neuriten (dopaminerge Neurone weisen unter physiologischen Bedingungen eine ausgeprägte Verzweigung auf) anfällig für die Ausbildung von Lewy-Neuriten sind (Kanazawa et al. 2012).

Da eine veränderte Neuritenmorphologie und die Degeneration der Neuriten zentrale Charakteristika im frühen Krankheitsstadium des IPS sind und zugleich dem Protein $\alpha$-Syn eine wichtige Rolle in der Pathogenese des IPS zugeschrieben wird, wurden in der vorliegenden Arbeit morphologische Effekte einer milden Überexpression vom a-Syn-WT und seinen Mutanten A30P und A53T in einem In-vitro-Modell, d. h. in der Zellkultur von primären dopaminergen und nicht-dopaminergen Ratten-Mittelhirnneuronen, untersucht. Dabei wurden die Neuritenmorphologie und das neuronale Überleben in einem frühen embryonalen Entwicklungsstadium ausgewertet. 


\subsection{Dosis-Effekte intraneuronaler $\alpha-S y n-K o n z e n t r a t i o n e n$}

Die Überexpression von $\alpha$-Syn ist ein gängiges Parkinson-Modell sowohl zellkulturell als auch im Tier-Modell, um die dadurch veränderten zellulären Abläufe besser zu verstehen. Es ist bekannt, dass eine Überexpression von a-Syn in Tiermodellen ein Krankheitsbild ähnlich dem idiopathischen Parkinsonsyndroms bedingt (Kirik et al. 2003, Lauwers et al. 2003, Singleton et al. 2003).

Auf Grundlage der besonderen Bedeutung des Proteins a-Syn und des bekannten GenDosis-Effektes in Parkinsonsyndromen (Tan et al. 2003), wurden in der vorliegenden Arbeit der humane a-Syn-WT und seine pathogenen Isoformen A30P und A53T in primären Mittelhirnneuronen der embryonalen Ratte (E14) für insgesamt 5 Tage (DIV5) über die

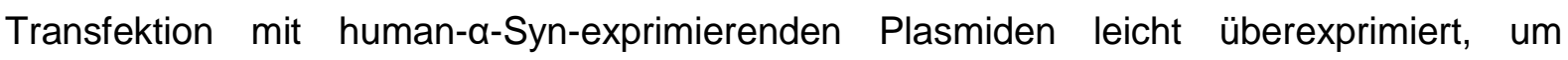
anschließend die Effekte auf das Neuritenwachstum zu quantifizieren.

Eine artifizielle Überexpression durch die Transfektion von $\alpha$-Syn-Plasmiden, wie in diesem Modell, spiegelt daneben Veränderungen wie bei einer (speziellen) genetisch-familiären Form des Parkinsonsyndroms wider. Bei dieser genetischen Form führen Multiplikationen des a-Syn-Locus, d. h. die Duplikation oder Triplikation des a-Syn-WT-Gens oder Polymorphismen im Promotorgen, ebenfalls zu einer Überexpression von $\alpha$-Syn und induzieren über eine erhöhte intraneuronale $\alpha$-Syn-Proteinmenge einen Gen-Dosis-Effekt (Bendor et al. 2013, Chartier-Harlin et al. 2004, Singleton et al. 2003, Tan et al. 2003).

Zwar konnte in menschlichen Gehirnen von postmortalen IPS-Patienten keine erhöhte Transkription des $\alpha$-Syn-Locus in Form von vermehrter $\alpha$-Syn-mRNA gefunden werden (Kingsbury et al. 2004), dennoch kann angesichts der a-Syn-Aggregate in Form von LK auch beim IPS von einer erhöhten intraneuronalen a-Syn-Menge ausgegangen werden, die in diesem Fall nicht Folge einer erhöhten Transkription, sondern z. B. Folge eines gestörten Abbaus des Proteins $\alpha$-Syn sein kann.

Aufgrund des von Tan et al. beschriebenen Gen-Dosis-Effektes in einer Fall-Kontroll-Studie, in der durch eine Verdopplung oder auch Verdreifachung des a-Syn-Gens und einer damit einhergehenden 2-3-fach erhöhten Gesamtproteinmenge von $\alpha$-Syn ein Parkinsonsyndrom verursacht wird, sollte keine unverhältnismäßige $\alpha$-Syn-Proteinexpression, sondern eine vergleichbare milde Steigerung auf das 2-3-Fache der nativen a-Syn-Expression erzeugt werden, um ein realitätsnahes Modell der Parkinsonerkrankung zur weiteren Analyse zu etablieren.

In dem in dieser Arbeit verwendeten In-vitro-Modell wurde eine milde, durchschnittlich 2,1fache Überexpression von $\alpha$-Syn nach der Transfektion der human- $\alpha-S y n-e x p r i m i e r e n d e n$ Plasmide (s. 3.2.2.3) induziert, welche sehr gut, neben den pathogenetischen Effekten der Mutationsformen, den Gen-Dosis-Effekt, z. B. der krankheitsassoziierten a-Syn-Duplikationen oder die anders induzierten, pathologisch erhöhten intraneuronalen $\alpha$-Syn- 
Konzentrationen, widerspiegelt. Hier wurde zwischen der milden 2,1-fachen Überexpression und der physiologischen intrinsischen Expression unterschieden. Zukünftig wäre es vielversprechend, anlehnend an dieses Transfektionsmodell, die Effekte verschiedener Transfektionsdosen und konsekutive Proteinkonzentrationen zu testen, um eine Aussage verschieden starker Überexpressionen von $\alpha$-Syn treffen zu können und daraus resultierend, ab welcher Konzentration ein negativer Effekt - im Sinne eines Schwellenwertes - entsteht, ob niederschwellige Konzentrationserhöhungen möglicherweise auch positive Auswirkungen haben könnten und ob sich daraus übertragbar auf den Menschen ggfs. eine Messgröße im peripheren Blut entwickeln lässt, die zur Frühdiagnostik eines Parkinsonrisikos verwendet werden kann und somit eine präsymptomatische Kuration ermöglicht, sofern bis dato eine kurative Therapie zur Verfügung steht.

\section{$4.2 \quad \alpha-S y n-i n d u z i e r t e r$ neuronaler Zelltod}

Die Überexpression aller eingesetzter $\alpha$-Syn-Varianten zeigte in der vorliegenden Arbeit im Vergleich zu physiologischen a-Syn-Konzentrationen eine leichte Zytotoxizität, was sich in einer Reduktion der dopaminergen und der nicht-dopaminergen Neuronen im Vergleich zur Kontrolle ausdrückte.

Das IPS zeichnet sich durch progressive intraneuronale Ablagerungen von $\alpha$-Syn in verschiedenen Hirnregionen aus (Braak et al. 2003). In vielen dieser Regionen, wie z. B. in der Amygdala, kommt es allerdings im direkten Vergleich zur SNpc mit ihren dopaminergen Neuronen zu einem relativ geringen Zellverlust, obwohl sich bereits früh $\alpha$-Syn-Aggregate finden lassen (Harding et al. 2002).

Passend dazu konnte gezeigt werden, dass sich die dopaminergen Neurone der SNpc durch eine besondere Vulnerabilität gegenüber der $\alpha$-Syn-Pathologie auszeichnen, was zu einem signifikant erhöhten neuronalen Zelltod in dieser Region führte (Damier et al. 1999, Fearnley und Lees 1991, Hirsch et al. 1988). Dieser Unterschied der spezifischen Vulnerabilität der dopaminergen Neurone gegenüber anderen Neuronen konnte in diesem Modell zwar nicht nachgewiesen werden, dennoch ist es denkbar, dass der Zelltod der dopaminergen Neurone frühzeitiger als bei den nicht-dopaminergen Neuronen eingetreten ist oder erst zu einem späteren Zeitpunkt überproportional in Erscheinung tritt. Die Auswertung einer gestaffelten Zeitreihe (bspw. DIV1-5) sowie Beobachtungen nach einer längeren Zeitperiode könnten unter den Gegebenheiten dieses Modells eingesetzt werden, um auch in dieser Versuchsanordnung die zahlreichen Hinweise einer höheren Sensibilität der dopaminergen Neurone gegenüber der $\alpha$-Syn-Pathologie zu erfassen.

Der Grund für die beschriebene erhöhte Vulnerabilität der dopaminergen Neurone ist bis heute nicht abschließend verstanden. Da man unter physiologischen Bedingungen eine besonders hohe Dichte an protektiver Mikroglia in der Substantia nigra finden konnte, wurde 
eine ausgeprägte Vulnerabilität der dopaminergen Neurone gegenüber inflammatorischen Prozessen postuliert (Kim YS und Joh 2006). Protektive Mikroglia gleicht dieses Defizit bis zu einem gewissen Grad aus. Fehlt diese Protektion, wirken sich inflammatorische Prozesse auf einen neuronalen Zellverlust aus. $\mathrm{Da}$ in dem verwendeten Modell dieser Arbeit durch entsprechende Präparation eine Selektion insbesondere von dopaminergen und nichtdopaminergen Neuronen angestrebt wurde, ist die Menge der Mikroglia hier auf ein relatives Minimum reduziert. Somit ist potentiell von einem inflammatorischen Milieu ohne relevanten Schutzmechanismus der Mikroglia auszugehen, welches sich in einem erhöhten Zelltod aller Neurone (dopaminerg und nicht-dopaminerg) äußert und daher die bekannte Vulnerabilität der dopaminergen Neurone nicht mehr nachgewiesen werden kann.

Oxidativer Stress, bspw. ausgelöst durch inflammatorische Ereignisse, ist eine mutmaßlich vorgeschaltete und beeinträchtigende Komponente. Dopaminerge Neurone haben nachgewiesenermaßen eine erhöhte Sensibilität gegenüber oxidativem Stress, die möglicherweise mit den Besonderheiten des Dopaminstoffwechsels zusammenhängt (Faucheux et al. 2003, Jenner und Olanow 1998). Oxidativer Stress kann wiederum die proteasomale Funktion inhibieren (Ding und Keller 2001) und auch die intrazelluläre Aggregationsbildung ist abhängig von oxidativen Ereignissen (Demasi und Davies 2003). Unter diesem Gesichtspunkt und anlehnend an dieses Modell, ist es von besonderem Interesse die proteasomale Funktion sowie die Aggregationsbildung über eine insgesamt verlängerte Zeitperiode $z u$ beobachten. In den Experimenten dieser Arbeit sind diese exogenen Faktoren bzw. Pathomechanismen, die eine erhöhte Vulnerabilität der dopaminergen Neurone bedingen könnten, nicht differenziert worden, wären aber bei der veränderten Neuritenmorphologie von Interesse.

Zusammenfassend konnte hier gezeigt werden, dass eine milde Überexpression von a-Syn eine toxische Wirkung auf dopaminerge und nicht-dopaminerge Mittelhirnneurone hat, wobei die zugrundeliegenden Mechanismen hier nicht weiter untersucht wurden. Mögliche Erklärungsansätze bestehen jedoch im oxidativen Stress oder inflammatorischen Prozessen.

\subsection{Neuritenmorphologie primärer Mittelhirnneurone}

\subsubsection{Durchschnittsneuritenlänge}

Die milde Überexpression von $\alpha$-Syn-WT und seinen Mutanten A30P und A53T führte zu einer signifikanten Reduktion im Längenwachstum der Neuriten eines Neurons (Durchschnittsneuritenlänge), sowohl der primären dopaminergen als auch der nichtdopaminergen Mittelhirnneurone der embryonalen Ratten. Zwischen den einzelnen $\alpha$-SynGruppen ergaben sich keine signifikanten Unterschiede. Neben dieser Beobachtung ist es jedoch auch von wesentlicher Bedeutung zu erwähnen, dass sich keinerlei Unterschiede 
zwischen den beiden Kontrollgruppen im Rahmen der spezifischen Analyse dopaminerger Neurone ergaben. So konnten sowohl in der eGFP-transfizierten als auch in der untransfizierten dopaminergen Neuronenpopulation nahezu identische Werte festgestellt werden. Hieraus ist zu entnehmen, dass neben der Methode der Transfektion auch die alleinige eGFP-Expression keinen Einfluss auf die erhobenen Parameter haben und somit die in den a-Syn-transfizierten Versuchsgruppen erfassten Veränderung spezifisch auf die Überexpression von humanen $\alpha$-Syn zurückzuführen sind, wenngleich es zukünftig weiterer mechanistischer Klärung dieser Effekte auf das Neuritenwachstum zum Verständnis der Pathophysiologie bedarf.

Korrelierend mit den o. g. Ergebnissen konnte in einer Studie gezeigt werden, dass das Längenwachstum der „Major Neuriten“ (Axone) primärer hippocampaler Neurone allein durch die Expression der A30P-Mutation (ohne Überexpression), signifikant vermindert war. Die „Minor Neuriten“ (Dendriten) zeigten beim a-Syn-WT und A30P jedoch keine signifikanten Änderungen des Längenwachstums (Sousa et al. 2009). Somit hat die Expression der Mutation A30P einen primären Effekt auf das Längenwachstum der längsten Fortsätze (Axone), sodass der A30P-Variante eine gesonderte Bedeutung zukommt und eine erhöhte Vulnerabilität der langen und filigranen Axone im Vergleich zu den wesentlich kürzeren Dendriten suggeriert wird. Zudem wird dadurch die dying back-Theorie (Burke und O'Malley 2013) und die retrograde Degeneration, welche am distal gelegensten Bereich der Neurone (Axon) beginnt, untermauert. In dieser Arbeit wurden Axone und Dendriten nicht separat untersucht. Da die Zahl der Dendriten die der Axone deutlich übersteigt und die Ergebnisse hier trotzdem hoch signifikant sind, ist davon auszugehen, dass die Effekte der Überexpression von $\alpha$-Syn und seinen Mutanten A30P und A53T unter den gegebenen Versuchsbedingungen nicht nur die Axone, sondern auch die Dendriten betreffen.

Insgesamt bleibt festzuhalten, dass der Dosis-Effekt eine entscheidende Rolle spielt, da die physiologische Expression bzw. intrazelluläre Konzentration von a-Syn-WT keinen Einfluss auf das Neuritenwachstum hat, wohingegen eine Überexpression, wie in dieser Arbeit, und somit gesteigerte intrazelluläre Konzentrationen des $\alpha$-Syn-WTs und seiner Mutationsformen das Neuritenwachstum partiell inhibiert bzw. zu einer reduzierten Neuritenlänge führt. Demgegenüber kann diskutiert werden, dass die Mutationsformen A30P und A53T per se, ohne dass es deren Überexpression bedarf, zu einer Beeinträchtigung des Neuritenwachstums führen. Diese Hypothese müsste jedoch in entsprechenden Zellkulturen mutanter Tiere überprüft werden, in denen eine Überexpression mittels Plasmid vermieden werden kann.

Kontroverserweise führte die Behandlung von primären Kortexneuronen der Ratte mit erhöhten Konzentrationen von humanem a-Syn-WT-Protein (durch passive Diffusion), im Gegensatz zu den Ergebnissen in dieser Arbeit, zu einer signifikanten Steigerung der 
Neuritenlänge im Vergleich zu einer Kontrollgruppe, in der lediglich endogenes a-Syn exprimiert wurde (Liu et al. 2013). Dieser Widerspruch könnte insbesondere dadurch erklärt werden, dass in dem Modell von Lui et al. keine Überexpression induziert wurde, sondern dass erhöhte Proteinkonzentrationen direkt in die Neurone eingebracht wurden. Erhöhte intrazelluläre a-Syn-Konzentrationen können sich somit offenbar unter spezifischen Bedingungen auch positiv auf das Neuritenwachstum auswirken. Somit könnten vorgeschaltete Prozesse in der Proteinexpression, bspw. eine gesteigerte mRNAExpression, negative Auswirkungen auf das Neuritenwachstum haben. Eine weitere Erklärung für die durch Lui et al. kontrovers beobachtete Zunahme des Längenwachstums bei dem a-Syn-WT verglichen mit den vorliegenden Ergebnissen ist, dass das Neuritenwachstum zu einem frühen Zeitpunkt und somit noch in der Phase der Neuritenbildung (Initiation), d. h. 1-4 Stunden nach der Aussaat der Zellen beobachtet wurde und nicht nach 5 Tagen (DIV5) der a-Syn-Überexpression, wie in dieser Arbeit (s. auch 3.4.1). Interessant wäre es daher unter den gegebenen Versuchsbedingungen dieser Arbeit die Neuritenbildung während DIV1-4 zu vergleichen, wobei zuvor die entsprechend exprimierte Proteinkonzentration an DIV1-4 bestimmt werden müsste, da initial von einer geringeren Proteinkonzentration ausgegangen werden muss, welche im Rahmen der Expression stetig ansteigt bis die durchschnittlich gemessene 2,1-fache Proteinkonzentration an DIV5 erreicht wird. Wenn man in der Studie von Lui et al. lediglich die a-Syn-WT-Gruppe (ohne Berücksichtigung der Kontrollgruppe) mit den humanen Isoformen A30P und A53T vergleicht, könnte auch andersherum postuliert werden, dass die Mutationsformen zu einer signifikant verkürzten Neuritenlänge führen. Dies würde zumindest für die Mutationsformen mit den vorliegenden Ergebnissen korrelieren und könnte die zuvor beschriebenen Aspekt aufgreifen, dass die Mutationsformen unabhängig von ihrem Expressionsgrad pathogene Eigenschaften aufweisen.

Weiterhin wurde in der Studie von Lui et al. ausschließlich der längste Neurit eines Neurons (konsekutiv dem Axon entsprechend) in die Quantifizierung einbezogen, wohingegen in der vorliegenden Arbeit die Neuritenlängen der Dendriten und Axone kummuliert wurden. Da Sousa et al. bereits einen inkongruenten Effekt des $\alpha$-Syn-WT und A30P auf Dendriten und Axone beschrieb, liegt es nahe, dass sich ein direkter Vergleich dieser Studien als schwierig erweist. Dagegen beziehen sich Lui et al. und Sousa et al. zumindest beide auf die längsten Neuriten (mutmaßlich Axone), allerdings wurde durch Sousa et al. keine Überexpression konstruiert, sodass auch hier der Vergleich erschwert wird. Dennoch konnten in dieser Arbeit und in den beiden beschriebenen Studien ein Einfluss durch $\alpha$-Syn auf das Neuritenwachstum nachgewiesen werden. Dabei kann sich die Expression sowohl negativ als auch positiv auswirken. 
Lui et al. erklärt das durch erhöhte intrazelluläre $\alpha$-Syn-WT-Konzentrationen gesteigerte Längenwachstum durch Interaktionen zwischen Tubulin und a-Syn. Es gibt zahlreiche Studien, welche Interaktionen zwischen $\alpha$-Syn und Tubulin sowie Mikrotubuli zeigen. $\alpha$-Syn bindet direkt an Tubulin und bewirkt eine erhöhte Polymerisationsrate von Tubulin (Lui et al 2013). Der a-Syn-WT fördert folglich als Mikrotubuli-assoziiertes Protein (MAP) die Polymerisation von Tubulin in Mikrotubuli, wohingegen die beiden Mutanten A30P und A53T diese Eigenschaft interessanterweise nicht aufweisen (Liu et al. 2013, Yin et al. 2011, Alim et al. 2004). Durch diesen Verlust der Polymerisationsfähigkeit der Punktmutationen wäre das verminderte Neuritenwachstum bei den pathogenen Mutationsformen in dieser Arbeit erklärbar, ohne dass diese eine Überexpression bedürfen.

Wodurch wird dennoch eine verminderte Neuritenlänge bei intraneuronal erhöhten Konzentrationen der physiologischen WT-Form in dieser Arbeit verursacht? Ein ungestörtes Längenwachstum von Neuriten benötigt die Polymerisation von Tubulin an Mikrotubuli, wodurch diese wachsen und sich somit erst lange Zellfortsätze entwickeln können (TsanevaAtanasova et al. 2009, Gordon-Weeks 1991). Mikrotubuli sind polarisierte Polymere mit einem Plus- und einem Minusende, welche sich an ihrem Plusende durch eine Guanosintriphosphat-abhängige Polymerisation verlängern (Flynn 2013). Da die Polymerisation von Tubulin für das Längenwachstum von zentraler Bedeutung ist, kann das Neuritenwachstum sowohl positiv als auch negativ durch Interaktionen mit a-Syn beeinflusst werden. Bezogen auf das reduzierte Längenwachstum der Neuriten in dieser Arbeit ist es denkbar, dass es durch erhöhte intrazelluläre Konzentrationen von $\alpha$-Syn-WT zu vermehrten Tubulin- $\alpha$-SynBindungen kommt. Beispielsweise konnte in-vitro gezeigt werden, dass durch Tubulin- $\alpha-$ Syn-Bindungen sogar eine Inhibierung der Mikrotubuli-Formierung entsteht (Zhou RM et al. 2010). Die Überexpression von $\alpha$-Syn in primären Zellkulturen von Hinterstrangzellen hatte ebenfalls einen negativen Effekt auf das Mikrotubuli-Netzwerk und in degenerierenden Neuriten zeigten sich vermehrt Co-Aggregate von Tubulin und $\alpha$-Syn (Lee et al. 2006). Eine beeinträchtigte Polymerisation von Tubulin an Mikrotubuli wäre ein mögliches Erklärungsmodell der vorliegenden Ergebnisse.

Das Längenwachstum von Mikrotubuli und damit verbunden das Neuritenwachstum wird über die NAC-Einheit (Mittelstück) und das C-terminale Ende (61-140) von $\alpha$-Syn durch eine Faszilitation der Polymerisation von Tubulin in Mikrotubuli vermittelt (Chen et al. 2007, Liu et al. 2013). Somit agiert $\alpha$-Syn als Chaperon-Protein und diese Eigenschaft ist in der NACEinheit und dem C-terminalen verankert (Kim TD et al. 2002, Rekas et al 2012). Chaperone sind Proteine, die neu synthetisierten Proteinen zu einer korrekten Faltung verhelfen. Bezogen auf die vorliegenden Ergebnisse kann der Verlust dieser Eigenschaft ein vermindertes Längenwachstum erklären. Da die Mutationsformen A30P und A53T das 
benannte Charakteristikum nicht aufweisen (Liu et al. 2013, Yin et al. 2011, Alim et al. 2004), erklärt die Expression und Überexpression beider ein gestörtes Neuritenwachstum.

Wodurch wird darüber hinaus über gesteigerte Konzentrationen von $\alpha$-Syn-WT-Produkten ein negativer Einfluss auf das Neuritenwachstum ausgelöst? Vermehrt anfallende Aggregate oder Zwischenprodukte auf dem Wege der Aggregatbildung könnten herbei negativ in den Prozess des Neuritenwachstums eingreifen. Die Überexpression des $\alpha$-Syn-WTs führte zu einer gesteigerten Akkumulation von a-Syn in der Taufliege Drosophila (Feany et al. 2000) und in transgenen Mäusen (Kahle et al. 2000, Masliah et al. 2000). A30P und A53T führen ebenfalls bereits ohne Überexpression zu einer erhöhten Oligomerisierung (Conway et al. 2000). A30P führt zwar zu einer verminderten Fibrillenbildung, darüber jedoch konsekutiv zu einer vermehrten Akkumulation von Oligomeren (Conway et al. 2000). Gemeinsam ist folglich beiden a-Syn-Mutanten A30P und A53T wie auch der Überexpression des a-SynWTs (mit erhöhten intrazellulären Konzentrationen) eine erhöhte Oligomerisierungsrate. Durch Fehlfaltungen von $\alpha$-Syn entstehen Oligomere und aus innen wiederum Fibrillen. Allerdings wird angenommen, dass die Oligomere und Protofibrillen die eigentlich toxischen Produkte sind, welche hier vermehrt anfallen (Conway et al. 2000, Goldberg und Lansbury 2000, Masliah et al. 2000). Im Vergleich zu Fibrillen konnte in einem In-vivo-Rattenmodell gezeigt werden, dass a-Syn-Oligomere die toxischen Produkte sind, welche einen erhöhten dopaminergen Neuronenverlust zur Folge hatten (Winner et al. 2011). Ein wichtiger Beweis dafür ist, dass eine Überexpression von a-Syn in Zellkultursystemen zur Apoptose sowie Schädigung von Zellorganellen ohne das Vorhandensein von Fibrillen führte (Gosavi et al. 2002).

Darüber hinaus induzierte die Behandlung von primären Kortexneuronen mit $\alpha$-SynOligomeren eine signifikant reduzierte Neuritenlänge (Danzer et al. 2009). Erklärt wird diese Beobachtung damit, dass Zwischenprodukte auf dem Wege der Aggregatbildung das Neuritenwachstum dadurch stören, indem a-Syn Oligomere ebenfalls die Polymerisation von Tubulin inhibieren. Bspw. konnte in dopaminergen Neuronen (MES-Zellkulturlinie) gezeigt werden, dass extrazelluläres, aggregiertes a-Syn (einschließlich Oligomere) eine verminderte Tubulin-Polymerisation und mitochondriale Funktion sowie morphologische Veränderungen zur Folge hat (Chen et al. 2007). Multimere Formen insbesondere Oligomere von $\alpha$-Syn beeinträchtigen in-vitro ebenfalls die Polymerisation von Tubulin und darüber die Mikrotubuli-Bildung und -Interaktion (Prots et al. 2013, Lee et al. 2006). Diese Zusammenhänge sind ein Erklärungsmodell, über welches $\alpha$-Syn das Neuritenwachstum in primären Neuronen negativ beeinflusst. Da a-Syn die Funktion als MAP durch die Bildung von Oligomeren verliert (Chen et al. 2007), liegt es nahe, dass die in dieser Arbeit induzierte milde Überexpression eine vermehrte Oligomerisationsrate zur Folge hat, obwohl in diesem Modell nicht explizit zwischen Aggregaten und freien a-Syn-Monomeren differenziert wurde, 
sodass eine Unterscheidung zwischen $\alpha$-Syn-Monomeren und Oligomeren mittels WesternBlot-Verfahren eine vielversprechende Methode wäre, um diese Hypothese weiter zu untermauern.

Zusammenfassend konnte hier gezeigt werden, dass alle getesteten a-Syn-Formen einen negativen Einfluss auf die Länge der Neuriten der dopaminergen und nicht-dopaminergen Neurone haben. Als möglicher Mechanismus kann auf Basis der vorhandenen Literatur vor allem eine Interaktion von $\alpha$-Syn, möglicherweise auch in der oligomeren Form, mit Tubulin und der dadurch gestörten Bildung von Mikrotubuli diskutiert werden.

\subsubsection{Neuriteninitiation}

Neben der beschriebenen Neuritenlänge wurde die initiale Neuriteneubildung bzw. Neuriteninitiation durch die Quantifizierung der Neuritenanzahl, welche direkt dem Soma entsprangen bewertet, da diesem zellulären Ereignis andere Mechanismen als dem reinen Neuritenwachstum zu Grunde liegen. Bei der Betrachtung der Neuritenanzahl eines einzelnen Mittelhirnneurons zeigte sich interessanterweise eine Erhöhung der Neuritenanzahl, wenn die dopaminergen Neurone $\alpha$-Syn-WT und die Mutationsformen A30P oder A53T moderat überexprimierten. Die Neuritenanzahl war bei dem $\alpha$-Syn-WT und den Mutationsformen (A30P und A53T) derart erhöht, dass dadurch die Gesamtneuritenlänge des Neuritenbaumes eines Neurons gleich blieb, obwohl im Vergleich zu den Kontrollgruppen kürzere Neuriten ausgebildet wurden.

Ein pathomechanistischer Ansatz ist die Polymerisation von Aktin, da die initiale Neuritenbildung stark von Aktin abhängig ist. Die Umverteilung von Aktin in große AktinAggregate legt die Neuritenneubildung/-initiation fest. Dabei muss zum einen für die Initiation der Neuriten genügend nicht-polymerisiertes Aktin, d. h. freie Aktin-Monomere vorliegen und zum anderen eine ungehinderte Polymerisation möglich sein, sodass ein ungestörter dynamischer Fluss zwischen der Polymerisation und Depolymerisation erfolgt.

Eine artifiziell übermäßig gesteigerte Polymerisation von Aktin führt zu einer Hemmung der Initiation, weil dadurch kein freies monomeres Aktin mehr vorhanden ist. Andersherum fördern artifiziell hinzugeführte, stark depolymerisierende Agenzien die Initiation, weil ausreichend freie Aktinmonomere zur Verfügung stehen (Zhang SX et al. 2016). Da a-Syn mit Aktin interagiert und dadurch dessen Eigenschaften beeinflusst, könnten hierdurch die Effekte von $\alpha$-Syn auf die Neuritenneubildung vermittelt werden. Erstmalig wurde eine CoLokalisation von a-Syn mit Aktin in zwei neuronalen Zelllinien von Esposito et al. 2007 beschrieben. Die in dieser Arbeit herbeigeführte milde Überexpression des $\alpha$-Syn-WTs und den Mutationen, führte zu einer vermehrten Neuritenbildung bei den dopaminergen Mittelhirnneuronen, sodass postuliert werden kann, dass erhöhte Konzentrationen des $\alpha$ Syn-WTs und den Mutationen Einfluss auf den vorliegenden Pool freier Aktinmonomere 
nehmen und hierrüber die Neuritogenese fördern. Anlehnend an die Ergebnisse von Zhang SX et al. wäre eine durch erhöhte intraneuronale Konzentrationen des WTs oder der Mutationsformen gesteigerte Depolarisationsrate denkbar. In primären hippocampalen Neuronen, in denen physiologische Konzentrationen vom a-Syn-WT oder A30P vorlagen, zeigt der a-Syn-WT eine erhöhte Tendenz an Aktin-Monomere zu binden, verlangsamt deren Polymerisation und erhöht die Depolymerisation, d. h. eine erhöhte Absonderung von Aktin-Monomeren. Dies ist eine weitere Erklärung dafür, dass wie in der vorliegenden Arbeit bei einer Überexpression eine vermehrte Neuritenbildung induziert wird.

In der vorliegenden Arbeit zeigte sich bei den überexprimierenden nicht-dopaminergen Mittelhirnneuronen der Effekt der erhöhten Neuritenanzahl ausschließlich bei $\alpha$-Syn-A30P und nicht bei dem a-Syn-WT oder der A53T-Mutation. A30P induziert somit in dem vorliegenden Modell bei beiden Neuritenpopulationen eine Steigerung der Neuritenbildung und zeigt demgemäß einen weitreichenderen Einfluss auf die Neuriteninitiation als die Überexpression des $\alpha$-Syn-WTs und der A53T-Mutation.

Alternativ könnte argumentiert werden, dass dopaminerge Neurone insgesamt sensitiver auf die moderate Überexpression bei der Initiation der Neuritenbildung (Neuritenanzahl) reagieren als nicht-dopaminerge Neurone bzw. dass die WT-, A30P, und A53TÜberexpression vergleichbare Effekte auf dopaminerge Neurone im Gegensatz zu der Überexpression von A30P bei den nicht-dopaminergen Neuronen hat.

Esposito et al. 2007 zeigten bereits, dass der a-Syn-WT - anders als A30P - mit Aktin interagiert. Die A30P-Mutation verminderte sowohl die Interaktionen mit Tau als auch die Assoziation mit dem Aktin-Zytoskelett. A30P bindet nicht an Aktin-Monomere, sondern an Aktin-Filamente und stabilisiert diese. Es steigert somit die Polymerisationsrate von Aktin (Sousa et al. 2009). Solange zeitgleich genügend freie Aktin-Monomere vorliegen, könnte dieser Unterschied der Grund für die bei den nicht-dopaminergen Neuronen nur durch A30P beobachtete gesteigerte Neuriteninitiation (Neuritenanzahl) sein.

Interaktionen mit Aktin spielen darüber hinaus eine wichtige Rolle im Proteintransport. Ein pathologisch veränderter Transport des Proteins könnte eine weitere wichtige Schnittstelle sein. a-Syn wird sowohl über den schnellen als auch den langsamen axonalen Transport transportiert. $\mathrm{Zu} 76 \%$ wird a-Syn dabei aktiv über den langsamen axonalen Transport (anterograd vom Ort der Synthese im Perikaryon) über die Neuriten bis in die Axonterminalen bewegt (Jensen et al. 1999b und 1998). Der schnelle Transport ist mit tubulovesikulären Strukturen und der langsame Transport mit zytoskelettalen Komponenten assoziiert. Zu den zytoskelettalen Filamenten gehören Mikrotubuli und Aktin-Filamente. Es wurde bereits erwähnt, dass es zu Interaktionen dieser Komponenten mit $\alpha$-Syn kommt. $\alpha$ Syn selbst beeinflusst somit ebenfalls den Transport entlang neuronaler Axone. Ein zumindest für die A30P-Mutation bewiesener Mechanismus besteht in einer reduzierten 
Membranbindungsfähigkeit von $\alpha$-Syn. Hierdurch ist der Transport entlang der axonalen Strukturen gestört, was folglich zu einer vermehrten toxischen Akkumulation von $\alpha$-Syn führt. Dies konnte anhand quantitativer Proteinanalysen von Rattenhirnlysaten gezeigt werden (Jo et al. 2002, Jensen et al. 1998). Durch das Fehlen des schnellen Transportes könnte eine gesteigerte Akkumulation von A30P mit konsekutiv veränderter Neuritenmorphologie erklärt werden. A30P kommt in dieser Arbeit ebenso eine besondere Bedeutung zu, da nur eine milde Überexpression von A30P in beiden Neuronenpopulationen (dopaminerg und nichtdopaminerg) zu einer gesteigerten Neuriteninitiation führt.

Allerdings waren in dem Modell dieser Arbeit ebenso Veränderungen in der $\alpha$-Syn-WTVersuchgruppe und A53T-Population bei den dopaminergen Neuroenen zu beobachten. So konnte in einer weiteren Studie bei der Transfektion von primären kortikalen Neuronen der Ratte mit $\alpha$-Syn-A30P und -A53T gezeigt werden, dass die Geschwindigkeit des axonalen $\alpha-$ Syn-Transportes im Vergleich zum a-Syn-WT reduziert wird (Saha et al. 2004), was die Wahrscheinlichkeit erhöht, dass $\alpha$-Syn akkumuliert und sich Aggregate bilden. Im weiteren zeitlichen Verlauf dieser Studie kam es zu einer Angleichung der Geschwindigkeiten des $\alpha$ Syn-Transportes zwischen den Versuchsgruppen, sodass ebenfalls eine Beeinträchtigung des axonalen Transports durch den a-Syn-WT denkbar wäre, der hier nicht mit einer untransfizierten Kontrolle verglichen wurde. Es ist noch unklar, ob die Veränderungen des axonalen Transports zur Akkumulation von $\alpha$-Syn führen oder ob die Akkumulation von $\alpha-$ Syn den axonalen Transport stört.

Zusammenfassend zeigt die vorliegende Arbeit, dass die Neuriteninitiation durch die $\alpha$-SynÜberexpression verstärkt wird. Als möglichen zugrundeliegenden Pathomechanismus wird vor allem eine Interaktion mit der Aktin-Polymerisierung diskutiert.

\subsection{Größe der Perikarya dopaminerger Neurone}

Da bereits ein Zusammenhang zwischen der Perikaryongröße und den Neuriten von speziellen Funktionstypen von Neuronen bekannt ist, wurden die Größen der Perikarya der dopaminergen Mittelhirnneurone vermessen, um herauszufinden, ob es einen Zusammenhang zwischen der Neuritenlänge und der Größe des Perikaryons gibt. So haben Projektionsneurone (Golgi-Typ I) entsprechend ihren weiten Projektionen bzw. Neuriten ein größeres Perikaryon als Interneurone (Golgi-Typ II), die mit ihren kurzen Neuriten lediglich relativ kurze Distanzen zur nächsten Synapse überbrücken (Lüllmann-Rauch 2009). Das Perikaryon ist das Zentrum für den Ernährungs- und Funktionsstoffwechsel. Da Neurone mit weit reichenden Projektionen über größere Distanzen einen höheren Versorgungsbedarf haben, benötigen diese ein größeres Perikaryon, in dem bspw. mehr Golgiapparate, rauhes endoplasmatisches Retikulum oder Mitochondrien beherbergt werden können. Bei den dopaminergen Mittelhirnneuronen, welche a-Syn-WT, A30P oder A53T überexprimierten, 
zeigte sich allerdings kein signifikanter Unterschied bei der Größe der Perikarya im Vergeich zur Kontrollgruppe. Somit konnte kein direkter Zusammenhang zwischen der verkürzten Neuritenlänge und einer veränderten Somagröße hergestellt werden. Der Grund dafür könnte dadurch erklärt werden, dass sich zwar eine reduzierte Neuritenlänge ereignet, aber ebenso eine gesteigerte Neuriteninitiation induziert wird und somit bspw. der Energieaufwand oder Versorgunsbedarf annähernd gleich bleibt und konsekutiv zu keiner veränderten Somagröße führt. Ein anderer denkbarer Ansatz wäre, dass die eigentlichen pathomechanistischen Ereignisse primär in den Neuriten selbst und nicht in den Somata auftreten. Dieser Erklärungsansatz würde sich zudem gut mit der dying back-Theorie ergänzen, welche von einer distal in den Neuriten beginnenden und erst im späteren Verlauf auf die Somata ausbreitenden Patholgie des IPS ausgeht.

\subsection{Sholl-Analyse: Verzweigungsverhalten}

Die Analysen der $\alpha$-Syn-induzierten Veränderungen der Neuritenmorphologie von Mittelhirnneuronen wurden in der vorliegenden Arbeit erweitert durch eine Untersuchung des Verzweigungsverhaltens (branching) der Neuriten mittels einer Sholl-Analyse. Dopaminerge Neurone haben lange, dünne und unmyelinisierte Axone (Braak und Del Tredici 2009), die unter physiologischen Bedingungen eine starke Verzweigung mit Ausbildung multipler Synapsen aufweisen. In diesem Zelltyp kommt es aus diesem Grund zu einem hohen Energieumsatz im Bereich der Axonterminalen, was insbesondere unter pathologischen Bedingungen zu erhöhtem oxidativem Stress führen kann (Pissadaki et al. 2013). Das Verzweigungsverhalten der Neuriten wurde in der vorliegenden Arbeit näher beschrieben, indem die maximale Anzahl an Neuritenverzweigungen an einem beliebig vom Soma entfernten Messradius pro Neuron (Neuritenmaximum), die durchschnittliche Distanz vom Soma, an der es zu diesem Maximum an Kreuzungen kommt (kritischer Wert), sowie der Verzweigungsindex (= Schoenen-Ramifikationsindex), welcher beides zusammenfasst, ermittelt wurden. Der Verzweigungsindex trifft eine Aussage darüber, wie ausgeprägt sich die am Soma entspringenden Neuriten weiter aufzweigen und korreliert somit direkt mit dem Grad der Verzweigung des Neuritenbaums. Zusätzlich wurden die durchschnittlichen Neuritenkreuzungen an bestimmten vom Soma entfernten Distanzpunkten ermittelt. Es zeigte sich eine reduzierter Verzweigungsrad bei erhöhten intrazellulären Konzentrationen des $\alpha$-Syn-WT und A30P bei den dopaminergen und nicht-dopaminergen Neuronen. Bei den nicht-dopaminergen Neuronen wurde ebenfalls durch A53T ein geringerer Verzweigungsgrad induziert. Eine reduzierte Verzweigung wäre hierbei sogar ein anzunehmender Schutzmechanismus eines Neurons seinen Energieumsatz zu drosseln und konsekutiv erhöhten oxidativen Stress zu vermindern. 
Interessanterweise konnte in einer Studie gezeigt werden, dass bei der LK-Pathologie vorwiegend stark verzweigte Neuriten im menschlichen Gehirn befallen waren (Kanazawa et al. 2012). Hier zeigten sich quantitativ mehr Lewy-Neuriten in sich stärker verzweigenden Axonen.

So konnten Kanazawa et al. 2012 zeigen, dass zu einem späten Zeitpunkt der Erkrankung stark verzweigte Neurone anfälliger sind, Lewy-Neuriten auszubilden, und man könnte andersherum annehmen, dass zu einem sehr frühen Zeitpunkt in der Pathogenese oder bereits in der Embryogenese, wie in diesem Modell eher vertreten, die Verzweigung bereits negativ beeinträchtigt bzw. reduziert wird.

Darüber hinaus wird angenommen, dass LK vornehmlich direkt an den Verzweigungsstellen entstehen und sich von dort aus centripedal nach proximal ausbreiten oder vielleicht sogar Lewy-Neuriten zu LK werden. Dabei gilt das Anschwellen der Axone als das früheste Zeichen von $\alpha$-Syn-Ablagerungen und ist dementsprechend hauptsächlich an axonalen Verzweigungsstellen zu beobachten (Uchihara und Giasson 2016). Auch wenn in dem hier verwendeten In-vitro Modell keine Detektion von LK vorgenommen wurde, so führen erhöhte a-Syn-Konzentrationen, welche durch die Überexpression induziert werden, nachweislich zu einem reduzierten Verzweigungsgrad. Kontroverserweise zeigte die Betrachtung des Durchschnitt/Mittelwertes der Anzahl an Neuritenkreuzungen eines bestimmten Abstandes vom Soma der Mittelhirnneurone (Radius), dass in Soma-nahen Abständen vor allem bei $12,5 \mu \mathrm{m}$ und $25 \mu \mathrm{m}$, die mit $\alpha$-Syn transfizierten Neurone deutlich mehr Neuriten und somit Neuritenkreuzungen in diesem Bereich aufwiesen. Postuliert werden könnte entsprechend, dass primär distale Verzweigungen reduziert werden; was wiederrum passend zur dying back-Theorie bzw. einer von centripedal nach proximal fortschreitenden Beeinträchtigung zu sehen ist. Die erhöhten Soma-nahen durchschnittlichen Neuritenkreuzungen spiegeln dabei indirekt die erhöhte Neuriteninitiation wider. 


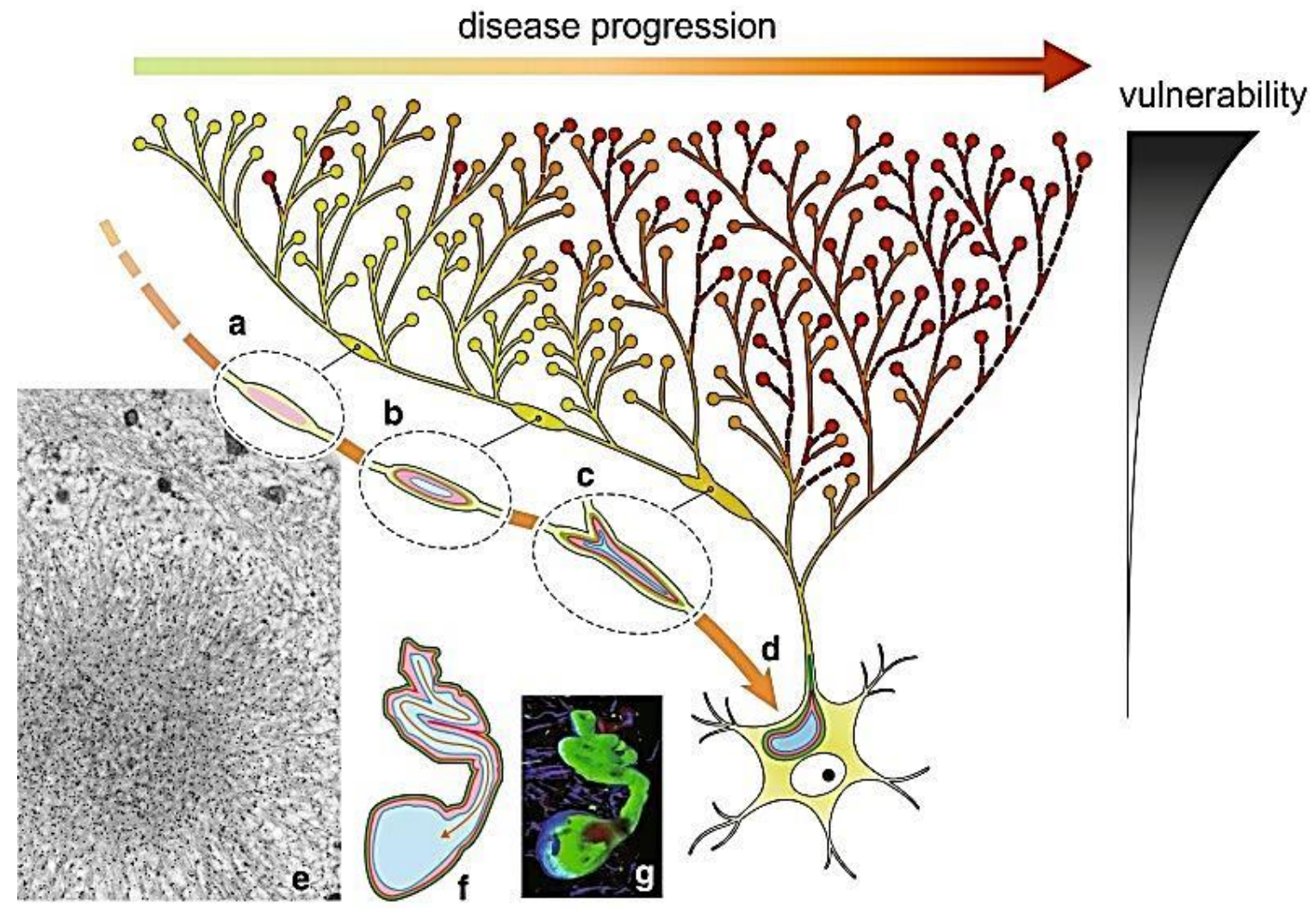

Abb. 4.1 Schematische Darstellung eines stark verzweigten, dünnen und langen Axons eines dopaminergen Neurons mit intraneuronaler Progression der LK-Pathologie von den distalen Axonterminalen zum Soma fortschreitend. Der obere Pfeil zeigt in Richtung des Krankheitsprogresses, bei dem sich die ersten Aggregate von a-Syn in den distalen Terminalen finden und sich dann in Richtung Soma (hier nach unten) ausbreiten. a) Das Anschwellen der Axone gilt als das früheste Zeichen für eine $\alpha$-Syn-Ansammlung, welche vornehmlich an Verzweigungsstellen auftritt. b) und c) Lewy-Neuriten treten von distal nach proximal in Richtung Perikaryon auf. d) Perikaryon mit LK (äußere Schicht grün: Neurofilament, innere Schicht blau: Ubiquitin, mittlere Schicht rot: $\alpha$-Syn). e) Dreischichtung in der Immunoelektronenmikroskopie in LK (d) und Lewy-Neuriten (c). Wenn ein Lewy-Neurit in Verbindung mit einem LK steht (f) finden sich ununterbrochene Schichten, sodass angenommen wird, dass Lewy-Neuriten zu LK werden oder die Lewy-Neuriten von den Neuriten zum Soma wandern (oranger Pfeil). $f$ und g) abgeändert aus Kanazawa et al. 2008 (unverändert aus Uchihara und Giasson 2016, doi: 10.1007/s00401-015-1485-1).

Auf pathomechanistischer Ebene betrachtet, entstehen im Bereich von Verzweigungsstellen (und auch während des Längenwachstums) von Neuriten physiologischerweise Wachstumskegel. Sie können erst entstehen, wenn die Neurogenese eines Neuriten (Neuriteninitiation) bereits abgeschlossen ist. Bei der Entstehung von Wachstumskegeln von wachsenden Neuriten entwickeln sich wiederum Filopodia. Filopodia, auch Mikrospikes genannt, sind lange, unipolare und gebündelte Aktin-Filamente, die über die führenden Kanten von Lamellipodia, die aus kurz verzweigten Aktin-Filamenten bestehen, hinausragen (Flynn 2013). Neurone die keine Filopodia bilden, weil bei diesen die Polymerisation von AktinFilamenten partiell gehemmt wurde, können zwar Wachstumskegel ausbilden, allerdings ist deren Ausrichtung beeinträchtigt und stark verändert (Bentley et al. 1986), was sich zum einen in einer Beeinträchtigung des Längenwachstums und zum anderen in einer verminderten distalen Verzweigung (s. 4.5) der Neuriten widerspiegeln könnte, welches ebenfalls in dem Modell dieser Arbeit gezeigt werden konnte. Somit könnte eine beeinträchtigte Polymerisation von Aktin-Filamenten eine pathomechanistische Ursache sein. 
Zusammenschauend konnte im Rahmen dieser Arbeit gezeigt werden, dass eine Überexpression von humanem a-Syn einen ausgeprägten Einfluss auf die Morphologie und das Auswachsen neuronaler Ausläufer der dopaminergen aber auch der nichtdopaminergen Mittelhirnneurone hat. Die milde Überexpression von $\alpha-S y n-W T$ und seinen Mutationen A30P und A53T induziert eine verminderte Neuritenlänge mit einer reduzierten Verzweigung bei gesteigerter Neuriteninitiation in dopaminergen Neuronen.

Dabei spielen vermutlich verschiedene Mechanismen, wie in früheren Arbeiten teils schon diskutiert, eine wesentliche Rolle. Inwieweit diese Mechanismen für sich allein oder in Kombination diese Veränderungen auslösen, muss in weiteren Untersuchungen, die sich z. B. auf gemeinsame Signalmoleküle fokussieren, eruiert werden. Von entscheidender Bedeutung dabei sind jedoch vor allem Interaktionen zwischen a-Syn und Tubulin, Mikrotubuli und/oder Aktin und dadurch gestörte Mechanismen des zellulären sowie axonalen Transportes oder Prozesse der Autophagie. Störungen hierbei können eine Fehlverteilung von $\alpha$-Syn zwischen Soma und Synapse der Neurone bedingen, was einen toxischen Einfluss haben kann und bspw. der Grund für eine retrograde Degeneration von Neuriten oder die Progression der LK-Pathologie von den distalen Axonterminalen beginnend sein könnte, da diese Anhäufungen nicht adäquat degradiert werden können. Diese Mechanismen werden einen entscheidenden Einfluss auf die hier dargestellten Veränderungen haben. Ein besseres Verständnis dieser Zusammenhänge könnte in Zukunft für kausale Therapieansätze bei der Behandlung des IPS sorgen, indem vor dem irreversiblen Verlust von Neuronen oder pathologisch veränderten Neuriten in die Pathogenese eingegriffen werden kann. 


\section{$5 \quad$ Zusammenfassung}

Das klassische klinische Erscheinungsbild des IPS umfasst insbesondere motorische Symptome, welche auf zellulärer Ebene durch einen Dopaminmangel insbesondere in der SNpc erklärt werden. Allerdings gehen der motorischen Symptomatik, dem Dopaminmangel und dem Untergang dopaminerger Neurone zahlreiche pathologische Mechanismen auf molekularer Ebene voran, welche näher an dem eigentlich zugrunde liegenden Pathomechanismus liegen. Der Untergang einer dopaminergen Zelle steht dabei am Ende eines langen pathologischen Prozesses. Ihm voran geht bspw. eine Degeneration der zugehörigen Neuriten. Die genauen pathomechanistischen Zusammenhänge, welche zu einer Anreicherung von toxischen Substanzen, wie bspw. fehlgefaltetem $\alpha-S y n$, führen, sind dabei noch nicht vollständig verstanden. Um Therapien mit kurativem Ansatz zu entwickeln, müssen die zugrunde liegenden pathologischen Ereignisse am Anfang der Erkrankung des IPS analysiert werden. Ein therapeutischer Ansatz auf der Basis der zu Beginn dieser Erkrankung vorliegenden Pathomechanismen kann den irreversiblen Untergang der dopaminergen Neurone vermeiden und würde symptomatische Therapiestrategien in den Hintergrund drängen, wenn nicht sogar vollständig ersetzen.

In dieser Arbeit wurden die Auswirkungen einer milden Überexpression des a-Syn-WT und seinen pathogenen Isoformen A30P und A53T auf primäre Mittelhirnneurone untersucht, um die Auswirkungen auf die Neuritenmorphologie von dopaminergen und nicht-dopaminergen primären Mittelhirnneuronen zu analysieren.

Insgesamt konnte gezeigt werden, dass eine milde Überexpression vom $\alpha$-Syn-WTs und seinen Mutantionsformen das durchschnittliche Längenwachstum bei den dopaminergen und nicht-dopaminergen Neuronen vergleichbar reduziert und somit beeinträchtigt.

Sehr interessant ist, dass die latente Überexpression des a-Syn-WTs und seinen Mutantionsformen A30P und A53T die Neuriteninitiation (Neuritenanzahl, die dem Soma entspringt) bei den dopaminergen Neuronen erhöht und zwar derart, dass dadurch die Gesamtneuritenlänge unbeeinträchtigt ist, obwohl kürzere Neuriten ausgebildet wurden.

Hervorzuheben ist, dass die a-Syn-A30P-Variante auch bei den nicht-dopaminergen Neuronen eine signifikant erhöhte Neuriteninitiation (Neuritenanzahl) induziert. Insgesamt zeigte die Isoform A30P in diesem Modell somit die stärksten Effekte bei beiden Neuronenpopulationen.

Die verminderte durchschnittliche Neuritenlänge (s. 3.4.3) in den transfizierten dopaminergen und nicht-dopaminergen Neuronen spiegelt sich auch in dem abnehmenden Verzweigungsgrad in den distalen Neuritenbereichen und in dem kritischen Wert in der Sholl-Analyse wider. Somit hemmt $\alpha$-Syn in diesem Modell nicht nur das Neuritenauswachstum, sondern auch deren Verzweigung. 
Des Weiteren wurden in dieser Arbeit die Auswirkungen der leichten Überexpression auf das Neuronenüberleben und die Perikaryongröße untersucht. Die milde Überexpression des $\alpha-$ Syn-WTs und seinen Mutanten in primären Mittelhirnneuronen induziert hierbei einen vermehrten neuronalen Zelltod gleichermaßen bei den dopaminergen und nichtdopaminergen Neuronen. Die Größe der Perikarya bleibt dabei, trotz reduzierter Neuritenlänge, unbeeinflusst.

Das Wissen über die molekularbiologischen Mechanismen, welche auf dem Weg bis zur vollständigen Ausbildung eines Parkinsonsyndroms beteiligt sind, könnte genutzt werden, indem versucht wird, diese pathologischen Mechanismen positiv zu beeinflussen und darüber das Fortschreiten der Erkrankung zu verlangsamen und irreversible Neuronenverluste zu inhibieren, sodass das IPS zukünftig vielleicht kurativ behandelt werden kann. Hierbei spielen die Neuriten eine zentrale Rolle, wie in der vorliegenden Arbeit gezeigt wurde. 


\section{$6 \quad$ Literaturverzeichnis}

Abeliovich A, Schmitz Y, Fariñas I, Choi-Lundberg D, Ho WH, Castillo PE, Shinsky N, Verdugo JM, Armanini M, Ryan A et al. (2000): Mice lacking alpha-synuclein display functional deficits in the nigrostriatal dopamine system. Neuron 25(1), 239-252

Alim MA, Hossain MS, Arima K, Takeda K, Izumiyama Y, Nakamura M, Kaji H, Shinoda T, Hisanaga S, Ueda K(2002): Tubulin seeds alpha-synuclein fibril formation. J Biol Chem $\underline{277}(3), 2112-2117$

Alim MA, Ma QL, Takeda K, Aizawa T, Matsubara M, Nakamura M, Asada A, Saito T, Kaji H, Yoshii $M$ et al. (2004): Demonstration of a role for alpha-synuclein as a functional microtubule-associated protein. J Alzheimers Dis $\underline{6}(4), 435-449$

Andersen JK (2004): Oxidative stress in neurodegeneration: cause or consequence? Nat Med 10 Suppl, $18-25$

Appel-Cresswell S, Vilarino-Guell C, Encarnacion M, Sherman $H, Y u I$, Shah B, Weir D, Thompson C, Szu-Tu C, Trinh J (2013): Alpha-synuclein p.H50Q, a novel pathogenic mutation for Parkinson's disease. Mov Disord 28(6), 811-813

Arima K, Uéda K, Sunohara N, Arakawa K, Hirai S, Nakamura M, Tonozuka-Uehara H, Kawai M (1998): NACP/alpha-synuclein immunoreactivity in fibrillary components of neuronal and oligodendroglial cytoplasmic inclusions in the pontine nuclei in multiple system atrophy. Acta Neuropathol 96(5), 439-444

Bähr M, Frotscher M: Duus' neurologisch-topische Diagnostik. 8. Auflage; Thieme Verlag, Stuttgart 2003

Barbeau A (1969): L-Dopa Therapy in Parkinson's Disease A Critical Review of Nine Years' Experience. Can Med Assoc J 101(13), 59-68

Barbour R, Kling K, Anderson JP, Banducci K, Cole T, Diep L, Fox M, Goldstein JM, Soriano $F$, Seubert Pet al. (2008): Red blood cells are the major source of alpha-synuclein in blood. Neurodegener Dis $\underline{5}(2), 55-59$

Bartels T, Choi JG, Selkoe DJ (2011): a-Synuclein occurs physiologically as a helically folded tetramer that resists aggregation. Nature $\underline{477}$ (7362), 107-110

Bellucci A, Zaltieri M, Navarria L, Grigoletto J, Missale C, Spano P(2012): From a-synuclein to synaptic dysfunctions: new insights into the pathophysiology of Parkinson's disease. Brain Res $\underline{1476}, 183-202$

Bendor JT, Logan TP, Edwards RH (2013): The function of $\alpha$-synuclein. Neuron $\underline{79}(6), 1044-$ 1066

Bentley D, Toroian-Raymond A (1986): Disoriented pathfinding by pioneer neurone growth cones deprived of filopodia by cytochalasin treatment. Nature $1986 \underline{323(6090), 712-715}$

Beyer K, Domingo-Sàbat M, Ariza A (2009): Molecular pathology of Lewy body diseases. Int J Mol Sci 10(3), 724-745 
Bidwell LC, McClernon FJ, Kollins SH(2011): Cognitive enhancers for the treatment of ADHD. Pharmacol Biochem Behav 99(2), 262-274

Bisaglia M, Mammi S, Bubacco L(2009): Structural insights on physiological functions and pathological effects of alpha-synuclein. FASEB J 233(2), 329-340

Björklund A, Dunnett SB (2007): Dopamine neuron systems in the brain: an update. Trends Neurosci $\underline{30}(5), 194-202$

Bloem BR, Van Dijk JG, Beckley DJ, Roos RA, Remler MP, Bruyn GW (1992): Altered postural reflexes in Parkinson's disease: a reverse hypothesis. Med Hypotheses 39(3), 243247

Bolam JP, Pissadaki EK(2012): Living on the edge with too many mouths to feed: why dopamine neurons die. Mov Disord 27(12), 1478-1483

Bonifati V, Rizzu P, van Baren MJ, Schaap O, Breedveld GJ, Krieger E, Dekker MC, Squitieri $F$, Ibanez $P$, Joosse $M$ et al. (2003): Mutations in the DJ-1 gene associated with autosomal recessive early-onset parkinsonism. Science 299(5604), 256-259

Bonini NM, Giasson BI(2005): Snaring the function of alpha-synuclein. Cell 123(3), 359-361

Braak H, Del Tredici K(2004): Poor and protracted myelination as a contributory factor to neurodegenerative disorders. Neurobiol Aging 25(1), 19-23

Braak H, Del Tredici K(2009): Neuroanatomy and pathology of sporadic Parkinson's disease. Adv Anat Embryol Cell Biol 201, 1-119

Braak H, Braak E, Yilmazer D, de Vos RA, Jansen EN, Bohl J, Jellinger K(1994): Amygdala pathology in Parkinson's disease. Acta Neuropathol 88(6), 493-500

Braak H, Del Tredici K, Rüb U, de Vos RA, Jansen Steur EN, Braak E(2003): Staging of brain pathology related to sporadic Parkinson's disease. Neurobiol Aging 24(2), 197-211

Braak H, Sastre M, Bohl JR, de Vos RA, Del Tredici K (2007): Parkinson's disease: lesions in dorsal horn layer $I$, involvement of parasympathetic and sympathetic pre and postganglionic neurons. Acta Neuropathol 113(4), 421-429

Bravo SA, Rangel-Barajas C, Garduño BF: Pathophysiology of L-Dopa Induced Dyskinesia - Changes in D1/D3 Receptors and Their Signaling Pathway; in A Synopsis of Parkinson's Disease; hrsg. v. Dr. Abdul Qayyum Rana; InTech, London 2014

Burda H, Bayer P, Zrzavý J: Humanbiologie. 1. Auflage; Utb Basics, Eugen Ulmer, Stuttgart 2014

Burke RE, O'Malley K(2013): Axon degeneration in Parkinson's disease. Exp Neurol $\underline{246}$, $72-83$

Burré J, Sharma M, Tsetsenis T, Buchman V, Etherton MR, Südhof TC(2010): Alphasynuclein promotes SNARE-complex assembly in vivo and in vitro. Science $\underline{329}$ (5999), 1663-1667 
Cabin DE, Shimazu K, Murphy D, Cole NB, Gottschalk W, Mcllwain KL, Orrison B, Chen A, Ellis CE, Paylor $R$ et al.(2002): Synaptic vesicle depletion correlates with attenuated synaptic responses to prolonged repetitive stimulation in mice lacking alpha-synuclein. $J$ Neurosci 22(20), 8797-8807

Calabresi P, Picconi B, Tozzi A, Ghiglieri V, Di Filippo $M$ (2014): Direct and indirect pathways of basal ganglia: a critical reappraisal. Nat Neurosci 17(8), 1022-1030

Campion D, Martin C, Heilig R, Charbonnier F, Moreau V, Flaman JM, Petit JL, Hannequin $D$, Brice A, Frebourg T(1995): The NACP/synuclein gene: chromosomal assignment and screening for alterations in Alzheimer disease. Genomics $\underline{26}$ (2), 254-257

Carboni E, Lingor P (2015): Insights on the interaction of alpha-synuclein and metals in the pathophysiology of Parkinson's disease. Metallomics $\underline{7}(3), 395-404$

Carmona A, Devès G, Roudeau S, Cloetens P, Bohic S, Ortega R(2010): Manganese accumulates within golgi apparatus in dopaminergic cells as revealed by synchrotron $X$-ray fluorescence nanoimaging. ACS Chem Neurosci 11(3), 194-203

Caudle WM, Guillot TS, Lazo CR, Miller GW(2012): Industrial toxicants and Parkinson's disease. Neurotoxicology $\underline{33}(2), 178-188$

Cesnulevicius K, Timmer M, Wesemann M, Thomas T, Barkhausen T, Grothe C (2006): Nucleofection is the most efficient nonviral transfection method for neuronal stem cells derived from ventral mesencephali with no changes in cell composition or dopaminergic fate. Stem Cells 24 (12), 2776-2791

Chalfie M, Tu Y, Euskirchen G, Ward WW, Prasher DC (1994): Green fluorescent protein as a marker for gene expression. Science 263(5148), 802-805

Chandra S, Gallardo G, Fernández-Chacón R, Schlüter OM, Südhof TC(2005): Alphasynuclein cooperates with CSPalpha in preventing neurodegeneration. Cell 123(3), 383-396

Chartier-Harlin MC, Kachergus J, Roumier C, Mouroux V, Douay X, Lincoln S, Levecque C, Larvor L, Andrieux J, Hulihan M (2004): Alpha-synuclein locus duplication as a cause of familial Parkinson's disease. Lancet 364(9440), 1167-1169

Chaudhuri KR, Schapira AH(2009): Non-motor symptoms of Parkinson's disease: dopaminergic pathophysiology and treatment. Lancet Neurol $\underline{8}(5), 464-474$

Chen L, Jin J, Davis J, Zhou Y, Wang Y, Liu J, Lockhart PJ, Zhang J (2007): Oligomeric alpha-synuclein inhibits tubulin polymerization. Biochem Biophys Res Commun $\underline{356}$ (3), 548553

Cheng HC, Ulane CM, Burke RE (2010): Clinical progression in Parkinson disease and the neurobiology of axons. Ann Neurol $\underline{67}(6), 715-725$

Chu Y, Kordower JH (2007): Age-associated increases of alpha-synuclein in monkeys and humans are associated with nigrostriatal dopamine depletion: Is this the target for Parkinson's disease? Neurobiol Dis 25 (1), 134-149

Coleman MP, Freeman MR (2010): Wallerian degeneration, wld(s), and nmnat.Annu Rev Neurosci33, 245-267 
Conway KA, Harper JD, Lansbury PT (1998): Accelerated in vitro fibril formation by a mutant alpha-synuclein linked to early-onset Parkinson disease. Nat Med $\underline{4}, 1318-1320$

Conway KA, Lee S-J, Rochet J-C, Ding TT, Williamson RE, Lansbury PT Jr (2000): Acceleration of oligomerization, not fibrillization, is a shared property of both a-synuclein mutations limked to early-onset Parkinson's disease: Implications for pathogenesis and therapy. Proc Natl Acad Sci U S A 97(2), 571-576

Cookson MR (2009): alpha-Synuclein and neuronal cell death. Mol Neurodegener $\underline{4}, 9$

Cooper AA, Gitler AD, Cashikar A, Haynes CM, Hill KJ, Bhullar B, Liu K, Xu K, Strathearn KE, Liu Fet al. (2006): Alpha-synuclein blocks ER-Golgi traffic and Rab1 rescues neuron loss in Parkinson's models. Science $\underline{313}$ (5785), 324-328

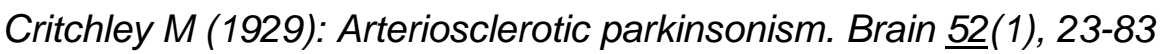

Cuervo AM, Stefanis L, Fredenburg R, Lansbury PT, Sulzer D(2004): Impaired degradation of mutant alpha-synuclein by chaperone-mediated autophagy. Science 305(5688), 12921295

Cuervo AM, Bergamini E, Brunk UT, Dröge W, Ffrench M, Terman A(2005): Autophagy and aging: the importance of maintaining "clean" cells. Autophagy 1 (3), 131-140

Dahlstroem A, Fuxe K (1964): Evidence for the existence of monoamine-containing neurons in the central nervous system. I. Demonstration of monoamines in the cell bodies of brain stem neurons. Acta Physiol Scand Suppl 232, 1-55

Damier P, Hirsch EC, Agid Y, Graybiel AM (1999): The substantia nigra of the human brain. II. Patterns of loss of dopamine-containing neurons in Parkinson's disease. Brain 122(Pt8), 1437-1448

Danzer KM, Krebs SK, Wolff M, Birk G, Hengerer B (2009): Seeding induced by alphasynuclein oligomers provides evidence for spreading of alpha-synuclein pathology. $J$ Neurochem 111(1), 192-203

de Lau LM, Koudstaal PJ, Hofman A, Breteler MM(2006): Serum cholesterol levels and the risk of Parkinson's disease. Am J Epidemiol 164(10), 998-1002

Del Tredici K, Hawkes CH, Ghebremedhin E, Braak H (2010): Lewy pathology in the submandibular gland of individuals with incidental Lewy body disease and sporadic Parkinson's disease. Acta Neuropathol 119(6), 703-713

Deleersnijder A, Gerard M, Debyser Z, Baekelandt V(2013): The remarkable conformational plasticity of alpha-synuclein: blessing or curse? Trends Mol Med 19(6), 368-377

Demasi M, Davies KJ (2003): Proteasome inhibitors induce intracellular protein aggregation and cell death by an oxygen-dependent mechanism. FEBS Lett 542(1-3), 89-94

DGN-Leitlinien 2016 zur Diagnostik und Therapie in der Neurologie: Idiopathisches Parkinsonsyndrom. o. Verl., o. O. 2016

Dice JF(1990): Peptide sequences that target cytosolic proteins for lysosomal proteolysis. Trends Biochem Sci 15(8), 305-309 
Ding Q, Keller JN (2001): Proteasome inhibition in oxidative stress neurotoxicity: implications for heat shock proteins. J Neurochem $\underline{77}(4), 1010-1017$

Dohm CP, Kermer P, Bähr M (2008): Aggregopathy in neurodegenerative diseases: mechanisms and therapeutic implication. Neurodegener Dis $\underline{5}(6), 321-338$

Dorsey ER, Constantinescu R, Thompson JP, Biglan KM, Holloway RG, Kieburtz K, Marshall FJ, Ravina BM, Schifitto G, Siderowf Aet al. (2007): Projected number of people with Parkinson disease in the most populous nations, 2005 through 2030. Neurology 68(5), 384386

Driver JA, Logroscino G, Gaziano JM, Kurth T(2009): Incidence and remaining lifetime risk of Parkinson disease in advanced age. Neurology 72(5), 432-438

Dubach M: Telencephalic dopamine cells in monkeys, humans and rats; in: Phylogeny and Development of Catecholamine System in the CNS of Vertebrates. hrsg. v.Wilhelmus JAJ Smeets WJAJ und Reiner A unter Mitarbeit namhafter Autoren; Cambridge University Press, Cambridge 1994, 273-292

Duda JE, Giasson BI, Mabon ME, Lee VM, Trojanowski JQ (2002): Novel antibodies to synuclein show abundant striatal pathology in Lewy body diseases. Ann Neurol 52(2), 205210

Edwards TL, Scott WK, Almonte C, Burt A, Powell EH, Beecham GW, Wang L, Züchner S, Konidari I, Wang G et al. (2010): Genome-wide association study confirms SNPs in SNCA and the MAPT region as common risk factors for Parkinson disease. Ann Hum Genet 74(2), 97-109

Esposito A, Dohm CP, Kermer P, Bahr M, Wouters FS (2007): alpha-Synuclein and its disease-related mutants interact differentially with the microtubule protein tau and associate with the actin cytoskeleton. Neurobiol Dis $\underline{26}(3), 521-531$

Faucheux BA, Martin ME, Beaumont C, Hauw JJ, Agid Y, Hirsch EC (2003): Neuromelanin associated redox-active iron is increased in the substantia nigra of patients with Parkinson's disease. J Neurochem $\underline{86}(5), 1142-1148$

Feany MB, Bender WW (2000): A Drosophila model of Parkinson's disease. Nature 404(6776), 394-398

Fearnley JM, Lees AJ(1991): Ageing and Parkinson's disease: substantia nigra regional selectivity. Brain 114(Pt5), 2283-2301

Felten DL, Sladek JR Jr(1983): Monoamine distribution in primate brain V. Monoaminergic nuclei: anatomy, pathways and local organization. Brain Res Bull 10(2), 171-284

Flanagan LA, Rebaza LM, Derzic S, Schwartz PH, Monuki ES(2006): Regulation of human neural precursor cells by laminin and integrins. J Neurosci Res 83(5), 845-856

Flynn KC (2013): The cytoskeleton and neurite initiation. Bioarchitecture $\underline{3}(4), 86-109$

Fortin DL, Troyer MD, Nakamura K, Kubo S, Anthony MD, Edwards RH(2004): Lipid rafts mediate the synaptic localization of alpha-synuclein. J Neurosci 24(30), 6715-6723 
Friedman LG, Lachenmayer ML, Wang J, He L, Poulose SM, Komatsu M, Holstein GR, Yue Z(2012): Disrupted autophagy leads to dopaminergic axon and dendrite degeneration and promotes presynaptic accumulation of $\alpha$-synuclein and LRRK2 in the brain. J Neurosci 32(22), 7585-7593

Gagne JJ, Power MC (2010): Anti-inflammatory drugs and risk of Parkinson disease: a meta-analysis. Neurology $\underline{74}$ (12), 995-1002

Gallegos S, Pacheco C, Peters C, Opazo CM, Aguayo LG(2015): Features of alphasynuclein that could explain the progression and irreversibility of Parkinson's disease. Front Neurosci $\underline{9}, 59$

Galpern WR, Lang AE(2006): Interface between tauopathies and synucleinopathies: a tale of two proteins. Ann Neurol 59(3), 449-458

Galvin JE, Uryu K, Lee VM, Trojanowski JQ(1999): Axon pathology in Parkinson's disease and Lewy body dementia hippocampus contains alpha-, beta-, and gamma-synuclein. Proc

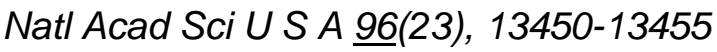

Gassmann M, Grenacher B, Rohde B, Vogel J (2009): Quantifying Western blots: pitfalls of densitometry. Electrophoresis $\underline{30}(11), 1845-1855$

George JM(2002): The synucleins. Genome Biol. 3(1), REVIEWS3002

George JM, Jin H, Woods WS, Clayton DF(1995): Characterization of a novel protein regulated during the critical period for song learning in the zebra finch. Neuron 15(2), 361372

Ghebremedhin E, Del Tredici K, Langston JW, Braak H (2009): Diminished tyrosine hydroxylase immunoreactivity in the cardiac conduction system and myocardium in Parkinson's disease: an anatomical study. Acta Neuropathol 118(6), 777-784

Giasson BI, Duda JE, Quinn SM, Zhang B, Trojanowski JQ, Lee VM (2002): Neuronal alphasynucleinopathy with severe movement disorder in mice expressing A53T human alphasynuclein. Neuron 34(4), 521-533

Giasson BI, Lee VM, Trojanowski JQ(2003): Interactions of amyloidogenic proteins. Neuromolecular Med 4 (1-2), 49-58

Goedert M, Spillantini MG, Del Tredici K, Braak H(2013): 100 years of Lewy pathology. Nat Rev Neurol $\underline{9}(1), 13-24$

Goldberg MS, Lansbury PT Jr (2000): Is there a cause-and-effect relationship between alpha-synuclein fibrillization and Parkinson's disease? Nature Cell Biology 2(7), 115-119

Goldman SM, Quinlan PJ, Ross GW, Marras C, Meng C, Bhudhikanok GS, Comyns K, Korell M, Chade AR, Kasten Met al (2012): Solvent exposures and Parkinson disease risk in twins. Ann Neurol 71(6), 776-784

Gordon-Weeks PR (1991): Control of microtubule assembly in growth cones. Journal o f Cell Science Suppl 15, $45-49$ 
Gosavi N, Lee HJ, Lee JS, Patel S, Lee SJ (2002): Golgi fragmentation occurs in the cells with prefibrillar alpha-synuclein aggregates and precedes the formation of fibrillar inclusion. $J$ Biol Chem 277(50), 48984-48992

Gstraunthaler G, Lindl T: Zell- und Gewebekultur: Allgemeine Grundlagen und spezielle Anwendungen. 7.Auflage; Springer-Verlag Berlin, Heidelberg 2013

Harding AJ, Stimson E, Henderson JM, Halliday GM (2002): Clinical correlates of selective pathology in the amygdala of patients with Parkinson's disease. Brain 125(Pt11), 2431-2445

Hernán MA, Takkouche B, Caamaño-Isorna F, Gestal-Otero JJ(2002): A meta-analysis of coffee drinking, cigarette smoking, and the risk of Parkinson's disease. Ann Neurol 52(3),276-284

Herting B, Bietenbeck S, Scholz K, Hähner A, Hummel T, Reichmann H(2008): [Olfactory dysfunction in Parkinson's disease: its role as a new cardinal sign in early and differential diagnosis]. Nervenarzt $\underline{79}(2), 175-184$

Hirsch E, Graybiel AM, Agid YA (1988): Melanized dopaminergic neurons are differentially susceptible to degeneration in Parkinson's disease. Nature 334(6180), 345-348

Huang X, Abbott RD, Petrovitch H, Mailman RB, Ross GW(2008): Low LDL cholesterol and increased risk of Parkinson's disease: prospective results from Honolulu-Asia Aging Study. Mov Disord 23(7), 1013-1018

Hughes AJ, Daniel SE, Kilford L, Lees AJ(1992): Accuracy of clinical diagnosis of idiopathic Parkinson's disease: a clinico-pathological study of 100 cases. J Neurol Neurosurg Psychiatry 55(3), 181-184

Iwai A, Masliah E, Yoshimoto M, Ge N, Flanagan L, de Silva HA, Kittel A, Saitoh T(1995): The precursor protein of non-A beta component of Alzheimer's disease amyloid is a presynaptic protein of the central nervous system. Neuron 14(2), 467-475

Iwanaga K, Wakabayashi K, Yoshimoto M, Tomita I, Satoh H, Takashima H, Satoh A, Seto $M$, Tsujihata M, Takahashi $H$ (1999): Lewy body type degeneration in cardiac plexus in

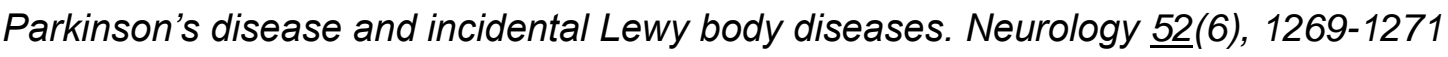

Javitch JA, D'Amato RJ, Strittmatter SM, Snyder SH(1985): Parkinsonism-inducing neurotoxin, $N$-methyl-4-phenyl-1,2,3,6 -tetrahydropyridine: uptake of the metabolite $N$ methyl-4-phenylpyridine by dopamine neurons explains selective toxicity. Proc Natl Acad Sci U S A $\underline{\text { 82(7), 2173-2177 }}$

Jellinger KA (2005): Neurodegenerative Erkrankungen (ZNS) - Eine aktuelle Übersicht. J Neurol Neurochir Psychiatr $\underline{6(1)}$, 9-18

Jenner P, Olanow CW (1998): Understanding cell death in Parkinson's disease. Ann Neurol 44 (3Supp/1), 72-84

Jensen PH, Nielsen MS, Jakes R, Dotti CG, Goedert M (1998): Binding of alpha-synuclein to brain vesicles is abolished by familial Parkinson's disease mutation. J Biol Chem 273(41), 26292-26294 
Jensen PH, Hager H, Nielsen MS, Hojrup P, Gliemann J, Jakes R (1999a): alpha-synuclein binds to Tau and stimulates the protein kinase A-catalyzed tau phosphorylation of serine residues 262 and 356. J Biol Chem 274(36), 25481-25489

Jensen PH, Li, JY, Dahlstrom A, Dottin CG (1999b): Axonal transport of synucleins is mediated by all rate components. Eur J Neurosci 11(10), 3369-3376

Jo E, Fuller N, Rand RP, St George-Hyslop P, Fraser PE (2002): Defective membrane interactions of familial Parkinson's disease mutant A30P alpha-synuclein. J Mol Biol 315(4), 799-807

Joshi HC, Chu D, Buxbaum RE, Heidemann SR (1985): Tension and compression in the cytoskeleton of PC 12 neurites. J Cell Biol 101(3), 697-705

Kahle PJ, Neumann M, Ozmen L, Muller V, Jacobsen H, Schindzielorz A, Okochi M, Leimer $U$, van Der Putten H, Probst Aet al. (2000): Subcellular localization of wild-type and Parkinson's disease-associated mutant alpha -synuclein in human and transgenic mouse brain. J Neurosci 20(17), 6365-6373

Kanazawa T, Uchihara T, Takahashi A, Nakamura A, Orimo S, Mizusawa H (2008): Threelayered structure shared between Lewy bodies and lewy neurites-three-dimensional reconstruction of triple-labeled sections. Brain Pathol 18(3), 415-422

Kanazawa T, Adachi E, Orimo S, Nakamura A, Mizusawa H, Uchihara $T$ (2012): Pale neurites, premature $\alpha$-synuclein aggregates with centripetal extension from axon collaterals. Brain Pathol 22(1), 67-78

Karpinar DP, Balija MB, Kügler S, Opazo $F$, Rezaei-Ghaleh $N$, Wender $N$, Kim HY, Taschenberger G, Falkenburger BH, Heise H (2009): Pre-fibrillar alpha-synuclein variants with impaired beta-structure increase neurotoxicity in Parkinson's disease models. EMBO J 28(20), 3256-3268

Kim CS, Sung YH, Kang MJ, Park KH(2016): Rapid Eye Movement Sleep Behavior Disorder in Parkinson's Disease: A Preliminary Study. J Mov Disord 9(2), 114-119

Kim HY, Cho MK, Kumar A, Maier E, Siebenhaar C, Becker S, Fernandez CO, Lashuel HA, Benz R, Lange $A$ et al. (2009): Structural properties of pore-forming oligomers of alphasynuclein. J Am Chem Soc 131(47), 17482-17489

Kim TD, Paik SR, Yang CH (2002): Structural and functional implications of C-terminal regions ofalpha-synuclein.Biochemistry 41 (46), 13782-13790

Kim YS, Joh TH (2006): Microglia, major player in the brain inflammation: their roles in the pathogenesis of Parkinson's disease. Exp Mol Med 38(4), 333-347

Kingsbury AE, Daniel SE, Sangha H, Eisen S, Lees AJ, Foster OJ (2004): Alteration in alpha-synuclein mRNA expression in Parkinson's disease. Mov Disord 19(2), 162-170

Kirik D, Annett LE, Burger C, Muzyczka N, Mandel RJ, Björklund A (2003): Nigrostriatal alpha-synucleinopathy induced by viral vector-mediated overexpression of human alphasynuclein: a new primate model of Parkinson's disease. Proc Natl Acad Sci U S A 100(5), 2884-2889 
Kitada T, Asakawa S, Hattori N, Matsumine H, Yamamura Y, Minoshima S, Yokochi M, Mizuno $Y$, Shimizu N(1998): Mutations in the parkin gene cause autosomal recessive juvenile parkinsonism. Nature 392(6676), 605-608

Klebe S (2014): Sekundäre Parkinsonsyndrome. J Neurol Neurochir Psychiatr 15(2), 69-75

Koch JC, Barski E, Lingor P, Bähr M, Michel U (2011): Plasmids containing NRSE/RE1 sites enhance neurite outgrowth of retinal ganglion cells via sequestration of REST independent of NRSE dsRNA expression. FEBS J 278(18), 3472-3483

Kokhan VS, Afanasyeva MA, Van'kin GI(2012): a-Synuclein knockout mice have cognitive impairments. Behav Brain Res 231(1), 226-230

Kramer ML, Schulz-Schaeffer WJ (2007): Presynaptic alpha-synuclein aggregates, not Lewy bodies, cause neurodegeneration in dementia with Lewy bodies. J Neurosci $\underline{27}(6), 1405-$ 1410

Krieglstein K, Suter-Crazzolara C, Fischer WH, Unsicker K (1995): TGF-beta superfamily members promote survival of midbrain dopaminergic neurons and protect them against $M P P+$ toxicity. EMBO J 14(4), 736-742

Krüger R, Kuhn W, Müller T, Woitalla D, Graeber M, Kösel S, Przuntek H, Epplen JT, Schöls L, Riess O (1998): Ala30Pro mutation in the gene encoding alpha-synuclein in Parkinson's disease. Nat Genet 18(2), 106-108

Kutzing MK, Firestein BL(2008): Altered uric acid levels and disease states. J Pharmacol Exp Ther 324(1), 1-7

Lang AE, Lozano AM(1998): Parkinson's disease. First of two parts. $N$ Engl J Med 339(15), 1044-1053

Langston JW, Ballard P, Tetrud JW, Irwin I(1983): Chronic Parkinsonism in humans due to a product of meperidine-analog synthesis. Science 219(4587), 979-980

Lauwers E, Debyser Z, Van Dorpe J, De Strooper B, Nuttin B, Baekelandt V (2003): Neuropathology and neurodegeneration in rodent brain induced by lentiviral vector-mediated overexpression of alpha-synuclein. Brain Pathol 13(3), 364-372

Lavedan C(1998): The synuclein family. Genome Res $\underline{8}(9), 871-880$

Lee HJ, Choi C, Lee SJ(2002): Membrane-bound alpha-synuclein has a high aggregation propensity and the ability to seed the aggregation of the cytosolic form. J Biol Chem 277(1), 671-678

Lee HJ, Khoshaghideh F, Lee S, Lee SJ (2006): Impairment of microtubule-dependent trafficking by overexpression of alpha-synuclein. Eur J Neurosci 24(11), 3153-3162

Leitlinie Idipathisches Parkinsonsyndrom. s. DGN-Leitlinie 2016

Leroy E, Boyer R, Auburger G, Leube B, Ulm G, Mezey E, Harta G, Brownstein MJ, Jonnalagada S, Chernova $T$ et al (1998): The ubiquitin pathway in Parkinson's disease. Nature 395(6701), 451-452 
Lesage S, Anheim M, Letournel F, Bousset L, Honoré A, Rozas N, Pieri L, Madiona K, Dürr $A$, Melki $R$ (2013): G51D $\alpha$ - synuclein mutation causes a novel parkinsonian-pyramidal syndrome. Ann Neurol 73(4), 459-471

Lewy F: Paralysis agitans; n: Handbuch der Neurologie, Band I: Pathologische Anatomie; hrsg. v. Lewandowsky M; SpringerVerlag, Berlin 1912, 920-933

Li W, West N, Colla E, Pletnikova O, Troncoso JC, Marsh L, Dawson TM, Jäkälä P, Hartmann T, Price DLet al. (2005): Aggregation promoting C-terminal truncation of alphasynuclein is a normal cellular process and is enhanced by the familial Parkinson's diseaselinked mutations. Proc Natl Acad Sci U S A 102(6), 2162-2167

Lim SY, Lang AE (2010): The nonmotor symptoms of Parkinson's disease--an overview. Mov Disord 25 Suppl 1, 123-130

Lindersson E, Beedholm R, Højrup P, Moos T, Gai W, Hendil KB, Jensen PH (2004): Proteasomal inhibition by alpha-synuclein filaments and oligomers. J Biol Chem 279(13), 12924-12934

Lingor P, Liman J, Kallenberg K, Sahlmann CO, Bähr M: Diagnosis and differential diagnosis of Parkinson's disease; in: Diagnosis and Treatment of Parkinson's Disease; hrsg. v. Rana AQ; InTech Europe, Rijeka 2011, 1-20

Liu G, Zhang C, Yin J, Li X, Cheng F, Li Y, Yang H, Uéda K, Chan P, Yu S(2009): alphaSynuclein is differentially expressed in mitochondria from different rat brain regions and dose-dependently down-regulates complex I activity. Neurosci Lett $\underline{454(3), ~ 187-192 ~}$

Liu G, Wang P, Li X, Li Y, Xu S, Ueda K, Chan P, Yu S (2013): Alpha-synuclein promotes early neurite outgrowth in cultered primary neurons. J Neural Transm 120(9), 1331-1343

Lowe J, McDermott H, Landon M, Mayer RJ, Wilkinson KD(1990): Ubiquitin carboxylterminal hydrolase (PGP 9.5) is selectively present in ubiquitinated inclusion bodies characteristic of human neurodegenerative diseases. J Pathol 161(2), 153-160

Lüllmann-Rauch R:Taschenlehrbuch Histologie. 3. Auflage; Georg Thieme Verlag KG, Stuttgart 2009

Luo L, O'Leary DD(2005): Axon retraction and degeneration in development and disease. Annu Rev Neurosci 28, 127-156

Lv Z, Qi H, Wang L, Fan X, Han F, Wang H, Bi S(2014): Vitamin D status and Parkinson's disease: a systematic review and meta-analysis. Neurol Sci 35(11), 1723-1730

Maasho K, Marusina A, Reynolds NM, Coligan JE, Borrego F (2004): Efficient gene transfer into the human natural killer cell line, NKL, using the Amaxa nucleofection system. $J$ Immunol Methods 284(1-2), 133-140

Madine J, Doig AJ, Middleton DA(2006): A study of the regional effects of alpha-synuclein on the organization and stability of phospholipid bilayers. Biochemistry $\underline{45}$ (18), 5783-5792

Markey SP, Johannessen JN, Chiueh CC, Burns RS, Herkenham MA (1984): Intraneuronal generation of a pyridinium metabolite may cause drug-induced parkinsonism. Nature 311(5985), 464-467 
Maroteaux L, Campanelli JT, Scheller RH(1988): Synuclein: a neuronspecific protein localized to the nucleus and presynaptic nerve terminal. J Neurosci $\underline{8}(8), 2804-2815$

Martinez-Vicente M, Talloczy Z, Kaushik S, Massey AC, Mazzulli J, Mosharov EV, Hodara $R$, Fredenburg R, Wu DC, Follenzi $A$ et al. (2008): Dopamine-modified alpha-synuclein blocks chaperone-mediated autophagy. J Clin Invest 118(2), 777-788

Masliah E, Rockenstein E, Veinbergs I, Mallory M, Hashimoto M, Takeda A, Sagara Y, Sisk A, Mucke L (2000): Dopaminergic loss and inclusion body formation in a-synuclein mice: Implications for neurodegenerative disorders. Science 287(5456), 1265-1269

Matsuda W, Furuta T, Nakamura KC, Hioki H, Fujiyama F, Arai R, Kaneko T(2009): Single nigrostriatal dopaminergic neurons form widely spread and highly dense axonal arborizations in the neostriatum. J Neurosci 29(2), 444-453

McLean PJ, Kawamata H, Ribich S, Hyman BT (2000):Membrane association and protein conformation of alpha-synuclein in intact neurons. Effect of Parkinson's disease-linked mutations. J Biol Chem 275(12), 8812-8816

Middleton ER, Rhoades E(2011): Effects of curvature and composition on a-synuclein binding to lipid vesicles. Biophys J 99(7), 2279-2288

Millecamps S, Julien JP(2013): Axonal transport deficits and neurodegenerative diseases. Nat Rev Neurosci 14(3), 161-176

Morawski M, Meinecke C, Reinert T, Dörffel AC, Riederer P, Arendt T, Butz T (2005): Determination of trace elements in the human substantia nigra. Nucl Instrum Meth B 231(14), 224-228

Mülhardt C: Der Experimentator Molekularbiologie/Genomics.6. Auflage; Springer Spektrum, Berlin 2008

Murphy DD, Rueter SM, Trojanowski JQ, Lee VM (2000): Synucleins are developmentally expressed, and alpha-synuclein regulates the size of the presynaptic vesicular pool in primary hippocampal neurons. J Neurosci 20(9), 3214-3220

Nemani VM, Lu W, Berge V, Nakamura K, Onoa B, Lee MK, Chaudhry FA, Nicoll RA, Edwards $R H$ (2010): Increased expression of alpha-synuclein reduces neurotransmitter release by inhibiting synaptic vesicle reclustering after endocytosis. Neuron 65(1), 66-79

Nestler EJ, Hyman SE, Malenka RC: Chapter 13: Higher Cognitive Function and Behavioral Control; in: Molecular neuropharmacology: a foundation for clinical neuroscience. 2. Auflage; hrsg. v. Syder A, Brown RY; McGraw-Hill Professionel, New York 2008, 313-334

Nicklas WJ, Vyas I, Heikkila RE(1985): Inhibition of NADH-linked oxidation in brain mitochondria by 1-methyl-4-phenyl-pyridine, a metabolite of the neurotoxin, 1-methyl-4phenyl-1,2,5,6-tetrahydropyridine. Life Sci 36(26), 2503-2508

Orimo S, Amino T, Itoh $Y$, Takahashi A, Kojo T, Uchihara $T$, Tsuchiya K, Mori $F$, Wakabayashi K, Takahashi $H$ (2005): Cardiac sympathetic denervation precedes neuronal loss in the sympathetic ganglia in Lewy body disease. Acta Neuropathol 109(6), 583-588 
Orimo S, Uchihara T, Nakamura A, Mori F, Kakita A, Wakabayashi K, Takahashi H(2008): Axonal alpha-synuclein aggregates herald centripetal degeneration of cardiac sympathetic nerve in Parkinson's disease. Brain 131(Pt3), 642-650

Palchevskiy V, Finkel SE(2006): Escherichia coli competence gene homologs are essential for competitive fitness and the use of DNA as a nutrient. J Bacteriol 188(11), 3902-3910

Pan-Montojo F, Schwarz M, Winkler C, Arnhold M, O'Sullivan GA, Pal A, Said J, Marsico G, Verbavatz JM, Rodrigo-Angulo Met al. (2012): Environmental toxins trigger PD-like progression via increased alpha-synuclein release from enteric neurons in mice. Sci Rep $\underline{2}, 898$

Parkinson J: An essay on the shaking palsy. Sherwood, Neely, und Jones, London 1817

Paxinos G: The rat nervous system.3. Auflage; Elsevier, San Diego Californien U S A 2004

Pirker W, Brücke T (2004): SPECT in der Diagnostik von Parkinsonsyndromen. J Neurol Neurochir Psychiatr $\underline{5}(2), 9-20$

Pissadaki EK, Bolam JP (2013): The energy cost of action potential propagation in dopamine neurons: clues to susceptibility in Parkinson's disease. Front Comput Neurosci $\underline{7}, 13$

Polymeropoulos MH, Lavedan C, Leroy E, Ide SE, Dehejia A, Dutra A, Pike B, Root H, Rubenstein J, Boyer $R$ et al. (1997): Mutation in the alpha-synuclein gene identified in families with Parkinson's disease. Science 276(5321), 2045-2047

Pouclet H, Lebouvier $T$, Coron E, des Varannes SB, Rouaud $T$, Roy $M$, Neunlist $M$, Derkinderen $P$ (2012): A comparison between rectal and colonic biopsies to detect Lewy pathology in Parkinson's disease. Neurobiol Dis 45 (1), 305-309

Prots I, Veber V, Brey S, Campioni S, Buder K, Riek R, Böhm KJ, Winner B(2013): $\alpha$ Synuclein oligomers impair neuronal microtubule-kinesin interplay. J Biol Chem 288(30), 21742-21754

Raff MC, Whitmore AV, Finn JT(2002): Axonal self-destruction and neurodegeneration. Science 296(5569), 868-871

Ramsay RR, Dadgar J, Trevor A, Singer TP (1986): Energy-driven uptake of N-methyl-4phenylpyridine by brain mitochondria mediates the neurotoxicity of MPTP. Life Sci 39(7), 581-588

Rekas A, Ahn KJ, Kim J, Carver JA (2012): The chaperone activity of $\alpha$-synuclein: Utilizing deletion mutants to map its interaction with target proteins. Proteins. 10 (5), 1316-1325

Rideout HJ, Larsen KE, Sulzer D, Stefanis L (2001): Proteasomal inhibition leads to formation of ubiquitin/alpha-synuclein-immunoreactive inclusions in PC12 cells. J Neurochem $\underline{78}(4), 899-908$

Rochet JC, Outeiro TF, Conway KA, Ding TT, Volles MJ, Lashuel HA, Bieganski RM, Lindquist SL, Lansbury PT(2004): Interactions among alpha-synuclein, dopamine, and biomembranes: some clues for understanding neurodegeneration in Parkinson's disease. $J$ Mol Neurosci 23(1-2), 23-34 
Saal KA, Koch JC, Tatenhorst L, Szegö EM, Ribas VT, Michel U, Bähr M, Tönges L, Lingor $P$ (2015): AAV.shRNA-mediated downregulation of ROCK2 attenuates degeneration of dopaminergic neurons in toxin-induced models of Parkinson's disease in vitro and in vivo. Neurobiol Dis $\underline{73}, 150-162$

Saha AR, Hill J, Utton MA, Asuni AA, Ackerley S, Grierson AJ, Miller CC, Davies AM, Buchman VL, Anderton BH et al. (2004): Parkinson's disease alpha-synuclein mutations exhibit defective axonal transport in cultured neurons. J Cell Sci 117(Pt7), 1017-1024

Sambrook JF, Russell DW: Molecular Cloning. A laboratory manual. 3. Auflage; Cold Spring Harbor Laboratory Press, Cold Spring Harbor, New York 2001

Sato H, Kato T, Arawaka S(2013): The role of Ser129 phosphorylation of a-synuclein in neurodegeneration of Parkinson's disease: a review of in vivo models. Rev Neurosci 24(2), 115-123

Schlesinger I, Schlesinger N(2008): Uric acid in Parkinson's disease. Mov Disord 23(12), 1653-1657

Schmitz S: Der Experimentator: Zellkultur. 3.Auflage; Spektrum akademischer Verlag, Heidelberg 2011, 72-74

Schröder KF, Hopf A, Lange H, Thörner G (1975): Morphometrical-statistical structure analysis of human striatum, pallidum and subthalamic nucleus. J Hirnforsch 16 (4), 333-350

Schultz W (2007): Multiple dopamine functions at different time courses. Annu Rev Neurosci 30, 259-288

Schwarzschild MA, Schwid SR, Marek K, Watts A, Lang AE, Oakes D, Shoulson I, Ascherio A; Parkinson Study Group PRECEPT Investigators, Hyson C(2008): Serum urate as a predictor of clinical and radiographic progression in Parkinson disease. Arch Neurol 65(6), 716-723

Serpell LC, Berriman J, Jakes R, Goedert M, Crowther RA(2000): Fiber diffraction of synthetic alpha-synuclein filaments shows amyloid-like cross-beta conformation. Proc Natl Acad Sci U S A 97(9), 4897-4902

Shen L, Ji HF(2013): Low uric acid levels in patients with Parkinson's disease: evidence from meta-analysis. BMJ Open $\underline{3}(11)$, e003620

Shimoda K, Sauve Y, Marini A, Schwartz JP, Commissiong JW (1992): A high percentage yield of tyrosine hydroxylase-positive cells from rat E14 mesencephalic cell culture. Brain Res $\underline{586}(2), 319-331$

Shine JM, Naismith SL, Lewis SJ (2011): The pathophysiological mechanisms underlying freezing of gait in Parkinson's Disease. J Clin Neurosci 18(9), 1154-1157

Sholl DA (1953): Dendritic organization in the neurons of the visual and motor cortices of the cat. J Anat $\underline{87}(4)$, 387-406

Simon KC, Chen $H$, Schwarzschild M, Ascherio A(2007): Hypertension, hypercholesterolemia, diabetes, and risk of Parkinson disease. Neurology $\underline{69}(17), 1688-$ 1695 
Singleton $A B$, Farrer $M$, Johnson $J$, Singleton $A$, Hague $S$, Kachergus $J$, Hulihan $M$, Peuralinna T, Dutra A, Nussbaum $R$ (2003): alpha-Synuclein locus triplication causes Parkinson's disease. Science $\underline{\text { 302(5646), } 841}$

Smeets WJAJ, Reiner A: Catecholamines in the CNS of vertebrates: current concepts of evolution and functional significance; in: Phylogeny and Development of Catecholamine Systems in the CNS of Vertebrates; hrsg. v. Smeets WJAJ, Reiner A; Cambridge University Press, Cambridge 1994, 463-476

Smith PK, Krohn RI, Hermanson GT, Mallia AK, Gartner FH, Provenzano MD, Fujimoto EK, Goeke NM, Olson BJ, Klenk DC (1985): Measurement of protein using bicinchoninic acid. Anal Biochem 150(1), 76-85

Snyder H, Mensah K, Theisler C, Lee J, Matouschek A, Wolozin B (2003): Aggregated and monomeric alpha-synuclein bind to the $S 6^{\prime}$ proteasomal protein and inhibit proteasomal function. J Biol Chem 278(14), 11753-11759

Sotiriou S, Gibney G, Baxevanis AD, Nussbaum RL(2009): A single nucleotide polymorphism in the 3'UTR of the SNCA gene encoding alpha-synuclein is a new potential susceptibility locus for Parkinson disease. Neurosci Lett 461(2), 196-201

Soto C(2012): Transmissible proteins: expanding the prion heresy. Cell 149(5), 968-977

Sousa VL, Bellani S, Giannandrea M, Yousuf M, Valtorta F, Meldolesi J, Chieregatti E(2009): \{alpha\}-synuclein and its A30P mutant affect actin cytoskeletal structure and dynamics. Mol Biol Cell 20(16), 3725-3739

Spatola M, Wider C (2014) Genetics of Parkinson's disease: the yield. Parkinsonism Relat Disord 20 Suppl 1, 35-48

Spencer B, Potkar R, Trejo M, Rockenstein E, Patrick C, Gindi R, Adame A, Wyss-Coray T, Masliah E(2009): Beclin 1 gene transfer activates autophagy and ameliorates the neurodegenerative pathology in alpha-synuclein models of Parkinson's and Lewy body diseases. J Neurosci 29(43), 13578-13588

Spillantini MG, Schmidt ML, Lee VM, Trojanowski JQ, Jakes R, Goedert M(1997): Alphasynuclein in Lewy bodies. Nature 388(6645), 839-840.

Spillantini MG, Crowther RA, Jakes R, Hasegawa M, Goedert M(1998): alpha-Synuclein in filamentous inclusions of Lewy bodies from Parkinson's disease and dementia with lewy bodies. Proc Natl Acad Sci U S A 95(11), 6469-6473

St Martin JL, Klucken J, Outeiro TF, Nguyen P, Keller-McGandy C, Cantuti-Castelvetri I, Grammatopoulos TN, Standaert DG, Hyman BT, McLean PJ(2007): Dopaminergic neuron loss and up-regulation of chaperone protein mRNA induced by targeted over-expression of alpha-synuclein in mouse substantia nigra. J Neurochem 100(6), 1449-1457

Steenland K, Hein MJ, Cassinelli RT 2nd, Prince MM, Nilsen NB, Whelan EA, Waters MA, Ruder AM, Schnorr TM(2006): Polychlorinated biphenyls and neurodegenerative disease mortality in an occupational cohort. Epidemiology 17(1), 8-13

Strickland D, Bertoni JM (2004): Parkinson's prevalence estimated by a state registry. Mov Disord 19 (3), 318-323 
Suslick KS (1989): The Chemical Effects of Ultrasound. Scientific American 260, 80-86

Tagliaferro P, Burke RE (2016): Retrograde Axonal Degeneration in Parkinson Disease. J Parkinsons Dis $\underline{6}(1), 1-15$

Takenouchi T, Hashimoto M, Hsu LJ, Mackowski B, Rockenstein E, Mallory M Masliah E (2001): Reduced neuritic outgrowth and cell adhesion in neuronal cells transfectd with human alpha-synuclein Mol Cell Neurosci 17(1),141-150

Tan EK, Tan C, Shen H, Chai A, Lum SY, Teoh ML, Yih Y, Wong MC, Zhao Y (2003): Alpha synuclein promoter and risk of Parkinson's disease: microsatellite and allelic size variability. Neurosci Lett 336, 70-72

Thews G, Mutschler E, Vaupel P: Anatomie Physiologie und Pathophysiologie des Menschen. 5. Auflage; Wissenschaftliche Verlagsgesellschaft, Stuttgart 1999

Thompson PD, Marsden CD(1987): Gait disorder of subcortical arteriosclerotic encephalopathy: Binswanger's disease. Mov Disord 2(1), 1-8

Thümler R: Die Parkinson-Krankheit - Mehr wissen - besser verstehen. 3. Auflage; TRIAS, Stuttgart 2006

Trepel M: Neuroanatomie: Struktur und Funktion. 2. Auflage; Urbanund Fischer, München 1999

Tretiakoff C: Contribution a l'etude de l'Anatomie pathologique du Locus Niger de Soemmering: avec quelques déductions relatives à la pathogénie des troubles du tonus musculaire et de la maladie de Parkinson. Jouve, Paris 1919

Tsaneva-Atanasova K, Burgo A, Galli T, Holcman D (2009): Quantifying neurite growth mediated by interactions among secretory vesicles, microtubules, and actin networks. Biophys J $\underline{96}(3), 840-857$

Tsigelny IF, Bar-On P, Sharikov Y, Crews L, Hashimoto M, Miller MA, Keller SH, Platoshyn $O$, Yuan JX, Masliah E(2007): Dynamics of alpha-synuclein aggregation and inhibition of pore-like oligomer development by beta-synuclein. FEBS J 274(7), 1862-1877

Uchihara T, Giasson BI (2016): Propagation of alpha-synuclein pathology: hypotheses, discoveries, and yet unresolved questions from experimental and human brain studies Acta Neuropathol 131(1), 49-73, Lizenzlink: creativecommons.org/licenses/by/4.0/

Uéda K, Fukushima H, Masliah E, Xia Y, Iwai A, Yoshimoto M, Otero DA, Kondo J, Ihara Y, Saitoh T(1993): Molecular cloning of cDNA encoding an unrecognized component of amyloid in Alzheimer disease. Proc Natl Acad Sci U S A g0(23), 11282-11286

Uversky VN, Li J, Fink AL (2001): Metal-triggered structural transformations, aggregation, and fibrillation of human alpha-synuclein. A possible molecular NK between Parkinson's disease and heavy metal exposure. J Biol Chem 276(47), 44284-44296

van den Bos $F$, Speelman $A D$, van Nimwegen $M$, van der Schouw YT, Backx FJ, Bloem BR, Munneke M, Verhaar HJ(2013): Bone mineral density and vitamin D status in Parkinson's disease patients. J Neurol 260(3), 754-760 
Van Den Eeden SK, Tanner CM, Bernstein AL, Fross RD, Leimpeter A, Bloch DA, Nelson LM(2003): Incidence of Parkinson's disease: variation by age, gender, and race/ethnicity. Am J Epidemiol 157(11), 1015-1022

van Hilten JJ, van Eerd AA, Wagemans EA, Middelkoop HA, Roos RA(1998): Bradykinesia and hypokinesia in Parkinson's disease: what's in a name? J Neural Transm (Vienna) 105(23), 229-237

Varkey J, Isas JM, Mizuno N, Jensen MB, Bhatia VK, Jao CC, Petrlova J, Voss JC, Stamou DG, Steven ACet al. (2010): Membrane curvature induction and tubulation are common features of synucleins and apolipoproteins. J Biol Chem 285(42), 32486-32493

Vogiatzi T, Xilouri M, Vekrellis K, Stefanis L(2008): Wild type alpha-synuclein is degraded by chaperone-mediated autophagy and macroautophagy in neuronal cells. $J$ Biol Chem $\underline{283}(35), 23542-23556$

Volles MJ, Lansbury PT Jr (2002): Vesicle permeabilization by protofibrillar alpha-synuclein is sensitive to Parkinson's disease-linked mutations and occurs by a pore-like mechanism. Biochemistry $\underline{41}$ (14), 4595-4602

Volles MJ, Lee SJ, Rochet JC, Shtilerman MD, Ding TT, Kessler JC, Lansbury PT Jr (2001): Vesicle permeabilization by protofibrillar alpha-synuclein: implications for the pathogenesis and treatment of Parkinson's disease. Biochemistry 40(26), 7812-7819

Wakabayashi K, Takahashi H (1997): Neuropathology of autonomic nervous system in Parkinson's disease. Eur Neurol 38 Suppl 2, 2-7

Wakabayashi K, Takahashi H, Ohama E, Ikuta F (1990): Parkinson's disease: an immunohistochemical study of Lewy body containing neurons in the enteric nervous system. Acta Neuropathol 79 (6), 581-583

Wersinger C, Sidhu A (2003): Attenuation of dopamine transporter activity by alphasynuclein. Neurosci Lett 340(3), 189-192

Wheeler $R$ (2007): A diagram of the main components of an electroporator with cuvette loaded (Own work), Lizenzlink: creativecommons.org/licenses/by-sa/3.0/deed.de

Wilfinger WW, Mackey K, Chomczynski P(1997): Effect of $\mathrm{pH}$ and ionic strength on the spectrophotometric assessment of nucleic acid purity. Biotechniques 22(3), 474-476, 478481

Winner B, Jappelli R, Maji SK, Desplats PA, Boyer L, Aigner S, Hetzer C, Loher T, Vilar M, Campioni $S$ et al. (2011): In vivo demonstration that alpha-synuclein oligomers are toxic. Proc Natl Acad Sci U S A 108(10), 4194-4199

Withers GS, George JM, Banker GA, Clayton DF(1997): Delayed localization of synelfin (synuclein, NACP) to presynaptic terminals in cultured rat hippocampal neurons. Brain Res Dev Brain Res 99(1), 87-94

Rey ER: Psychotische Störungen und Schizophrenie; in: Klinische Psychologie und Psychotherapie, 2. Auflage; hrsg. v. Wittchen HU, Hoyer J; Springer-Medizin, Heidelberg 2011 
Wooten GF, Currie LJ, Bovbjerg VE, Lee JK, Patrie J (2004): Are men at greater risk for Parkinson's disease than women? J Neurol Neurosurg Psychiatry 75(4), 637-639

Wright Willis A, Evanoff BA, Lian M, Criswell SR, Racette BA(2010): Geographic and ethnic variation in Parkinson disease: a population-based study of US Medicare beneficiaries. Neuroepidemiology $\underline{34}(3), 143-151$

Xilouri M, Vogiatzi T, Vekrellis K, Park D, Stefanis L(2009): Abberant alpha-synuclein confers toxicity to neurons in part through inhibition of chaperone-mediated autophagy. PLoS One 4(5), e5515

Xu Q, Park Y, Huang X, Hollenbeck A, Blair A, Schatzkin A, Chen H(2010): Physical activities and future risk of Parkinson disease. Neurology 75(4), 341-348

Yang F, Trolle Lagerros Y, Bellocco R, Adami HO, Fang F, Pedersen NL, Wirdefeldt K(2015): Physical activity and risk of Parkinson's disease in the Swedish National March Cohort. Brain 138(Pt2), 269-275

Yavich L, Jäkälä P, Tanila H(2006): Abnormal compartmentalization of norepinephrine in mouse dentate gyrus in alpha-synuclein knockout and A30P transgenic mice. J Neurochem 99(3), 724-732

Yavich L, Tanila H, Vepsäläinen S, Jäkälä $P(2004)$ : Role of alpha-synuclein in presynaptic dopamine recruitment. J Neurosci244(49), 11165-11170

Yin J, Han J, Zhang C, Ma QL, Li X, Cheng F, Liu G, Li Y, Uéda K, Chan P et al. (2011): Cterminal part of $\alpha$-synuclein mediates its activity in promoting proliferation of dopaminergic cells. J Neural Transm (Vienna) 118(8), 1155-1164

Yu S, Li X, Liu G, Han J, Zhang C, Li Y, Xu S, Liu C, Gao Y, Yang Het al. (2007): Extensive nuclear localization of alpha-synuclein in normal rat brain neurons revealed by a novel monoclonal antibody. Neuroscience 145(2), 539-555

Zarranz JJ, Alegre J, Gómez-Esteban JC, Lezcano E, Ros R, Ampuero I, Vidal L, Hoenicka $J$, Rodriguez O, Atarés $B$ et al. (2004): The new mutation, E46K, of alpha-synuclein causes Parkinson and Lewy body dementia. Ann Neurol 55(2), 164-173

Zeitelhofer M, Vessey JP, Thomas S, Kiebler M, Dahm R (2009): Transfection of cultured primary neurons via nucleofection. Curr Protoc Neurosci Chapter 4:Unit4, 32

Zeng BY, Medhurst AD, Jackson M, Rose S, Jenner P(2005): Proteasomal activity in brain differs between species and brain regions and changes with age. Mech Ageing Dev 126(67), $760-766$

Zhang L, Zhang C, Zhu Y, Cai Q, Chan P, Uéda K, Yu S, Yang H(2008): Semi-quantitative analysis of alpha-synuclein in subcellular pools of rat brain neurons: an immunogold electron microscopic study using a C-terminal specific monoclonal antibody. Brain Res 1244, 40-52

Zhang NY, Tang Z, Liu CW (2008): alpha-Synuclein protofibrils inhibit 26 S proteasomemediated protein degradation: understanding the cytotoxicity of protein protofibrils in neurodegenerative disease pathogenesis. J Biol Chem 283(29), 20288-20298 
Zhang SX, Duan LH, Qian H, Yu X (2016): Actin Aggregations Mark the Sites of Neurite Initiation. Neurosci Bull 32(1), 1-15

Zhao Y, Sun Y, Ji HF, Shen L (2013): Vitamin D levels in Alzheimer's and Parkinson's diseases: a meta-analysis. Nutrition $\underline{29}(6), 828-832$

Zhou B, Westaway SK, Levinson B, Johnson MA, Gitschier J, Hayflick SJ(2001): A novel pantothenate kinase gene (PANK2) is defective in Hallervordenspatz syndrome. Nat Genet $\underline{28}(4), 345-349$

Zhou RM, Huang YX, Li XL, Chen C, Shi Q, Wang GR, Tian C, Wang ZY, Jing YY, Gao $C$ et al. (2010): Molecular interaction of $\alpha$-synuclein with tubulin influences on the polymerization of microtubule in vitro and structure of microtubule in cells. Mol Biol Rep 37(7), 3183-3192

Zhou W, Hurlbert MS, Schaack J, Prasad KN, Freed CR (2000): Overexpression of human alpha-synuclein causes dopamine neuron death in rat primary culture and immortalized mesencephalon-derived cells. Brain Res $\underline{866}(1-2), 33-43$ 
Teile dieser Arbeit wurden in folgendem Beitrag vorab veröffentlicht:

Koch JC, Bitow F, Haack J, d'Hedouville Z, Zhang JN, Tönges L, Michel U, Oliveira LM, Jovin TM, Liman J et al. (2015): Alpha-Synuclein affects neurite morphology, autophagy, vesicle transport and axonal degeneration in CNS neurons. Cell Death Dis $\underline{6}$, e1811 


\section{Danksagung}

An dieser Stelle möchte ich meinen besonderen Dank nachstehenden Personen entgegenbringen, ohne deren Mithilfe die Anfertigung dieser Promotionsarbeit nicht zustande gekommen wäre.

An erster Stelle möchte ich mich bei Prof. Dr. med. M. Bähr für die Aufnahme in seine Arbeitsgruppe und somit die Möglichkeit, diese Dissertation zu verfassen, bedanken.

Mein ganz besonderer Dank gilt an dieser Stelle meinem Doktorvater Herrn PD Dr. med. Jan C. Koch, der es verstand, mir die ausreichende Menge an Freude und Motivation an dieser experimentellen Doktorarbeit zu vermitteln, insbesondere wenn Rückschläge und Frustrationen zu Tage kamen. Er unterstützte mich umfangreich bei der Weiterentwicklung meiner Arbeit, indem die konstruktiven Diskussionen und Gespräche mit ihm zu neuen Ansatz- und Gesichtspunkten führten und mir einen kritischen Zugang zu dieser Thematik eröffneten. Zudem möchte ich Herrn Koch für die unheimlich zügigen schriftlichen Korrekturen danken. Die hieraus entstandene Freundschaft möchte ich keinesfalls missen.

Daneben möchte ich mich bei Herrn Prof. Dr. med Paul Lingor, als Leiter meiner Arbeitsgruppe, für die Bereitsstellung des Dissertationsthemas und vor allem für die zahlreichen Denkanstöße, konstruktiven Anmerkungen und mannigfachen Ideengebungen sowie für die Entfaltungsmöglichkeit in dieser Thematik bedanken.

Ein großer Dank geht an alle Mitglieder der Arbeitsgruppe von Prof. Bähr, insbesondere die AG Lingor. Hervorheben möchte ich Elisabeth Barski, die mich mit viel Geduld und Ruhe in die notwendigen praktischen Fertigkeiten einwies und mich ebenfalls mit konstruktiven Anmerkungen im Voranschreiten dieser Arbeit unterstützte. Weiterhin gilt mein Dank Dr. rer. nat. Sebastian Kügler für die Bereitsstellung der a-Syn-Plasmide sowie Prof. Uwe Michel für die Bereitstellung des eGFP-Plasmids.

Tief verbunden und dankbar bin ich meinem Kommilitonen, Mitdoktoranden und Lebensgefährten Florian Bitow. Er hatte zu jeder Zeit ein offenes Ohr bei speziellen Fragestellungen, die er kritisch durchdachte. 
Lebenslauf 
